DUBERNEY HINCAPIE LADINO

RESISTÊNCIA À CORROSÃO E AO TRINCAMENTO INDUZIDO POR HIDROGÊNIO DE AÇOS PARA TUBOS API 5L X65

Dissertação apresentada à Escola
Politécnica da Universidade de São
Paulo como parte dos requisitos para a
obtenção do título de Mestre em
Engenharia

São Paulo

2012 
DUBERNEY HINCAPIE LADINO

\title{
RESISTÊNCIA À CORROSÃO E AO TRINCAMENTO INDUZIDO POR HIDROGÊNIO DE AÇOS PARA TUBOS API 5L X65
}

\begin{abstract}
Dissertação apresentada à Escola Politécnica da Universidade de São Paulo como parte dos requisitos para a obtenção do titulo de Mestre em Engenharia
\end{abstract}

Área de Concentração:

Engenharia Metalúrgica e de Materiais

Orientadora:

Professora Doutora Neusa Alonso-Falleiros

São Paulo

2012 
Este exemplar foi revisado e alterado em relação à versão original, sob responsabilidade única do autor e com a anuência de seu orientador.

São Paulo, de dezembro de 2012.

Assinatura do autor

Assinatura do orientador

Hincapie Ladino, Duberney

Resistência à corrosão e ao trincamento induzido por hidrogênio de aços para tubos API 5L X65 / D. Hincapie Ladino. -ed.rev. -- São Paulo, 2012.

$140 \mathrm{p}$.

Dissertação (Mestrado) - Escola Politécnica da Universidade de São Paulo. Departamento de Engenharia Metalúrgica e de Materiais.

1. Corrosão (Resistência) 2. Hidrogênio 3. Aço 4. Tubos I. Universidade de São Paulo. Escola Politécnica. Departamento de Engenharia Metalúrgica e de Materiais II. t. 


\section{AGRADECIMENTOS}

À minha família, em especial a meus pais e irmão que sempre me apoiaram.

Especialmente à minha orientadora Prof (a) . Dr(a). Neusa Alonso Falleiros que com sua paciência e dedicação foi fundamental para a realização deste trabalho.

Aos meus amigos pela sincera amizade e grandes ajudas durante esta etapa da minha vida.

Aos técnicos do Departamento de Engenharia Metalúrgica da USP, especialmente, Antonio Livio da Silva Nunes pela ajuda.

Ao Prof. Dr. Rodrigo Magnabosco (UNIFEI), Prof.(a) Dr.(a) Darlene Yuko Kobayashi Ranzini (CTMSP) e a Lea Sarita Montagna (CTMSP), pela grande ajuda na realização deste trabalho.

E a todos que direta ou indiretamente me auxiliaram neste trabalho.

À CAPES, ao CNPq e à CBMM pelo auxílio à pesquisa, que viabilizaram este projeto. 


\section{RESUMO}

Com a descoberta de novas fontes de petróleo e gás, em regiões remotas e de difícil acesso, tem-se a necessidade do desenvolvimento de novas tecnologias para garantir a eficácia da exploração destes recursos. Essa exploração e extração muitas vezes se dão em ambientes altamente corrosivos e os equipamentos devem apresentar propriedades que garantam um fator de segurança em serviço. Os aços de alta resistência e baixa liga ( $A R B L$ ) são utilizados em tubulações para o transporte de gás natural e petróleo. Estes estão constantemente expostos a ambientes ácidos os quais são compostos de umidade e sulfeto de hidrogênio $\left(\mathrm{H}_{2} \mathrm{~S}\right)$, podendo causar falha induzida pela presença de hidrogênio (Hydrogen Induced Cracking - HIC).

Este tipo de falha é normalmente abordado na literatura através de ensaios em solução contendo ácido acético e/ou sais (cloreto de sódio, entre outros), sempre com a injeção de $\mathrm{H}_{2} \mathrm{~S}$. Há vários mecanismos propostos, no entanto, o assunto não está totalmente resolvido. As alterações de composição química dos aços, processos de refino do aço e processos de conformação mecânica são responsáveis pela microestrutura final e determinantes da resistência à fragilização por hidrogênio.

O objetivo deste trabalho é analisar e comparar o comportamento quanto à resistência à corrosão e resistência à HIC de quatro materiais: tubo X65 sour, sua região de solda, tubo X65 não-sour e uma chapa destinada a confecção de tubo X65.

Os eletrólitos empregados foram: solução A (ácido acético contendo cloreto de sódio) e a solução $B$ (água do mar sintética), os quais correspondem às soluções recomendadas pela norma NACE TM0284-2003. Os materiais foram submetidos a: ensaios de polarização (Polarização Linear para determinação da Resistência de Polarização - Rp) e ensaios de resistência a HIC segundo a norma NACE TM0284-2003; exames em microscópio óptico e eletrônico de varredura para caracterização da morfologia da corrosão e do trincamento.

Os ensaios de $R p$ revelaram que a solução $A$ é mais agressiva do que a solução $B$, sendo isso explicado pela diferença de $\mathrm{pH}$ entre estas duas 
soluções. Os resultados mostraram ainda que a máxima resistência à corrosão sempre é obtida para o tubo sour, enquanto a mínima ocorreu para o tubo nãosour.

Após o ensaio de resistência a HIC os exames em microscópio óptico revelaram que, em ambas as soluções, o tubo de X65 sour, e a sua solda não apresentaram trincas, bem como a chapa destinada a tubo X65; já o tubo de X65 não-sour apresentou trincamento principalmente na região central. Os exames das trincas revelaram que a presença de cementita intergranular e a estrutura bandeada foram as causas do trincamento.

No caso do tubo sour, o bom desempenho foi discutido em termos da microestrutura de ferrita poligonal, acicular e microconstituinte M/A.

Já o comportamento distinto encontrado para a chapa (para tubo X65), foi discutido levando-se em conta que esta chapa apresentou menor quantidade de cementita intergranular, uma vez que, sua microestrutura é bandeada e não foi encontrado trincamento.

Os resultados também revelaram que a solução $B$, como no caso da resistência à corrosão, é uma solução menos agressiva, pois o trincamento obtido foi muito menor.

Palavras-chave: Aços ARBL, Ácido Sulfídrico $\left(\mathrm{H}_{2} \mathrm{~S}\right)$, Fragilização por hidrogênio, Trinca Induzida por Hidrogênio, Resistência à corrosão. 


\section{ABSTRACT}

The discovery of new oil and gas reserves, at remote and hard to reach locations, makes imperative the development of new technologies to ensure effective exploitation of these resources. This exploitation is often performed at highly corrosive environments and equipment such as pipelines should have special mechanical and corrosion properties to guarantee safety levels in service. High-Strength Low Alloy (HSLA) steels are used in pipelines for transporting gas and oil. These steels are in constant exposure to acid environments containing hydrogen sulfide $\left(\mathrm{H}_{2} \mathrm{~S}\right)$ and water, that can cause pipeline failures due to Hydrogen-Induced Cracking - HIC.

The literature reports that Hydrogen-Induced Cracking in steels is normally tested in solutions containing acetic acid and/or, salts (sodium chloride and others) with addition of $\mathrm{H}_{2} \mathrm{~S}$. Chemical composition, steel refining processes and metal forming processes are responsible for the final microstructure of the steel and have effect on the hydrogen embrittlement resistance.

The purpose of this work is to analyze and compare the corrosion resistance and $\mathrm{HIC}$ resistance, and compare of four materials: pipeline steel API $5 \mathrm{~L}$ X65 for sour service, its welded junctions, pipeline steel API 5L X65 for non-sour service and pipeline steel plate API $5 \mathrm{~L}$ X65.

The materials were submitted to linear polarization test $(\mathrm{Rp})$ and $\mathrm{HIC}$ resistance test according to NACE TM0284-2003 standard. Both tests were carried out with two different electrolytes: the solution $A$ (acetic acid and sodium chloride) and solution B (synthetic seawater). Subsequently; the surface of the steels were evaluated by optical microscope and scanning electron microscopy in order to characterize the cracking modes and corrosion morphology.

The $\mathrm{Rp}$ tests showed that the solution $\mathrm{A}$ is more aggressive than solution $\mathrm{B}$, behavior attributed to the $\mathrm{pH}$ difference between solutions. Steel API 5L X65 for sour service had the highest corrosion resistance and pipeline steel API $5 \mathrm{~L}$ X65 for non-sour service had the lowest.

The HIC test and the surface examination revealed that in both solutions, pipeline steel API $5 \mathrm{~L}$ X65 for sour service, the welded junctions and the pipeline 
steel plate API $5 \mathrm{~L}$ X65 showed no cracks. On the other hand, pipeline steel API $5 \mathrm{~L}$ X65 for non-sour service presented cracking mainly in the central region. The tests revealed that the cracks nucleated at the intergranular cementite in the banded structure.

The good performance of the pipeline steel API 5L X65 for sour service was discussed in terms of the microstructure, formed by polygonal ferrite, acicular ferrite and $\mathrm{M} / \mathrm{A}$ microconstituent.

The performance of steel plate (for pipeline API $5 \mathrm{~L}$ X65) was different. This material did not exhibit cracks in the matrix in spite of its banded microstructure. This result was discussed taking into account that the plate studied had a small amount of intergranular cementite.

The results also showed that the solution $B$, as in the case of corrosion resistance tests, was less aggressive than solution $A$, because the cracks produced were smaller.

Keywords: HSLA steels, Hydrogen sulfide $\left(\mathrm{H}_{2} \mathrm{~S}\right)$, Hydrogen embrittlement, Hydrogen induced cracking, corrosion resistance. 


\section{SUMÁRIO}

1 INTRODUÇÃO E JUSTIFICATIVA

2 REVISÃO DA LITERATURA 2

2.1 AÇOS ALTA RESISTÊNCIA BAIXA LIGA (ARBL) E A LAMINAÇÃO CONTROLADA

2.2 ESPECIFICAÇÕES DA AMERICAN PETROLEUM INSTITUTE - API PARA TUBULAÇÕES 4

2.3 METALURGIA DOS AÇOS ARBL 9

2.3.1 Aços laminados termomecanicamente (TMCP) com resfriamento acelerado

2.4 DANOS DEVIDO AO HIDROGÊNIO 15

2.4.1 Fragilização pelo Hidrogênio - HE 16

2.4.2 Efeito dos elementos de liga sobre a fragilização por hidrogênio 23

2.4.3 Permeabilidade de hidrogênio em aços ARBL 30

2.5 RESISTÊNCIA À CORROSÃO 32

2.5.1 Corrosão atmosférica 32

3 OBJETIVOS 43

4 MATERIAIS E MÉTODOS 43

$\begin{array}{lll}\text { 4.1 MATERIAIS } & 43\end{array}$

4.2 MÉTODOS 44

4.2.1 ENSAIOS DE POLARIZAÇÃO LINEAR 45

4.2.2 ENSAIO DE TRINCAMENTO INDUZIDO POR HIDROGÊNIO 52

4.2.3 CARACTERIZAÇÃO MICROESTRUTURAL 57

5 RESULTADOS 58 
5.1 ANÁLISE DAS INCLUSÕES

5.1.1 Tubo Api $5 \mathrm{~L}$ X65 sour

5.1.2 Região soldada do tubo API $5 \mathrm{~L}$ X65 sour

61

5.1.3 Chapa grossa de aço para tubo API $5 \mathrm{~L}$ X65

5.1.4 Tubo API 5L X65 não-sour

5.2 EXAMES MICROESTRUTURAIS

5.2.1 Tubo Api $5 \mathrm{~L}$ X65 sour 66

5.2.2 Região soldada do tubo API $5 \mathrm{~L}$ X65 sour 68

5.2.3 Chapa grossa de aço para tubo API 5L X65

5.2.4 Tubo API 5L X65 não-sour

5.3 POLARIZAÇÃO LINEAR

5.3.1 Resistência de polarização - solução $A$

$\left(5 \% \mathrm{NaCl}+0,5 \% \mathrm{CH}_{3} \mathrm{COOH}+\mathrm{H}_{2} \mathrm{~S}\right) \quad 76$

5.3.2 Resistência de polarização - solução B (Água do mar sintètica) 78

5.3.3 Morfologia da corrosão 81

5.4 TRINCAMENTO INDUZIDO POR HIDROGÊNIO - HIC 98

$\begin{array}{ll}5.4 .1 \text { Solução } A & 98\end{array}$

$\begin{array}{ll}5.4 .2 \text { Solução B } & 107\end{array}$

6 DISCUSSÃO 112

6.1 POLARIZAÇÃO LINEAR 112

6.2 TRINCAMENTO INDUZIDO POR HIDROGÊNIO 125

6.3 COMENTÁRIOS FINAIS 128

7 CONCLUSÕES 131

8 REFERÊNCIAS 132 


\section{LISTA DE FIGURAS}

Figura 1 Propriedades de tubos usados em projetos a partir de 1980.

Modificado. (INTERNATIONAL IRON AND STEEL INSTITUTE, 1987)...... 3

Figura 2 Desenvolvimento dos aços ARBL. Modificado (HILLENBRAND;

KALWA, 2002)

Figura 3 llustração da laminação controlada com e sem resfriamento acelerado

durante a última etapa. Modificado (Hillenbrand 2001). 11

Figura 4 Tubo X65, espessura 31,4 mm. (a) processo TMCP; (b) processo

TMCP + Resfriamento acelerado 2. (BAUER, 2005) 12

Figura 5 Classificação dos danos produzidos pelo hidrogênio. Modificado

(NAMBOODHIRI, 2008). 16

Figura 6 (a) Nucleação da trinca por hidrogênio (b) Propagação de trinca em

degraus induzida por hidrogênio. Modificado (SASTRI et al., 2007)......... 18

Figura 7 Esquema de formação de trincas na presença de inclusões alongadas.

Modificado. (HULKA, 2001 apud GORNI, 2006) 20

Figura 8 Amostra de tubo API 5L X65, submetido à solução A da NACE

TM0284-2003, após polimento metalográfico da superfície $(1 \square \mathrm{m})$. Nota-se dissolução da interface inclusão / matriz. Trata-se de uma inclusão de Al e Mg. (COSTA, 2010) 20

Figura 9 Esquema de trincas produzidas por SOHIC. Modificado. (SASTRI et al., 2007). 22

Figura 10 Efeito do teor de manganês sobre o parâmetro $C R L$ de resistência a

HIC. Modificado. (TAIRA et al., 1983) 25

Figura 11 Efeito da concentração de enxofre e tempo do ensaio de $\mathrm{HIC} \mathrm{pH}=3$, sobre o comprimento das trincas. Modificado. (GOLOVANENKO et al., 1978). 26

Figura 12 Susceptibilidade a HIC (indicador de comprimento Ultrasonic attenuation level UAL\%) em função do teor de enxofre. Modificado. (DOMINIZZI et al., 2001).

Figura 13 Efeito do molibdênio sobre a resistência a HIC. Modificado. (RAVI et al., 1993). 28

Figura $14 \mathrm{CLR}$ em aços ARBL com teores $(\mathrm{Cr} / 15+\mathrm{Mo} / 5)$ e $(\mathrm{Cr}+\mathrm{Mo}) / 5 \mathrm{em}$ solução A da NACE TM0284. Modificado. (LIOU et al., 1993). 28 
Figura 15 Trincamento propagando-se entre a interfase inclusão / matriz (LIOU et al., 1993).

Figura 16 Corrosão atmosférica de aços em função do tempo num ambiente industrial. Modificado. (REVIE; UHLIG, 2008)

Figura 17 Velocidade de corrosão (em MPY: milipolegada por ano) em função da porcentagem em peso de fósforo. Modificado. (CLEARY; GREENE, 1967) 34

Figura 18 Velocidade de corrosão em função do tempo obtida por espectroscopia de impedância eletroquímica (EIS) em solução 10\% em massa de $\mathrm{H}_{2} \mathrm{SO}_{4}$, a temperatura ambiente. Modificado. (NAM; KIM, 2010).

Figura 19 Efeito da concentração de cloreto de sódio sobre a corrosão do ferro numa solução desaerada a temperatura ambiente. (REVIE; UHLIG, 2008)

Figura 20 Velocidade de corrosão (mm/ano) em função do tempo (dias), em eletrólito contendo 50ppm de $\mathrm{H}_{2} \mathrm{~S}$. Modificado. (FANG et al, 2010) 36

Figura 21 Efeito da concentração de oxigênio sobre a velocidade de corrosão do aço carbono. Modificado. (REVIE; UHLIG, 2008).

Figura 22 Efeito do $\mathrm{pH}$ sobre a velocidade de corrosão do ferro (ipy: polegada por ano) numa solução aerada. Modificado. (REVIE; UHLIG, 2008) 38

Figura 23 Variação da velocidade de corrosão (mpy: milipolegada por ano) de aço carbono em diferentes concentrações de $\mathrm{CH}_{3} \mathrm{COOH}$ em função do tempo a $25^{\circ} \mathrm{C}$. Modificado. (SINGH; GUPTA, 1999).

Figura 24 Diagrama potencial de eletrodo $(E)$ em função do $\mathrm{pH}$ para o sistema $\mathrm{Fe}-\mathrm{H}_{2} \mathrm{O}-\mathrm{S}$, a $25^{\circ} \mathrm{C}$. Estabilidade da água $(\mathrm{A})$ e $(\mathrm{B})$; ---------, espécies ferrosas dissolvidas; -- , sistema $\mathrm{S}-\mathrm{H}_{2} \mathrm{O}$; , equilíbrios envolvendo espécies sólidas de ferro. (BIERNAT; ROBINS, 1972). ............................ 40

Figura 25 Estabilidade das substâncias que contém enxofre em solução aquosa, a $25^{\circ} \mathrm{C}$. Modificado. (NACE MR0103-2007)

Figura 26 Curva de polarização linear para a obtenção da resistência de polarização (ASTMG59-10).

Figura 27 Face a ser examinada nos ensaios de polarização linear: seção transversal do tubo (ou chapa), com área de $1 \mathrm{~cm}^{2}$, mantendo-se a espessura total da amostra original. 
Figura 28 Corpos-de-prova antes e após embutimento. 50

Figura 29 a) Primeira desaeração. b) Eletrólito transferido até a célula eletrolítica. 51

Figura 30 Arranjo experimental utilizado no levantamento das curvas de polarização linear (determinação de Rp). 52

Figura 31 Indicação da posição de extração dos corpos-de-prova para o ensaio de HIC. 53

Figura 32 Disposição dos corpos-de-prova dentro da célula, sugerida pela norma NACE TM0284-2003. 54

Figura 33 Esquema do arranjo experimental de injeção de $\mathrm{H}_{2} \mathrm{~S}$ construído no interior de uma capela de gases. 55

Figura 34 Detalhe da célula durante o período de imersão dos corpos-de-prova nos eletrólitos contendo $\mathrm{H}_{2} \mathrm{~S}$. 55

Figura 35 (a) Amostras obtidas do corpo-de-prova ensaiado. (b) Amostras embutidas para exames de HIC. 56

Figura 36 Distribuição das inclusões no tubo API 5L X65 sour. Polimento $1 \mu \mathrm{m}$ sem ataque. Classificação das inclusões: nível D1. Aumento: 100X. MO. Seção examinada conforme recomendação na norma ASTM E45.

Figura 37 Imagem de elétrons secundários de inclusão encontrada no aço do T-X65S. (a) Aspecto da inclusão. Aumento 5000X. (b) Análise química por EDS da inclusão: Al, Mn, Ca e S. (Seção examinada: transversal.) 60

Figura 38 Distribuição das inclusões na região de solda do tubo API 5L X65 sour (RS-X65S). Polimento: $1 \mu \mathrm{m}$ sem ataque. Classificação das inclusões: nível D1. Aumento: 100X. MO. Seção examinada conforme recomendação na norma ASTM E45. 61

Figura 39 Imagem de elétrons secundários de inclusão encontrada na região de solda do tubo API 5L X65 sour (RS-X65S). (a) Aspecto da inclusão. Aumento 8000X. (b) Análise química (da região indicada pelo tracejado) por EDS da inclusão: Al, Si, Ti e Mn. (Seção examinada: transversal.) .... 62 Figura 40 Distribuição das inclusões na chapa para tubo API 5L X65 (C-X65). Polimento: $1 \mu \mathrm{m}$, sem ataque. Classificação das inclusões: nível D3. Aumento: 100X. MO. Seção examinada conforme recomendação na norma ASTM E45. 
Figura 41 Imagem de elétrons retrospalhados de inclusão encontrada na chapa para construção de tubo API 5L X65 (C-X65). (a) Aspecto da inclusão. Aumento 5000X. (b) Análise química (da região indicada) por EDS da inclusão: Al, Ti, Mn, Ca e S. (Seção examinada: transversal.). 63

Figura 42 Distribuição das inclusões para o tubo API 5L X65 não-sour (TX65NS). Polimento: $1 \mu \mathrm{m}$, sem ataque. Classificação das inclusões: nível D4. Aumento: 100X. MO. Seção examinada conforme recomendação na norma ASTM E45.

Figura 43 Imagem de elétrons retrospalhados de inclusão encontrada no tubo API 5L X65 (T-X65NS). (a) Aspecto da inclusão. Aumento 5000X. (b) Análise química (da região indicada) por EDS da inclusão: Al, Ti, Mn, Mg, Ca e S. (Seção examinada: transversal.). 65

Figura 44 T-X65S: Microestrutura da região central da seção transversal do tubo. Nota-se microestrutura homogênea de grãos refinados. Ataque: nital 2\%. Aumento: 100x. MO. 66

Figura 45 T-X65S: Microestrutura da região central da seção transversal do tubo. Ataque: nital 2\%. Aumento: 500x. MO.

Figura 46 T-X65S: Imagem de elétrons secundários, mostrando a microestrutura. Nota-se a matriz de ferrita poligonal $\left({ }^{*}\right)$ e ferrita acicular (\#), além do microconstituinte M/A. Ataque: nital 2\%. Aumento: 3500X. MEV.

Figura 47 RS-X65S: Região soldada do tubo API 5L X65 sour. Polimento: $1 \mu \mathrm{m}$. Ataque: nital $2 \%$. MO.

Figura 48 C-X65: Microestrutura da região central da seção transversal da chapa para tubo API 5L X65 sour. Nota-se estrutura bandeada de ferrita e perlita. Ataque: nital 2\%. Aumento:100x. MO. 72

Figura 49 - continuação: C-X65 (b) Cementita intergranular, indicada pelas setas. Ataque: nital $2 \%$. MEV. 73

Figura 50 T-X65NS: Microestrutura da região central da seção transversal do tubo API 5L X65 não-sour. Nota-se bandeamento. Ataque: nital 2\%. Aumento:100x. MO. 74

Figura 51 - continuação T-X65NS, Imagem de elétrons secundários: (b)

Cementita intergranular. Ataque: nital 2\%. Aumento: 2500X. MEV 75 
Figura 52 Exemplo de curva de polarização linear para a amostra C-X65 imersa na solução A. O valor da Rp é obtido por regressão linear, desprezandose os pontos não alinhados. No presente caso, tem-se $\mathrm{Rp}$ com valor de $142,4 \Omega . \mathrm{cm}^{2}$. Em todos os casos foram obtidos ótimos ajustes $\left(R^{2}\right.$ sempre maiores do que 0,998$)$. 76

Figura 53 Resistência de Polarização (Rp) em função do tempo de imersão na solução A. Foram realizados 03 (três) ensaios para cada material. Os 03 resultados obtidos estão aqui apresentados. Destacam-se o tubo T-X65S por apresentar maiores valores de Rp e o tubo T-X65NS pelos menores valores.

Figura 54 Valores médios e desvio padrão da Resistência de Polarização (Rp) em função do tempo de imersão. Solução $A$. 78

Figura 55 Exemplo de curva de polarização linear para a amostra C-X65 imersa na solução B. O valor da Rp é obtido por regressão linear, desprezando-se os pontos não alinhados. No presente caso, tem-se Rp com valor de 364 $\Omega . \mathrm{cm}^{2}$. Os ajustes obtidos $R^{2}$ foram sempre maiores do que 0,997 . 79

Figura 56 Resistência de Polarização (Rp) em função do tempo de imersão na solução B. Foram realizados 03 (três) ensaios para cada material. Destacam-se o tubo T-X65NS pelos menores valores de Rp, os outros aços apresentaram valores próximos. 80

Figura 57 Valores médios e desvio padrão da Resistência de Polarização (Rp) em função do tempo de imersão. Solução $B$.

Figura 58 Morfologia da corrosão T-X65S. Pouca Corrosão uniforme, com baixo nível de corrosão localizada. . Solução A. Aumento:100X. MO....... 82 Figura 59 Morfologia de corrosão T-X65S, imagem de elétrons retrospalhados solução A. (a) Aspecto da superfície. (b) Análise química por EDS da superfície. MEV.....

Figura 60 Morfologia da corrosão RS-X65S. Baixa corrosão uniforme, baixo nível de corrosão localizada. Solução A. Aumento: 100X. MO.

Figura 61 Morfologia de corrosão da RS-X65S, solução A. Imagem de elétrons retrospalhados. (a) Aspecto da superfície. (b) Análise química por EDS da superfície. MEV. 85

Figura 62 Morfologia da corrosão C-X65. Corrosão uniforme com nível médio de corrosão localizada. Solução A. Aumento: 100X. MO 
Figura 63 Morfologia de corrosão C-X65, solução A. Imagem de elétrons retrospalhados, (a) Aspecto da superfície. (b) Análise química por EDS da superfície. MEV.

Figura 64 Morfologia da corrosão T-X65NS. Intensa corrosão uniforme com alto nível de corrosão localizada. Solução A. Aumento: 100X. MO. 88

Figura 65 Morfologia de corrosão C-X65, solução A. Imagem de elétrons retrospalhados, (a) Aspecto da superfície. (b) Análise química por EDS da superfície. MEV. 89

Figura 66 Morfologia da corrosão T-X65S. Corrosão uniforme com corrosão localizada, formando cavidades rasas, cercadas de regiões pouco corroídas. Solução B. Aumento: 100X. MO.

Figura 67 Morfologia de corrosão T-X65S, solução B. Imagem de elétrons secundários. (a) Aspecto da superfície. (b) Análise química por EDS da superfície. MEV.

Figura 68 Morfologia da corrosão RS-X65S. Corrosão uniforme com de corrosão localizada. Solução B. Aumento: 100X. MO. 92

Figura 69 Morfologia de corrosão RS-X65S, solução B. Imagem de elétrons secundários. (a) Aspecto da superfície. (b) Análise química por EDS da superfície. MEV.

Figura 70 Morfologia da corrosão da C-X65. Corrosão uniforme com corrosão localizada. Solução B. Aumento: 100X. MO.

Figura 71 Morfologia de corrosão C-X65, solução B. Imagem de elétrons secundários. (a) Aspecto da superfície. (b) Análise química por EDS da superfície. MEV.

Figura 72 Morfologia da corrosão T-X65NS. Corrosão uniforme com corrosão localizada. Solução B. Aumento: 100X. MO. 96

Figura 73 Morfologia de corrosão T-X65NS, solução B. Imagem de elétrons secundários. (a) Aspecto da superfície. (b) Análise química por EDS da superfície. MEV.

Figura 74 Superfície do tubo T-X65S após ensaio de HIC, solução A.

Polimento: $1 \mu \mathrm{m}$, sem ataque. Aumento: 100X. MO. 99

Figura 75 Superfície do tubo RS-X65S após ensaio de HIC, solução A.

Polimento: $1 \mu \mathrm{m}$, sem ataque. Aumento: 100X. MO. 99 
Figura 76 Superfície do tubo C-X65 após ensaio de HIC, solução A. Polimento: $1 \mu \mathrm{m}$, sem ataque. Aumento: 100X. MO. 100

Figura 77 Trincamento encontrado na superfície do tubo T-X65NS (a) trincamento por toda a região central da amostra, aumento 50X, (b) e (c) trincamento em duas regiões especificas. Polimento $1 \mu \mathrm{m}$. Sem ataque. Aumento 100X. MO. 101

Figura 78 T-X65NS Imagem de elétrons restroespalhados. (a) Inclusões no caminho de propagação da trinca. Polimento $1 \mu \mathrm{m}$ sem ataque. (b) Análise química por EDS das inclusões: Mn e Ca. MEV. 102

Figura 79 T-X65NS Imagem de elétrons secundários. Trinca na banda de segregação. Ataque nital $2 \%$. MEV. 104

Figura 80 T-X65NS Imagem de elétrons secundários. Trinca na banda de segregação. Ataque nital $2 \%$. MEV. 105

Figura $81 \mathrm{~T}$-X65NS Imagem de elétrons retroespalhados. Trinca na banda de segregação. Ataque nital 2\%. MEV. 105

Figura 82 T-X65NS Imagem elétrons secundários. (a) Propagação da trinca na banda de segregação. (b) e (c) Análise por EDS de duas inclusões próximas da trinca: $\mathrm{Fe}, \mathrm{Mn}$ e $\mathrm{S}$. 106

Figura 83 T-X65NS com trinca nucleada na interface Ferrita/Cementita.

Observam-se vários contornos de ferrita contendo cementita intergranular. 107

Figura 84 Aspecto da superfície do tubo T-X65NS após ensaio de HIC na solução B. Polimento $1 \mu \mathrm{m}$. Sem ataque. MO. (a) trincamento na região central da espessura, 500X. (b) trincamento na região central da espessura, 1000X. 108

Figura 85 T-X65NS Imagem de elétrons restroespalhados, com Inclusões fora do caminho de propagação da trinca. Polimento $1 \mu \mathrm{m}$ sem ataque. MEV. 108

Figura 86 T-X65NS Imagem de elétrons secundários. Trinca nucleada na banda de segregação. Ataque nital $2 \%$. MEV. 109

Figura 87 T-X65NS Imagem de elétrons secundários. Trinca nucleada na banda de segregação. Ataque nital $2 \%$. MEV.

Figura 88 T-X65NS: trincamento propagando-se pela fase frágil. Ataque nital $2 \%$. MEV. 
Figura 89 Detalhe do diagrama de Pourbaix para o sistema $\mathrm{Fe}-\mathrm{H}_{2} \mathrm{O}-\mathrm{S}$, da Figura 24, com as indicações dos valores de $E_{\text {corr }}$ para as soluções $A$ e $B$.

Figura 90 Potenciais de eletrodo de equilíbrio para os sistemas da presente pesquisa e potenciais de corrosão obtidos experimentalmente.

Figura 91 Comparação dos valores médios de Rp para as duas soluções e diferentes amostras.

Figura 92 Curvas de polarização para as reações do sistema ferro em solução

A. Indica-se o $\mathrm{E}_{\text {corr }}$ médio das amostras nessa solução.

Figura 93 Curvas catódica e anódica resultantes para o sistema ferro em solução $A$. Indica-se o $E_{\text {corr }}$ médio das amostras nessa solução.

Figura 94 Curvas de polarização para as reações do sistema ferro em solução

B. Indica-se o $E_{\text {corr }}$ médio das amostras nessa solução.

Figura 95 Curvas catódica e anódica resultantes para o sistema ferro em solução $B$. Indica-se o $E_{\text {corr }}$ médio das amostras nessa solução.

Figura 96 Comparação entre as soluções A e B. Curvas de polarização resultantes em cada caso, indicando o $E_{\text {corr }}$ e a $\mathrm{i}_{\text {corr }}$ 


\section{LISTA DE TABELAS}

Tabela 1 Composição química requerida para tubos PSL 1. Modificado (API, 2004).

Tabela 2 Composição química requerida para tubos PSL 2. Modificado (API, 2004).

Tabela 3 Propriedades mecânicas requeridas para tubos PSL 1. Modificado (API, 2004)

Tabela 4 Propriedades mecânicas requeridas para tubos PSL 2. Modificado (API 5L, 2004)

Tabela 5 Efeito dos elementos de liga nas propriedades dos aços. Modificado (PALMER; KING, 2004; ASM Handbook).

Tabela 6 Características das amostras disponíveis para esta pesquisa.......... 43

Tabela 7 Composição química das amostras desta pesquisa. ........................ 44

Tabela 8 Composição Solução A norma NACE TM 0284-03 .......................... 48

Tabela 9 Composição química da Solução B da norma NACE TM 0284-03,

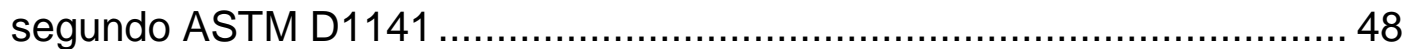




\section{LISTA DE ABREVIATURAS E SIGLAS}

API: $\quad$ American Petroleum Institute

ARBL: $\quad$ Alta Resistência Baixa Liga

CE: $\quad$ Carbono Equivalente

CLR: $\quad$ Crack Length Ratio

CSA: $\quad$ Canadian Standard Association

CSR: $\quad$ Crack Sensivity Ratio

CTR: $\quad$ Crack Thickness Ratio

DIN: $\quad$ Deutsches Institut für Normung

E: Potencial

$E_{B}$ oxidado/B reduzido : potencial de eletrodo de equilíbrio da espécie $B$.

$\mathrm{E}_{\text {corr }}$ : Potencial de corrosão

ECS: $\quad$ Eletrodo de Calomelano Saturado

EDS: $\quad$ Energy Dispersive Spectroscopy

$\mathrm{EH}: \quad \quad$ Eletrodo de hidrogênio

EIS Electrochemical Impedance Spectroscopy

F/FA: $\quad$ Ferrita/ Ferrita Acircular

F/P: $\quad$ Ferrita/Perlita

FRT: $\quad$ Finish Rolling Temperature

Gmd: $\quad$ gramas por metro quadrado por dia

GOST: $\quad$ Gosudarstvennyy Standart - State Standards

$\mathrm{H}_{2} \mathrm{~S}$ : $\quad$ Sulfeto de Hidrogênio

HE: $\quad$ Hydrogen Embrittlement (Fragilização por hidrogênio)

HIC: Hydrogen Induced Cracking (trincamento induzido por hidrogênio)

HSLA: $\quad$ High Strength Low Alloy (Alta Resistencia Baixa Liga)

HTP: $\quad$ High Temperature Processing

| $\mathrm{i} \mid: \quad$ densidade de corrente

Icorr: $\quad$ Corrente de corrosão 
IIW

International Institute of Welding

ipy: inch per year

ksi: 1000 psi (libras por polegada quadrada; equivale a 9,895 Mpa aprox.)

M/A: $\quad$ Microconstituinte agregado de martensita e austenita

MEV: Microscópio Eletrônico de Varredura

MO:

Microscópio Ótico

MPa:

Megapascal

MPY:

Milli-inches Per Year.

NACE:

National Association of Corrosion Engineers

$\mathrm{Pcm}$

Parameter of crack measurement

Psi:

Pounds per square inch (Libras por polegada quadrada)

PSL: $\quad$ Product Specification Level

Rp:

Resistência de Polarização

SOHIC:

Stress-Oriented Hydrogen-Induced Cracking

SRT:

Slab Reheating Temperature

SSC:

Sulfide Stress cracking

SSCC:

Sulfide Stress Corrosion Cracking (trincamento por corrosão sob tensão associada a sulfeto)

TMCP: Thermomechanical Controlled Process 


\section{INTRODUÇÃO E JUSTIFICATIVA}

A crescente demanda mundial de energia requer a rápida exploração de novas reservas em sítios de difícil acesso; o gás tem se projetado como uma das principais fontes de energia para as próximas décadas, isso tem como vantagem um menor impacto sobre as mudanças climáticas já que as emissões de gases perigosos à saúde são bem menores do que aquelas originadas pela queima de carvão e óleo. Segundo Hill, 2007, o consumo anual de gás para o ano de 2025, deve alcançar níveis recordes de 150 trilhões de pés cúbicos por ano (4,2 trilhões de metros cúbicos por ano). Estes incrementos também ocorrerão no caso do petróleo. A avaliação do impacto ambiental, tanto quanto o impacto social e econômico, na construção dos dutos para condução de gás natural, petróleo e seus derivados tem grande importância, levando a desafios técnicos e científicos.

Para o transporte de gás natural e petróleo, desde os locais de exploração até as refinarias, são utilizados tubos de aço de alta resistência que obedecem a American Petroleum Institute (API) como o API 5L X65, o qual tem sido utilizado amplamente em projetos. A procura por redução de custos, no transporte de combustíveis por longas distâncias, tem demandado o desenvolvimento de aços com uma combinação de alta resistencia e maior ductilidade, que permitam a operação a maiores pressões. A diminuição da ductilidade leva à perda nas propriedades de soldabilidade e resistência à fragilização por hidrogênio. A falha destes dutos pode causar sérios danos ambientais, à saúde e trazer perdas econômicas. Quando os aços alta resistência baixa liga corroem em meio aquoso na presença de $\mathrm{H}_{2} \mathrm{~S}$, podem sofrer danos devido ao hidrogênio. Segundo Craid et al. (1993) apud Bezerra (1995), 25\% das falhas em equipamentos de refinarias de petróleo estão de alguma maneira associadas aos danos causados pelo hidrogênio.

O presente trabalho estuda os danos por hidrogênio e a resistência à corrosão de tubos API 5L X65 (sour e não-sour) e chapa grossa destinada a produção de tubo API $5 \mathrm{~L}$ X65, na presença de meios aquosos contendo cloreto e sulfeto. 


\section{REVISÃO DA LITERATURA}

\subsection{AÇOS ALTA RESISTÊNCIA BAIXA LIGA (ARBL) E A LAMINAÇÃO CONTROLADA}

Aços alta resistência e baixa liga ( $A R B L)$, ou aços microligados, são projetados para oferecer melhores propriedades mecânicas e/ou maior resistência à corrosão atmosférica que os aços carbono convencionais. Eles não são considerados aços ligados, no sentido normal da palavra, pois eles são projetados para atender às propriedades mecânicas específicas, em vez de uma composição química específica. (SASTRI et al., 2007) Tais aços seguem a especificação API (USA), DIN (França e Alemanha), CSA (Canadá), e GOST (Rússia), as quais têm contribuído com especificações padrão. Os padrões API são largamente usados no mundo e são a base das especificações da maioria dos usuários, enquanto as outras têm sido usadas em projetos locais. As normas API classificam os tubos (gasodutos e oleodutos) conforme o valor de limite de escoamento. Segundo a norma API $5 \mathrm{~L}$ as tubulações têm designações $A, B$ (para os casos de menor limite de escoamento) ou $X$ (para os casos de maior limite de escoamento), sendo que a designação $A, B$ ou $X$ é seguida pelo valor do limite mínimo de escoamento, que é dado em dois dígitos em unidade ksi (INTERNATIONAL IRON AND STEEL INSTITUTE, 1987).

Segundo Gray (1973), os aços microligados laminados a quente datam do final da década de 30. A adição de elementos microligantes como nióbio, vanádio e titânio foi utilizada para dar melhores propriedades por meio do controle da transformação de austenita em ferrita, porque estes elementos retardam a recristalização da austenita, e por endurecimento por precipitação (GRAY, 1973). Os resultados foram aços com maior resistência mecânica, os quais apresentaram limite de escoamento entre $42 \mathrm{ksi}$ a $52 \mathrm{ksi}(290 \mathrm{MPa}$ a $310 \mathrm{MPa}$ ) -hoje a produção de um tubo em aço $A R B L$ com tal propriedade receberia a designação X42 a X52. Durante os 25 anos seguintes houve um período de calma devido à ausência de incentivos comerciais e à falta de um maior fornecimento de ferro-nióbio. A utilização de microligas em aços ocorreu 
inicialmente em chapas, vigas, barras de reforço e peças forjadas tratadas termicamente. Somente a partir de 1959 iniciou-se seu uso em tubulação de aço (GRAY, 1973). A necessidade de tubos de aço alta resistência e baixa liga para o transporte de petróleo e gás, desde regiões distantes com condições extremas, e também a necessidade de redução de custos, levaram a maiores exigências de resistência mecânica. Isso forçou o rápido desenvolvimento das tecnologias usadas na fabricação dos aços ARBL (STALHEIM et al., 2007). A Figura 1 mostra a correlação entre as tendências e os requisitos correspondentes para tubos.

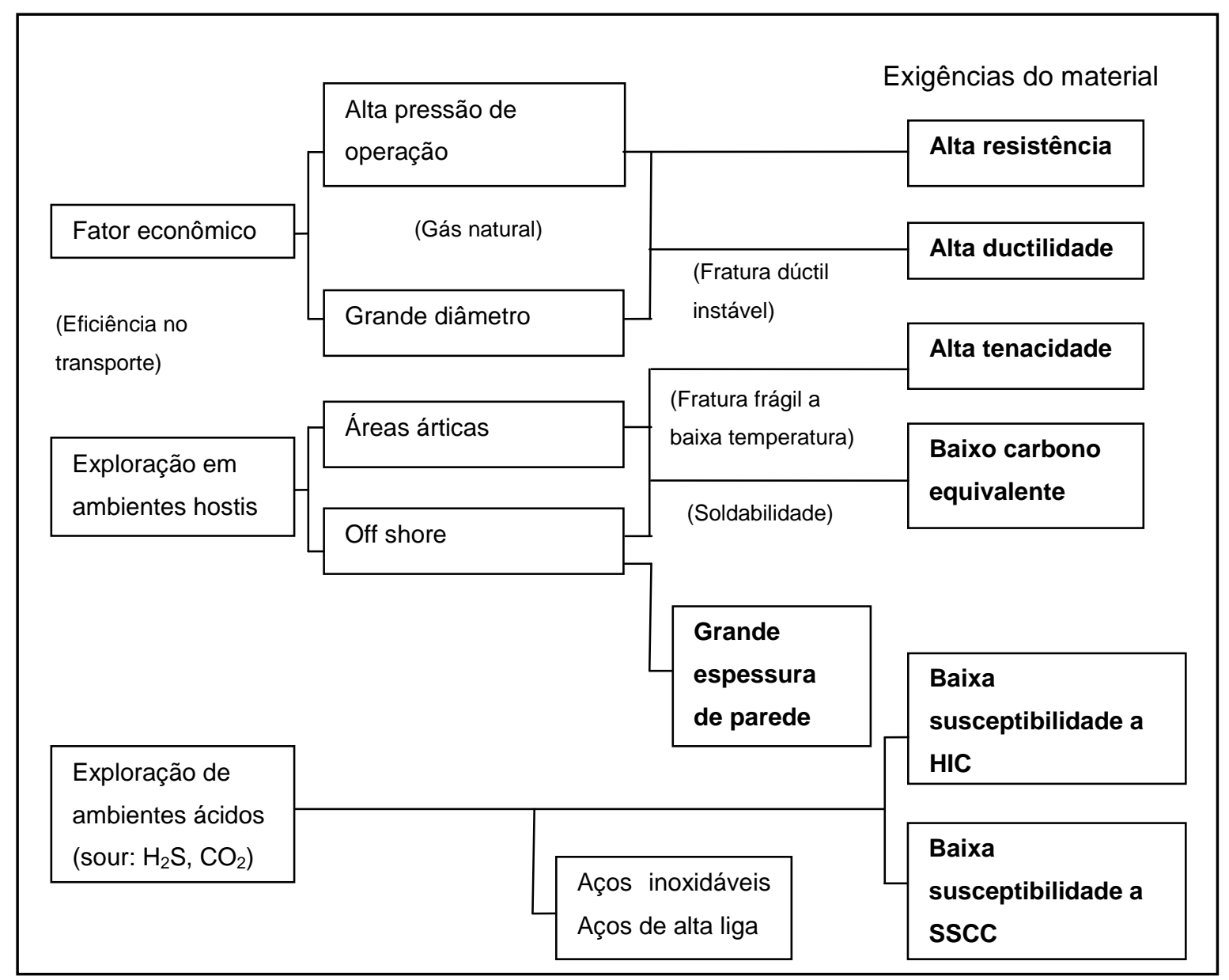

Figura 1 Propriedades de tubos usados em projetos a partir de 1980. Modificado. (INTERNATIONAL IRON AND STEEL INSTITUTE, 1987)

Inicialmente as chapas de aço eram produzidas por laminação a quente e normalização; com o desenvolvimento dos aços ARBL houve mudanças nos 
processos de fabricação: na aciaria, ocorreram as adições de $\mathrm{Nb}$, Ti e/ou V, além da redução do teor de C; e, o processo de conformação mecânica teve alterações para um processo de laminação controlada, que envolve tratamento termomecânico e resfriamento acelerado. Tais desenvolvimentos permitiram a obtenção de aços ARBL com boas propriedades de resistência mecânica, tenacidade e soldagem (Figura 2) (INTERNATIONAL IRON AND STEEL INSTITUTE, 1987).

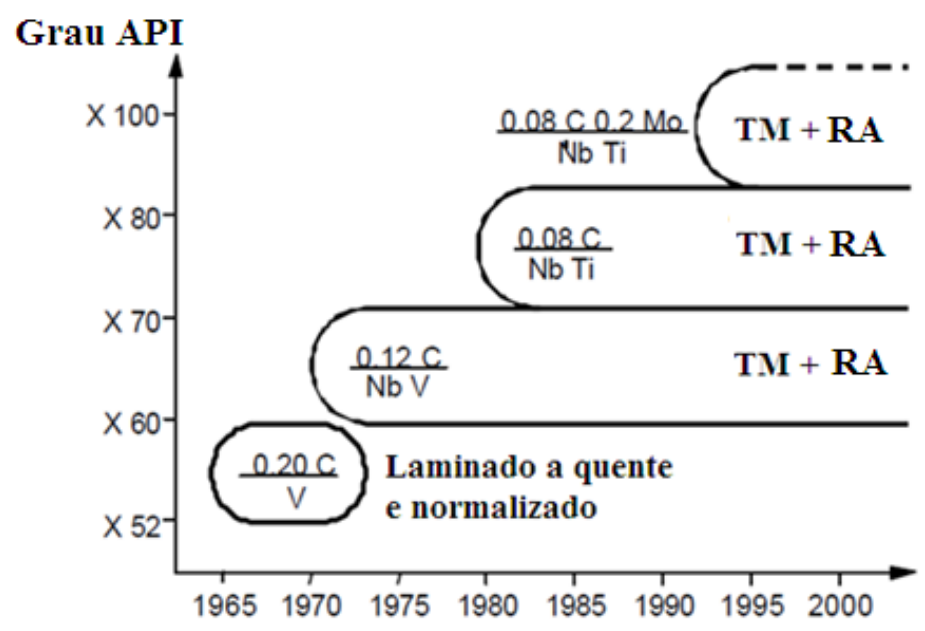

Figura 2 Desenvolvimento dos aços ARBL. Modificado (HILLENBRAND; KALWA, 2002) TM: Tratamento Termomecânico

RA: Resfriamento Acelerado

\subsection{ESPECIFICAÇÕES DA AMERICAN PETROLEUM INSTITUTE - API - PARA TUBULAÇÕES}

O objetivo da norma API $5 \mathrm{~L}$ é fornecer padrões para uso adequado de tubulações que transportem gás, água e petróleo, incluindo tubos sem costura e soldados. Esta norma estabelece um critério de classificação dos tubos chamado Product Specification Level (PSL), que divide os tubos entre PSL 1 e PSL 2, cada uma destas classificações define diferentes níveis de exigências técnicas. Tubos que se encaixam entre os graus A25 até X70 são classificados como PSL 1 e tubos que se encaixam entre os graus $B$ até X80 são classificados como PSL 2. O comprador pode adicionar critérios que não estão presentes na avaliação dos tubos PSL 1 e PSL 2, como: limites específicos de 
Carbono Equivalente (CE), tenacidade, limite de escoamento e limite de resistência à tração.

Os níveis de qualidade se diferem, principalmente, pela composição química e pelas propriedades mecânicas. A Tabela 1 mostra a composição química requerida para tubos PSL 1 e a Tabela 2 mostra a composição química requerida para tubos PSL 2. Para tubos PSL 2 exige-se também o cálculo do CE.

O CE é uma ferramenta simples de predizer a suscetibilidade ao trincamento por resfriamento, este parâmetro empírico representa a capacidade do aço endurecer-se em função da composição.

Para teores de carbono menores ou iguais a $0,12 \%$ o CE deve ser calculado pela equação 1, comumente chamada Ito-Bessyo (Parameter of crack measurement - Pcm) desenvolvida especialmente para aços ARBL (API 5L, 2004).

$$
C E(P c m)=C+\frac{S i}{30}+\frac{M n}{20}+\frac{C u}{20}+\frac{N i}{60}+\frac{C r}{20}+\frac{M o}{15}+\frac{V}{10}+5 B
$$

Quando o teor de carbono é maior do que $0,12 \%$ o CE é calculado pela equação 2, comumente chamada IIW (International Institute of Welding). (API 5L, 2004).

$$
C E(I I W)=C+\frac{M n}{6}+\frac{(C r+M o+V)}{5}+\frac{(\mathrm{Ni}+\mathrm{Cu})}{15}
$$

Para graus X80 o valor do CE é o acertado entre o produtor e o comprador. Quando aplicável, pode-se usar os teores máximos de 0,25\% (Pcm) e 0,43\% (IIW), embora para aços modernos estes podem ser reduzidos a 0,18-0,22 (Pcm) e a 0,32-0,34 (IIW) (PALMER, KING 2004). 
Tabela 1 Composição química requerida para tubos PSL 1. Modificado (API, 2004).

\begin{tabular}{|c|c|c|c|c|c|c|c|}
\hline & Carbono, & Manganês & \multicolumn{2}{|c|}{ Fósforo } & Enxofre & Titânio & Outros \\
\hline Grau \& classe & $\operatorname{Max}^{a}$ & $\operatorname{Max}^{\mathrm{a}}$ & Min & $\max$ & $\max$ & $\operatorname{Max}$ & \\
\hline \multicolumn{8}{|c|}{ Sem costura } \\
\hline A25, C1 I & 0,21 & 0,60 & & 0,030 & 0,030 & & \\
\hline A25, C1 II & 0,21 & 0,60 & 0,045 & 0,080 & 0,030 & & \\
\hline A & 0,22 & 0,90 & & 0,030 & 0,030 & & \\
\hline B & 0,28 & 1,20 & & 0,030 & 0,030 & 0,04 & $b, c, d$ \\
\hline $\mathrm{X} 42$ & 0,28 & 1,30 & & 0,030 & 0,030 & 0,04 & $c, d$ \\
\hline $\mathrm{X} 46, \mathrm{X} 52, \mathrm{X} 56$ & 0,28 & 1,40 & & 0,030 & 0,030 & 0,04 & $c, d$ \\
\hline $\mathrm{X} 60^{\top}$ & 0,28 & 1,40 & & 0,030 & 0,030 & 0,04 & $c, d$ \\
\hline $\mathrm{X} 65^{\dagger}, \mathrm{X} 70^{\dagger}$ & 0,28 & 1,40 & & 0,030 & 0,030 & 0,06 & $\overline{c, d}$ \\
\hline \multicolumn{8}{|c|}{ Soldados } \\
\hline A25, C1 I & 0,21 & 0,60 & & 0,030 & 0,030 & & \\
\hline A25, C1 II & 0,21 & 0,60 & 0,045 & 0,080 & 0,030 & & \\
\hline A & 0,22 & 0,90 & & 0,030 & 0,030 & & \\
\hline B & 0,26 & 1,20 & & 0,030 & 0,030 & 0,04 & $b, c, d$ \\
\hline $\mathrm{X} 42$ & 0,26 & 1,30 & & 0,030 & 0,030 & 0,04 & $c, d$ \\
\hline $\mathrm{X} 46, \mathrm{X} 52, \mathrm{X} 56$ & 0,26 & 1,40 & & 0,030 & 0,030 & 0,04 & $c, d$ \\
\hline $\mathrm{X} 60^{\top}$ & 0,26 & 1,40 & & 0,030 & 0,030 & 0,04 & $\mathrm{c}, \mathrm{d}$ \\
\hline$X 65^{\dagger}$ & 0,26 & 1,45 & & 0,030 & 0,030 & 0,06 & $c, d$ \\
\hline$X 70^{\dagger}$ & 0,26 & 1,65 & & 0,030 & 0,300 & 0,06 & $c, d$ \\
\hline
\end{tabular}

Obs: A legenda, com o significado de cada símbolo, está na Tabela 2. 
Tabela 2 Composição química requerida para tubos PSL 2. Modificado (API, 2004).

\begin{tabular}{|c|c|c|c|c|c|c|}
\hline & Carbono & Manganês & Fósforo & Enxofre & Titânio & Outros \\
\hline Grau \& classe & $\operatorname{Max}^{\mathrm{a}}$ & $\operatorname{Max}^{\mathrm{a}}$ & Max & $\max$ & $\operatorname{Max}$ & \\
\hline \multicolumn{7}{|c|}{ Sem costura } \\
\hline$B$ & 0,24 & 1,20 & 0,025 & 0,015 & 0,04 & d,e \\
\hline X42 & 0,24 & 1,30 & 0,025 & 0,015 & 0,04 & $c, d$ \\
\hline $\begin{array}{c}\mathrm{X} 46, \mathrm{X}^{\mathrm{X}} \mathrm{52,} \mathrm{X} 56, \\
\mathrm{X} 60^{\dagger}\end{array}$ & 0,24 & 1,40 & 0,025 & 0,015 & 0,04 & $c, d$ \\
\hline$\times 65^{\dagger}, X 70^{\dagger}, \times 80^{\dagger}$ & 0,24 & 1,40 & 0,025 & 0,015 & 0,04 & $c, d$ \\
\hline \multicolumn{7}{|c|}{ Soldados } \\
\hline $\mathrm{B}$ & 0,22 & 1,20 & 0,025 & 0,015 & 0,04 & $\mathrm{~d}, \mathrm{e}$ \\
\hline X42 & 0,22 & 1,30 & 0,025 & 0,015 & 0,04 & $c, d$ \\
\hline $\mathrm{X} 46, \mathrm{X} 52, \mathrm{X} 56$ & 0,22 & 1,40 & 0,025 & 0,015 & 0,04 & $c, d$ \\
\hline $\mathrm{X} 60^{\top}$ & 0,22 & 1,40 & 0,025 & 0,015 & 0,04 & $c, d$ \\
\hline$\times 65^{\dagger}$ & 0,22 & 1,45 & 0,025 & 0,015 & 0,06 & $c, d$ \\
\hline$\times 70^{\dagger}$ & 0,22 & 1,65 & 0,025 & 0,015 & 0,06 & $c, d$ \\
\hline $\mathrm{X} 80^{\dagger}$ & 0,22 & 1,85 & 0,025 & 0,015 & 0,06 & $c, d$ \\
\hline
\end{tabular}

${ }^{\text {a }}$ Para cada redução de $0,01 \%$ abaixo do teor máximo de carbono, é permitido um incremento de 0,05\% acima do teor máximo de manganês, até um máximo de $1,50 \%$ para graus $X 42$ até $X 52$, até um máximo de $1,65 \%$ para graus superiores a X52 até X70, e acima de $2,00 \%$ para graus $X 70$ e superiores.

${ }^{b}$ A soma do teor de nióbio e vanádio não pode exceder $0,03 \%$, a não ser que seja um acordo entre o comprador e o fabricante, podendo-se estabelecer outro limite máximo.

${ }^{\mathbf{c}}$ Nióbio, vanádio, ou combinações podem ser usados a critério do fabricante.

d A soma dos teores de nióbio, vanádio, e titânio não deve exceder $0,15 \%$.

e A soma dos teores de nióbio e vanádio não deve exceder $0,06 \%$ a não se que seja um acordo entre o comprador e o fabricante, podendo-se estabelecer outro limite máximo.

f Outras composições químicas podem ser fornecidas por meio de um acordo entre o comprador e o fabricante, desde que os limites da observação "d", e os limites máximos de fósforo e enxofre sejam cumpridos.

A Tabela 3 apresenta as propriedades mecânicas mínimas para tubos PSL 1 e a Tabela 4 para tubos PSL 2 .

Tabela 3 Propriedades mecânicas requeridas para tubos PSL 1. Modificado (API, 2004)

\begin{tabular}{|c|c|c|c|c|c|}
\hline & \multicolumn{2}{|c|}{ Limite de Escoamento } & \multicolumn{2}{c|}{ Limite de Resistência } & Alongamento em 2 pol (50,8mm) \\
\hline Grau & $\mathrm{ksi}$ & $\mathrm{MPa}$ & $\mathrm{ksi}$ & $\mathrm{Mpa}$ & Porcentagem mínima \\
\hline A25 & 25 & 172 & 45 & 310 & $\mathrm{a}$ \\
\hline $\mathrm{A}$ & 30 & 207 & 48 & 331 & $\mathrm{a}$ \\
\hline $\mathrm{B}$ & 35 & 241 & 60 & 414 & $\mathrm{a}$ \\
\hline X42 & 42 & 290 & 60 & 414 & $\mathrm{a}$ \\
\hline X46 & 46 & 317 & 63 & 434 & $\mathrm{a}$ \\
\hline X52 & 52 & 359 & 66 & 455 & $\mathrm{a}$ \\
\hline X56 & 56 & 386 & 71 & 490 & $\mathrm{a}$ \\
\hline X60 & 60 & 414 & 75 & 517 & $\mathrm{a}$ \\
\hline X65 & 65 & 448 & 77 & 531 & $\mathrm{a}$ \\
\hline X70 & 70 & 483 & 82 & 565 & \\
\hline
\end{tabular}

Obs: A legenda, com o significado de cada símbolo está na Tabela 4. 
Tabela 4 Propriedades mecânicas requeridas para tubos PSL 2. Modificado (API 5L, 2004)

\begin{tabular}{|c|c|c|c|c|c|c|c|c|c|}
\hline \multirow{3}{*}{ Grau } & \multicolumn{4}{|c|}{ Limite de Escoamento } & \multicolumn{4}{|c|}{ Limite de Resistência } & \multirow{3}{*}{$\begin{array}{c}\text { Alongamento em } \\
2 \text { pol }(50,8 \mathrm{~mm}) \\
\text { Porcentagem } \\
\text { mínima }\end{array}$} \\
\hline & \multicolumn{2}{|c|}{ Mínimo } & \multicolumn{2}{|c|}{ Máximo } & \multicolumn{2}{|c|}{ Mínimo } & \multicolumn{2}{|c|}{ Máximo ${ }^{C}$} & \\
\hline & ksi & $\mathrm{MPa}$ & ksi & $\mathrm{MPa}$ & ksi & Mpa & ksi & $\mathrm{MPa}$ & \\
\hline B & 35 & 241 & $65^{\mathrm{d}}$ & 448 & 60 & 414 & 110 & 758 & a \\
\hline $\mathrm{X} 42$ & 42 & 290 & 72 & 496 & 60 & 414 & 110 & 758 & a \\
\hline $\mathrm{X} 46$ & 46 & 317 & 76 & 524 & 63 & 434 & 110 & 758 & a \\
\hline $\mathrm{X} 52$ & 52 & 359 & 77 & 531 & 66 & 455 & 110 & 758 & a \\
\hline $\mathrm{X} 56$ & 56 & 386 & 79 & 544 & 71 & 490 & 110 & 758 & a \\
\hline $\mathrm{X} 60$ & 60 & 414 & 82 & 565 & 75 & 517 & 110 & 758 & a \\
\hline $\mathrm{X} 65$ & 65 & 448 & 87 & 600 & 77 & 531 & 110 & 758 & a \\
\hline $\mathrm{X} 70$ & 70 & 483 & 90 & 621 & 82 & 565 & 110 & 758 & a \\
\hline $\mathrm{X} 80$ & 80 & 552 & $100^{e}$ & 690 & 90 & 621 & 120 & 827 & a \\
\hline
\end{tabular}

a $\mathrm{O}$ alongamento mínimo em 2 pol $(50,8 \mathrm{~mm})$ deve ser determinado no sistema internacional com a seguinte equação:
$e=1944 \frac{A^{0.2}}{U^{0.9}}$
$\boldsymbol{e}$ : Alongamento mínimo 50,8mm em porcentagem arredondado a

porcentagem mais próxima; $\boldsymbol{U}$ : limite de resistência mínimo dado em MPa; $\boldsymbol{A}$ : área da seção transversal útil do corpo de prova, com dimensões da seguinte maneira:

Para corpos de prova em forma de barra redonda:

- $130 \mathrm{~mm}^{2}$ para corpos de prova de $12.7 \mathrm{~mm}$ e $8.9 \mathrm{~mm}$ de diâmetro.

- $65 \mathrm{~mm}^{2}$ para corpos de prova de $6.5 \mathrm{~mm}$ de diâmetro.

Para corpos de prova de secção completa:

- Quando a área calculada, usando-se o diâmetro exterior especificado e a espessura especificada da tubulação, é maior do que $485 \mathrm{~mm}^{2}$, utiliza-se o valor de $485 \mathrm{~mm}^{2}$; quando o valor calculado é menor do que $485 \mathrm{~mm}^{2}$, o valor deve ser arredondado, considerando-se os $10 \mathrm{~mm}$ mais próximos.

Para corpos de prova retangulares:

- Quando a área calculada, usando-se a espessura especificada do corpo de prova e a espessura especificada da tubulação, é maior do que $485 \mathrm{~mm}^{2}$, utiliza-se o valor de 485 $\mathrm{mm}^{2}$; quando o valor calculado é menor do que $485 \mathrm{~mm}^{2}$, o valor deve ser arredondado, considerando-se os $10 \mathrm{~mm}$ mais próximos.

b Máximo limite de escoamento para um grau intermediário deve ser o máximo do grau seguinte.

c Todos os graus intermediários tem um limite de resistência de $110 \mathrm{ksi}(758 \mathrm{MPa})$.

d Máximo limite de escoamento para tubo grau B em tamanhos sujeitos a ensaios na secção longitudinal é 72 ksi (496 MPa).

e Para espessuras de parede maiores de 0,984 pol. (25,0 mm), o máximo limite de escoamento deve ser determinado como um acordo entre o comprador e o fabricante. 


\subsection{METALURGIA DOS AÇOS ARBL}

Os aços designados como ARBL (ou HSLA) são caracterizados por serem resistentes mecanicamente, conformáveis e soldáveis. Estas características são alcançadas modificando fatores tais como refino dos grãos de ferrita, endurecimento por solução sólida, endurecimento por precipitação e por transformação de fase.

Segundo a International Iron And Steel Institute (1987), o refino de grão de ferrita tornou-se um dos fatores mais importantes na fabricação de aços ARBL. Há várias maneiras para a redução dos tamanhos de grãos: uma das primeiras foi o uso de alumínio combinado com nitrogênio principalmente em aços normalizados; a adição de nióbio, vanádio e titânio também tem a propriedade de refinar os grãos de ferrita. Nos anos 80 a fabricação de aços ARBL era feita por técnicas de processamento termomecânico (thermomechanical Rolling controlled process - TMCP) as quais são termicamente mais eficientes e ainda são usadas na produção de tubulações de aço.

Atualmente as microestruturas de Ferrita/Perlita (F/P) e Ferrita/Ferrita Acicular (F/FA) são os dois projetos básicos de microestrutura em tubulações de aço com designações até X80 (STALHEIM et al., 2007). Com as melhorias feitas nos processos termomecânicos e no controle dos elementos de liga se tem alcançado tamanhos de grão de ferrita em aços comerciais TMCP de 3-5 $\mu \mathrm{m}$ (HOU et al., 2003; ZHAO et al., 2003). Também tem sido reportado o desenvolvimento de aços $A R B L$ com grãos ultrafinos de ferrita com tamanhos de grão ao redor de $1 \mu \mathrm{m}$ (até 0,8 $\mu \mathrm{m}$ ) (HOU et al., 2003; ZHAO et al., 2003; MAJTA; MUSZKA, 2003 ), mediante a otimização dos processos de laminação controlada.

O tamanho de grão é controlado por meio da temperatura final de laminação e da sequência de deformação; nestes processos o nióbio tem um papel importante no refino de grão porque atrasa a recristalização da austenita durante as primeiras fases de conformação (INTERNATIONAL IRON AND STEEL INSTITUTE, 1987; DEARDO, 2001; CAO, 2007). 


\subsubsection{AÇOS LAMINADOS TERMOMECANICAMENTE COM RESFRIAMENTO ACELERADO}

Também conhecida como laminação controlada (Thermomechanical Rolling Controlled Processing - TMCP), neste processo são aproveitadas todas as vantagens da laminação, alcançando propriedades mecânicas tais como resistência e tenacidade. Em aços ARBL TMCP os elementos microligantes mais importantes no processo são $\mathrm{Nb}, \mathrm{V}$ e $\mathrm{Ti}$ acompanhados de outros elementos como Mn e Mo, estes são adicionados para obter a microestrutura e propriedades mecânicas desejadas, particularmente o Mo é geralmente considerado como um elemento importante para a formação de ferrita acicular (INTERNATIONAL IRON AND STEEL INSTITUTE, 1987; TEOH,1995; XIAO, 2006; XU, 2010).

Maiores níveis de resistência mecânica e tenacidade são possíveis através de refino dos grãos, resultado da presença de elementos microligantes somado ao tratamento termomecânico aplicado. Os elementos microligantes remanescentes depois da laminação se precipitam na ferrita durante 0 resfriamento ao ar. A união de mecanismos de aumento da resistência como endurecimento por solução sólida, precipitação, transformação de fase e refino de grão, através do tratamento termomecânico, possibilitou a redução dos teores de carbono e elementos de liga, reduzindo o CE e aumentando a soldabilidade do material (INTERNATIONAL IRON AND STEEL INSTITUTE, 1987).

$\mathrm{Na}$ produção de tubos $\mathrm{ARBL}$ há duas estratégias básicas de laminação: laminação a quente (para graus menores que X52) e TMCP, onde se tem a laminação a quente, mas com temperatura controlada, que é usada para produzir tubos com graus $\mathrm{X} 60$ até $\mathrm{X} 80$. Nos últimos anos, tem ganhado popularidade o processo TMCP chamado HTP (High Temperature Processing), onde a laminação ocorre em temperatura mais elevada do que no processo TMCP, devido principalmente ao alto teor de nióbio, que provoca um aumento da faixa de temperatura na qual não há recristalização da austenita. $O$ processo HTP é principalmente utilizado para a produção comercial do grau 
X80 e desenvolvimento de graus maiores. O primeiro projeto comercial para X80 ocorreu em 1997/98 (STALHEIM, 2005; STALHEIM et al., 2007).

O processo de laminação controlada consiste de duas etapas:

- Desbaste da chapa (slab) a alta temperatura, com recristalização plena da austenita entre passes;

- Acabamento da chapa a baixa temperatura, sem recristalização da austenita entre passes.

$\mathrm{Na}$ Figura 3 é apresentado o desenvolvimento da microestrutura durante 0 processo de laminação controlada com resfriamento acelerado. Este começa com a etapa de reaquecimento das placas para a dissolução de carbonitretos. Nesta etapa o tamanho de grão de austenita é controlado cuidadosamente. $\mathrm{Na}$ fase seguinte as placas são esboçadas em cilindros de laminação para produzir finos grãos poligonais de austenita por meio de recristalização. Geralmente tem-se uma etapa intermediária de espera - sem aplicação de deformação - até que a chapa atinja a temperatura em que a austenita recristaliza dando origem a grãos de austenita menores (GORNI, 2006).

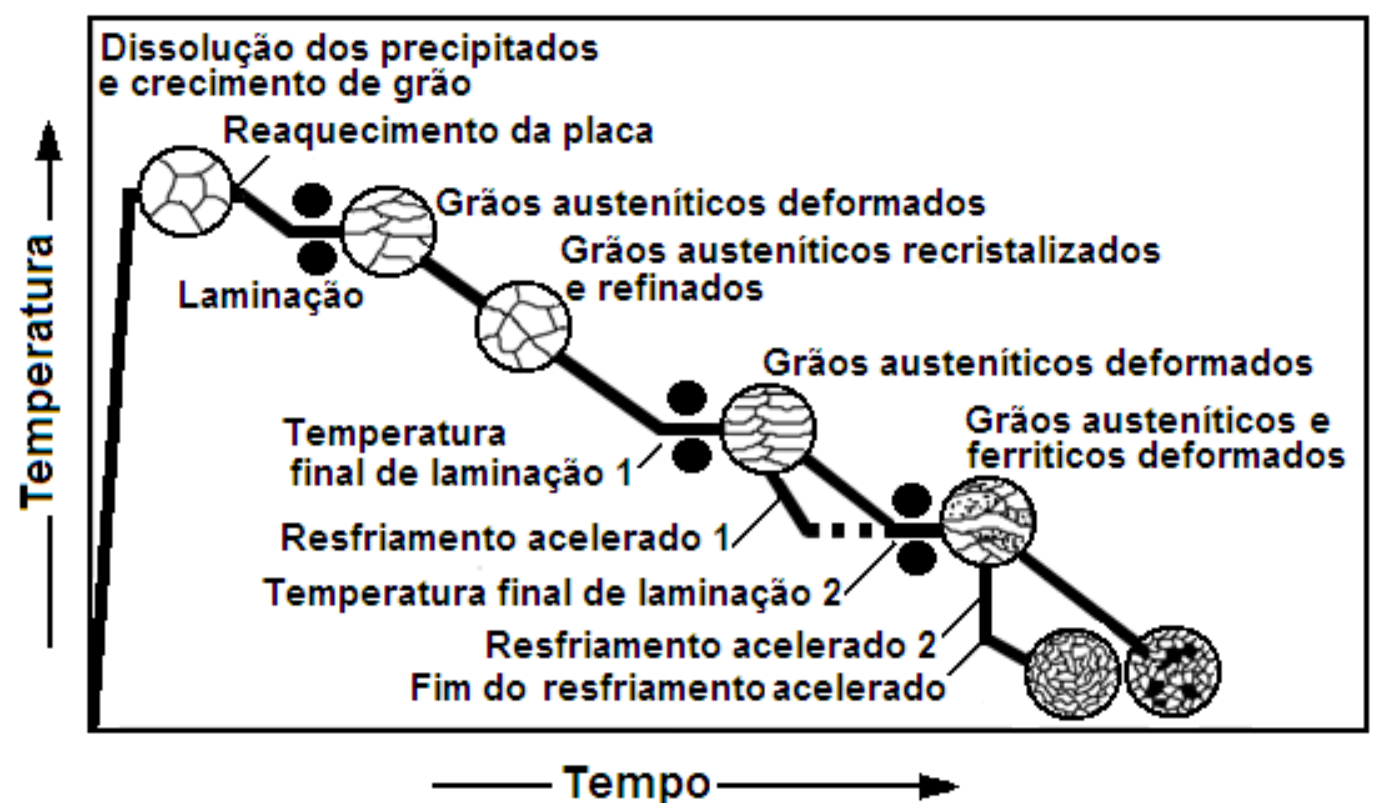

Figura 3 llustração da laminação controlada com e sem resfriamento acelerado durante a última etapa. Modificado (Hillenbrand 2001). 
A temperatura final de laminação 1 tem que ser mantida dentro da faixa de não-recristalização da austenita; nessa etapa tem-se o refino dos grãos de austenita por deformação. No processo de resfriamento acelerado tem-se um primeiro passo (Resfriamento acelerado 1, Figura 3) no qual ocorre a precipitação de ferrita no interior dos grãos deformados de austenita (constituindo assim um processo de refino de grão) o qual é seguido de deformação (Temperatura final de laminação 2) aumentando o refinamento dos grãos. O segundo passo de resfriamento (Resfriamento acelerado 2) impede a transformação da austenita remanescente em perlita durante o resfriamento. A transformação da austenita nesse resfriamento gera microconstituintes tais como bainita e microconstituinte M/A (Martensita/Austenita), melhorando assim a homogeneidade da microestrutura final comparativamente ao caso sem 0 Resfriamento acelerado 2, o qual originaria uma microestrutura de ferrita e perlita, inclusive com bandeamento (Figura 4).

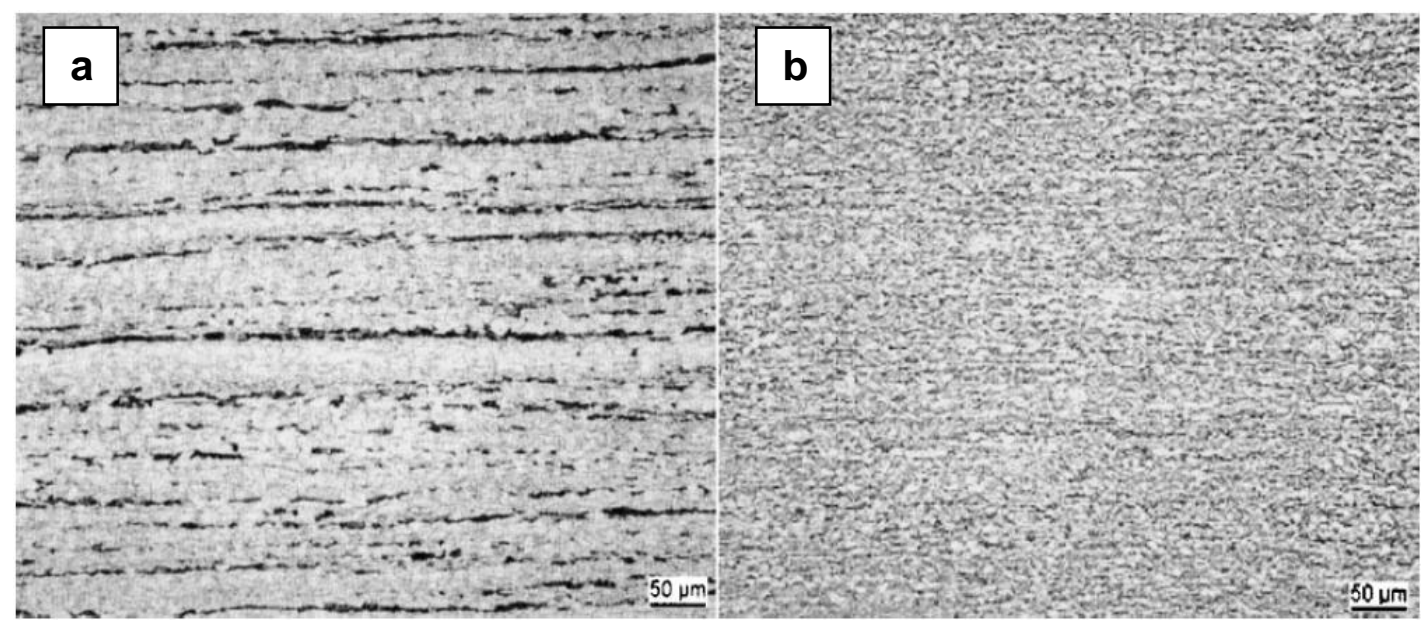

Figura 4 Tubo X65, espessura 31,4 mm. (a) processo TMCP; (b) processo TMCP + Resfriamento acelerado 2. (BAUER, 2005)

As variáveis mais importantes no resfriamento acelerado são a velocidade de resfriamento (aproximadamente $15^{\circ} \mathrm{C} / \mathrm{s}$ até $20^{\circ} \mathrm{C} / \mathrm{s}$ ) e a temperatura de parada (TSUKADA et al., 1993; TEOH, 1995; HILLENBRAND 2001; STALHEIM, 2005; BAUER 2005). A Figura 4a apresenta microestrutura em bandas de ferrita e perlita, enquanto a Figura $4 b$ apresenta uma microestrutura fina e uniforme 
constituída de ferrita, onde o aço passou pelos dois estágios de resfriamento. A homogeneidade desta microestrutura também melhorou as propriedades de resistência e tenacidade do material (BAUER, 2005).

Mediante o uso de teores adequados de elementos de liga e a aplicação de processos de laminação e de resfriamento adequados, as microestruturas resultantes são a ferrita acicular e quantidades menores de $\mathrm{M} / \mathrm{A}$ e bainita (BAUER et al., 2005). A fim de obter uma boa combinação de alta resistência e tenacidade em aços para tubulações, é necessário controlar os parâmetros termomecânicos de todo o processo produtivo com precisão, estes incluem o reaquecimento de placas, laminação controlada, resfriamento controlado, temperaturas de resfriamento com um conhecimento da utilização dos fatores que brindam dureza e tenacidade, como refinamento de grão, precipitação, ilhas de M/A como segunda fase e solução sólida (XIAO et al., 2006). Manter um estreito controle dos elementos de liga é um fator importante na produção de placas de aço destinadas a aplicações em gasodutos. Na Tabela 5 é apresentado o efeito de alguns dos elementos de liga nas propriedades mecânicas e de resistência à corrosão. 
Tabela 5 Efeito dos elementos de liga nas propriedades dos aços. Modificado (PALMER; KING, 2004; ASM Handbook, 1993).

\begin{tabular}{|c|c|c|}
\hline \multicolumn{2}{|c|}{ Elemento de liga } & Efeito sobre as propriedades mecânicas e de corrosão \\
\hline Carbono & C & $\begin{array}{l}\text { Aumenta o limite de resistência à tração e dureza, mas reduz a } \\
\text { tenacidade, a soldabilidade e diminui a resistência à corrosão }\end{array}$ \\
\hline Manganês & $\mathrm{Mn}$ & $\begin{array}{l}\text { Aumenta o limite de resistência à tração, à dureza e a resistência à } \\
\text { abrasão. Forma sulfetos que podem causar HIC }\end{array}$ \\
\hline Fósforo & $\mathrm{P}$ & $\begin{array}{l}\text { Aumenta a fragilidade e a susceptibilidade ao trincamento. É } \\
\text { restringido a teores menores do que } 0,015 \% \text { para aplicações ácidas } \\
\text { (sour service). }\end{array}$ \\
\hline Enxofre & $S$ & $\begin{array}{l}\text { Aumenta a fragilidade e trincamento. Forma sulfeto de manganês o } \\
\text { qual atua como sítio preferencial de acúmulo de hidrogênio, levando } \\
\text { a trincas internas. Na superfície os sulfetos são iniciadores de pites. } \\
\text { É restringido a teores menores do que } 0,005 \% \text { para aplicações } \\
\text { ácidas (sour service). }\end{array}$ \\
\hline Silício & Si & $\begin{array}{l}\text { Aumenta o limite de resistência à tração, mas reduz } \\
\text { acentuadamente a tenacidade, é adicionado para a remoção de } \\
\text { oxigênio: } 0,35-0,4 \% \text {. }\end{array}$ \\
\hline Alumínio & $\mathrm{Al}$ & $\begin{array}{l}\text { Usado para refino de grão. Aumenta a dureza. É adicionado como } \\
\text { desoxidante: } 0,02-0,05 \% \text {. }\end{array}$ \\
\hline Cobre & $\mathrm{Cu}$ & $\begin{array}{l}\text { Melhora a resistência a trincamento (sour cracking) para ambientes } \\
\text { com pH maior do que } 4,5 \text {. Na presença de Ni estabiliza a película de } \\
\text { óxidos aumentando a resistência à corrosão atmosférica. }\end{array}$ \\
\hline Cálcio & $\mathrm{Ca}$ & $\begin{array}{l}\text { Desoxidante e dessulfurante. É usado para o controle da forma (fina } \\
\text { globulização) das inclusões em aços destinados a gasodutos e } \\
\text { oleodutos para aplicações sour (sour service). }\end{array}$ \\
\hline Molibdênio & Mo & $\begin{array}{l}\text { Aumenta o limite de resistência à tração, e a resistência à corrosão, } \\
\text { reduz o ataque por pites. }\end{array}$ \\
\hline Titânio & $\mathrm{Ti}$ & $\begin{array}{l}\text { Aumenta o limite de resistência à tração, a temperabilidade. Refina o } \\
\text { grão. Precipita carboneto e/ou nitreto de titânio. }\end{array}$ \\
\hline Nióbio & $\mathrm{Nb}$ & $\begin{array}{l}\text { Aumenta o limite de resistência e o limite de escoamento. Refina o } \\
\text { grão. Precipita carboneto e/ou nitreto de nióbio. }\end{array}$ \\
\hline Vanádio & V & $\begin{array}{l}\text { Aumenta o limite de resistência à tração, a temperabilidade. Refina o } \\
\text { grão. Precipita carboneto e/ou nitreto de vanádio. }\end{array}$ \\
\hline Níquel & $\mathrm{Ni}$ & $\begin{array}{l}\text { Aumenta o limite de resistência à tração, a tenacidade, melhora a } \\
\text { resistência à corrosão. Aços com teores maiores do que } 1 \% \text { não são } \\
\text { permitidos para aplicações sour. }\end{array}$ \\
\hline Boro & B & $\begin{array}{l}\text { É adicionado, em teores de } 0,0005 \% \text { a } 0,003 \% \text {, a aços } \\
\text { completamente desoxidados para aumentar a temperabilidade. }\end{array}$ \\
\hline
\end{tabular}




\subsection{DANOS DEVIDO AO HIDROGÊNIO}

A energia transportada por tubos de aço é muito importante para a sociedade e para a economia, sendo que, no caso de falhas, estas acarretam danos ambientais e econômicos muito grandes. As fraturas associadas com 0 hidrogênio, em particular, constituem mais de $25 \%$ das falhas que ocorrem em indústrias de óleo e gás (CRAID et al.,1993 apud BEZERRA, 1995). Os mecanismos mediante os quais estes processos ocorrem estão descritos mais adiante.

Nas indústrias petrolíferas as falhas que ocorrem por causa do hidrogênio são altamente destrutivas e perigosas porque acontecem repentinamente. A partir de meados do século passado, as jazidas de petróleo e gás exploradas contém altos teores de ácido sulfídrico $\left(\mathrm{H}_{2} \mathrm{~S}\right)$ e dióxido de carbono $\left(\mathrm{CO}_{2}\right)$ (TOTAL, 2007). Esses gases, em meio aquoso, formam uma solução altamente corrosiva (GORNI, 2006; PALMIERI, 2011).

As interações do metal com o hidrogênio podem resultar na formação de soluções sólidas, hidrogênio molecular, produtos gasosos e hidretos. Dependendo da interação do hidrogênio e o metal, algum tipo de dano se manifesta. (SASTRI et al., 2007). Dentro da literatura especializada não se tem um consenso sobre a classificação e descrição dos mecanismos de danos pelo hidrogênio (hydrogen damage). Tal preocupação já esteve presente no trabalho de Okamoto (2010). Da mesma forma que Okamoto (2010), a premissa adotada também no presente trabalho será de que a fragilização por hidrogênio $(\mathrm{HE})$ é um fenômeno ligado à perda de ductilidade e não pode ser medido apenas através de evidências macroscópicas como as trincas. Sua relação com os outros tipos que envolvem trincas (HIC, Sulfide Stress Cracking - SSCe Stress-Oriented Hydrogen-Induced Cracking - SOHIC) é de que estes sejam favorecidos pelo fenômeno da fragilização, ou seja, a ocorrência da fragilização (que possui mecanismos próprios) auxilia a HIC, a SSC e a SOHIC e todos estão relacionados à presença de hidrogênio no interior do metal. 
Danos pelo hidrogênio podem ser classificados em quatro tipos: endurecimento por solução sólida, criação de defeitos internos, fragilização por hidretos e fragilização por hidrogênio (LOUTHAN, 2008). Na Figura 5 se apresenta um esquema com a classificação dos danos pelo hidrogênio.

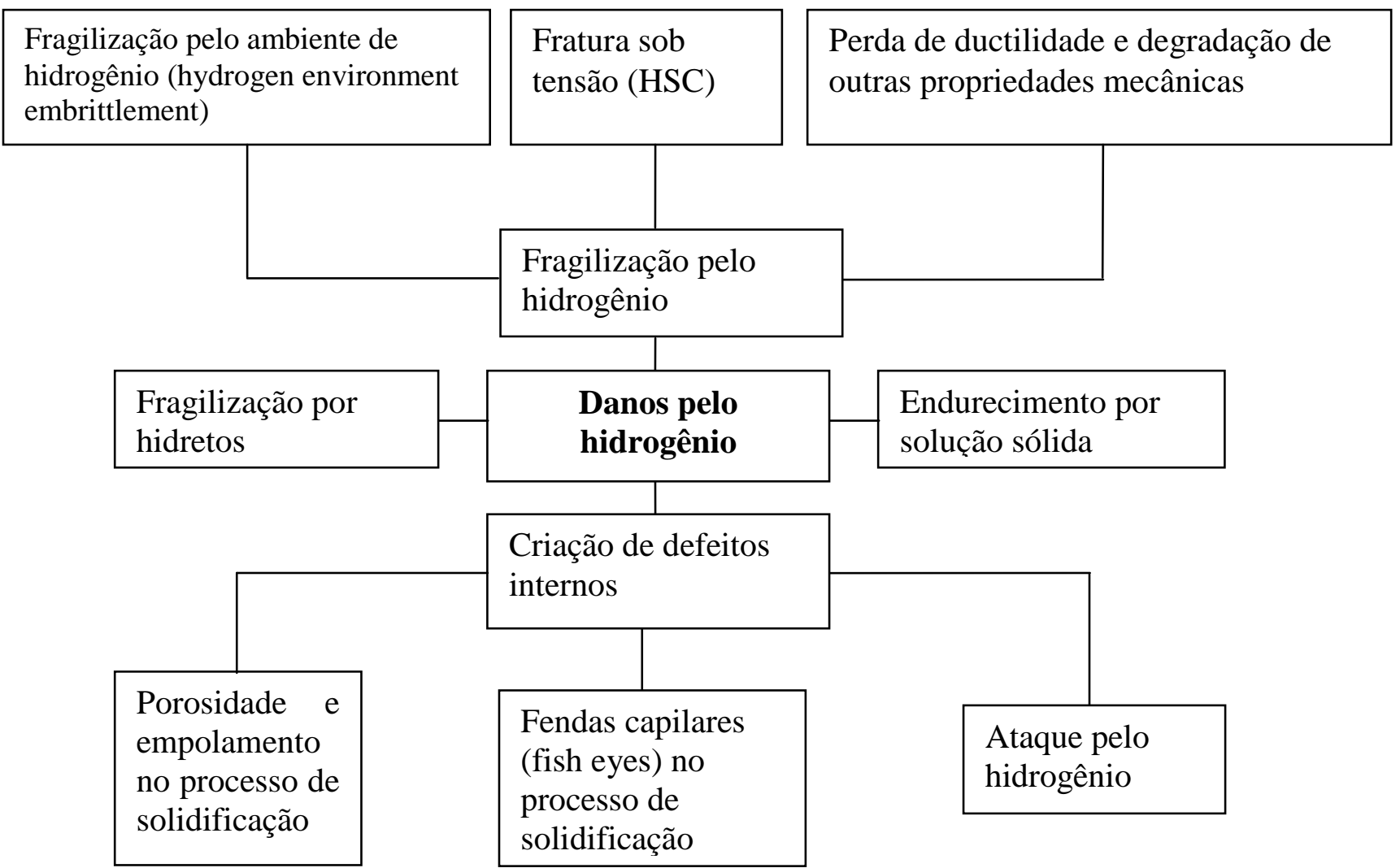

Figura 5 Classificação dos danos produzidos pelo hidrogênio. Modificado.

(NAMBOODHIRI, 2008).

\subsubsection{FRAGILIZAÇÃO PELO HIDROGÊNIO - HE}

O fenômeno da fragilização é definido como a redução da habilidade do metal absorver energia durante a fratura ou a diminuição da ductilidade do material contendo hidrogênio e ocorre mais frequentemente em aços com alta resistência principalmente em aços temperados e revenidos e endurecidos por precipitação com um limite de resistência à tração maior que $1034 \mathrm{MPa}$ (150 ksi) (SASTRI et al., 2007). 
Um dos agentes que promovem a $\mathrm{HE}$ é $\circ \mathrm{H}_{2} \mathrm{~S}$ úmido, o qual leva, por processos de corrosão do aço, à formação de hidrogênio atômico. As reações de corrosão do aço exposto ao $\mathrm{H}_{2} \mathrm{~S}$ em presença de umidade mais aceitas são (KIM et al., 2008; ZAKROCZYMSKI, 1985):

Reação Anódica:

$\mathrm{Fe} \rightarrow \mathrm{Fe}^{2+}+2 \mathrm{e}^{-}$

Reações de Dissociação:

$\mathrm{H}_{2} \mathrm{~S} \rightarrow \mathrm{H}^{+}+\mathrm{HS}^{-}$

$\mathrm{HS}^{-} \rightarrow \mathrm{H}^{+}+\mathrm{S}^{2-}$

Reação Catódica:

$2 \mathrm{H}^{+}+2 \mathrm{e}^{-} \rightarrow 2 \mathrm{H}$

Reação de formação de Hidrogênio Molecular:

$2 \mathrm{H} \rightarrow \mathrm{H}_{2} \uparrow$ gás

Os íons $\mathrm{H}^{+}$presentes na solução sofrem reações de redução, se combinando com os elétrons liberados pelo metal formando hidrogênio atômico na superfície. A maior parte dos átomos de hidrogênio pode se combinar e formar moléculas inofensivas para o metal, mas na presença de certas substâncias químicas a recombinação para a forma molecular fica prejudicada e o volume de hidrogênio atômico absorvido pelo metal aumenta (ZAKROCZYMSKI, 1985). Segundo ZAKROCZYMSKI (1985), dentro das espécies presentes no eletrólito que retardam a cinética da reação $2 \mathrm{H} \rightarrow \mathrm{H}_{2 \text { gás }}$, promovendo a entrada de hidrogênio no metal, estão:

- Certos compostos dos seguintes elementos: fósforo, arsênio, antimônio pertencentes ao Grupo 5A da tabela periódica, e enxofre, selênio e telúrio pertencentes ao Grupo 6A.

- Os seguintes ânions: $\mathrm{CN}^{-}$(cianeto), $\mathrm{CNS}^{-}$(tiocianato), $\mathrm{el}^{-}$(iodeto).

- Os compostos de carbono: $\mathrm{CS}_{2}$ (dissulfeto de carbono), $\mathrm{CO}$ (monóxido de carbono), $\mathrm{CON}_{2} \mathrm{H}_{4}$ (ureia) e $\mathrm{CSN}_{2} \mathrm{H}_{4}$ (tioureia). 
Mas os compostos que mais promovem a entrada de hidrogênio atômico no metal são aqueles combinados com elementos dos grupos $5 \mathrm{~A}$ e $6 \mathrm{~A}$ da tabela periódica.

\subsubsection{FRATURA INDUZIDA PELO HIDROGÊNIO (HYDROGEN INDUCED CRACKING - HIC)}

A fratura induzida por hidrogênio (Figura 6 (a): acúmulo de $H$ num sítio preferencial, formando $\mathrm{H}_{2}$ e nucleando a trinca; Figura 6 (b): esquema de trinca em degraus - stepwise cracking - em propagação) é caracterizada por ruptura frágil. Este mecanismo de fissuração depende da resistência do material, tratamento térmico / microestrutura, tensão aplicada, temperatura e da composição química do eletrólito (presença de venenos catódicos, como sulfeto). Esse tipo de trinca é tipicamente orientada, paralela à direção de laminação da chapa e está associada a inclusões e bandas de segregação do aço; essas trincas podem aparecer na ausência de tensão e se propagam na forma de linhas ou degraus (SASTRI et al., 2007).

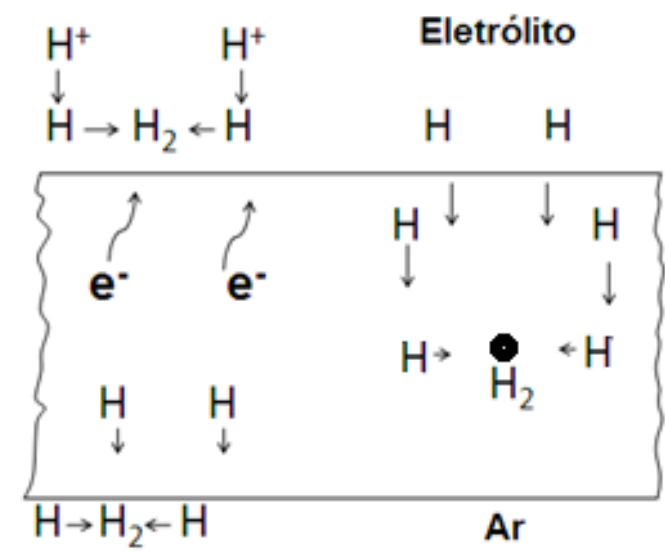

(a)

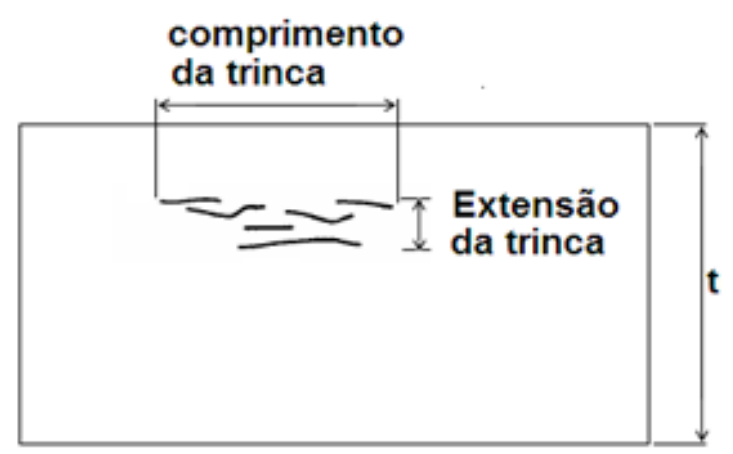

(b)

Figura 6 (a) Nucleação da trinca por hidrogênio (b) Propagação de trinca em degraus induzida por hidrogênio. Modificado (SASTRI et al., 2007)

Durante a corrosão do aço pelo meio aquoso são gerados átomos de hidrogênio $(H)$ na superfície do aço (Figura 6 e Figura 7). Parte destes átomos 
de hidrogênio podem se combinar e formar moléculas inofensivas $\left(\mathrm{H}_{2}\right)$ para 0 metal, uma vez que a penetração de $\mathrm{H}_{2}$ na microestrutura do aço é um processo impossível. Por outro lado, parte do hidrogênio atômico formado, na superfície do aço, difunde-se na rede cristalina. Os átomos de hidrogênio difundem pela estrutura metálica até atingirem sítios preferenciais de ancoramento, por exemplo, inclusões ou discordâncias, onde, ao ser atingido o limite de solubilidade, formam moléculas, gerando um campo de tensões ao seu redor, podendo causar a nucleação e propagação de trincas, geralmente ao longo da direção de laminação (ČIPERA; MIKULOVÁ, 2010).

A presença de inclusões é um fator importante na susceptibilidade dos aços à fratura induzida pelo hidrogênio (HUANG et al., 2010; XUE et al., 2011). A susceptibilidade a HIC está estreitamente relacionada com a composição química dos aços e aos parâmetros de fabricação, já que estes afetam a formação de inclusões e a facilidade do material acomodar hidrogênio na rede cristalina (DOMIZZI et al., 2001; HUANG et al., 2010). Inclusões não metálicas como sulfetos são sítios preferenciais para a nucleação de trincas (PRESSOUYRE et al., 1984). Estudos realizados em tubos com designações API $5 \mathrm{~L}$ X80 e X100 mostraram que, em materiais com relativa baixa quantidade de inclusões de MnS, as trincas estão associadas às inclusões enriquecidas de Al e Si (JIN et al., 2010; XUE et al., 2011). O formato das inclusões é um fator determinante para uma boa resistência ao HIC, pois as inclusões alongadas ou angulosas são fontes de tensões e sítios de ancoramento de hidrogênio livre (Figura 7). Trabalhos anteriores (MIGLIACCIO et al., 2010; GONZÁLEZ et al., 2011; HINCAPIE-LADINO et al., 2011) de grupo de pesquisa do PMT (Departamento de Engenharia Metalúrgica e de Materiais da Escola Politécnica da USP) também mostraram que ao redor das inclusões de tubos X80 e X65, submetidos a ensaios contendo $\mathrm{H}_{2} \mathrm{~S}$ (norma NACE TM0284-2003) tem-se a interface matriz/inclusão dissolvida devido ao acúmulo de hidrogênio (Figura 8). 


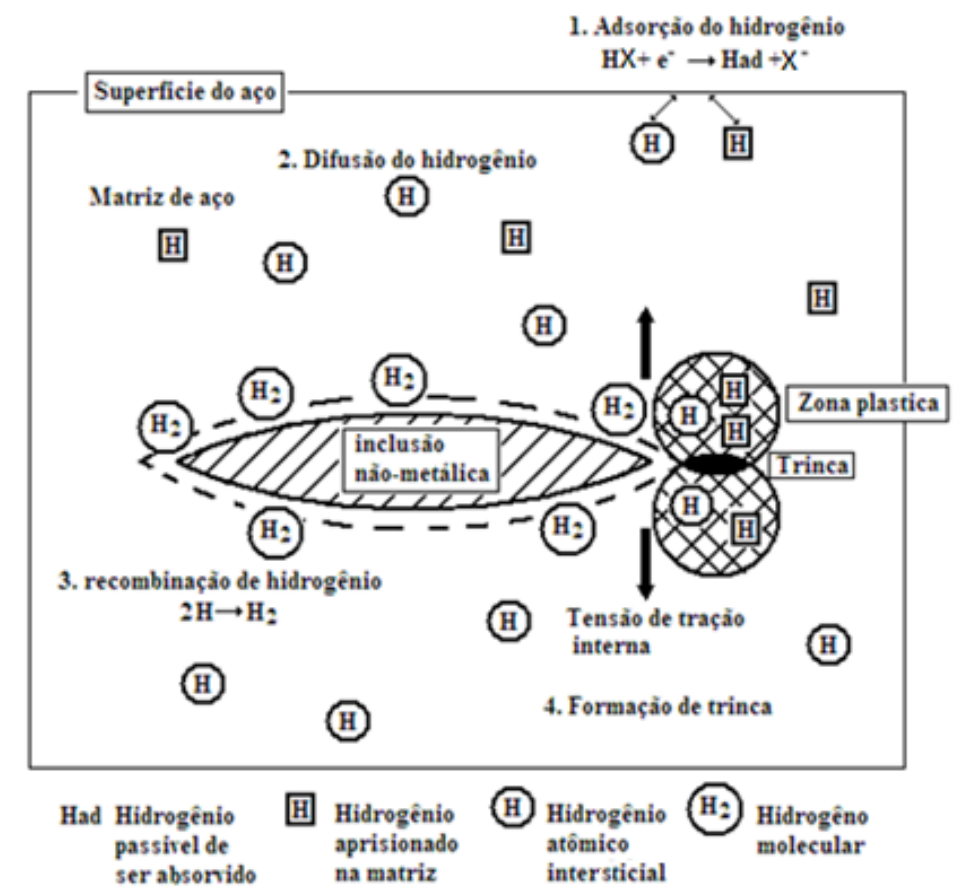

Figura 7 Esquema de formação de trincas na presença de inclusões alongadas. Modificado. (HULKA, 2001 apud GORNI, 2006)

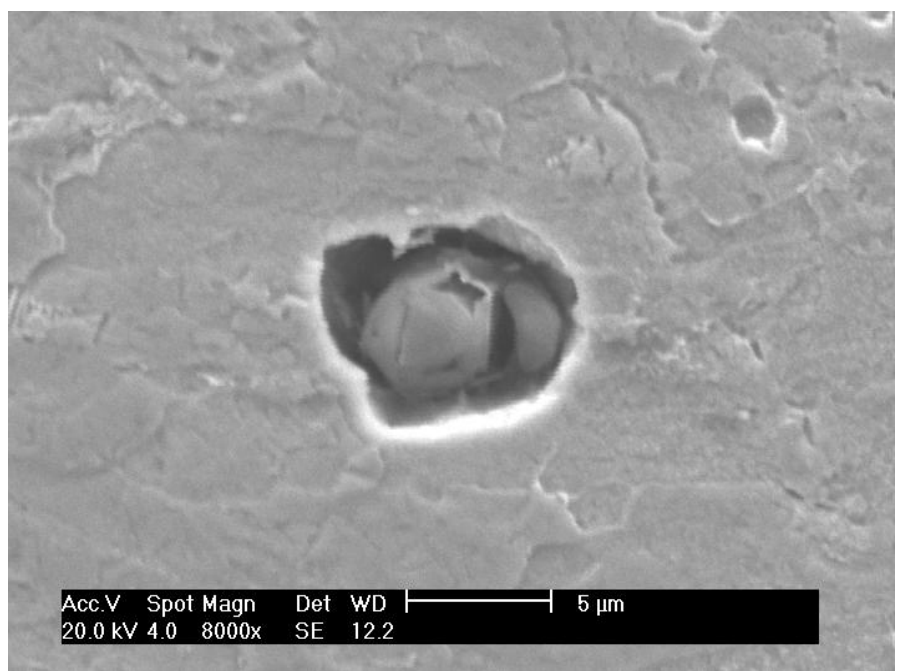

Figura 8 Amostra de tubo API 5L X65, submetido à solução A da NACE TM0284-2003, após polimento metalográfico da superfície $(1 \mu \mathrm{m})$. Nota-se dissolução da interface inclusão / matriz. Trata-se de uma inclusão de Al e Mg. (COSTA, 2010)

Para minimizar o aparecimento desse dano pode-se controlar a formação do gás hidrogênio na superfície do metal através da aplicação de inibidores de corrosão. Também a eliminação dos sítios preferenciais de acúmulo de hidrogênio, além do controle da geometria das inclusões não metálicas, são 
formas de prevenção contra a HIC. Assim, o controle da composição química também é muito importante destacando-se a redução do teor de enxofre. Adições de cálcio ou terras raras modificam a morfologia das inclusões deixando-as com um formato arredondado. $\mathrm{O}$ uso de elementos de liga como $\mathrm{O}$ cobre (o qual forma um filme protetor de sulfato quando o $\mathrm{pH}$ é maior do que 4,5 (REVIE; UHLIG, 2008)), níquel e cobalto, também têm sido descritos como benéficos para os aços submetidos a ambientes ácidos (sour service) (SASTRI et al., 2007).

\subsubsection{TRINCA INDUZIDA POR HIDROGÊNIO ORIENTADA POR TENSÃO (STRESS-ORIENTED HYDROGEN INDUCED CRACKING - SOHIC)}

A SOHIC é causada pelo hidrogênio dissolvido no aço o qual se combina irreversivelmente em forma de hidrogênio molecular. $O$ hidrogênio molecular preso produz micro fissuras que se alinham e se interligam (Figura 9).

Esse tipo de falha é uma forma clássica de HIC na qual a trinca tem uma orientação específica em relação à tensão aplicada e/ou tensão residual. Tem mecanismo similar ao HIC e tende a se empilhar na direção da espessura do tubo, tipicamente na zona afetada pelo calor (SASTRI et al., 2007) das soldas onde há tensões residuais e em áreas onde há tensão aplicada ou de concentração de tensões.

Embora o SOHIC possa se propagar a partir de trincas pré-existentes de $\mathrm{HIC} \mathrm{e}$ corrosão sob tensão, mais do que pelos defeitos de solda, nem o HIC nem a corrosão sob tensão são pré-requisitos para o SOHIC. Tal como acontece com o HIC, a principal causa de SOHIC é provavelmente o hidrogênio atômico produzido na superfície do aço (SASTRI et al., 2007). 


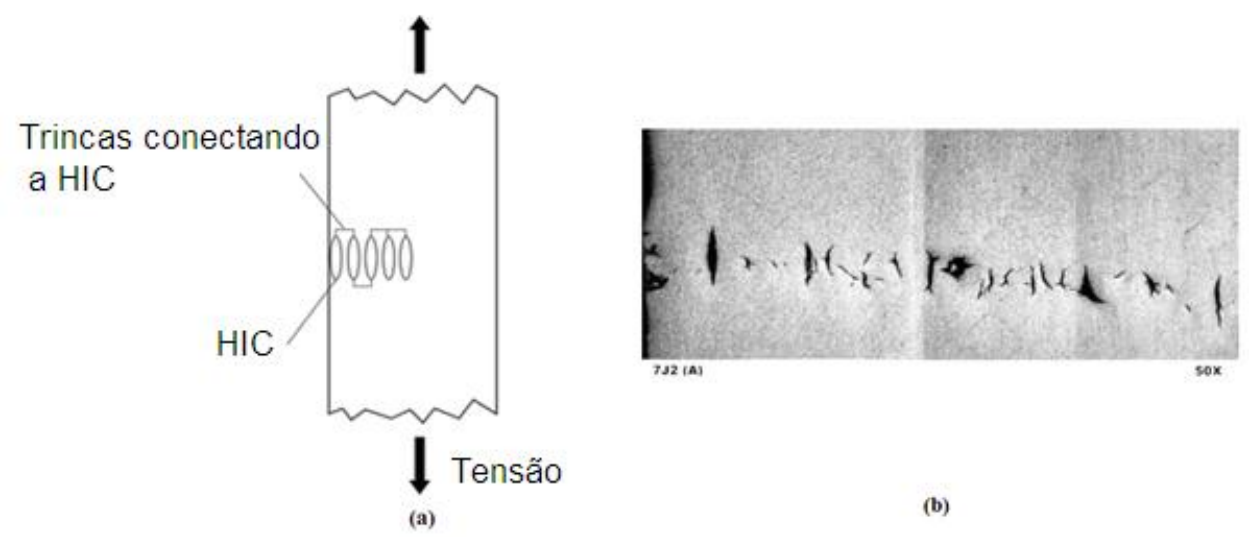

Figura 9 Esquema de trincas produzidas por SOHIC. Modificado. (SASTRI et al., 2007).

\subsubsection{CORROSÃO SOB TENSÃO NA PRESENÇA DE SULFETO (SULFIDE STRESS CRACKING - SSC)}

Ao contrário da fratura induzida por hidrogênio a SSC não envolve a formação de hidrogênio molecular num ponto de ancoragem, mas sim a fratura devido à presença de altas tensões num material fragilizado por hidrogênio em solução sólida.

A corrosão sob tensão ocorre em metais de mais alta resistência do que os metais que são mais susceptíveis ao HIC (como os aços usados em refinarias e equipamentos de petroquímicas) ou em pontos de alta dureza associados à solda ou tratamentos térmicos (SASTRI et al., 2007).

A SSC também depende da composição, microestrutura, resistência, e do nível total de tensão no aço (tensão residual mais tensão aplicada). A temperatura tem um papel importante segundo a norma NACE TM0177-2005, que menciona que a SSC é mais severa na temperatura ambiente, especialmente em temperaturas abaixo de $24^{\circ} \mathrm{C}\left(75^{\circ} \mathrm{F}\right)$. 


\subsubsection{EFEITO DOS ELEMENTOS DE LIGA SOBRE A FRAGILIZAÇÃO POR HIDROGÊNIO}

A principal função dos elementos de liga nos aços ARBL é o aumento da resistência mecânica através de: refinamento de grão, precipitação e solução sólida (LIOU et al., 1993). Elementos de liga como Nb ,V, Ti têm como função fundamental controlar o crescimento de grão de austenita e sua recristalização durante o TMCP (ASM Metal Handbook, 1993 ), sendo o Nb o elemento que tem maior influencia no atraso da recristalização da austenita (CUDDY, 1982), - $\mathrm{Cu}, \mathrm{Cr}$ e Mo são adicionados para melhorar a resistência à corrosão atmosférica (PALMER; KING, 2004, LIOU et al., 1993). Os relatos dos efeitos particulares dos elementos de liga na resistência a HIC dos aços ARBL são escassos na literatura especializada.

Deve ser ressaltado que esse tipo de correlação (teores de elementos de liga em função da ocorrência de trincamento ou não) só faz sentido quando é conhecido o mecanismo pelo qual o elemento atua sobre a propriedade. Isto é, não basta uma simples correlação entre composição química (teor do elemento considerado) e o valor do parâmetro da propriedade. Nenhum elemento tem exclusivamente um caráter prejudicial ou benéfico em qualquer propriedade considerada.

Com essa consideração, foi feito um levantamento bibliográfico sobre a correlação dos elementos presentes na composição química de aços ARBL e a susceptibilidade aos processos de fragilização por hidrogênio. $O$ resultado desse levantamento bibliográfico está apresentado a seguir.

Notou-se que em, na maioria dos trabalhos, as correlações são mencionadas sem que seja apresentado o mecanismo de melhoria ou dano da propriedade, inclusive, sem a pesquisa de como o referido elemento se encontra na microestrutura do aço: em solução sólida na ferrita, bainita ou martensita; ou precipitado como carboneto e/ou nitreto; ou como elementos segregados.

Por tal motivo, sempre que necessário, foi feita uma menção a essa ausência de informação, que é causada pela inerente dificuldade de determinação da 
composição química dos microconstituintes desses aços, uma vez que os elementos não estão distribuídos uniformemente como sugere a simples análise da composição química.

Carbono. Num estudo dos efeitos do C sobre a SSC, foram comparados dois aços estruturais com teores de $0,04 \% \mathrm{C}$ e $0,13 \% \mathrm{C}$, e com: $2,0 \% \mathrm{Cr}, 0,3 \% \mathrm{Al}$ e $0,2 \% \mathrm{Mo}$, e tratados termicamente para obter a mesma resistência mecânica. Foi observada uma redução na resistência a SSC, quando é aumentada a concentração de carbono de $0,04 \%$ para $0,13 \%$. O efeito negativo pelo aumento no teor de carbono é atribuído principalmente à formação de fases ricas em carbono as quais servem como núcleos de trincas (GOLOVANENKO et al., 1978).

Manganês: $\mathrm{Em}$ concentrações de $1 \%$ a $1,5 \%$ o manganês diminui a tenacidade, originando um efeito negativo sobre o HIC. Na Figura 10 é apresentado o efeito do manganês em aços com diferentes teores de C: podese observar, em aços laminados, com teores de carbono entre $0,05 \%$ e $0,15 \%$, um aumento na suscetibilidade a HIC quando existem teores maiores do que $1,0 \%$ de manganês - isso é causado pelo aumento da quantidade de estruturas duras nas bandas de segregação. Para aços temperados e revenidos com teores de carbono abaixo de $0,16 \%$ a suscetibilidade a HIC é pequena e independente da quantidade de manganês. Para aços contendo $0,02 \%$ de carbono foram obtidas boa resistência a HIC com teores de manganês até 2,0\% (TAIRA et al., 1983). Os autores não mencionam as respectivas propriedades mecânicas; no entanto, é de se esperar que com a diminuição de Mn e C, a resistência mecânica desses aços ficará comprometida. 


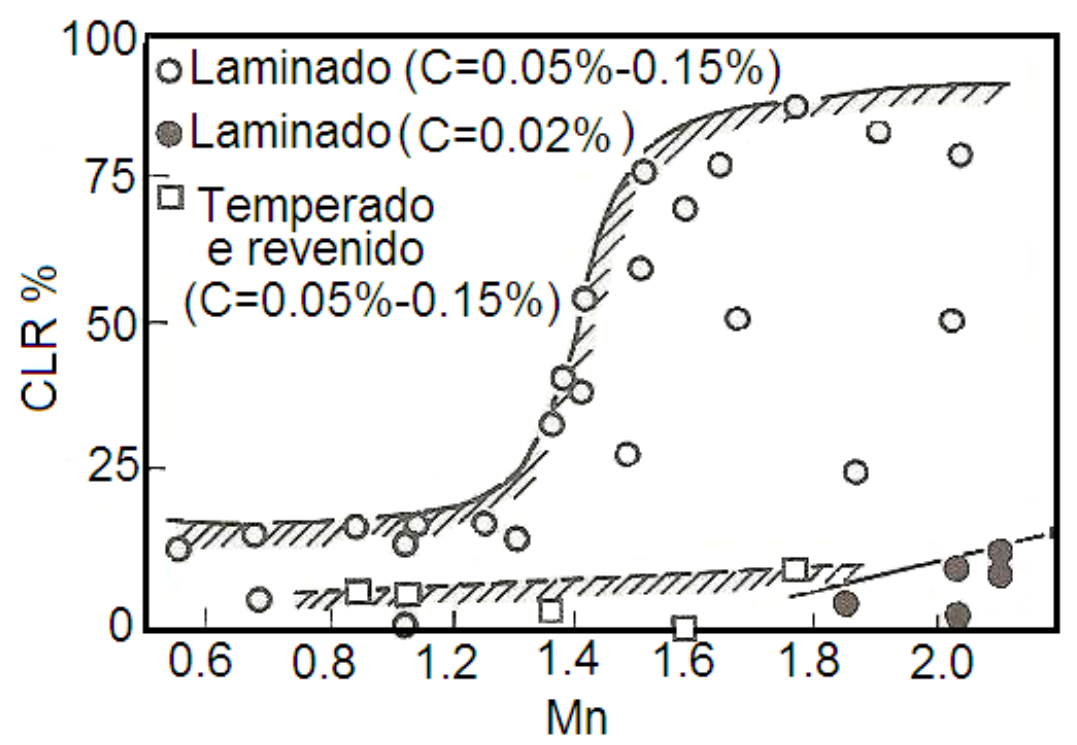

Figura 10 Efeito do teor de manganês sobre o parâmetro CRL de resistência a HIC. Modificado. (TAIRA et al., 1983)

Fósforo e Enxofre. O fósforo tem um efeito negativo nos aços ARBL, porque é um ativador do processo de absorção de hidrogênio atômico no metal (GOLOVANENKO et al., 1978); é reportado que com o aumento do teor de enxofre de $0,008 \%$ até $0,039 \%$ em aços $20 \mathrm{G}$ (designação russa: $0,15 \% \mathrm{C}$, $0,30 \% \mathrm{Si}, 0,93 \% \mathrm{Mn}$ e $0,04 \% \mathrm{~N}$ ), é favorecida a fragilização por hidrogênio em aços ARBL (GOLOVANENKO et al., 1978).

O enxofre reduz a resistência à fragilização por hidrogênio, já que as inclusões de sulfeto são sítios de nucleação e propagação de trincas em aços ARBL; em aços submetidos a testes de resistência a HIC foram encontrados um aumento no comprimento das trincas com o aumento do teor de enxofre Figura 11 (GOLOVANENKO et al., 1978). 


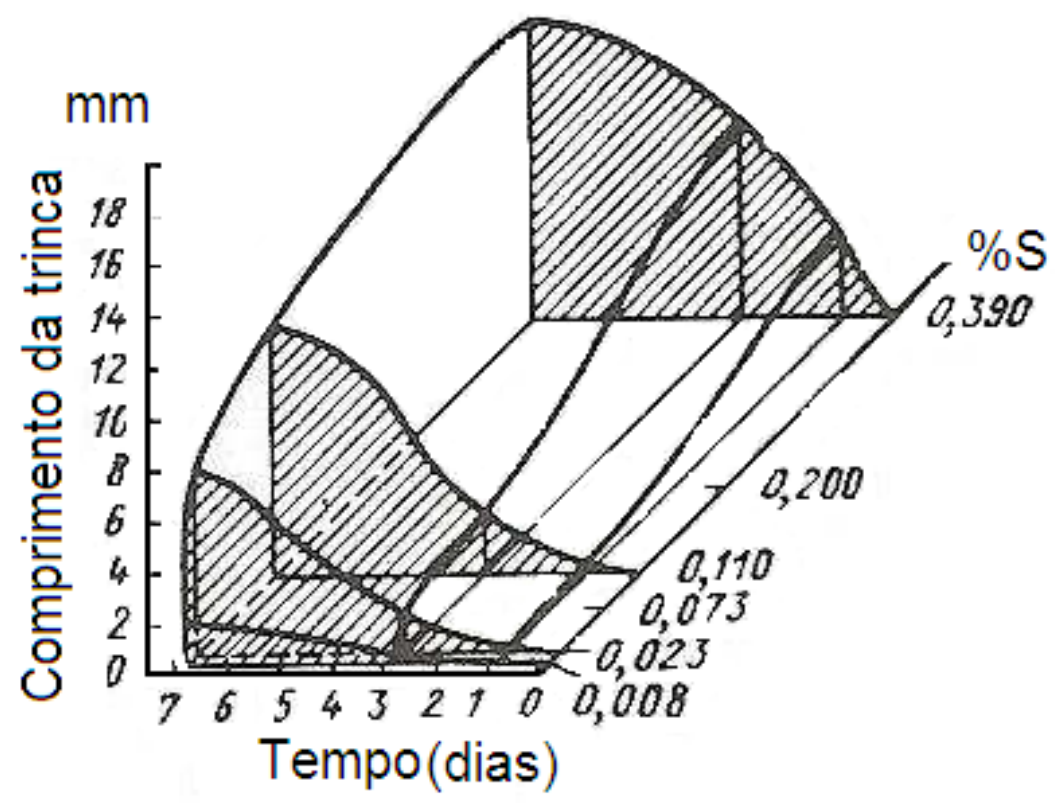

Figura 11 Efeito da concentração de enxofre e tempo do ensaio de $\mathrm{HIC} \mathrm{pH}=3$, sobre 0 comprimento das trincas. Modificado. (GOLOVANENKO et al., 1978).

Com o incremento de $\mathrm{S}$ de $0,002 \%$ para $0,02 \%$ em aços $30 \mathrm{G}(0,27-0,35 \% \mathrm{C}$, 0,7-1,0\%Mn, 0,17-0,37\%Si, Cr-Cu-Ni<0,3\% cada elemento), encontrou-se uma diminuição na resistência a $\mathrm{HIC}$, tendo como sítio de nucleação e propagação as inclusões de sulfeto (GOLOVANENCO et al., 1978) Estudos mais recentes sobre a influência do teor de enxofre e a distribuição das inclusões na resistência a HIC (DOMIZZI et al., 2001) em aços X60, X52 e ASTM 516g70 com teores de enxofre entre $0,005-0,015 \%$, encontrou-se que para teores abaixo de $0,005 \%$ de enxofre não há correlação entre a quantidade de S e a resistência a HIC - Figura 12 (DOMINIZZI et al., 2001). 


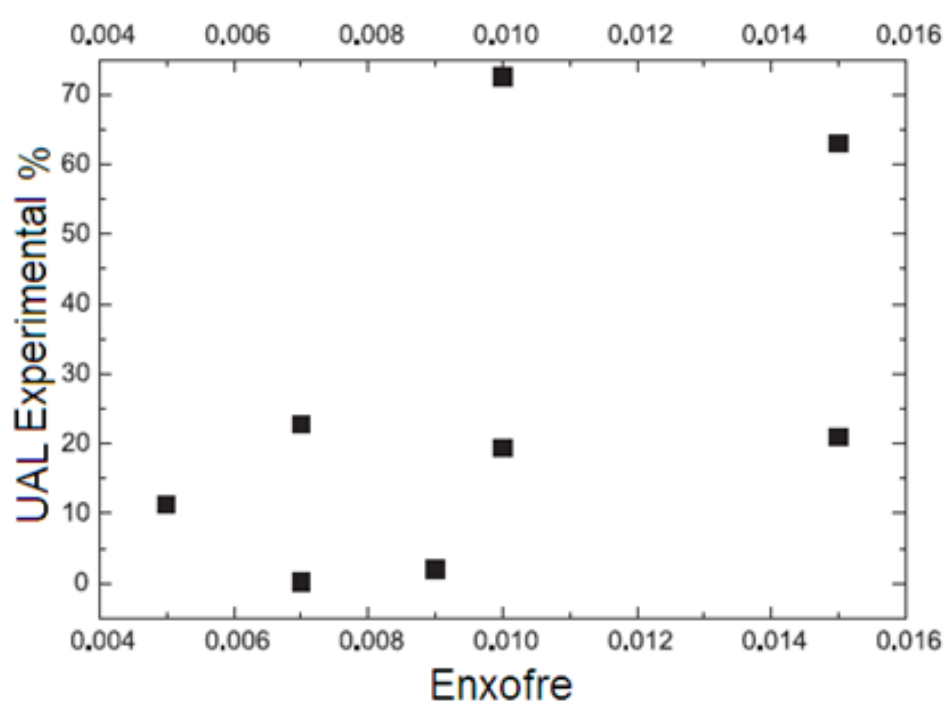

Figura 12 Susceptibilidade a HIC (indicador de comprimento Ultrasonic attenuation level UAL\%) em função do teor de enxofre. Modificado. (DOMINIZZI et al., 2001).

Alumínio. Foi documentado para aços $16 \mathrm{GS}(0,12-0,18 \% \mathrm{C}, 0,4-0,7 \% \mathrm{Si}, 0,9-$ $1,2 \% \mathrm{Mn}, 0,3 \%$ max. Cu e 0,3\%max. Cr) com teores de Al entre $0,2 \%$ e $0,47 \%$, que com o aumento no teor de Al tem-se um aumento na resistência a fragilização por hidrogênio (GOLOVANENKO et al., 1978). Neste caso, faltam informações sobre o mecanismo pelo qual o alumínio atua: pode-se pensar em formação de inclusões de óxido de alumínio, que seriam menos prejudiciais do que outros tipos de óxidos. No entanto, isso é apenas suposição, uma vez que os autores não comentaram as razões do efeito do alumínio.

Molibdênio e Cromo. Ligas com molibdênio geralmente tem resistência a fragilização por hidrogênio. Isso foi observado em aços estruturais do tipo $30 \mathrm{KH}(0,24-0,32 \% \mathrm{C})$ quando o teor de Mo era de 0,25-1\% (GOLOVANENKO et al., 1978).

Ravi et al. (1993) realizou estudos dos efeitos do molibdênio sobre a resistência a HIC de aços com diferentes teores desse elemento $(0 \%$ até $0,89 \%)$. Todos os aços receberam tratamento de controle da forma das inclusões, sendo observado que com o aumento do teor de Mo tem-se um aumento da resistência ao HIC - Figura 13 (RAVI et al., 1993). 


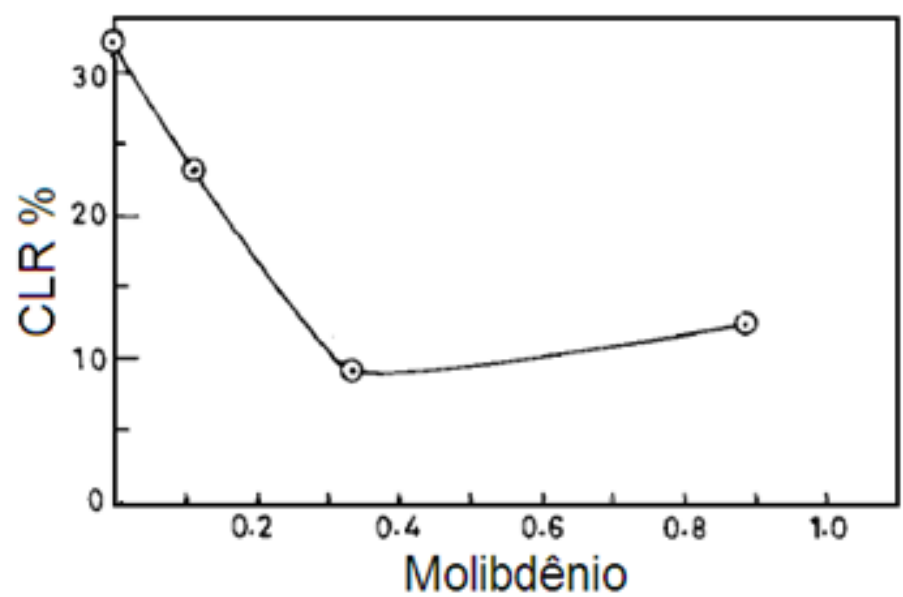

Figura 13 Efeito do molibdênio sobre a resistência a HIC. Modificado. (RAVI et al., 1993).

Este incremento na resistência a HIC também é mencionado por Golovanenko et al., 1978, em aços temperados e revenidos com teores de 0,3\% C, 0,7\% Mn e Mo de 0,05\% até 0,3\% e adições de Cr. Liou et al. (1993) estudou o efeito conjunto do $\mathrm{Cr}$ e Mo sobre a resistência a fragilização pelo hidrogênio, sem encontrar uma relação, Figura 14 (LIOU et al., 1993).

Observa-se que nenhum dos autores comenta o mecanismo pelo qual a adição de Mo é benéfica para a resistência aos danos provocados pelo hidrogênio.
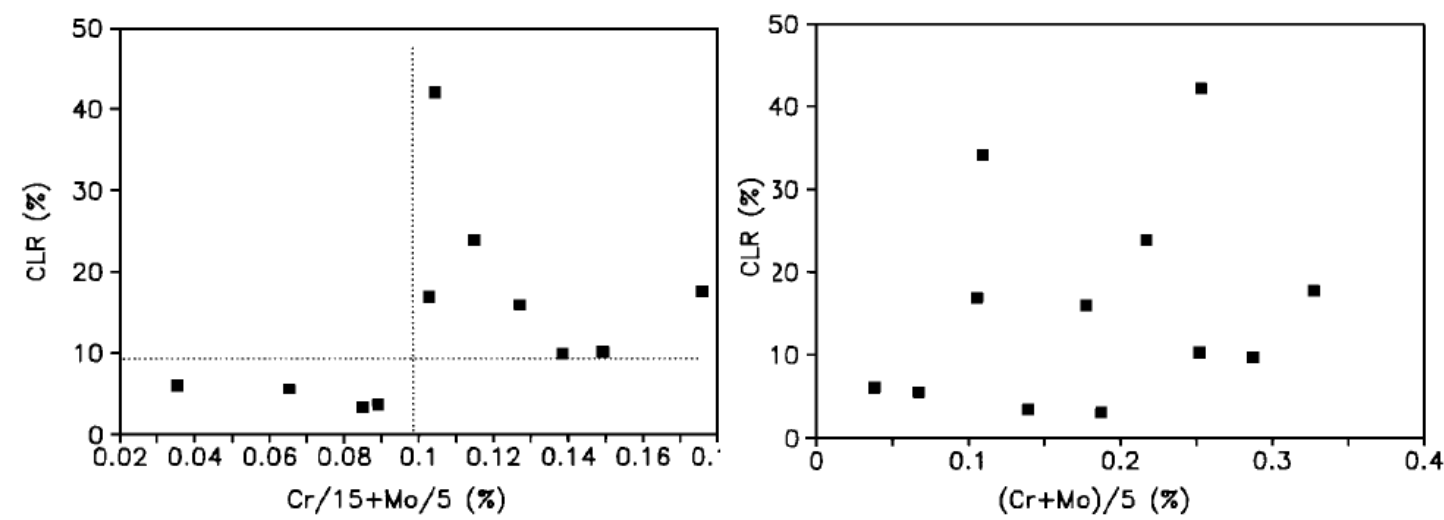

Figura $14 \mathrm{CLR}$ em aços ARBL com teores $(\mathrm{Cr} / 15+\mathrm{Mo} / 5)$ e $(\mathrm{Cr}+\mathrm{Mo}) / 5$ em solução $\mathrm{A}$ da NACE TM0284. Modificado. (LIOU et al., 1993).

Cobre. É considerado que o uso de cobre como elemento de liga incrementa a resistência a HIC dos aços estruturais. O efeito favorável do cobre na resistência dos aços à fragilização por hidrogênio em meios que contém $\mathrm{H}_{2} \mathrm{~S}$, é 
atribuído ao fato que o cobre e um elemento efetivo na redução da absorção do hidrogênio em processos na superfície (GOLOVANENKO et al., 1978).

Titânio. Liou et al. (1993) reportam que inclusões de TiN com comprimentos maiores de $1 \mu \mathrm{m}$ assim como as inclusões alongadas de MnS são sítios iniciadores de HIC, além disso inclusões de TiN e MnS combinadas aumentam a ocorrência de HIC; estas são sítios preferenciais para a nucleação e crescimento das trincas - Figura 15.

Neste caso, nota-se que os autores encontraram o mecanismo para o efeito deletério da adição de Ti. No entanto, deve-se lembrar de que a adição de Ti é um procedimento atual e necessário para a produção de aços ARBL (ver item: "Aços laminados termomecanicamente (TMCP) com resfriamento acelerado"). A falha aqui apresentada é devido à falta de controle de processo na produção da chapa. Os precipitados de Ti não podem ser grosseiros.

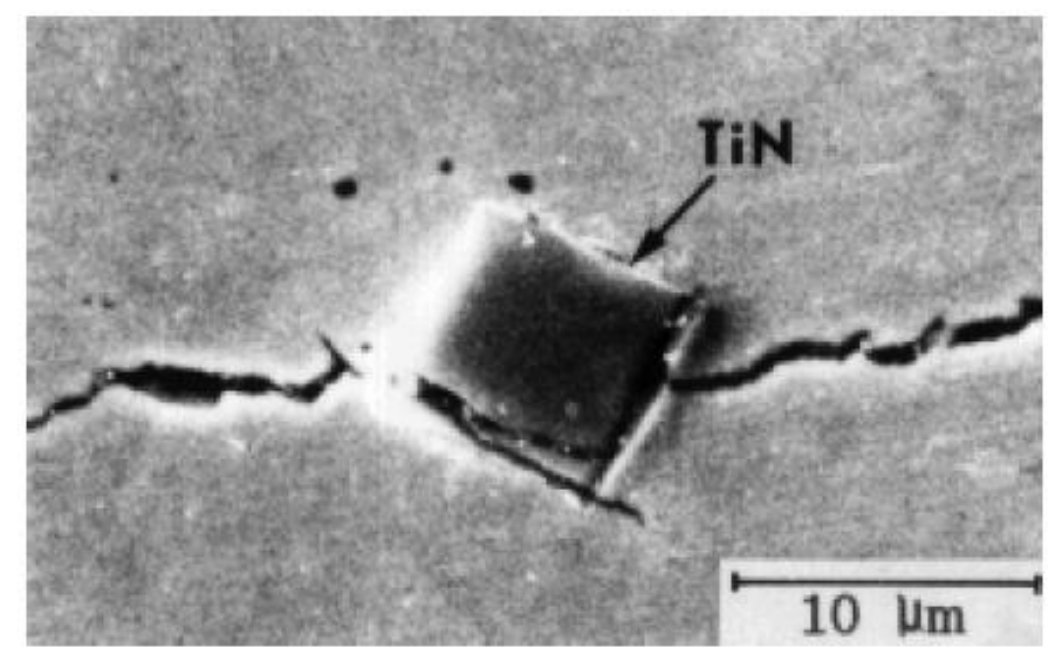

Figura 15 Trincamento propagando-se entre a interfase inclusão / matriz (LIOU et al., 1993).

Nióbio. Como o titânio, o nióbio é um elemento necessário para assegurar a alta resistência e o efeito da laminação controlada nos aços para a produção de tubulações (TAIRA et al., 1983).

Novamente, como no caso do titânio, atualmente o nióbio é um elemento necessário e empregado nos processos de produção de chapas de aços ARBL. E, como o titânio, a precipitação de carboneto de nióbio é o mecanismo de controle de crescimento de grão, durante os processos de conformação 
mecânica. Conforme mencionado anteriormente, o $\mathrm{Nb}$ é o elemento que tem maior influencia no atraso da recristalização da austenita (CUDDY, 1982). Caso ocorra precipitação grosseira ou heterogênea, as propriedades de tenacidade ficarão prejudicadas.

Outros elementos. Não há suficientes estudos sobre o efeito na fragilização pelo hidrogênio de outros elementos como $\mathrm{Ni}$, Si.

Nota-se desses relatos encontrados na literatura especializada, que os efeitos dos elementos presentes na composição química dos aços não podem ser examinados apenas em função do teor encontrado na análise da composição química. Sua forma de distribuição (segregação), presença em solução sólida ou precipitados entre os elementos, devem ser examinadas, além das diferentes contribuições das microestruturas e suas consequências no ganho de resistência mecânica e perda de tenacidade.

Conclui-se que ainda é necessária mais pesquisa sobre o assunto, para que todas as variáveis sejam compreendidas e relacionadas corretamente com os danos provocados pelo hidrogênio.

\subsubsection{PERMEABILIDADE DE HIDROGÊNIO EM AÇOS ARBL}

A fragilização por hidrogênio está associada à quantidade de hidrogênio absorvido e acumulado em precipitados, segundas fases, discordâncias e outros defeitos do metal, isso promove a ocorrência de fragilização e possíveis falhas no metal em serviço. Os danos se minimizam com o aumento da temperatura já que isto aumenta a taxa de difusão do hidrogênio, diminuindo os efeitos deletérios (SERNA et al., 2005).

Os principais fatores que afetam a difusividade e ancoramento do hidrogênio em aços microligados com resistências semelhantes são: densidade de discordâncias e a quantidade de precipitados e forma como estão distribuídos no metal, já que estes atuam como sítios preferenciais que aprisionam os átomos de hidrogênio (SERNA et al., 2005). 
Para descrever o ancoramento do hidrogênio na microestrutura do aço são encontrados na literatura (entre elas: PRESOUYRE, 1979; GRABKE; RIECKE, 2000; SERNA et al.,2005) os seguintes termos: flat traps; deep traps; reversible traps e irreversible traps. Expõe-se, a seguir, a tradução para a língua portuguesa assumida para esses termos no presente trabalho, bem como os seus significados, conforme norma ASTM G148 97.

- Traps: são os sítios de aprisionamento (ancoramento) de hidrogênio.

- Irreversible traps - ; deep traps: Sítio microestrutural onde um átomo de hidrogênio tem um tempo de permanência infinito ou longo em comparação com a duração do teste de permeação, como consequência de uma energia de ligação alta em relação com a energia necessária para que ocorra a difusão.

- Reversible Traps -; Flat Traps: Sítio microestrutural no qual um átomo de hidrogênio permanece por um tempo maior que os átomos no reticulado (Mobile hydrogen atoms), mas este tempo de permanência é pequeno em relação ao tempo necessário para que seja obtida a permeação em estado estacionário, como consequência de uma baixa energia de ligação.

- Mobile hydrogen atoms: átomos de hidrogênio que ocupam os interstícios do reticulado, mas não são traps.

Segundo Wang et. al. (2002) as interfaces carbeto-ferrita em aços perlíticos e esferoidizados são sítios preferencias para o acúmulo irreversível de hidrogênio. Estruturas como ferrita acicular e bainita atuam como acumuladores reversíveis do hidrogênio, sendo que o aumento na eficiência segue a seguinte ordem: perlita degenerada, bainita e ferrita acicular (PARK et al., 2008).

Grabke; Riecke (2000) estudando a absorção e difusão do hidrogênio, encontraram que os elementos $\mathrm{Cr}$ e $\mathrm{Si}$ diminuem a permeabilidade do hidrogênio no aço, sendo que o $\mathrm{Cr}$ atua como sítio preferencial para os átomos de hidrogênio e com o aumento do Si tem-se uma diminuição da solubilidade do hidrogênio; outros elementos em solução sólida como $\mathrm{Ni}, \mathrm{Sn}, \mathrm{Cu}, \mathrm{P}$ não apresentaram uma correlação com a permeabilidade. Já para precipitados 
como carbetos e nitretos de $\mathrm{Mo}, \mathrm{V}, \mathrm{Nb}, \mathrm{Ti}$ e $\mathrm{Zr}$ foi encontrado que estes elementos geram sítios preferenciais para o acúmulo irreversível de hidrogênio, mas não foi encontrada uma correlação entre a quantidade de hidrogênio acumulado nestes sítios e a ocorrência de HIC (GRABKE; RIECKE, 2000). (Os autores não explicam a causa, mas supõe-se que isso seja consequência do diminuto tamanho destes carbonetos, que impedem a nucleação da trinca.)

\subsection{RESISTÊNCIA À CORROSÃO}

Os aços ARBL são amplamente utilizados como material para construção de tubulações e depósitos na indústria petrolífera devido às suas propriedades mecânicas e de soldabilidade, mas eles são susceptíveis a apresentar corrosão uniforme ou localizada nas superfícies externa e interna quando em serviço. Para a proteção externa das tubulações expostas ao ambiente (enterradas ou ao ar), são utilizados recobrimentos para evitar o contato do metal com o ambiente. Quando ocorre a degradação do recobrimento tem-se como resultado a exposição do metal. A proteção catódica é utilizada como uma proteção complementar. Para evitar a corrosão no interior das tubulações são empregados inibidores, mas para alguns serviços o uso de inibidores não é suficiente para evitar a corrosão (PALMER; KING, 2004). Ocorre ainda que a aplicação de inibidores de corrosão pode não ser um procedimento possível, como por exemplo, em instalações submarinhas ou em lugares remotos; nesses casos, para minimizar o risco de falha, são usados recobrimentos ou outros materiais metálicos.

\subsubsection{CORROSÃO ATMOSFÉRICA}

Os metais e ligas não protegidos e que se encontram expostos à ação dos fatores climáticos podem sofrer corrosão. Esta é responsável por grandes custos para as indústrias. O processo de corrosão pode ocorrer rapidamente ao ar úmido o qual contém contaminantes como ácidos inorgânicos. $O$ 
processo da corrosão atmosférica sempre é resultado de uma reação eletroquímica na qual o eletrólito é a umidade do ar condensada. A umidade deposita-se por precipitação ou condensação como orvalho sobre as superfícies expostas. Para o caso de corrosão atmosférica foram criadas tabelas, mediante dados experimentais, da resistência à corrosão, por exemplo, a norma ASTM G101-2004/2010 apresenta a perda de espessura em função do tempo e do tipo de ambiente; para o caso de aços alta resistência baixa liga a resistência à corrosão atmosférica é maior que para os aços carbono (REVIE; UHLIG., 2008). A Figura 16 apresenta o desempenho de aços com diferentes adições de elementos de liga em atmosfera industrial.

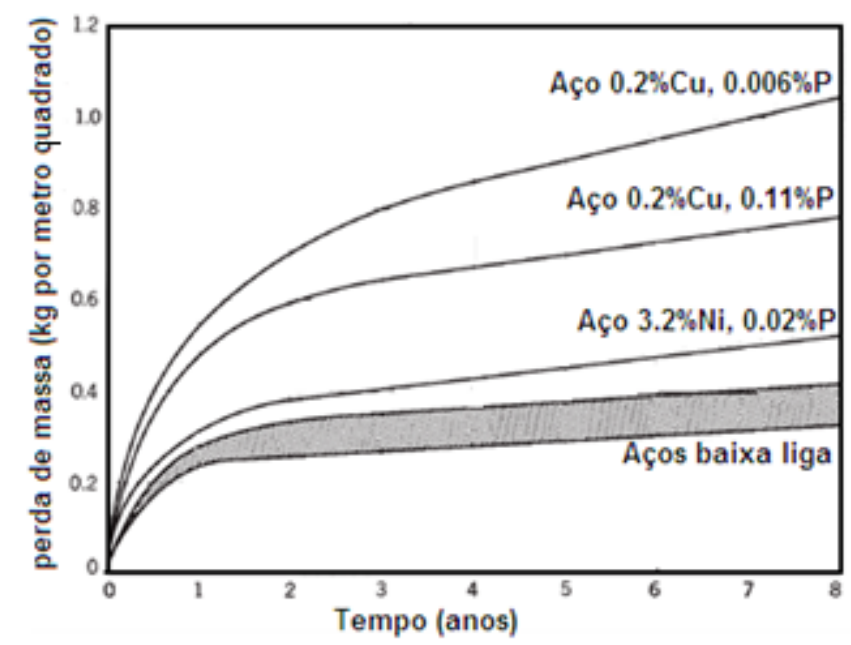

Figura 16 Corrosão atmosférica de aços em função do tempo num ambiente industrial. Modificado. (REVIE; UHLIG, 2008).

Segundo Palmer e King, 2004, a adição de certos elementos de liga ao aço, como cobre, cromo e níquel, pode diminuir a velocidade de corrosão. No entanto, Revie e Uhlig, 2008, (Figura 16) relatam que o efeito positivo de cada elemento de liga depende não só da quantidade adicionada, mas também está relacionada com as condições climáticas. Nota-se que na Figura 16, não foi observado efeito benéfico da adição de cobre. Stratmann et al., 1987, mencionam que a taxa de corrosão é praticamente a mesma em ferro e numa liga ferro-cobre se a superfície do metal é mantida sempre úmida ou está dentro de um eletrólito neutro. O efeito do cobre na velocidade de corrosão foi estudada por Stratmann et al. (1987), encontrando uma diminuição na taxa de 
corrosão em ensaios cíclicos de secagem e molhamento. Nos aços de baixa liga o ciclo de molhamento e secagem é benéfico porque favorece a formação de uma camada estável de óxido (MISAWA, 1974).

Cleary; Greene (1967) estudaram a velocidade de corrosão de aço carbono em ácido sulfúrico $\left(0,1 \mathrm{M} \mathrm{H}_{2} \mathrm{SO}_{4}\right)$, em função dos elementos de liga, reportando que o fósforo e o carbono aumentam de maneira significativa a velocidade de corrosão (Figura 17).

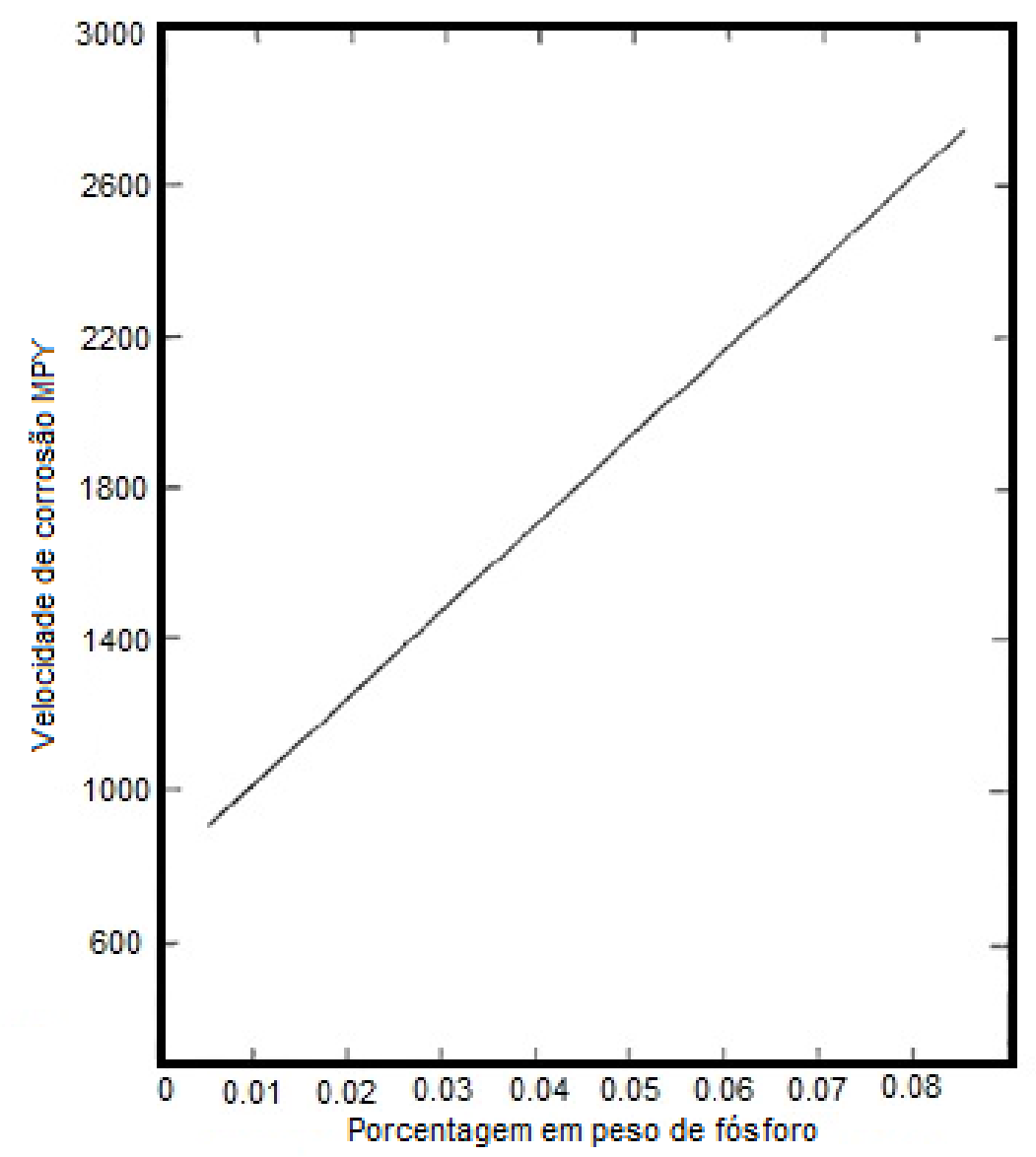

Figura 17 Velocidade de corrosão (em MPY: milipolegada por ano) em função da porcentagem em peso de fósforo. Modificado. (CLEARY; GREENE, 1967)

Estudos realizados (NAM; KIM, 2010) mostraram que o nióbio melhora a resistência à corrosão de aços microligados contendo $0,07 \% \mathrm{C}, 0,20 \% \mathrm{Mn}$, 0,01\%P, 0,01\%S, com teores de nióbio variando de 0,00 a $0,10 \%$. A Figura 18 mostra os resultados obtidos para as determinações em solução de $\mathrm{H}_{2} \mathrm{SO}_{4}$. Os autores atribuíram esse efeito do $\mathrm{Nb}$ ao fato que na superfície do metal é criada 
uma barreira de produtos de corrosão, a qual é formada pela interação do $\mathrm{Nb}$, Fe e S.

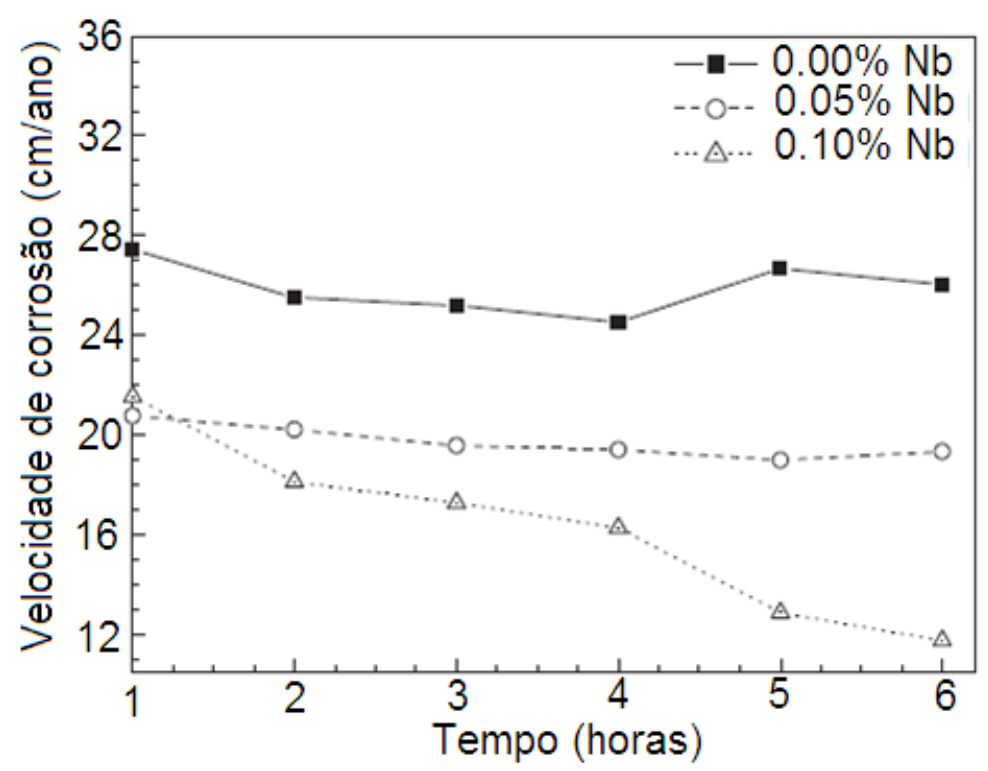

Figura 18 Velocidade de corrosão em função do tempo obtida por espectroscopia de impedância eletroquímica (EIS) em solução $10 \%$ em massa de $\mathrm{H}_{2} \mathrm{SO}_{4}$, a temperatura ambiente. Modificado. (NAM; KIM, 2010).

Na presença de alta concentração de íons agressivos como $\mathrm{Cl}^{-}$a velocidade de corrosão aumenta. Na Figura 19 é mostrado o efeito da concentração de cloreto de sódio sobre a velocidade de corrosão do ferro numa solução desaerada.

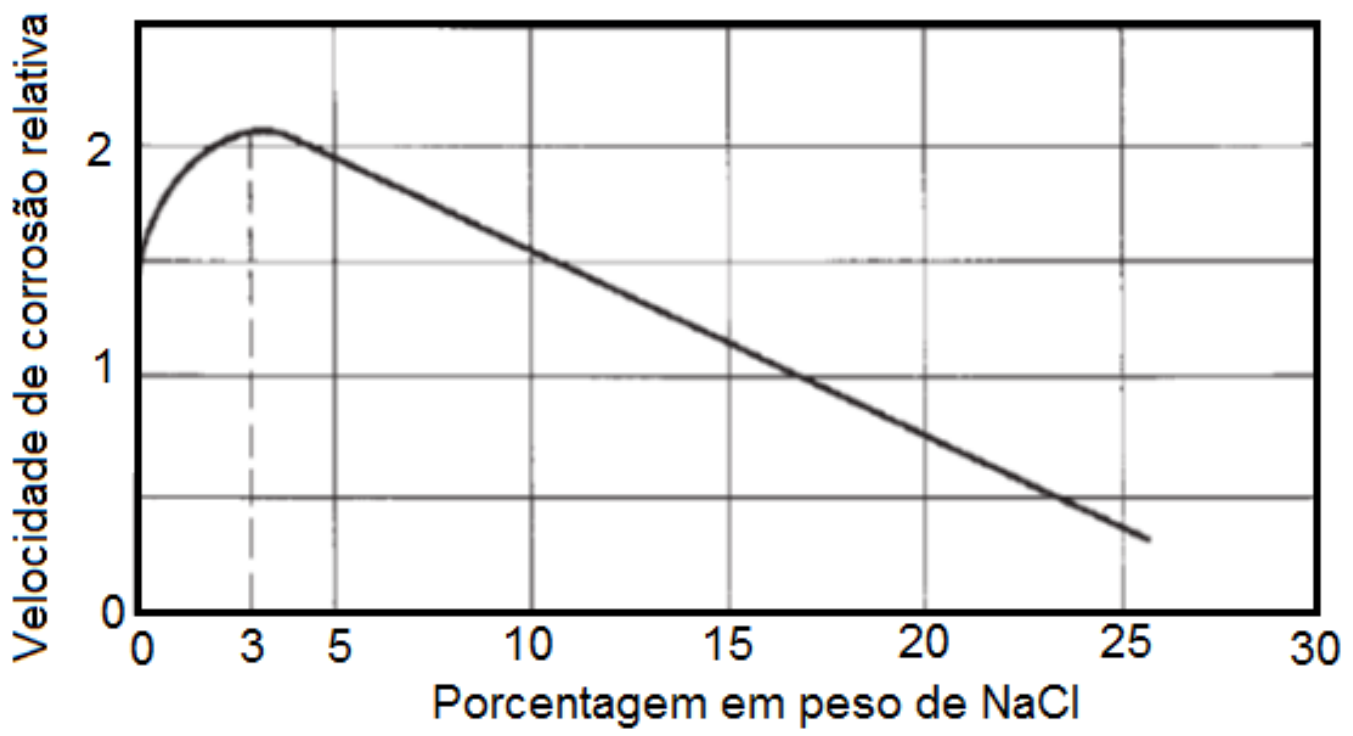

Figura 19 Efeito da concentração de cloreto de sódio sobre a corrosão do ferro numa solução desaerada a temperatura ambiente. (REVIE; UHLIG, 2008) 
A velocidade de corrosão primeiro se incrementa com a adição de $\mathrm{NaCl}$ dado 0 aumento da condutividade do eletrólito; após alcançar um valor máximo perto de $3 \% \mathrm{NaCl}$, a solubilidade do oxigênio diminui gradualmente e, consequentemente, a velocidade de corrosão diminui (CLEARY; GREENE, 1967).

Num aço 1018 foi encontrado que com a adição de $10 \% \mathrm{NaCl}$, numa solução desaerada e com a presença de pequenas quantidades de $\mathrm{H}_{2} \mathrm{~S}(50 \mathrm{ppm}, 1$ atm), a velocidade de corrosão é menor do que a condição sem adição de $\mathrm{NaCl}$ e, em ambos os casos, a velocidade de corrosão diminui com o tempo de imersão - Figura 20 (FANG et al., 2010).

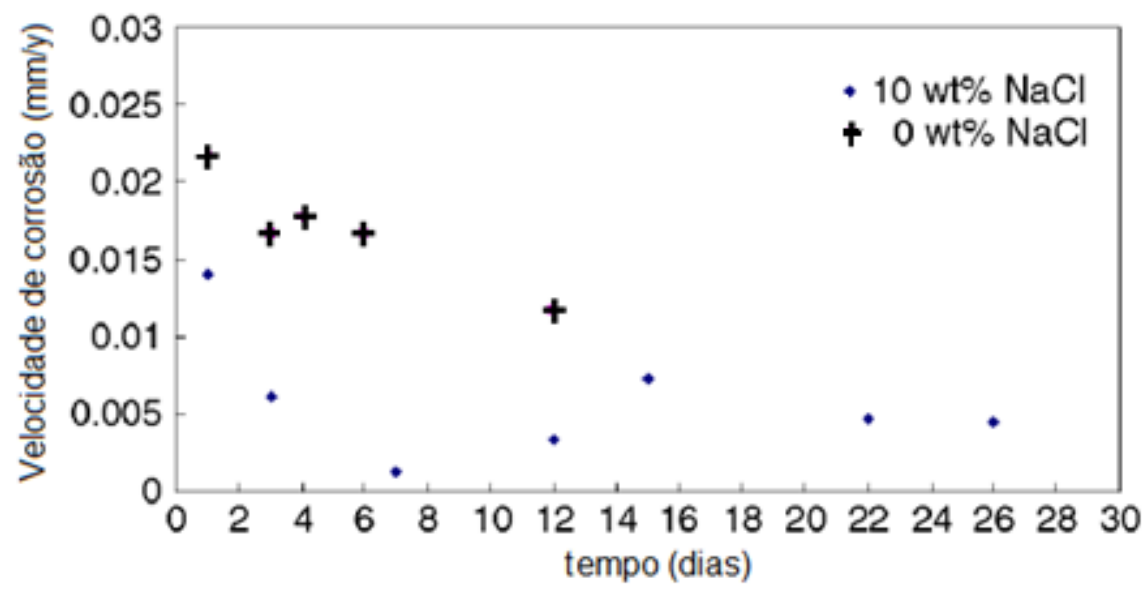

Figura 20 Velocidade de corrosão ( $\mathrm{mm} / \mathrm{ano}$ ) em função do tempo (dias), em eletrólito contendo 50ppm de $\mathrm{H}_{2} \mathrm{~S}$. Modificado. (FANG et al, 2010)

À temperatura ambiente é necessário se ter oxigênio dissolvido na água para que ocorra uma corrosão visível do aço. Em soluções aeradas a velocidade inicial de corrosão do aço é rápida (até $10 \mathrm{gmd}^{1}$ ). Após a formação de produtos de corrosão estes atuam como barreira para o oxigênio e a velocidade de corrosão diminui. Na Figura 21 pode-se ver que o aumento do teor de oxigênio até uma concentração crítica leva a um aumento na velocidade de corrosão, depois esta diminui. Os valores de velocidade de corrosão podem incrementar-

\footnotetext{
$\overline{{ }^{1} \text { gramas por metro quadrado por dia }}$
} 
se com o aumento de sais dissolvidos e da temperatura e pode diminuir com o aumento do $\mathrm{pH}$.

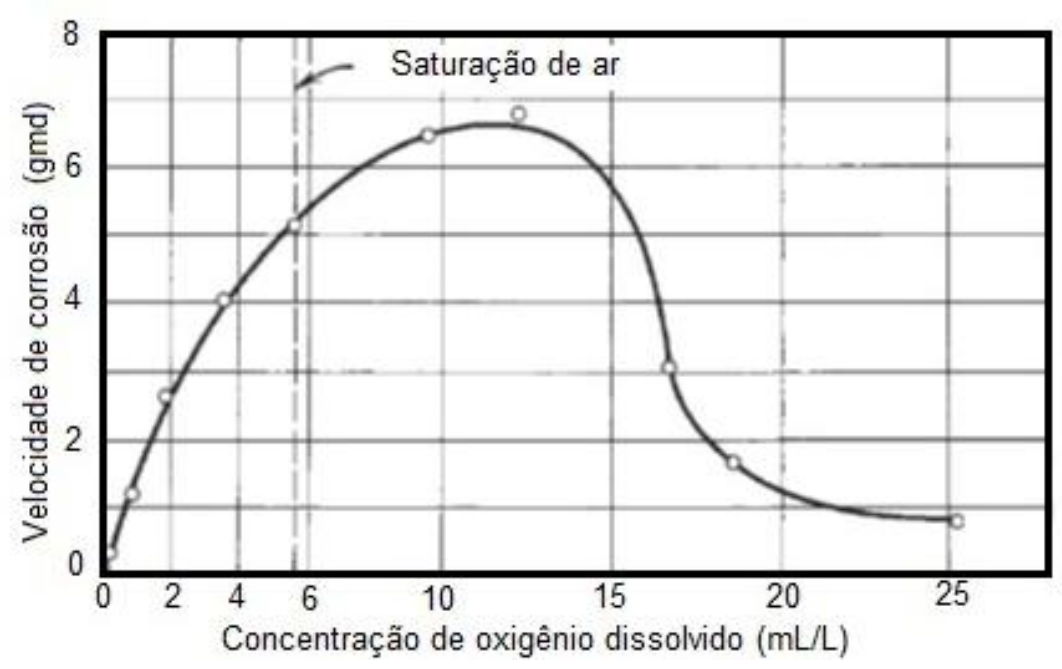

Figura 21 Efeito da concentração de oxigênio sobre a velocidade de corrosão do aço carbono. Modificado. (REVIE; UHLIG, 2008).

Para as condições de $\mathrm{pH}$ ao redor de 7 , as quais estão dentro da faixa de trabalho de aços em água doce e água do mar, o $\mathrm{pH}$ tem um efeito pequeno na velocidade de corrosão (Figura 22). Se o pH é superior a aproximadamente 10, a concentração de íon hidroxila é tão alta que leva a seguinte reação (ROSSUM, 1980).

$1 / 2 \mathrm{O}_{2}+\mathrm{H}_{2} \mathrm{O}+2 \mathrm{e} \leftrightarrow 2 \mathrm{OH}^{-}$

Para valores de $\mathrm{pH}$ abaixo de 4 , a concentração dos íons de hidrogênio é significativamente aumentada e disso resulta que o processo catódico também ocorre através da reação:

$2 \mathrm{H}^{+}+2 \mathrm{e} \leftrightarrow \mathrm{H}_{2}$

Singh; Gupta (1999), por meio de ensaios potenciodinâmicos e perda de massa, determinaram a velocidade de corrosão de aço carbono em soluções de ácido acético $(\mathrm{CH} 3 \mathrm{COOH})$, em concentrações de $5 \%$ a $80 \%$ em massa, constatando que a velocidade máxima de corrosão ocorre para concentrações de $20 \%$ (Figura 23). 


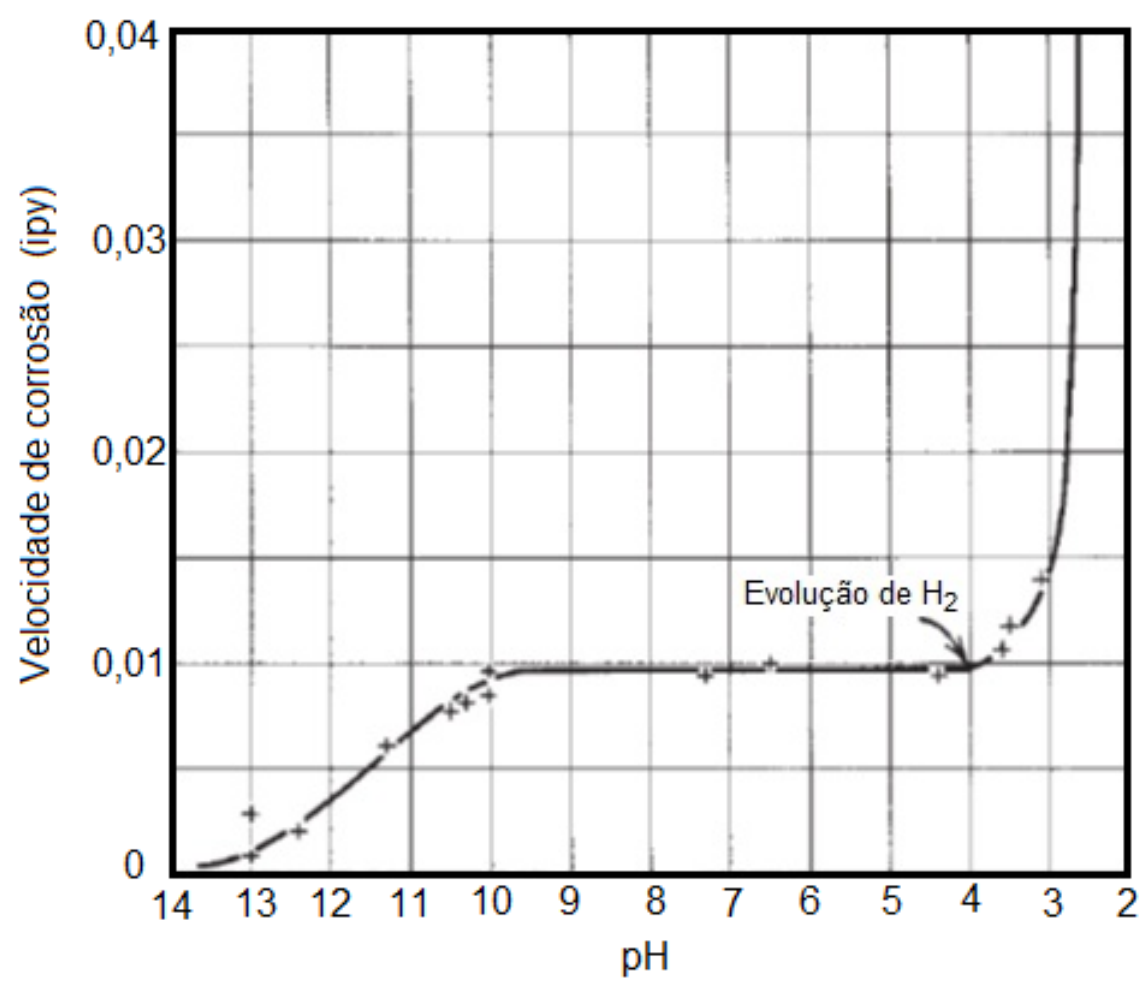

Figura 22 Efeito do pH sobre a velocidade de corrosão do ferro (ipy: polegada por ano) numa solução aerada. Modificado. (REVIE; UHLIG, 2008)

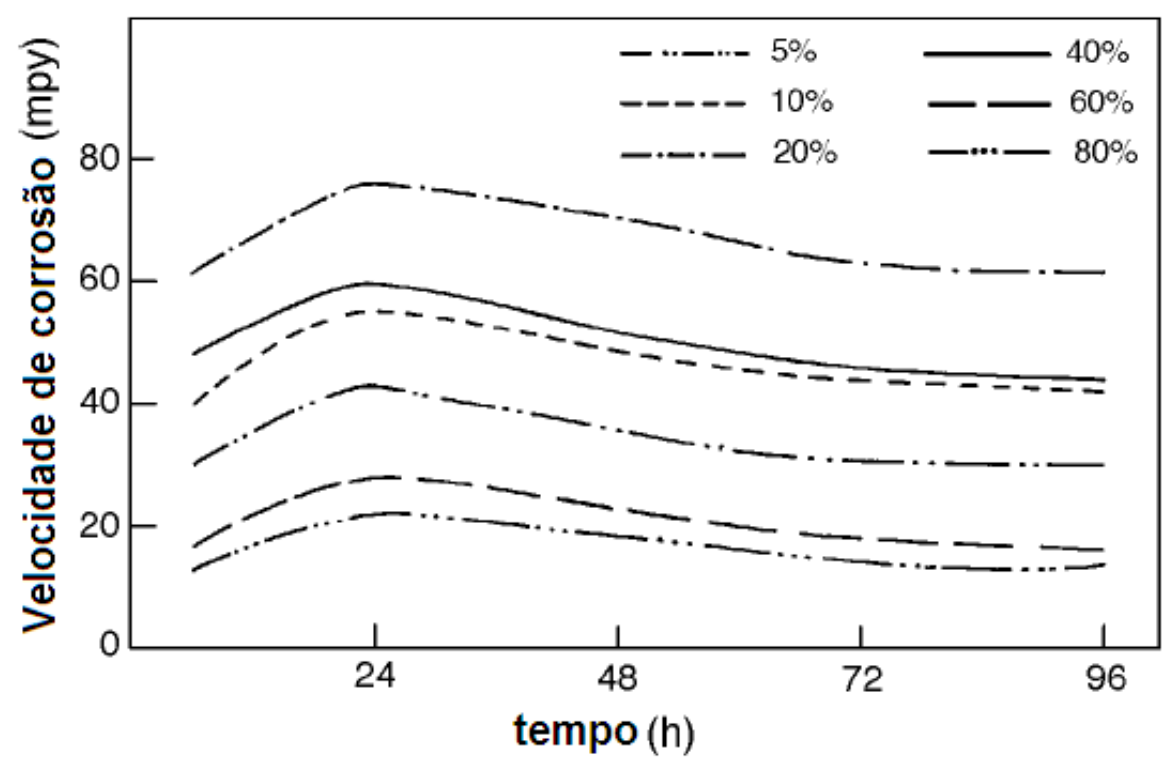

Figura 23 Variação da velocidade de corrosão (mpy: milipolegada por ano) de aço carbono em diferentes concentrações de $\mathrm{CH}_{3} \mathrm{COOH}$ em função do tempo a $25^{\circ} \mathrm{C}$. Modificado.

(SINGH; GUPTA, 1999). 
A corrosão em água doce ou água do mar, para o ferro, pode ser descrita mediante a separação de duas reações, uma anódica onde o metal corrói e uma catódica onde ocorre a redução de uma ou várias das espécies presentes no eletrólito; nenhuma destas reações ocorre sem a outra. Geralmente a água do mar é mais corrosiva que a água doce. Em aplicações de transporte de petróleo e gás as soluções aquosas contém gás carbônico $\left(\mathrm{CO}_{2}\right)$ e $\mathrm{H}_{2} \mathrm{~S} . \mathrm{O} \mathrm{CO}_{2}$ é altamente corrosivo aos metais, atacando especialmente o ferro em temperaturas acima da temperatura ambiente. $\mathrm{O}_{\mathrm{CO}_{2}}$ não apresenta uma reação eletroquímica, o processo corrosivo ocorre pela reação do $\mathrm{CO}_{2} \mathrm{com}$ a água formando ácido carbônico; a consequente diminuição do $\mathrm{pH}$ é a responsável pela aceleração da corrosão.

$\mathrm{CO}_{2}+\mathrm{H}_{2} \mathrm{O} \leftrightarrow \mathrm{H}_{2} \mathrm{CO}_{3}$

$\mathrm{O}$ sulfeto de hidrogênio $\left(\mathrm{H}_{2} \mathrm{~S}\right)$ é um ácido mais fraco que $\circ \mathrm{H}_{2} \mathrm{CO}_{3}$. Além disso, ele reage com o oxigênio dissolvido produzindo enxofre (S), por isso, um eletrólito que contém $\mathrm{H}_{2} \mathrm{~S}$ sinaliza a ausência de oxigênio (ROSSUM, 1980). O $\mathrm{H}_{2} \mathrm{~S}$ é fonte de íons de hidrogênio, e atua como um catalisador que promove a absorção dos átomos de hidrogênio, já que ele retarda a reação de formação de moléculas de hidrogênio, aumentando a concentração de hidrogênio atômico na superfície e intensificando sua penetração na matriz do metal (VAGAPOV et al., 2002). Numa solução de ácido sulfúrico com pH entre 0,5 e 2, foi encontrado que a taxa de corrosão do ferro é acelerada com a adição de $\mathrm{H}_{2} \mathrm{~S}$ (MA et al., 1998).

Na Figura 24 é mostrado o diagrama de Pourbaix para o sistema $\mathrm{Fe}-\mathrm{H}_{2} \mathrm{O}-\mathrm{S}$ o qual apresenta os equilíbrios termodinâmicos das diferentes reações. 


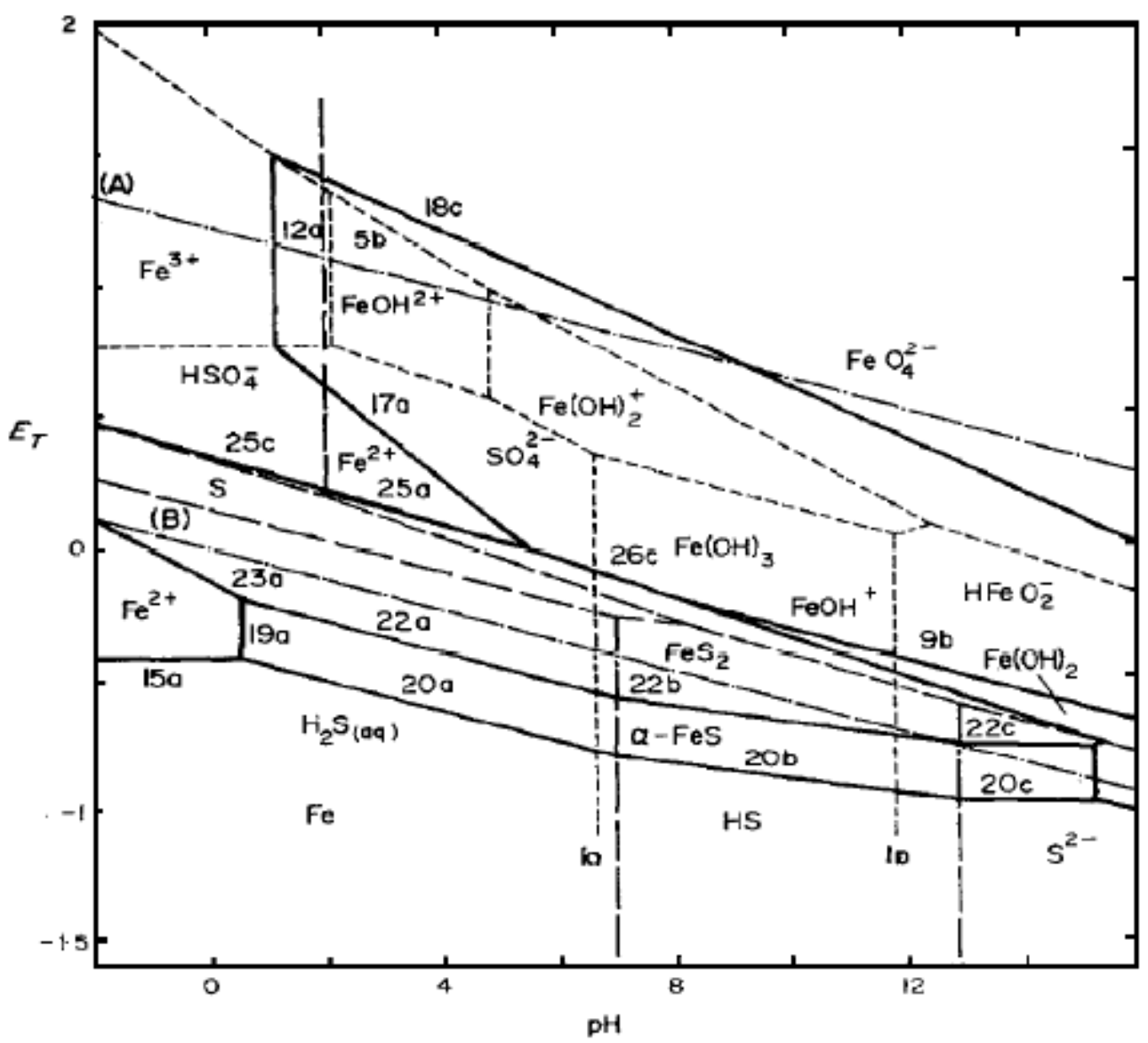

Figura 24 Diagrama potencial de eletrodo (E) em função do pH para o sistema $\mathrm{Fe}-\mathrm{H}_{2} \mathrm{O}-\mathrm{S}$, a $25^{\circ} \mathrm{C}$. Estabilidade da água $(\mathrm{A})$ e $(\mathrm{B})$; ---------, espécies ferrosas dissolvidas; - - , sistema S$\mathrm{H}_{2} \mathrm{O}$; equilíbrios envolvendo espécies sólidas de ferro. (BIERNAT; ROBINS, 1972).

O sulfeto de hidrogênio pode acelerar ou inibir a corrosão do aço dependendo de diferentes condições: para eletrólitos ácidos a velocidade de corrosão pode ter uma aceleração acentuada ( $\mathrm{pH}$ muito baixo - aproximadamente zero), mas pode ocorrer a inibição da corrosão através da formação de sulfeto de ferro $\left(\mathrm{Fe}_{\mathrm{x}} \mathrm{S}_{\mathrm{y}}\right)(\mathrm{MA}$ et al., 2000). A estrutura e composição da película protetora está relacionada com a concentração de $\mathrm{H}_{2} \mathrm{~S}$, o valor de $\mathrm{pH}$ da solução e do tempo de imersão do aço (MA et al., 2000). Também Garcia et al, 2001, mencionam que durante o ataque por $\mathrm{H}_{2} \mathrm{~S}$, para certo intervalo de $\mathrm{pH}$, um filme de $\mathrm{Fe}_{\mathrm{x}} \mathrm{S}_{\mathrm{y}}$ é formado na superfície do aço reduzindo a taxa da corrosão. Os produtos formados no sistema $\mathrm{Fe}-\mathrm{H}_{2} \mathrm{~S}$ são pirita $\left(\mathrm{FeS}_{2}\right)$, pirrotita $\left(\mathrm{Fe}_{1-\mathrm{x}} \mathrm{S}\right)$, sulfeto de ferro hexagonal (FeS) e "Mackinawite" (Fe $\left.{ }_{1+x} S\right) .(V E D A G E$ et al., 1993). 
Na Figura 25 são mostradas as espécies estáveis quando $\mathrm{H}_{2} \mathrm{~S}$ é injetado numa solução aquosa (NACE MR0103-2007). Este resultado também é observado no diagrama de Pourbaix (Figura 24). Segundo Salles, 1990, a quantidade de hidrogênio que penetra no aço é maior em valores de $\mathrm{pH}$ menores do que 8 (ataque ácido), e maior com o aumento da concentração de $\mathrm{H}_{2} \mathrm{~S}$. A diminuição do $\mathrm{pH}$ produz uma diminuição da camada de sulfeto de ferro, que atua como barreira entre o eletrólito e o metal (SALLES, 1990). De fato, para baixos pH $(3,3)$ e baixos potenciais de eletrodo (parte inferior do diagrama da Figura 24), as Figuras 24 e 25 mostram que o composto de enxofre termodinamicamente estável é o $\mathrm{H}_{2} \mathrm{~S}$ e não o $\mathrm{Fe}_{\mathrm{x}} \mathrm{S}_{\mathrm{y}}$. Consequentemente espera-se uma velocidade de corrosão maior em eletrólitos ácidos como a solução $A(p H \quad 3,3)$ comparativamente à solução $\mathrm{B},(4,8<\mathrm{pH}<5,4)$, ambas da norma NACE TM0284-2003, sendo que nessas soluções o agente oxidante $\mathrm{H}^{+}$provém da dissociação do ácido acético e da hidrólise pela presença de cloreto de sódio na solução $A$ e, na solução $B$, pela hidrólise devido a presença de vários tipos de sais $\left(\mathrm{NaCl}, \mathrm{MgCl}_{2}, \mathrm{Na}_{2} \mathrm{SO}_{4}, \mathrm{CaCl}_{2}\right.$ principalmente); quanto a contribuição do $\mathrm{H}_{2} \mathrm{~S}$ em $\mathrm{H}^{+}$esta é praticamente nula, devido ao seu baixo grau de dissociação (Figura 25). Deve-se lembrar que $\circ \mathrm{H}_{2} \mathrm{~S}$ está presente nestas soluções para promover a fragilização por hidrogênio (absorção do hidrogênio atômico) e não a acidez propriamente dita.

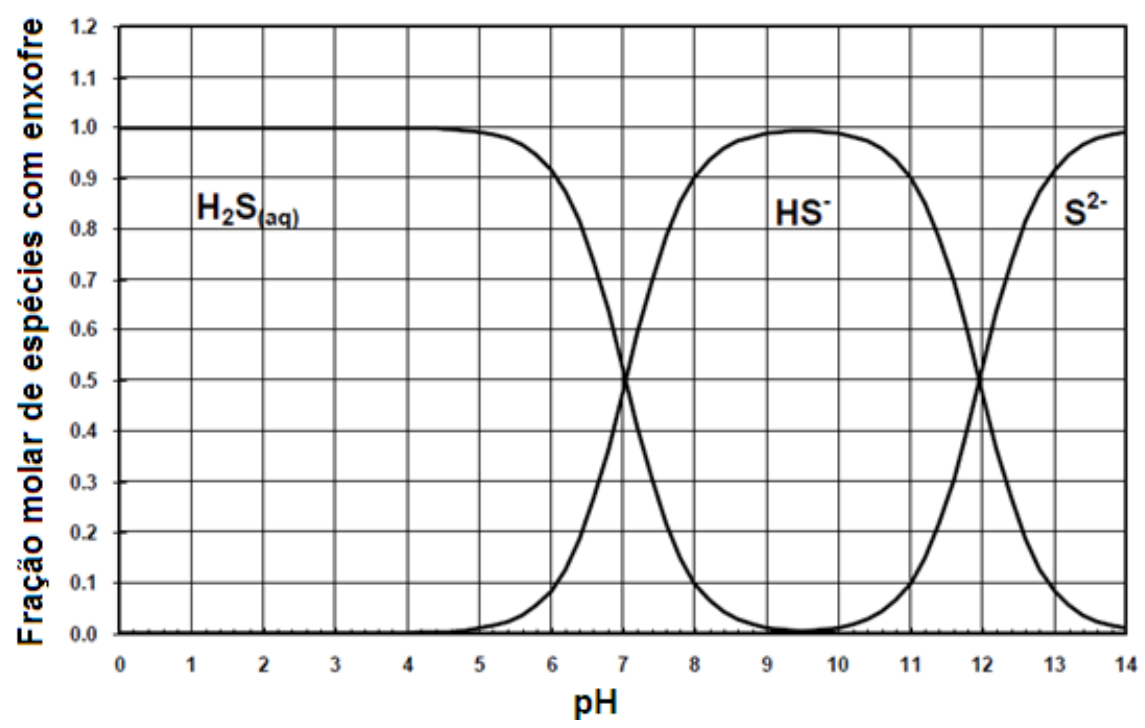

Figura 25 Estabilidade das substâncias que contém enxofre em solução aquosa, a $25^{\circ} \mathrm{C}$. Modificado. (NACE MR0103-2007) 
Para que ocorra a entrada de hidrogênio até a matriz do aço é necessário que sucedam vários fenômenos: precisa-se de íons $\mathrm{H}^{+}$, de uma espécie redutora e, além disso, é necessário um veneno catódico no eletrólito $\left(\mathrm{H}_{2} \mathrm{~S}\right)$ - sem o qual não se tem a fragilização do aço. $\mathrm{O} \mathrm{pH} \mathrm{(abaixo} \mathrm{de} \mathrm{5),} \mathrm{tem} \mathrm{um} \mathrm{papel} \mathrm{importante}$ neste processo, pois promove a formação de átomos de hidrogênio mediante a corrosão do ferro e dá estabilidade ao $\mathrm{H}_{2} \mathrm{~S}_{\text {aq }}$ (Figura 25), o qual tem como única função atrasar a cinética de formação de $\mathrm{H}_{2}$ e permitir a difusão de $\mathrm{H}$ na matriz.

Só uma fração de todo o hidrogênio formado na superfície consegue ser absorvido pelo metal, sendo que o total de hidrogênio absorvido pelo metal é a soma do hidrogênio aprisionado irreversivelmente (irreversible traps), reversivelmente (reversible traps) e o hidrogênio que difunde livremente (mobile hydrogen).

A realização desta revisão bibliográfica permite concluir que o trincamento induzido por hidrogênio (HIC), na presença de $\mathrm{H}_{2} \mathrm{~S}$, depende do $\mathrm{pH}$ do meio aquoso (concentração de $\mathrm{H}^{+}$no eletrólito), da resistência mecânica, bem como da microestrutura dos aços ARBL, uma vez que é a microestrutura que determinará a densidade e os tipos de sítios de aprisionamento (traps) de hidrogênio. Vale ressaltar que por microestrutura entende-se desde os defeitos cristalinos (discordâncias, contornos de grão), passando-se pelos microconstituintes propriamente ditos (carboneto, perlita, todas as formas de ferrita, todas as formas de bainita e martensita) até as inclusões (tipos e morfologias).

A proposta da presente dissertação é investigar a influência de algumas dessas variáreis sobre o HIC (composição química do eletrólito e microestrutura dos aços ARBL da designação API $5 \mathrm{~L}$ X65). 


\section{OBJETIVOS}

Analisar e comparar o comportamento quanto à resistência à corrosão e quanto à susceptibilidade ao trincamento induzido por hidrogênio de aços microligados, na forma de chapa grossa e tubos API $5 \mathrm{~L}$ grau $\mathrm{X} 65$, quando submetidos a meios contendo sulfeto de hidrogênio.

\section{MATERIAIS E MÉTODOS}

Neste capítulo são apresentados os materiais e procedimentos experimentais necessários para o estudo comparativo da resistência à corrosão e susceptibilidade ao trincamento induzido por hidrogênio dos aços para tubos API $5 \mathrm{~L}$ X65. Para tais fins foram realizados ensaios eletroquímicos (método da polarização linear) e de trincamento induzido por hidrogênio tomando-se por base as recomendações da norma NACE TM0284-2003.

\subsection{MATERIAIS}

Neste trabalho foram utilizadas amostras de chapa grossa e de tubos de aço destinados a gasodutos. As principais características (forma e dimensões) das amostras disponíveis para esta pesquisa estão apresentadas na Tabela 6 .

Tabela 6 Características das amostras disponíveis para esta pesquisa.

\begin{tabular}{|c|c|c|c|c|}
\hline \multirow[t]{2}{*}{ IDENTIFICAÇÃO } & \multirow[t]{2}{*}{ FORMA } & \multicolumn{2}{|c|}{ DIMENSÕES (mm) } & \multirow[t]{2}{*}{ OBSERVAÇÕES } \\
\hline & & Espessura & Diâmetro & \\
\hline T-X65S & Tubo & 22 & 460 & $\begin{array}{c}\text { Tubo API 5L X65 para aplicação } \\
\text { sour }\end{array}$ \\
\hline T-X65 & Tubo & 13 & 325 & $\begin{array}{l}\text { Tubo API 5L X65 não } \\
\text { recomendado para aplicação sour }\end{array}$ \\
\hline RS-X65S & $\begin{array}{l}\text { Região soldada } \\
\text { do tubo }\end{array}$ & 22 & 460 & $\begin{array}{l}\text { Região soldada do tubo API 5L } \\
\text { X65 para aplicação sour }\end{array}$ \\
\hline C-X65 & Chapa grossa & 17,5 & - & $\begin{array}{c}\text { Chapa grossa de aço para tubo } \\
\text { API 5L X65 }\end{array}$ \\
\hline
\end{tabular}


As composições químicas das amostras foram informadas pelas empresas doadoras e estão listadas na Tabela 7. As amostras têm composição química de acordo com a norma API 5L PSL1 e PSL2, grau X65 (Tabelas 1 e 2).

As amostras se diferem quanto à fabricação das chapas que originaram os tubos, uma delas é indicada para utilizações sour (X65S) e a outra (X65NS) não é especificada para tal aplicação, portanto é indicada apenas para aplicações com baixos ou nenhum teor de $\mathrm{H}_{2} \mathrm{~S}$.

Tabela 7 Composição química das amostras desta pesquisa.

\begin{tabular}{cccccc}
\hline T-X65S & RS-X65S & C-X65 & T-X65 NS & $\begin{array}{c}\text { Máximo } \\
\text { especificado norma } \\
\text { API 5L PSL2 }\end{array}$ \\
\hline $\mathbf{C}$ & 0,040 & 0,050 & 0,100 & 0,070 & 0,220 \\
$\mathbf{S}$ & 0,001 & 0,005 & 0,001 & 0,003 & 0,015 \\
$\mathbf{P}$ & 0,005 & 0,014 & 0,019 & 0,021 & 0,025 \\
$\mathbf{A l}$ & 0,035 & 0,017 & 0,044 & 0,043 & - \\
$\mathbf{S i}$ & 0,330 & 0,370 & 0,230 & 0,210 & - \\
$\mathbf{C u}$ & 0,013 & 0,030 & 0,010 & 0,010 & - \\
$\mathbf{C r}$ & 0,160 & 0,119 & 0,020 & 0,020 & - \\
$\mathbf{M n}$ & 1,520 & 1,420 & 1,510 & 1,520 & 1,45 \\
$\mathbf{N i}$ & 0,012 & 0,017 & 0,015 & 0,190 & - \\
$\mathbf{M o}$ & 0,003 & 0,167 & 0,000 & 0,010 & - \\
$\mathbf{N}$ & 0,004 & 0,007 & 0,000 & 0,005 & - \\
$\mathbf{V + T i + N b}$ & 0,059 & 0,047 & 0,116 & 0,103 & 0,15 \\
$\mathbf{C E}$ (Pcm) & 0,14 & 0,16 & 0,190 & 0,16 & - \\
$\mathbf{C E}$ (IIW) & 0,33 & 0,35 & 0,370 & 0,35 & - \\
\hline
\end{tabular}

\subsection{MÉTODOS}

$\mathrm{Na}$ fase inicial deste trabalho foram selecionados e preparados os corpos-deprova para cada um dos ensaios. Realizaram-se ensaios de polarização linear utilizando um eletrólito composto de $5 \% \mathrm{NaCl}$ (cloreto de sódio) e 0,5\% $\mathrm{CH}_{3} \mathrm{COOH}$ (ácido acético) em água destilada e deionizada, e um eletrólito de 
meio marinho sintético, os quais correspondem à solução $A$ e solução $B$ respectivamente, da norma NACE TM0284-2003. Os ensaios de fragilização por hidrogênio dos aços foram feitos baseados nas recomendações da norma NACE TM0284-2003.

Também foram realizadas as caracterizações microestruturais dos aços e caracterização da morfologia de corrosão utilizando-se microscópio ótico (MO) e microscópio eletrônico de varredura (MEV) pertencentes ao Departamento de Engenharia Metalúrgica e de Materiais da EPUSP (PMT); além disso, também foi utilizado o MEV pertencente ao Centro Técnico da Marinha de São Paulo (CTMSP) e o MEV do Centro Universitário da FEI.

Para compreender a natureza dos produtos de corrosão formados e os mecanismos de propagação das trincas foram realizadas análises por espectroscopia de energia dispersiva (EDS), cujo equipamento está acoplado aos MEV.

O MEV pertencente ao laboratório de microscopia eletrônica e de força atômica PMT-EPUSP é da marca Philips XL-30; o MEV do CTMSP é da marca Inspect S50-FEI e o MEV do Centro Universitário da FEl é da marca Obducat CamScan modelo CS3200LV.

\subsubsection{ENSAIOS DE POLARIZAÇÃO LINEAR}

Escolheu-se para a avaliação da resistência à corrosão a determinação da Resistência à Polarização (Rp) pelo método da Polarização Linear. Este método é baseado na obtenção de dados de corrente em potenciais próximos do potencial de corrosão (polarização catódica seguida de anódica). A Rp é a tangente à curva de polarização obtida no potencial de corrosão (na sobretensão zero). A resistência de polarização linear indica a resistência à corrosão de um determinado material, exposto a um dado eletrólito. Quanto mais altos os valores de $\mathrm{Rp}$, menores são as velocidades de corrosão do material. Como foi desenvolvida com base nos fundamentos de corrosão 
uniforme, a técnica só deve ser utilizada para avaliação deste tipo de corrosão, fornecendo pouca ou nenhuma informação sobre corrosão localizada.

A Rp de um eletrodo que se corrói é definida pela equação 3, que é o resultado da derivada da equação de Wagner e Traud (equação 4) em relação à sobretensão no ponto da sobretensão igual a zero. A equação de Wagner e Traud é a relação entre a densidade de corrente (i) e a sobretensão aplicada $(\Delta \mathrm{E})$ ). (ASTM G102-89, 2009 e G59-97, 2010).

$$
\begin{aligned}
& R p=\left(\frac{\partial \Delta E}{\partial i}\right)_{\Delta E \rightarrow 0}\left[\Omega \cdot \mathrm{cm}^{2}\right] \\
& i=i_{\text {corr }}\left[e^{\frac{2,303\left(E-E_{\text {corr }}\right)}{b_{a}}}-e^{\frac{2,303\left(E-E_{\text {corr }}\right)}{b_{c}}}\right]\left[\mathrm{A} / \mathrm{cm}^{2}\right]
\end{aligned}
$$$$
\text { Equação } 3
$$

Equação 4

$\mathrm{Na}$ equação (4), $\mathrm{i}_{\text {corr }}$ é a densidade de corrente de corrosão, E é o potencial de eletrodo aplicado, $E_{\text {corr }}$ é o potencial de corrosão, $b_{a}$ e $b_{c}$ são os valores dos declives de Tafel anódico e catódico.

A partir da equação (3) chega-se à densidade de corrente de corrosão que está relacionada com os declives de Tafel através da equação 5 (WOLYNEC, 2003).

$$
i_{c o r r}=\frac{b a b_{c}}{2,303\left(b_{a}+b_{c}\right)}\left[\frac{1}{R p}\right]=\frac{B}{R p}
$$

Equação 5

A unidade da Rp pode ser dada em $\mathrm{Ohm} . \mathrm{cm}^{2}$, enquanto que as unidades da $\mathrm{i}_{\text {corr }}$ e dos declives $b_{\mathrm{a}}$ e $\mathrm{b}_{\mathrm{c}}$ são respectivamente, A.cm ${ }^{-2}$ e V/década. A Figura 26 apresenta uma curva de polarização linear esquemática, para a obtenção da Rp. Nota-se que o valor da Rp é a tangente à curva de polarização no ponto do $\mathrm{E}_{\text {corr. }}$ 


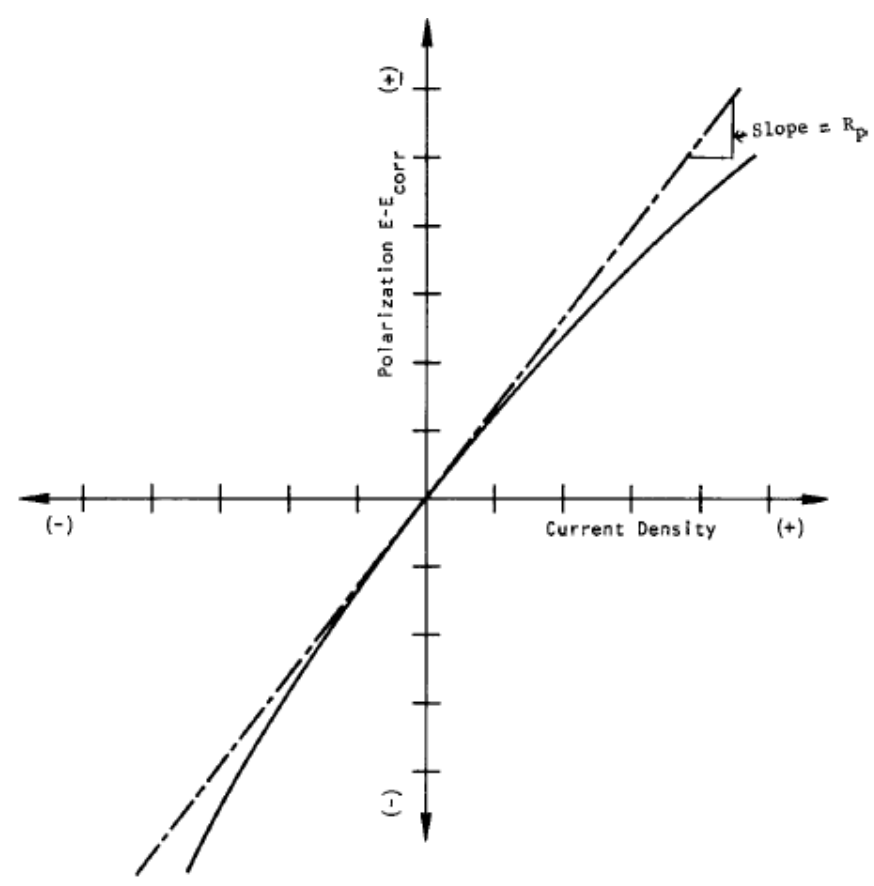

Figura 26 Curva de polarização linear para a obtenção da resistência de polarização (ASTMG59-10)

Estimar as taxas de corrosão a partir de uma curva de polarização linear, como a mostrada na Figura 26, pode estar limitada por um ou vários fatores (GONZÁLEZ et al.,1985):

- Os trechos de Tafel são desconhecidos, ou variam com o tempo.

- Falta de linearidade das curvas de polarização próximo do potencial de corrosão.

- O eletrólito ou os produtos de corrosão são altamente resistivos.

- O potencial de corrosão varia durante a medição.

- Há ocorrência de corrosão localizada (pite).

- A corrosão é controlada por difusão ou o metal é passivado.

- O sistema a ser polarizado requer tempo para alcançar um o estado estacionário.

Por tais motivos, se há a dificuldade para o cálculo da $\mathrm{i}_{\text {corr, }}$ faz-se a comparação da resistência à corrosão entre materiais distintos a partir do próprio valor da Rp. 


\subsubsection{ELETRÓLITOS PARA ENSAIOS DE POLARIZAÇÃO E FRAGILIZAÇÃO}

Nos ensaios foram utilizados os eletrólitos de composição conforme a norma TM 0284-03 da NACE, Solução A e Solução B segundo as Tabelas 8 e 9.

Tabela 8 Composição Solução A norma NACE TM0284-2003

\begin{tabular}{lll}
\hline Solução A & & \\
\hline & $\mathrm{NaCl}$ & $5,0 \%$ em massa \\
\hline & $\mathrm{CH}_{3} \mathrm{COOH}$ & $0,50 \%$ em massa \\
\hline & Água destilada \\
\hline Exemplo (1 L de solução A) & $50 \mathrm{~g} \mathrm{NaCl}$ e $5 \mathrm{~g} \mathrm{CH}_{3} \mathrm{COOH}$ dissolvidos em \\
& $945 \mathrm{~g}$ de água destilada \\
\hline pH & $2,7 \pm 0,1$ \\
\hline
\end{tabular}

Tabela 9 Composição química da Solução B da norma NACE TM0284-2003, segundo ASTM D1141

\begin{tabular}{|c|c|c|}
\hline \multicolumn{3}{|l|}{ Solução B ASTM D1141 } \\
\hline \multirow[t]{2}{*}{ Solução 0} & $\mathrm{NaCl}$ & $24,53 \mathrm{~g} / \mathrm{L}$ \\
\hline & $\mathrm{Na}_{2} \mathrm{SO}_{4}$ & $4,09 \mathrm{~g} / \mathrm{L}$ \\
\hline \multirow[t]{3}{*}{ Solução 1} & $\mathrm{MgCl}_{2} \cdot 6 \mathrm{H}_{2} \mathrm{O}$ & $555,6 \mathrm{~g} / \mathrm{L}$ \\
\hline & $\mathrm{CaCl}_{2}$ (anidro) & $57,9 \mathrm{~g} / \mathrm{L}$ \\
\hline & $\mathrm{SrCl}_{2} \cdot 6 \mathrm{H}_{2} \mathrm{O}$ & $2,1 \mathrm{~g} / \mathrm{L}$ \\
\hline \multirow[t]{5}{*}{ Solução 2} & $\mathrm{KCl}$ & $69,5 \mathrm{~g} / \mathrm{L}$ \\
\hline & $\mathrm{NaHCO}_{3}$ & $20,1 \mathrm{~g} / \mathrm{L}$ \\
\hline & $\mathrm{KBr}$ & $10,0 \mathrm{~g} / \mathrm{L}$ \\
\hline & $\mathrm{H}_{3} \mathrm{BO}_{3}$ & $2,7 \mathrm{~g} / \mathrm{L}$ \\
\hline & $\mathrm{NaF}$ & $0,3 \mathrm{~g} / \mathrm{L}$ \\
\hline $\begin{array}{l}\text { Preparação das } \\
\text { soluções } 1 \text { e } 2\end{array}$ & \multicolumn{2}{|c|}{$\begin{array}{l}\text { Dissolver as quantidades indicadas em água } \\
\text { destilada. }\end{array}$} \\
\hline \multirow[t]{2}{*}{ Exemplo (10 L de solução B) } & Preparar a $s$ & 0: Dissolver $245,34 \mathrm{~g}$ \\
\hline & \multicolumn{2}{|c|}{$\begin{array}{l}\mathrm{NaCl} \text { e } 40,94 \mathrm{~g} \mathrm{Na}_{2} \mathrm{SO}_{4} \text { em } 8 \text { a } 9 \mathrm{~L} \text { de água } \\
\text { destilada. Adicionar } 200 \mathrm{~mL} \text { da Solução } 1 \text {, } \\
\text { agitar e adicionar } 100 \mathrm{~mL} \text { da Solução } 2 . \\
\text { Completar até } 10,0 \mathrm{~L} \mathrm{com} \text { água destilada. } \\
\text { Ajustar o pH para } 8,2 \mathrm{com} \text { uma solução de } \\
0,1 \mathrm{~N} \mathrm{NaOH} \text {. }\end{array}$} \\
\hline pH & $8.2 \pm 0.1$ & \\
\hline
\end{tabular}




\subsubsection{ENSAIOS DE POLARIZAÇÃO: CORPOS-DE-PROVA E PROCEDIMENTOS}

Cada tipo de material (tubos e chapa) foi recortado em amostras de modo a se obter uma área exposta de $1 \mathrm{~cm}^{2}$, sendo mantida a espessura original da seção transversal (seção perpendicular ao sentido de laminação ou perpendicular ao sentido longitudinal do tubo). Estas amostras foram novamente recortadas, no seu comprimento, para permitir o embutimento em baquelite, sempre expondo a seção transversal e conservando toda a espessura original (Figura 27). Foi escolhida a seção transversal para a determinação da $\mathrm{Rp}$, pois esta é a seção examinada nos ensaios de trincamento induzido por hidrogênio; como uma das questões é existência de uma possível correlação entre resistência à corrosão e resistência ao trincamento induzido por hidrogênio, optou-se por examinar a mesma seção nos dois ensaios.

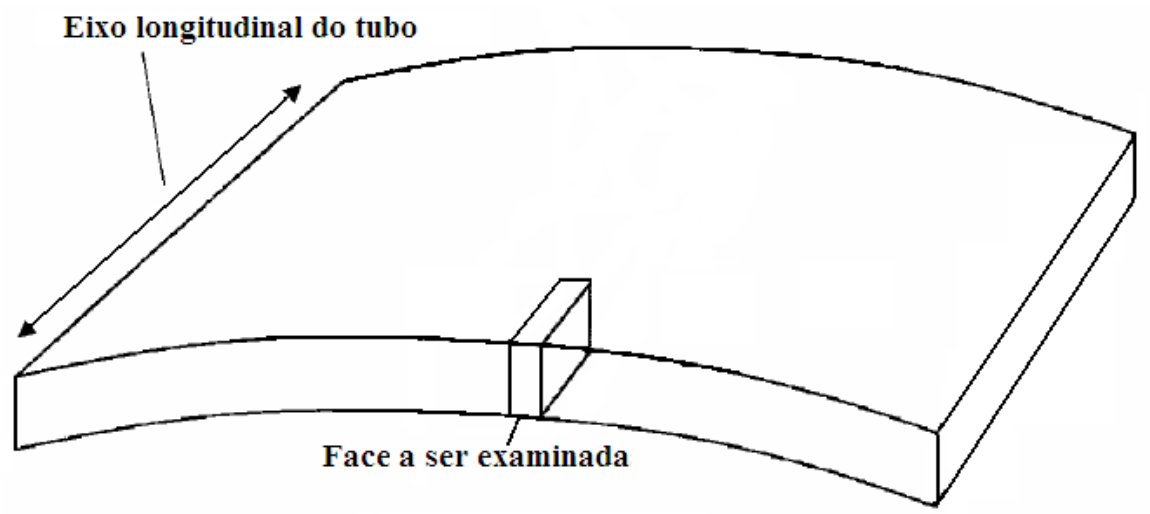

Figura 27 Face a ser examinada nos ensaios de polarização linear: seção transversal do tubo (ou chapa), com área de $1 \mathrm{~cm}^{2}$, mantendo-se a espessura total da amostra original.

Antes do embutimento as amostras tiveram todas as suas faces lixadas até lixa de granulometria 600 para eliminação das imperfeições superficiais. Em seguida foram embutidas e lixadas sequencialmente, por lixas de granulometria 100, 220, 320, 400 e 600 (Figura 28). Para se conseguir o contato elétrico entre os corpos-de-prova e o potenciostato, fez-se um furo de rosca na baquelite, por 
onde era rosqueada uma haste metálica. Este conjunto era instalado num suporte de vidro e introduzido na célula eletroquímica para a realização dos ensaios de polarização linear.

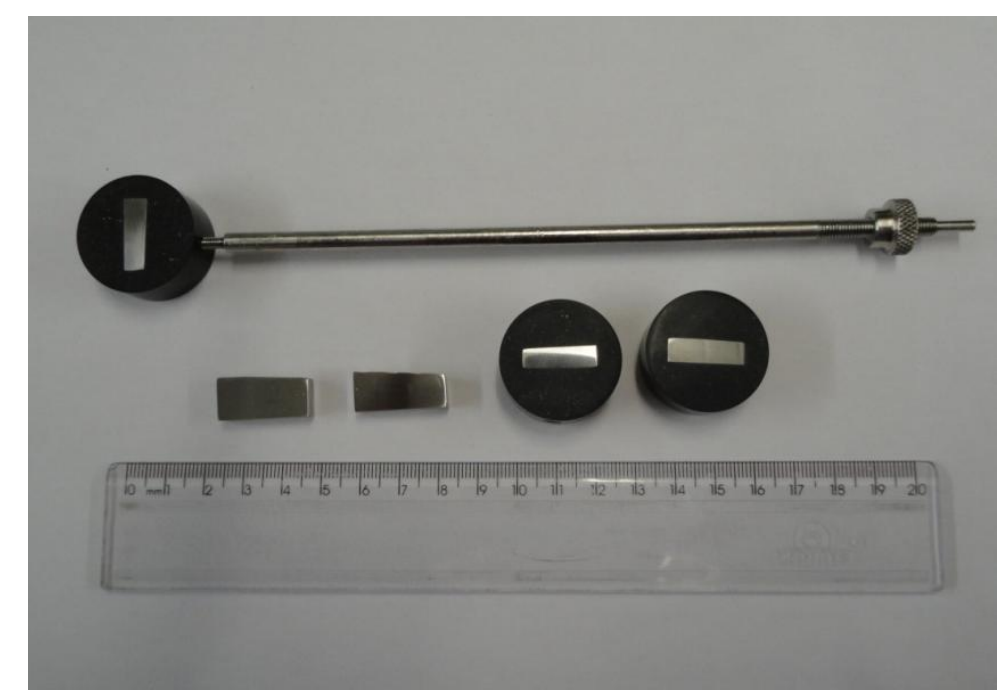

Figura 28 Corpos-de-prova antes e após embutimento.

Para os ensaios de polarização linear foi utilizado um potenciostato PAR 273A da Princeton Applied Reserch, conectado a um microcomputador controlado pelo programa Corrosion Measurement Software M-352 (versão 3.11). A célula eletroquímica era do tipo balão volumétrico, com cerca de $700 \mathrm{~mL}$ de eletrólito. O contra-eletrodo utilizado foi o de platina (fio de platina enrolado em forma de mola) e como eletrodo de referência foi utilizado o eletrodo de calomelano saturado (ECS). A Figura 29b apresenta a célula eletrolítica. 

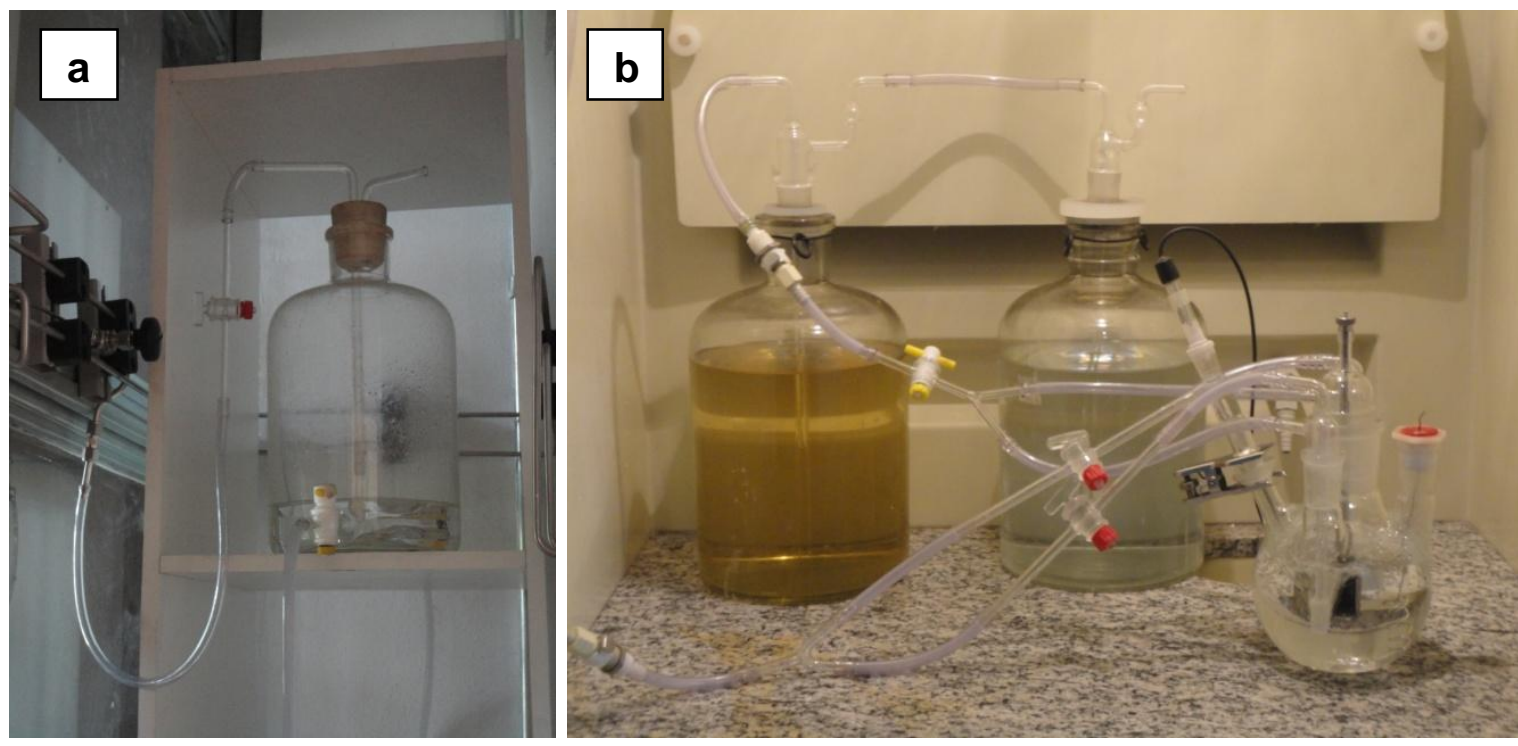

Figura 29 a) Primeira desaeração. b) Eletrólito transferido até a célula eletrolítica.

Cada um dos eletrólitos passou por um processo de desaeração onde foi borbulhado gás nitrogênio. $A$ injeção de $\mathrm{N}_{2}$ teve uma duração de 1 a $2 \mathrm{~h}$, com vazão superior a $200 \mathrm{~mL}$ por minuto por litro de eletrólito, o qual é o valor recomendado pela norma NACE TM0284-2003. Após a desaeração Figura 29-a, $700 \mathrm{~mL}$ de eletrólito foram transferidos à célula eletroquímica até cobrir completamente a amostra a ser ensaiada (Figura 29-b), e então foi realizada uma segunda desaeração por 30 minutos para garantir a eliminação de todo o oxigênio da solução. Depois se realizou a injeção de $\mathrm{H}_{2} \mathrm{~S}$ com vazão superior a $100 \mathrm{~mL}$ por minuto por litro de eletrólito, a qual foi realizada durante 1 hora. Nesse ponto, a célula eletroquímica foi conectada ao potenciostato, tal como aparece na Figura 30, e tomadas as medidas, iniciando numa sobretensão de $-10 \mathrm{mV}$, fazendo-se um varrimento de $1 \mathrm{mV} \cdot \mathrm{s}^{-1}$ até ser alcançada uma sobretensão de $10 \mathrm{mV}$. Os valores de potencial aplicado foram plotados em função da corrente, para determinar o valor da resistência de polarização. As medidas foram feitas em intervalos de 10 minutos durante 1 hora, obtendo-se um total de 7 valores de Rp de para cada amostra por ensaio. Os ensaios foram realizados dentro da faixa de $25 \pm 3^{\circ} \mathrm{C}$ a qual é a recomendada pela norma NACE TM0284-2003. Estes ensaios foram repetidos três (03) vezes para cada condição material/eletrólito. 


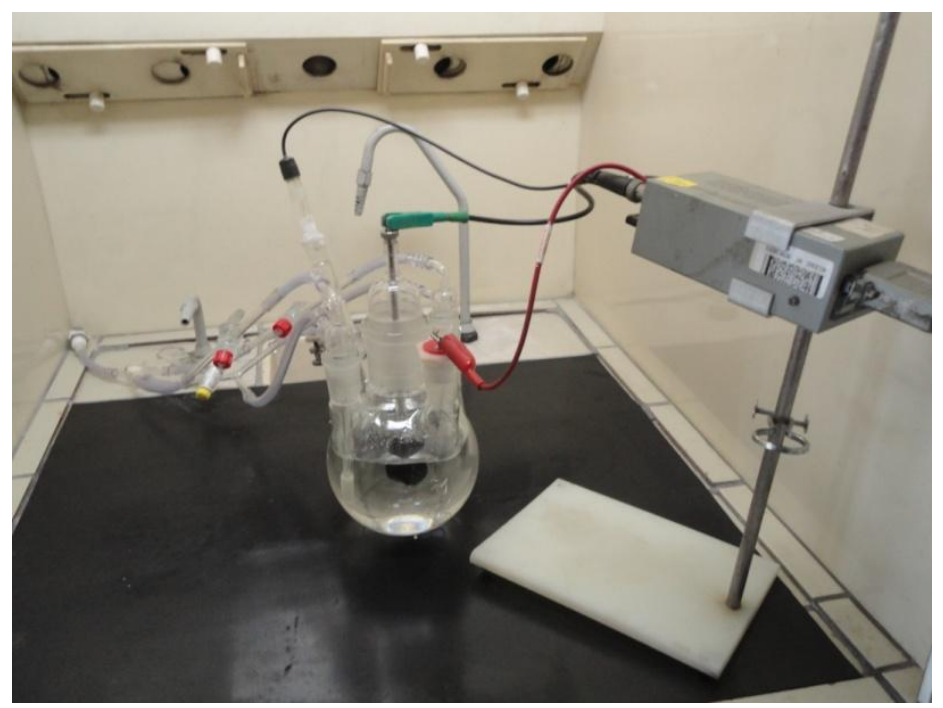

Figura 30 Arranjo experimental utilizado no levantamento das curvas de polarização linear (determinação de Rp).

\subsubsection{MORFOLOGIA DE CORROSÃO}

Após determinação da $\mathrm{Rp}$, os corpos-de-prova foram examinados em $\mathrm{MO}$ e MEV para visualização da morfologia de corrosão; foram realizados exames por espectroscopia de energia dispersiva (EDS) dos produtos de corrosão encontrados.

\subsubsection{ENSAIO DE TRINCAMENTO INDUZIDO POR HIDROGÊNIO}

As trincas causadas por $\mathrm{H}_{2} \mathrm{~S}$ são fonte de risco na indústria petroquímica e cada vez mais equipamentos estão expostos a ambientes ácidos. A norma NACE TM0284-2003 descreve os procedimentos para avaliar a resistência de tubulações e vasos de pressão, fabricados de aço, os quais são susceptíveis ao trincamento induzido por hidrogênio (Hydrogen induced cracking - HIC). Esta norma não especifica parâmetros para simular um ambiente ou condição de trabalho, apenas informa as condições para avaliação da resistência ao HIC e não outros tipos de danos causados pelos ambientes ácidos (NACE TM0284-2003). 


\section{CORPOS-DE-PROVA E PROCEDIMENTOS}

Os corpos-de-prova, para estes ensaios, foram extraídos com dimensões de $(100 \pm 1) \mathrm{mm}$ de comprimento por $(20 \pm 1) \mathrm{mm}$ de largura, sempre na direção de laminação da placa (eixo longitudinal do tubo). A espessura dos corpos-deprova é a própria espessura dos tubos. Na Figura 31 mostram-se o corpo-deprova e as faces que serão examinadas após o ensaio.

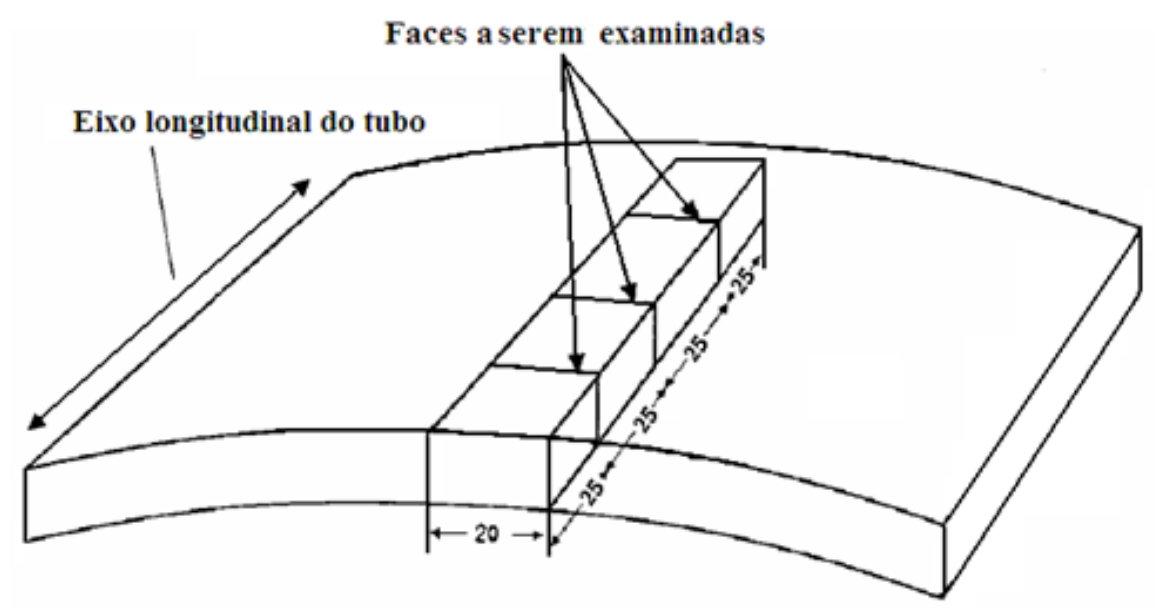

Figura 31 Indicação da posição de extração dos corpos-de-prova para o ensaio de HIC.

Os corpos-de-prova foram retirados com serra de fita, depois foram usinados para obter superfícies completamente planas com as medidas requeridas. Todas as superfícies dos corpos-de-prova foram lixadas passando por lixas com granulometria 100,180, 220 até 320; em seguida, foram limpos com álcool, secos com jato de ar e acondicionados em vácuo.

$O$ ensaio de trincamento induzido por hidrogênio foi realizado seguindo-se as recomendações da norma NACE TM0284-2003. Foram usadas as Soluções A e B desta norma, conforme mencionado nas Tabelas 8 e 9.

Cada uma das soluções foi preparada num recipiente separado e transferida para o recipiente onde ocorreu a purga com nitrogênio por uma hora à taxa superior à recomendada pela norma que é de $100 \mathrm{~mL}$ por minuto por litro de solução. O nitrogênio foi introduzido perto do fundo do recipiente. 
A seguir os corpos-de-prova foram colocados na célula de ensaio de maneira que não tocassem uns aos outros (Figura 32). A célula foi preenchida com 0 eletrólito proveniente do recipiente de purga, fechada e selada. $O$ volume de eletrólito de teste foi de $5 \mathrm{~L}$, o que garantiu um volume muito maior do que o exigido pela norma NACE TM0284-2003, que é de $3 \mathrm{~mL}$ por $\mathrm{cm}^{2}$.

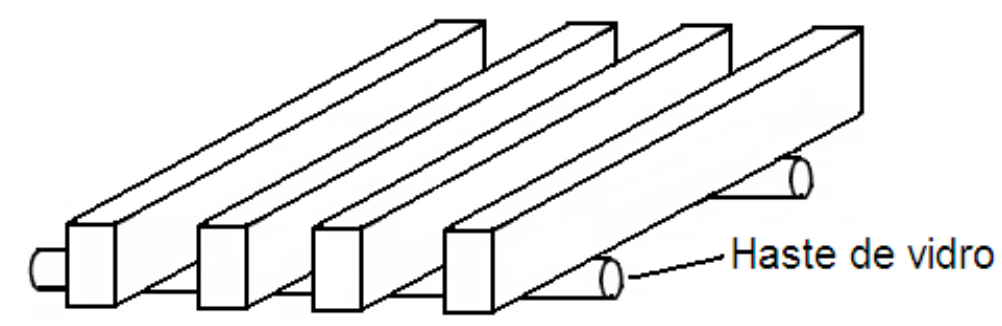

Figura 32 Disposição dos corpos-de-prova dentro da célula, sugerida pela norma NACE TM0284-2003.

Efetuou-se, então, nova purga, através da passagem de gás nitrogênio, introduzido perto do fundo da célula de ensaio, por 3 (três) horas, a uma taxa maior que $100 \mathrm{~mL}$ por minuto por litro de solução. Depois da purga, prosseguiu-se com a injeção de gás $\mathrm{H}_{2} \mathrm{~S}$ no eletrólito. A taxa de borbulhamento foi superior a $200 \mathrm{~mL}$ por minuto por litro de solução para os primeiros 60 minutos. $O$ excesso de gás injetado na célula era transferido para recipientes contendo $10 \% \mathrm{NaOH}$, a fim de promover a neutralização do $\mathrm{H}_{2} \mathrm{~S}$ residual. Uma vez que todo este arranjo experimental foi construído no interior de uma capela de gases, o gás, já neutralizado, era retirado por sucção até o lavador de gases localizado na área externa do laboratório. Na Figura 33 tem-se um esquema do arranjo experimental que foi construído no interior da capela de gases. 


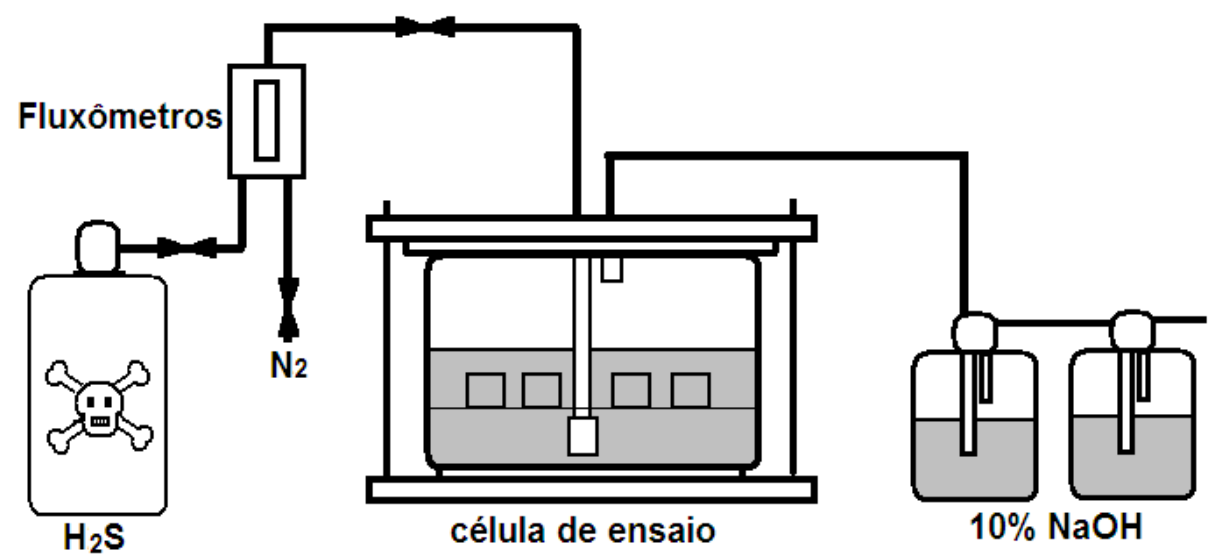

Figura 33 Esquema do arranjo experimental de injeção de $\mathrm{H}_{2} \mathrm{~S}$ construído no interior de uma capela de gases.

A duração do teste foi de 96 horas, conforme recomendação da norma NACE TM0284-2003. O tempo do teste foi computado imediatamente após o período de 60 minutos de injeção de $\mathrm{H}_{2} \mathrm{~S}$. A temperatura da solução foi monitorada, mantendo-se na faixa de $25 \pm 3^{\circ} \mathrm{C}$, que é a exigência da norma NACE TM02842003. A Figura 35 apresenta a célula com os corpos-de-prova durante 0 ensaio.

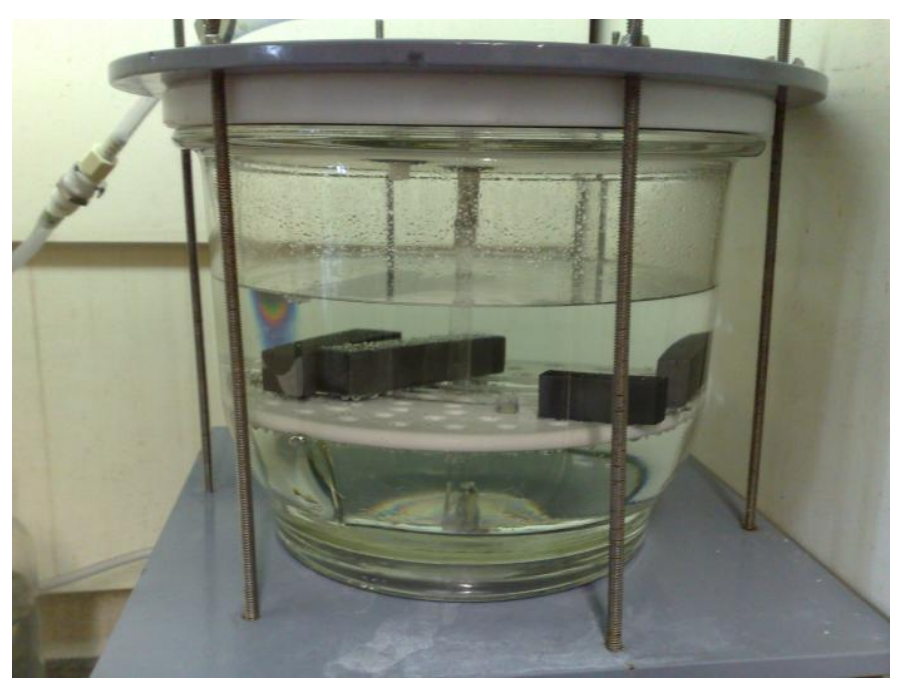

Figura 34 Detalhe da célula durante o período de imersão dos corpos-de-prova nos eletrólitos contendo $\mathrm{H}_{2} \mathrm{~S}$. 
Ao término das 96 horas de imersão, fez-se a injeção de nitrogênio, a fim de se remover parte do $\mathrm{H}_{2} \mathrm{~S}$ presente na célula. Esse procedimento permite uma menor contaminação da capela com este gás, facilitando a remoção dos corpos-de-prova do interior da célula. Ao término da injeção de nitrogênio a célula era aberta e os corpos-de-prova retirados e lavados com água corrente, sabão e secos com álcool e jato de ar quente. Após esta limpeza os corpos-deprova foram armazenados em ambiente mantido a vácuo.

O procedimento seguinte foi a realização dos cortes expondo a seção transversal, conforme indicado na Figura 31. Estes foram realizados numa cortadora de precisão ISOMET com serra diamantada.

Para exame em MO e MEV das faces indicadas na Figura 31, cada pedaço do corpo-de-prova foi embutido em baquelite e submetido às práticas metalográficas de polimento e ataque. Todas as amostras embutidas foram lixadas até lixa de granulometria 1200 e polidas até pasta de diamante $1 \mu \mathrm{m}$. Neste ponto foram examinadas em MO e MEV. Em seguida, fez-se o ataque metalográfico com reagente nital $2 \%$ e novamente examinadas em MO e MEV. Tais procedimentos tiveram o objetivo de examinar a nucleação e propagação das trincas, quando ocorridas. A Figura 35 ilustra as amostras cortadas e embutidas.
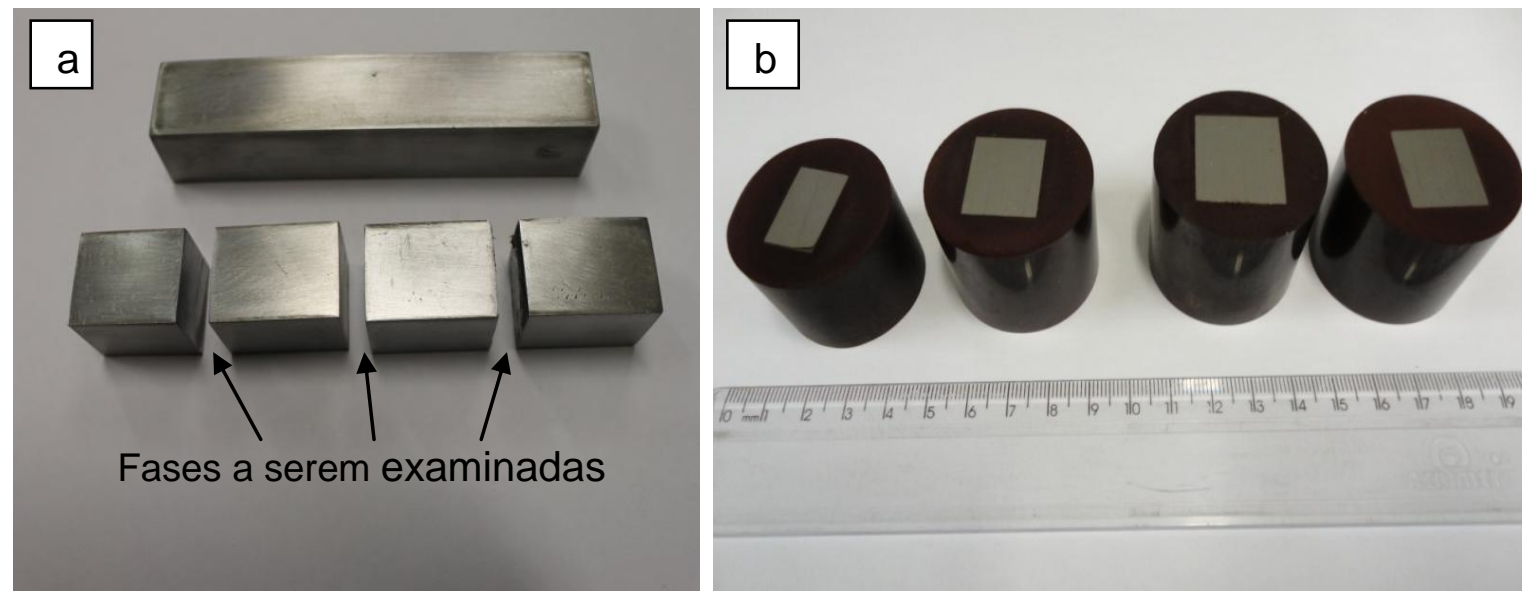

Figura 35 (a) Amostras obtidas do corpo-de-prova ensaiado. (b) Amostras embutidas para exames de HIC. 


\subsubsection{CARACTERIZAÇÃO MICROESTRUTURAL}

Para a identificação da morfologia das inclusões e microestrutura, foram retiradas amostras de cada tipo de aço e embutidas em baquelite. As amostras foram lixadas até lixa de granulometria 1200 e polidas até pasta de diamante $1 \mu \mathrm{m}$. Neste ponto foram examinadas em MO e MEV, também foram realizados exames por espectroscopia de energia dispersiva (EDS) das inclusões encontradas. Com o fim de realizar a caracterização microestrutural as amostras foram atacadas com nital 2\% (2\% ácido nítrico em álcool etílico), e examinadas em MO e MEV. 


\section{RESULTADOS}

\subsection{ANÁLISE DAS INCLUSÕES}

Apresentam-se a seguir os resultados obtidos com os exames em MO, MEV e análises por EDS das inclusões encontradas nos materiais da Tabela 7. O nível de inclusões foi determinado com um aumento de 100X examinando-se:

(i) tanto na chapa quanto nos tubos, a seção examinada é paralela ao eixo da laminação;

(ii) no caso da chapa a seção examinada é simultaneamente perpendicular ao plano de laminação;

(iii) e, no caso dos tubos, a seção examinada corresponde simultaneamente à seção radial.

Tais condições são recomendações da norma ASTM E45.

\subsubsection{TUBO API 5L X65 SOUR}

Na Figura 36 é apresentada uma imagem obtida em MO para o tubo API 5L X65 sour, sem ataque. O tubo API 5L X65 sour apresentou um nível baixo de inclusões distribuído uniformemente em toda a matriz, classificando o aço como nível D1 -ASTM E45. 


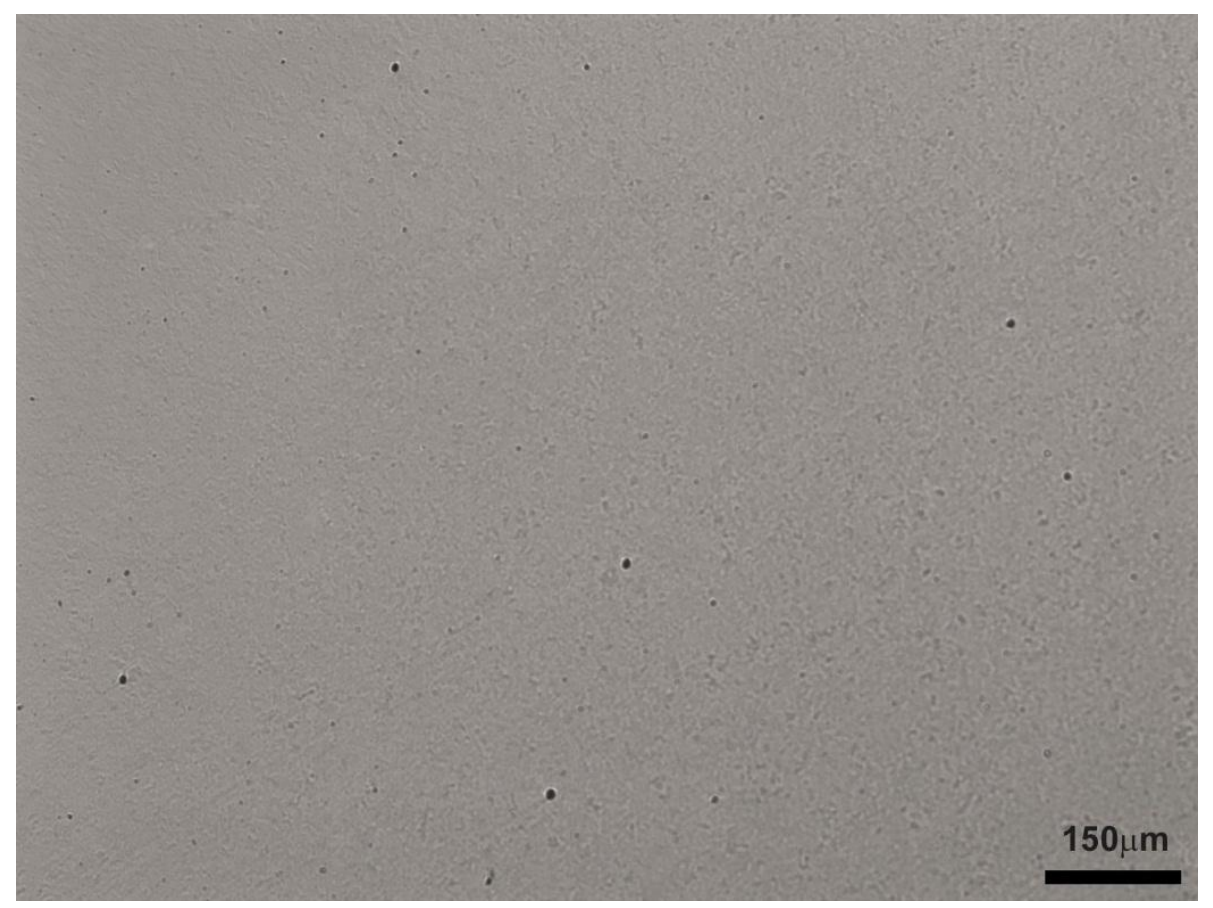

Figura 36 Distribuição das inclusões no tubo API $5 \mathrm{~L}$ X65 sour. Polimento $1 \mu \mathrm{m}$ sem ataque. Classificação das inclusões: nível D1. Aumento: 100X. MO. Seção examinada conforme recomendação na norma ASTM E45.

As inclusões encontradas no aço do T-X65S apresentaram formato arredondado, os exames por EDS mostraram a presença de, $\mathrm{Al}, \mathrm{Mn}, \mathrm{Ca}$ e $\mathrm{S}$ (Figura 37b). A presença de Ca deve estar relacionada com um processo de controle de forma e eliminação de inclusões de sulfeto (MnS), o qual dá origem a inclusões esféricas a partir de inclusões alongadas de MnS. A presença de Al indica uma provável etapa de desoxidação no processo de elaboração do aço. 

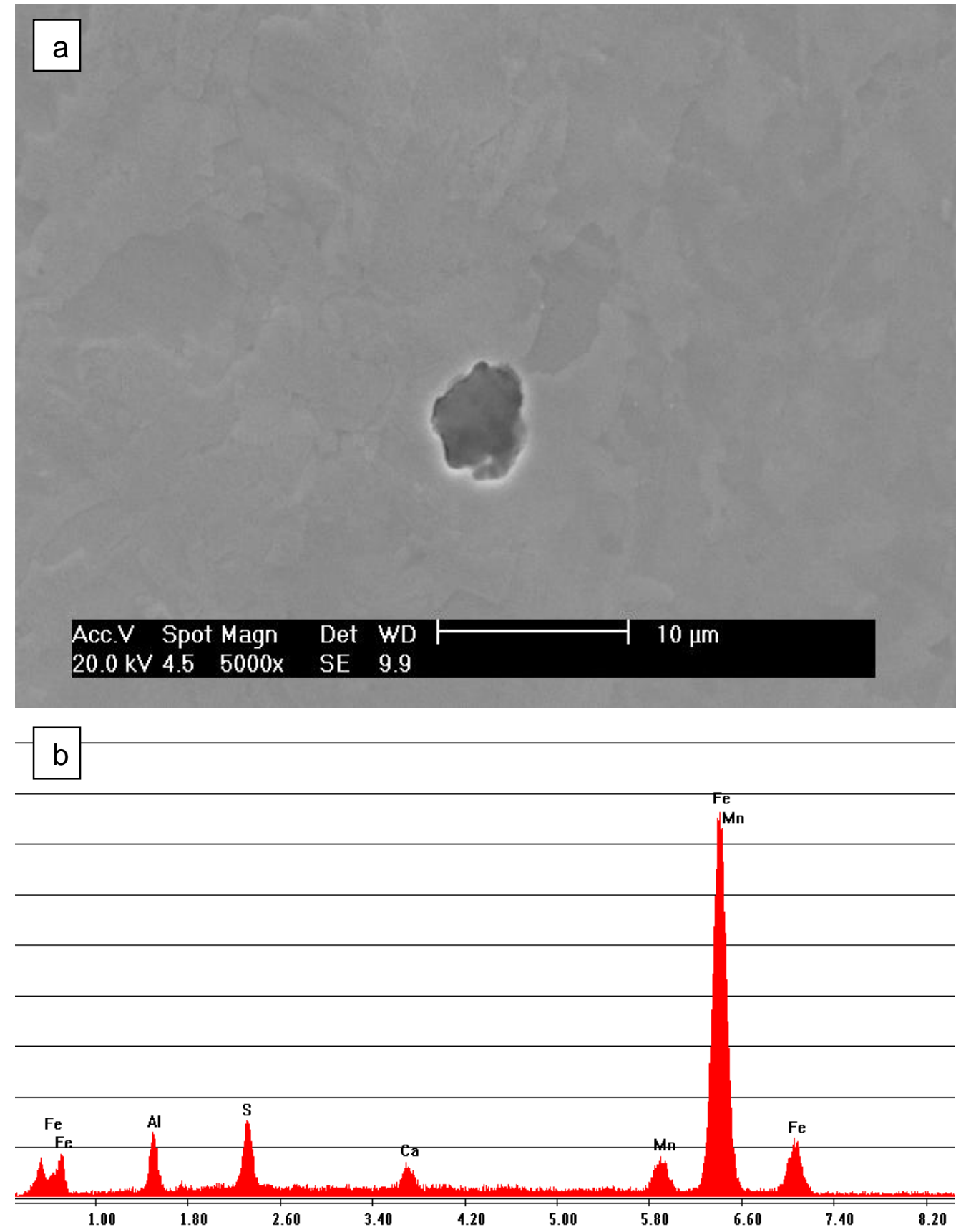

Figura 37 Imagem de elétrons secundários de inclusão encontrada no aço do T-X65S.

(a) Aspecto da inclusão. Aumento 5000X. (b) Análise química por EDS da inclusão: Al, Mn, Ca e S. (Seção examinada: transversal.) 


\subsubsection{REGIÃO SOLDADA DO TUBO API 5L X65 SOUR}

A amostra da região de solda do tubo API 5L X65S (RS-X65S) apresenta distribuição heterogênea de inclusões. Existem regiões onde a concentração é maior do que outras, como mostram as imagens da Figura 38 a e b, classificando o aço como nível D1. De modo geral o aço apresenta uma quantidade maior de inclusões que a amostra de metal base do tubo (T-X65S).
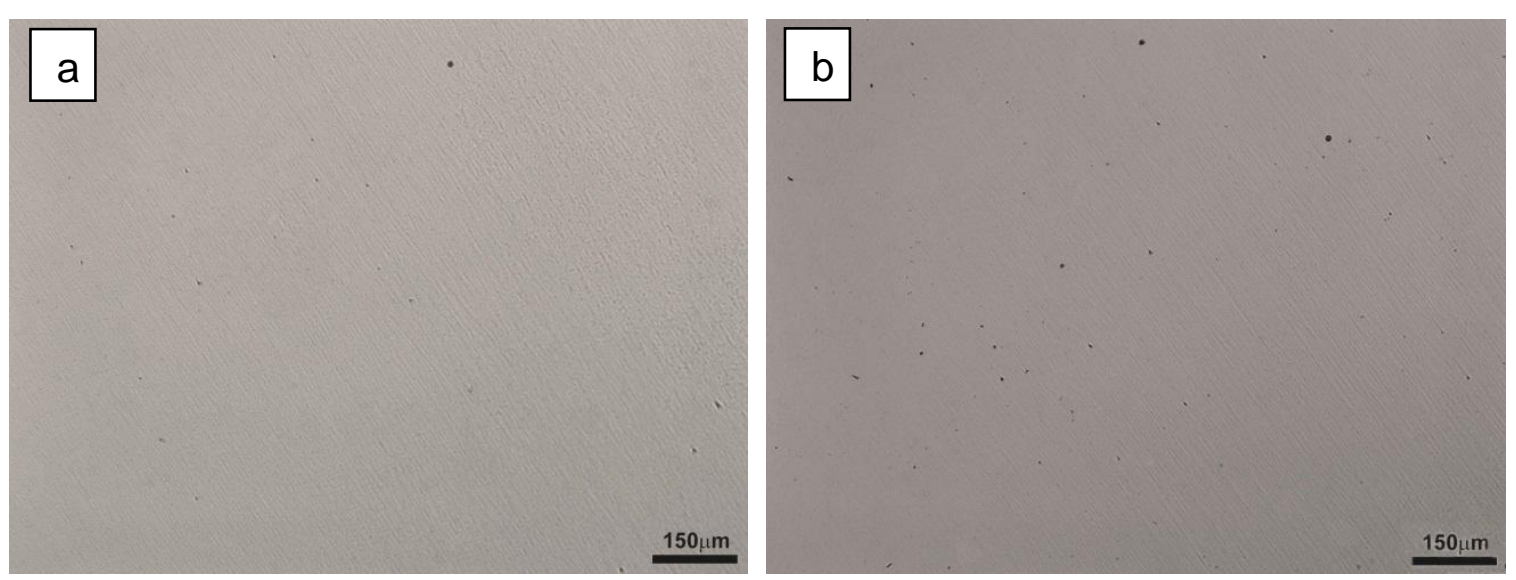

Figura 38 Distribuição das inclusões na região de solda do tubo API 5L X65 sour (RS-X65S). Polimento: $1 \mu \mathrm{m}$ sem ataque. Classificação das inclusões: nível D1. Aumento: 100X. MO. Seção examinada conforme recomendação na norma ASTM E45.

Na Figura 39 é apresentada uma inclusão encontrada na região soldada da amostra RS-X65S. As inclusões dispersas na. Os exames por EDS mostram a presença de $\mathrm{Al}, \mathrm{Si}$, Ti e Mn: provavelmente uma inclusão de óxido mista. 

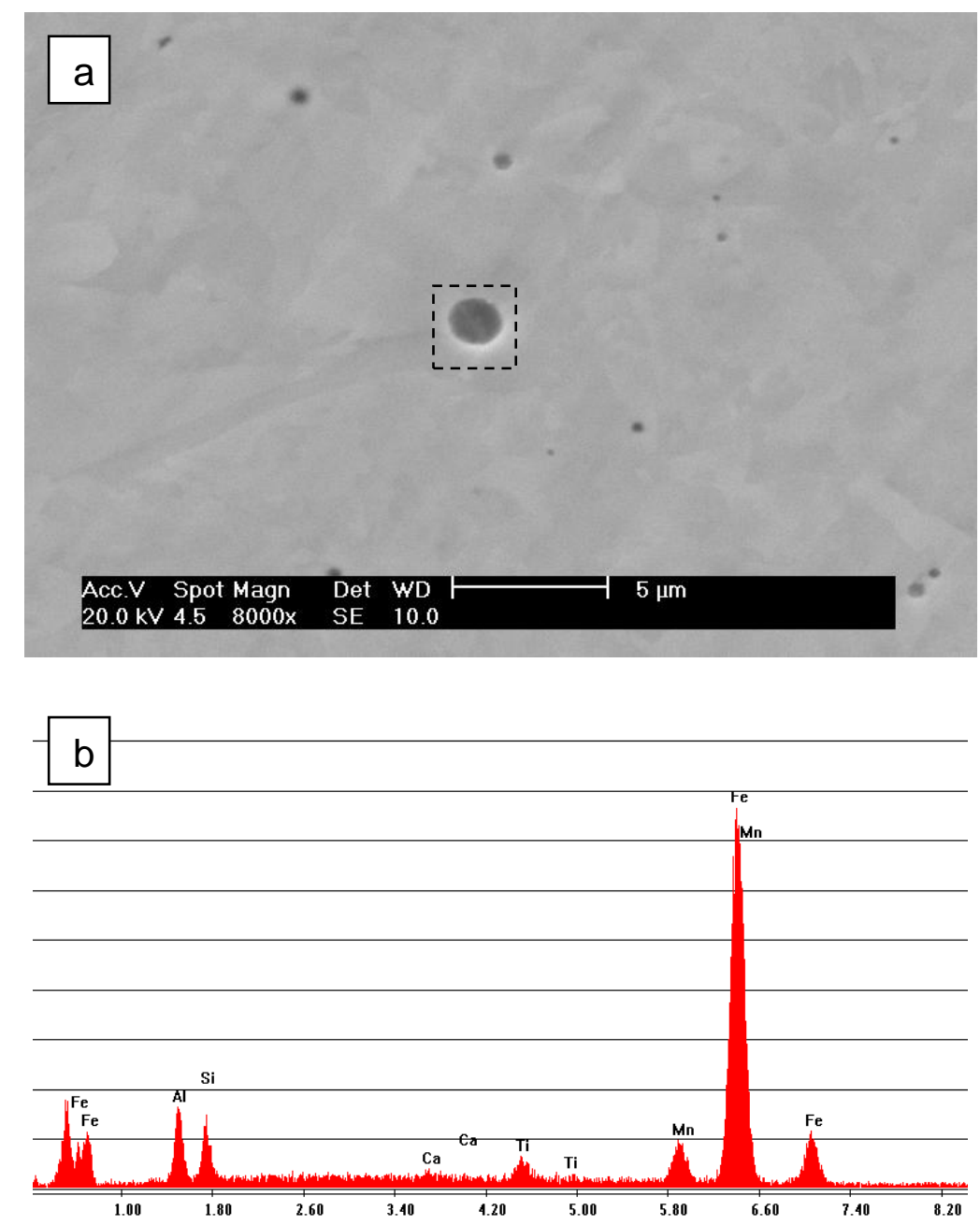

Figura 39 Imagem de elétrons secundários de inclusão encontrada na região de solda do tubo API 5L X65 sour (RS-X65S). (a) Aspecto da inclusão. Aumento 8000X. (b) Análise química (da região indicada pelo tracejado) por EDS da inclusão: Al, Si, Ti e Mn. (Seção examinada: transversal.)

\subsubsection{CHAPA GROSSA DE AÇO PARA TUBO API 5L X65}

A amostra da chapa para tubo API 5L X65 (C-X65), apresenta uma alta concentração de inclusões distribuídas uniformemente em toda a superfície analisada. O nível de inclusões foi classificado como nível D3 - ASTM E45 (Figura 40).

A Figura 41 apresenta uma inclusão encontrada na chapa destinada a construção de tubos API $5 \mathrm{~L}$ X65. Os exames por EDS mostram a presença de $\mathrm{Al}, \mathrm{Ti}, \mathrm{Mn}, \mathrm{Ca}$ e S. 


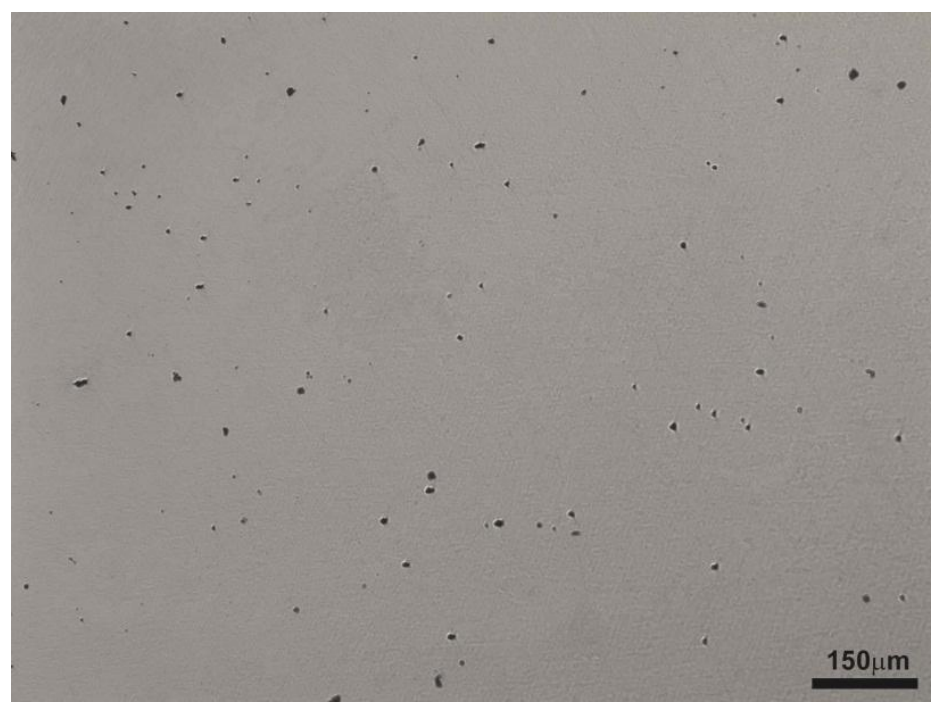

Figura 40 Distribuição das inclusões na chapa para tubo API 5L X65 (C-X65). Polimento: $1 \mu \mathrm{m}$, sem ataque. Classificação das inclusões: nível D3. Aumento: 100X. MO. Seção examinada conforme recomendação na norma ASTM E45.
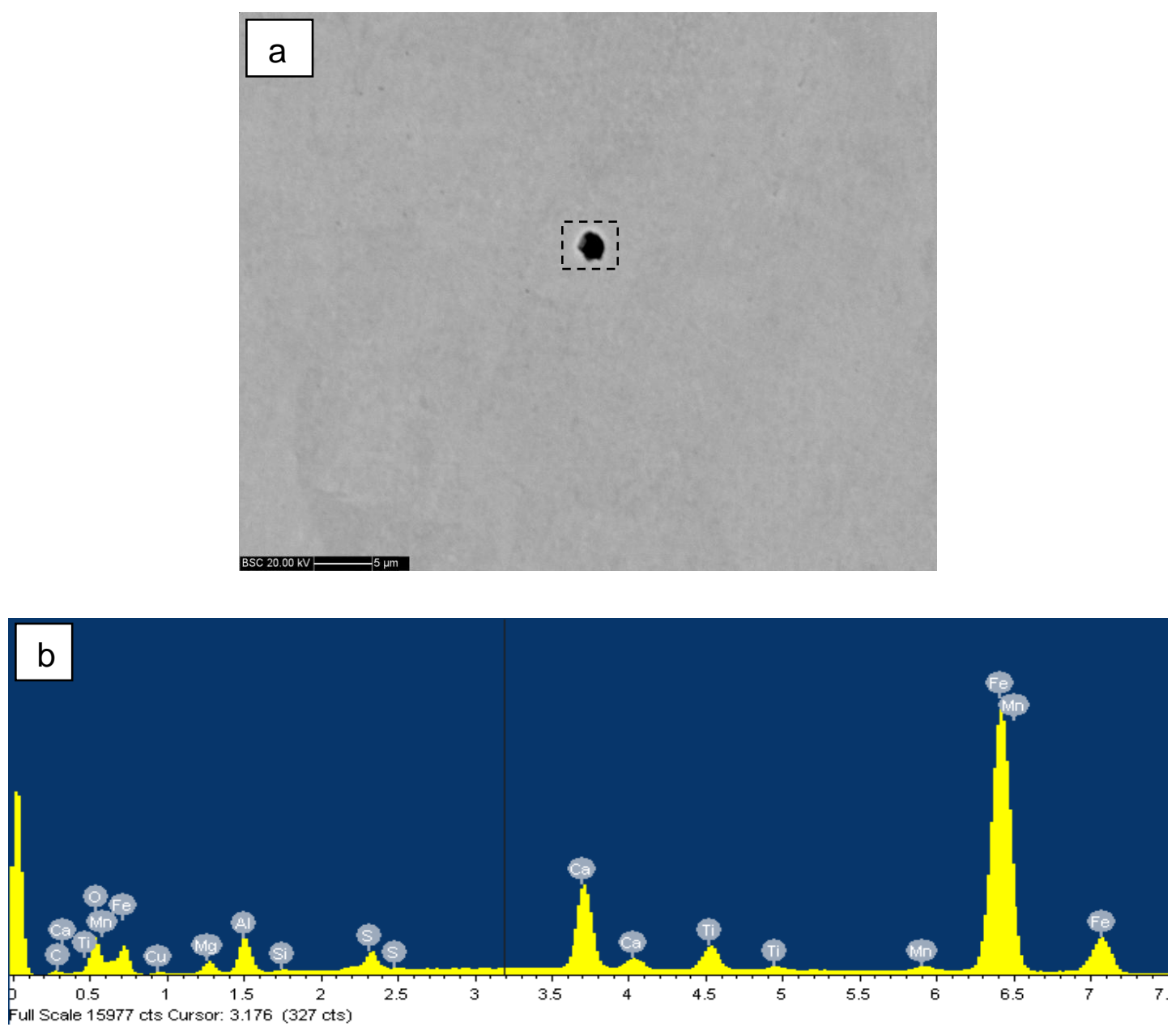

Figura 41 Imagem de elétrons retrospalhados de inclusão encontrada na chapa para construção de tubo API 5L X65 (C-X65). (a) Aspecto da inclusão. Aumento 5000X. (b) Análise química (da região indicada) por EDS da inclusão: Al, Ti, Mn, Ca e S. (Seção examinada: transversal.) 


\subsubsection{TUBO API 5L X65 NÃO-SOUR}

A amostra do tubo API 5L X65 não-sour (T-X65NS), apresenta uma alta concentração de inclusões distribuídas uniformemente em toda a superfície da amostra. O aço foi classificado com nível de inclusões: D4 - ASTM E45 (Figura 42).

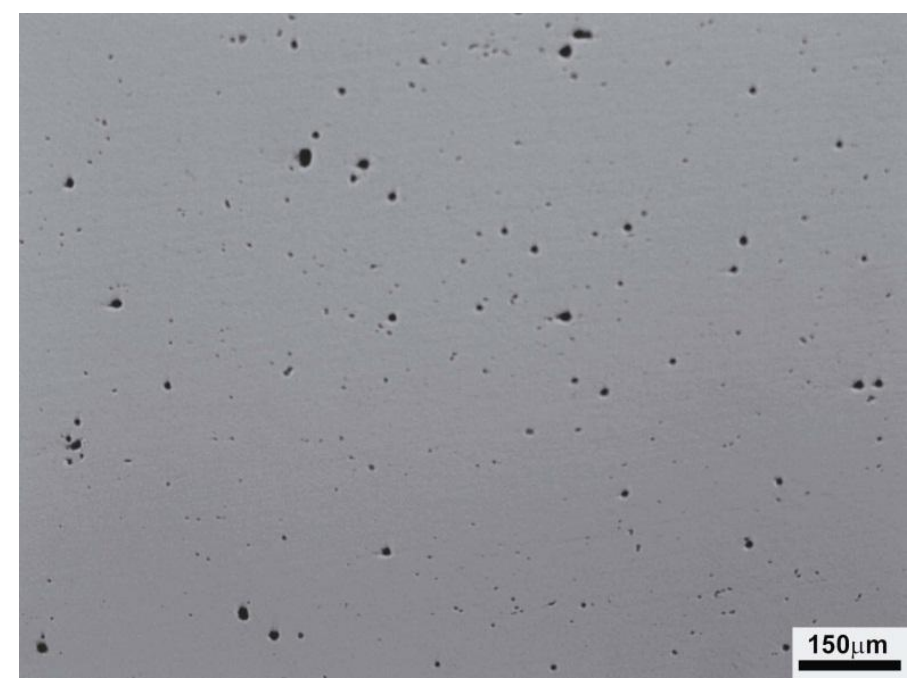

Figura 42 Distribuição das inclusões para o tubo API $5 \mathrm{~L}$ X65 não-sour (T-X65NS). Polimento: $1 \mu \mathrm{m}$, sem ataque. Classificação das inclusões: nível D4. Aumento: 100X. MO. Seção examinada conforme recomendação na norma ASTM E45.

Na Figura 43 é apresentada uma inclusão encontrada no tubo API 5L X65 nãosour (T-X65NS), As inclusões neste material apresentam formato arredondado. $\mathrm{Na}$ análise por EDS foram encontrados traços de Al, Ti, Mn, Mg, Ca e S. 

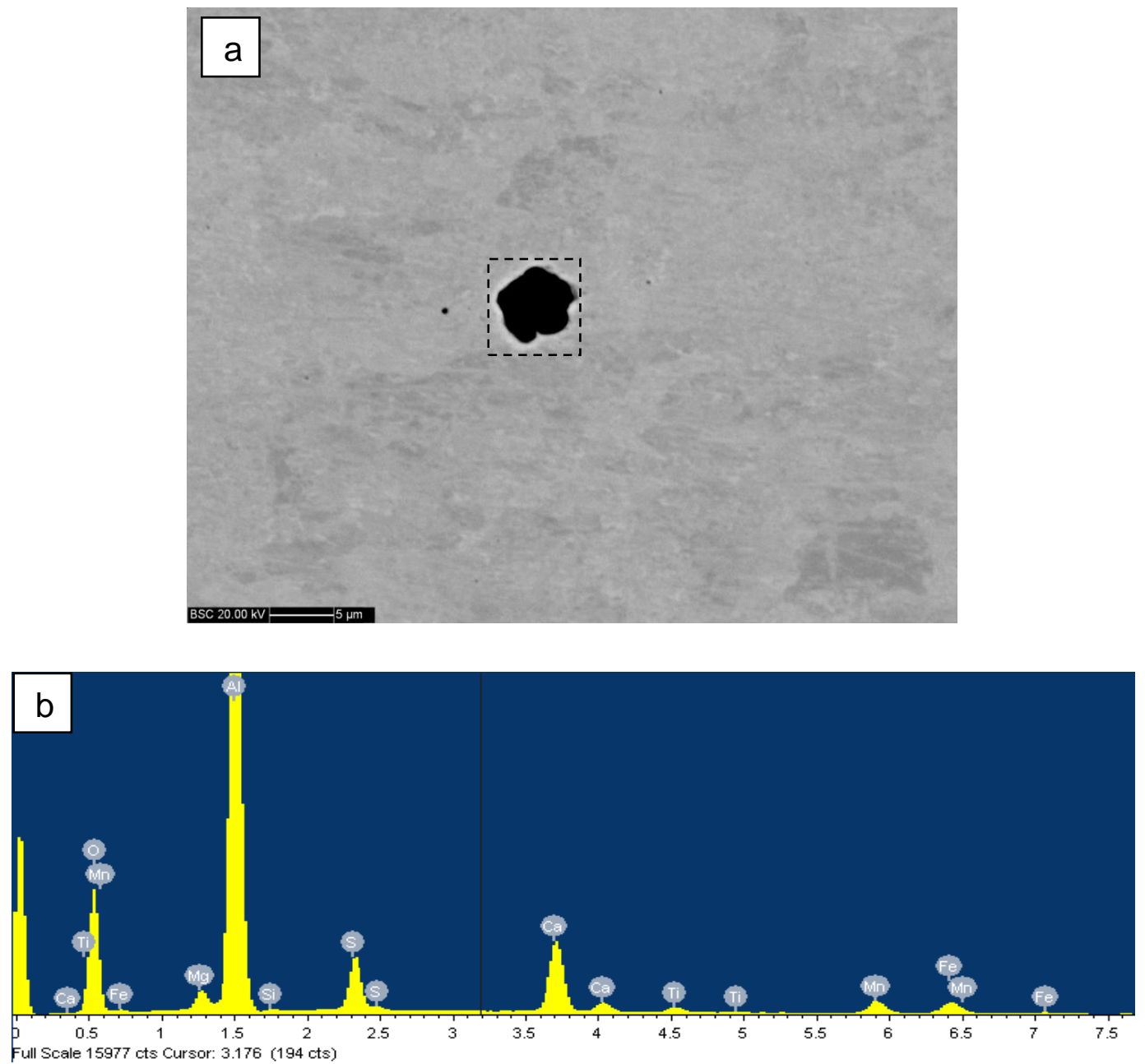

Figura 43 Imagem de elétrons retrospalhados de inclusão encontrada no tubo API $5 \mathrm{~L}$ X65 (T-X65NS). (a) Aspecto da inclusão. Aumento 5000X. (b) Análise química (da região indicada) por EDS da inclusão: Al, Ti, Mn, Mg, Ca e S. (Seção examinada: transversal.)

Após os exames das amostras sem ataque, das análises por EDS e da aplicação da norma ASTM E45, é possível classificar os aços de acordo com o nível de inclusões presentes na matriz. Sendo assim, o nível de inclusões aumenta na seguinte sequência: T-X65S, RS-X65S, C-X65 e T-X65NS. Observa-se que em todos os casos as inclusões apresentam formato arredondado. As análises de composição química das inclusões revelam a possível aplicação de processos de desoxidação por Al e de dessulfuração e arredondamento das inclusões por adição de $\mathrm{Ca}$, na elaboração dos aços utilizados no presente estudo. 


\subsection{EXAMES MICROESTRUTURAIS}

Para os exames microstruturais as amostras foram cortadas expondo a face perpendicular ao sentido da laminação (transversal), as amostras foram lixadas e polidas até pasta de diamante de $1 \mu \mathrm{m}$, e em seguinda atacadas com nital $2 \%$ (2\% ácido nítrico em álcool), com a finalidade de examinar a microestrutura de cada aço.

\subsubsection{TUBO API 5L X65 SOUR}

As Figuras 44 e 45 mostram a microestrutura do tubo API 5L X65 sour em microscópio ótico, nesta pode-se observar que 0 aço apresenta uma microestrutura homogênea, sem a presença de bandeamento.

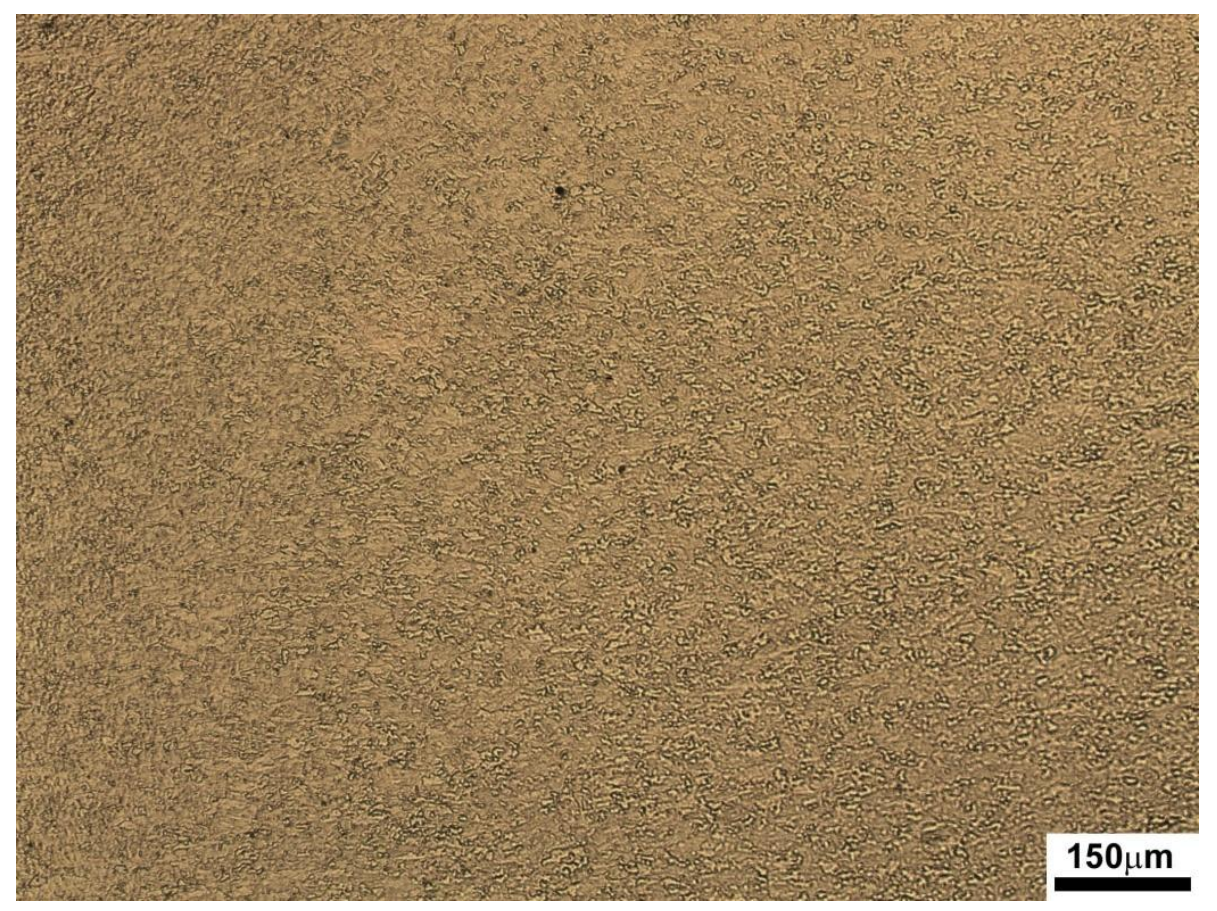

Figura 44 T-X65S: Microestrutura da região central da seção transversal do tubo. Nota-se microestrutura homogênea de grãos refinados. Ataque: nital 2\%. Aumento: 100x. MO. 


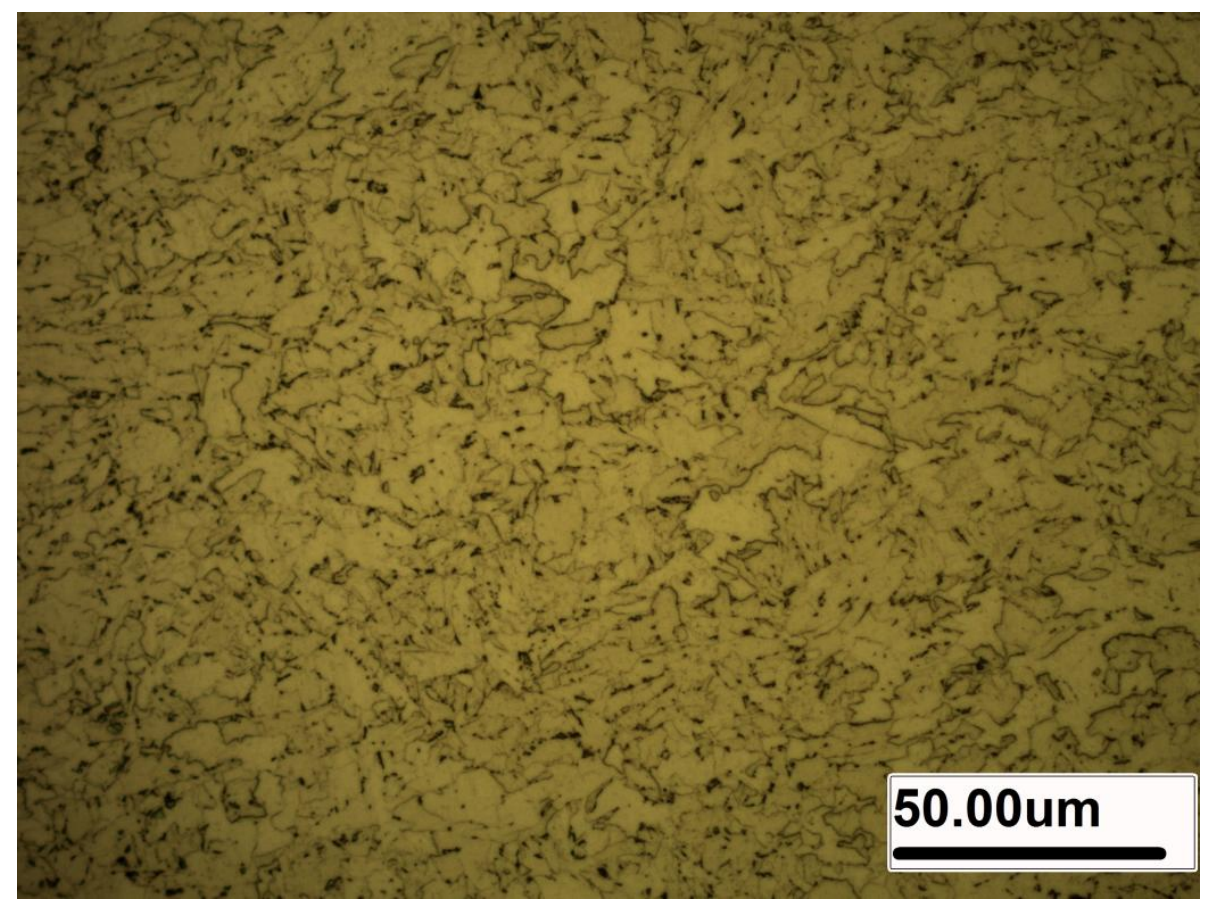

Figura 45 T-X65S: Microestrutura da região central da seção transversal do tubo. Ataque: nital 2\%. Aumento: 500x. MO.

Com o objetivo de se compreender melhor a microestrutura desse aço a amostra foi observada em MEV. Através da Figura 46 nota-se uma microestrutura formada por grãos de ferrita poligonal e presença de ferrita acicular. Além disso, a partir de trabalhos anteriores (HINCAPIE-LADINO et al,. 2011) a fase mais clara, que aparece distribuída uniformemente na microestrutura da Figura 46, é constituída por um agregado de martensita e austenita, conhecido pela sigla M/A. Como já foi mencionado, a microestrutura ao longo da espessura do tubo é homogênea e sem presença de bandas de segregação (Figura 44 e 45). Segundo Zhao et al. (2003), a presença de ferrita acicular leva a melhor resistência a HIC e SCC. 


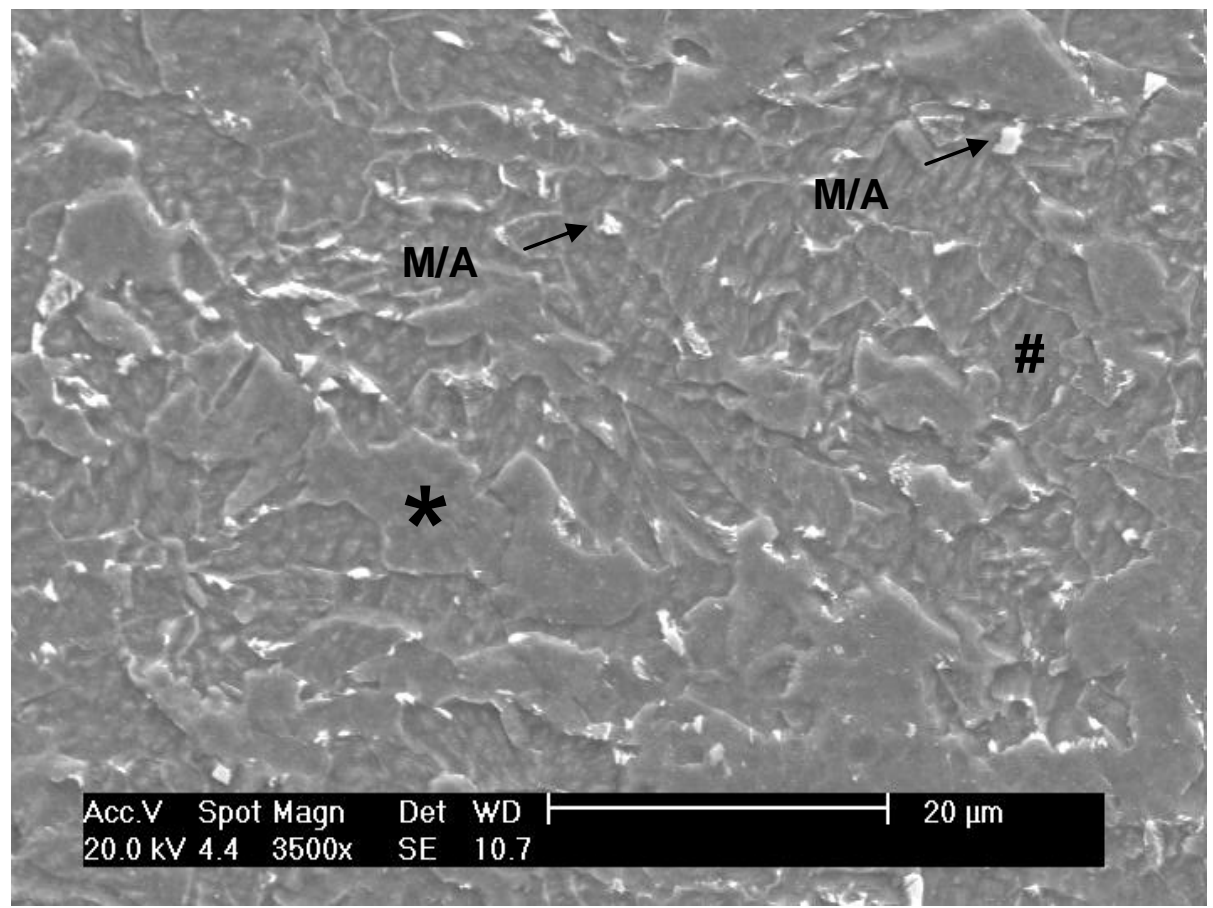

Figura 46 T-X65S: Imagem de elétrons secundários, mostrando a microestrutura. Nota-se a matriz de ferrita poligonal $\left({ }^{*}\right)$ e ferrita acicular (\#), além do microconstituinte $\mathrm{M} / \mathrm{A}$. Ataque: nital 2\%. Aumento: 3500X. MEV.

\subsubsection{REGIÃO SOLDADA DO TUBO API 5L X65 SOUR}

Na Figura 47 é apresentada a região de solda do tubo API 5L X65 sour (RS-X65S), após ataque com reagente nital $2 \%$, onde se observa a região bruta de fusão com grãos colunares e grosseiros. Na Figura 47b estão indicadas as regiões características, as quais estão apresentadas, com um aumento de 500x, nas Figuras 47c a 47f. Na Figura 47c nota-se a região bruta de fusão com estrutura ferrítica. A zona afetada pelo calor apresenta duas regiões com microestruturas diferentes: no limite com a região bruta de fusão aparecem grãos de ferrita grosseiros com evidências de precipitação nos contornos de grão de perlita fina (Figura 47d); afastando-se da zona fundida, os grãos de ferrita são mais finos, com uma distribuição uniforme de perlita fina, como no caso anterior (Figura 47e). Na Figura 47f apresenta-se a estrutura do metal base com grãos finos de ferrita; esta estrutura é a mesma descrita nas Figuras 44, 45 e 46, a qual consta de ferrita poligonal, acicular e microconstituinte M/A. A perlita fina mencionada nas outras regiões tem 0 
mesmo aspecto do microconstituinte $M / A$, quando se emprega o $M O$. No entanto, é necessário lembrar que a formação de M/A depende de deformação e resfriamento controlados durante a laminação da chapa; as regiões de solda se caracterizam por resfriamentos relativamente mais lentos.
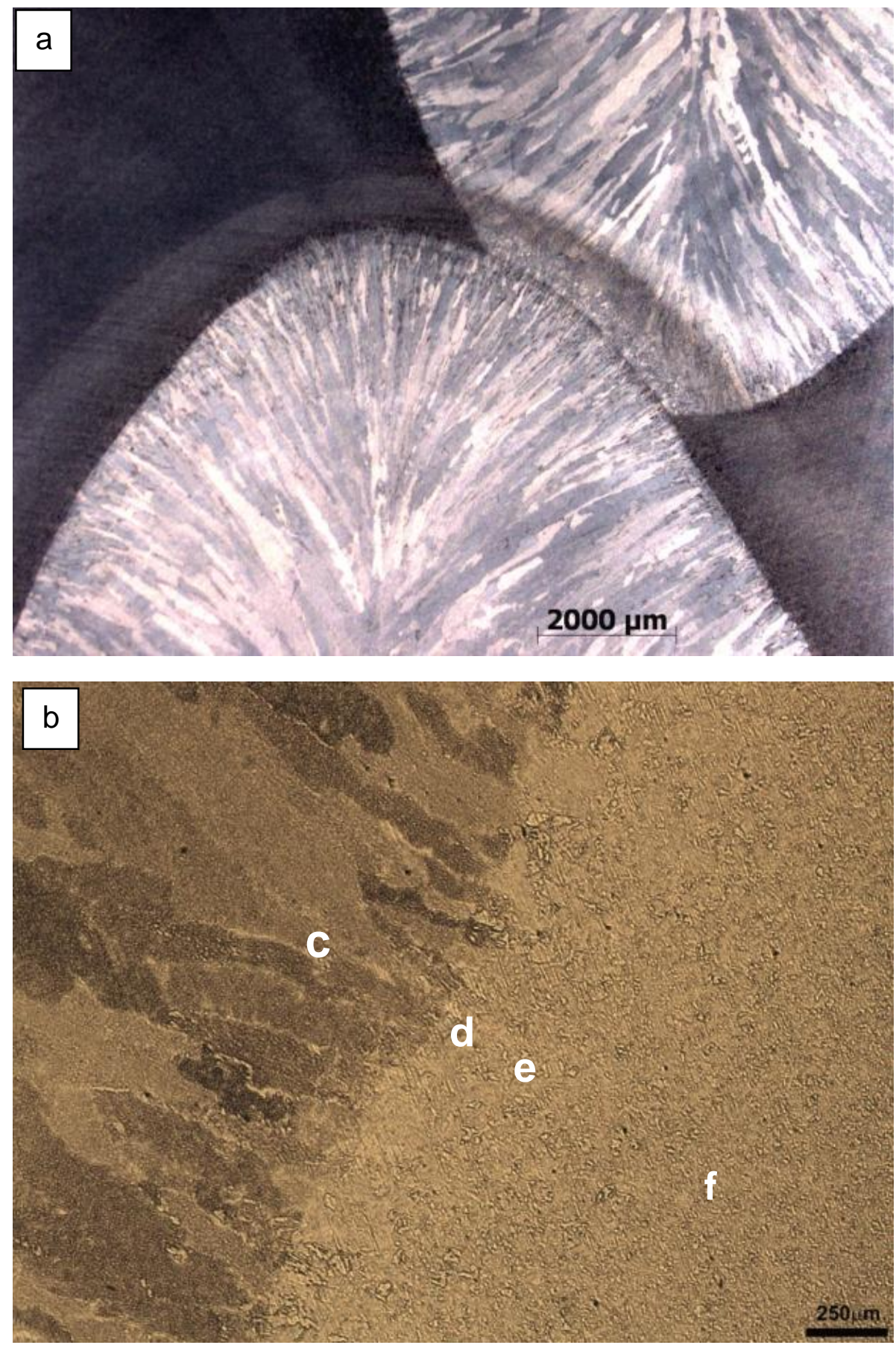

Figura 47 RS-X65S: Região soldada do tubo API 5L X65 sour (a) Região bruta de fusão; (b) principais microestruturas presentes na região soldada. Polimento: $1 \mu \mathrm{m}$. Ataque: nital $2 \%$. MO. 

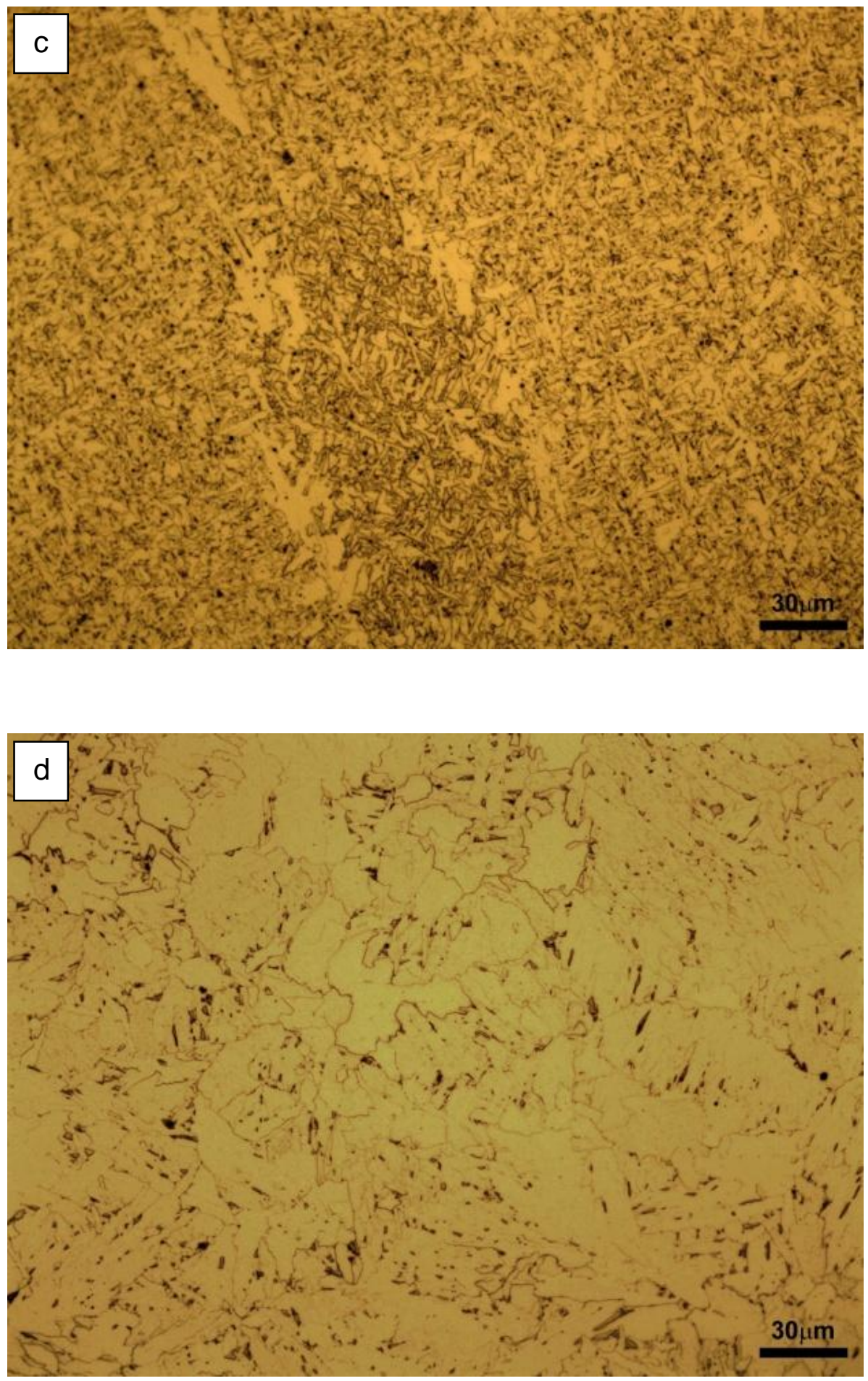

Figura 47 - continuação: RS-X65S: Região soldada do tubo API 5L X65 sour

(c) microestrutura da região fundida; (d) zona afetada pelo calor mais próxima da solda.

Polimento: $1 \mu \mathrm{m}$. Ataque: nital $2 \%$. MO. 

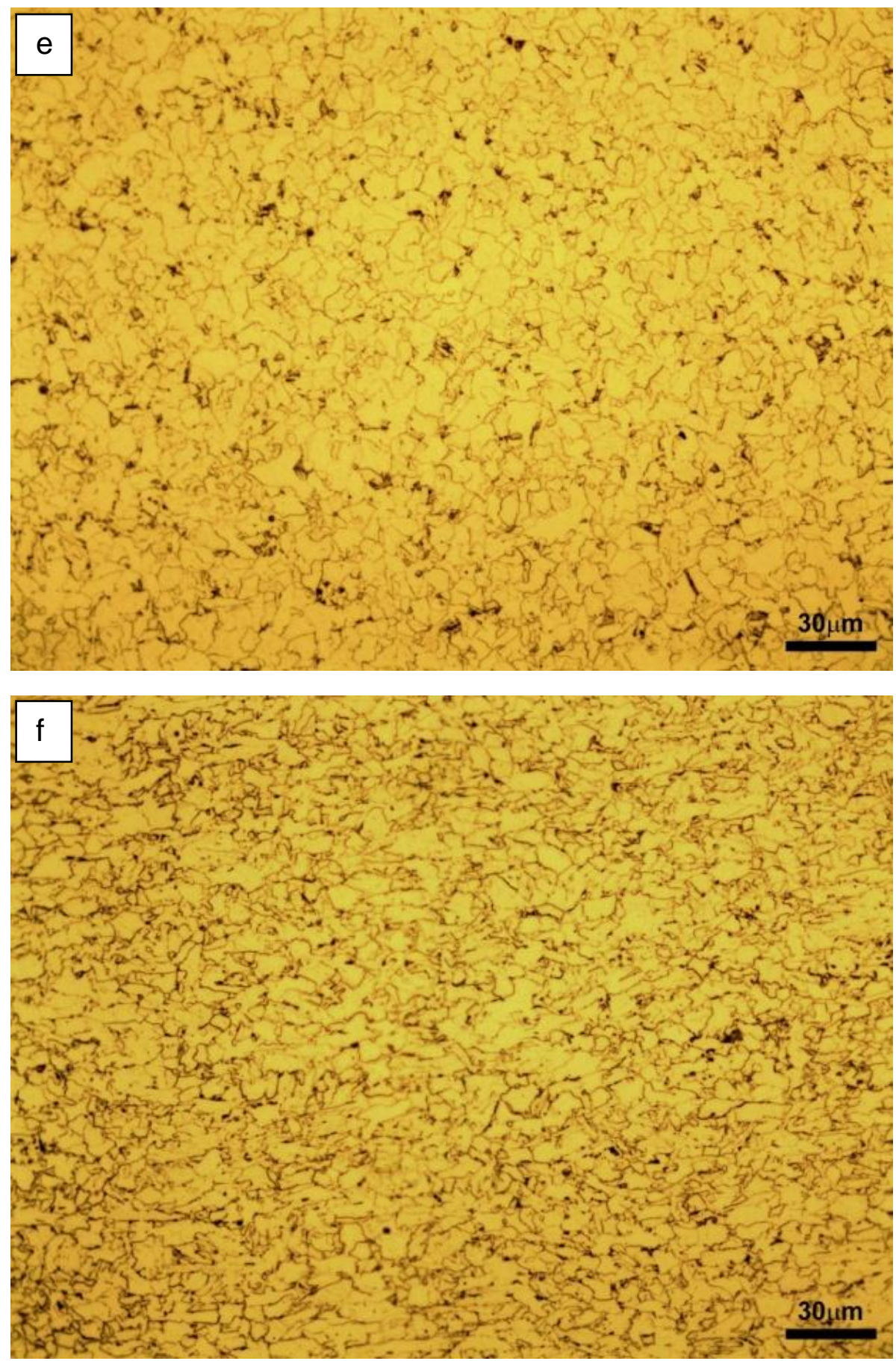

Figura 47 - continuação: RS-X65S: Região soldada do tubo API 5 L X65 sour. (e) zona afetada pelo calor mais distante da solda; (f) metal base. Polimento: $1 \mu \mathrm{m}$. Ataque: nital $2 \%$. MO.

\subsubsection{CHAPA GROSSA DE AÇO PARA TUBO API 5L X65}

$\mathrm{Na}$ Figura 50 pode-se observar o bandeamento na região central da seção transversal da chapa, orientado no sentido da laminação. Através de exames 
em MEV (Figura 49) encontrou-se ferrita, perlita (Figura 49 a) e cementita intergranular (Figura 49 b).

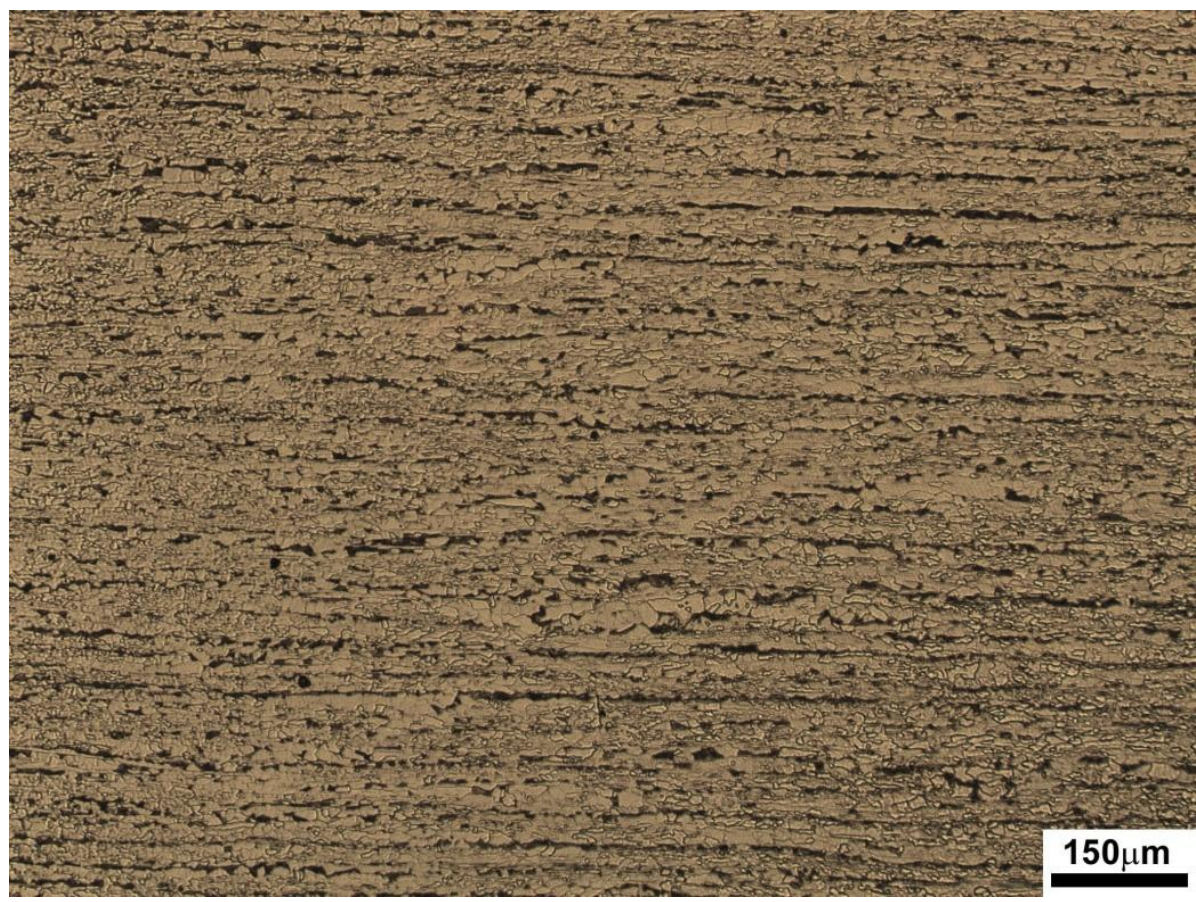

Figura 48 C-X65: Microestrutura da região central da seção transversal da chapa para tubo API $5 \mathrm{~L}$ X65 sour. Nota-se estrutura bandeada de ferrita e perlita. Ataque: nital $2 \%$. Aumento:100x. MO.

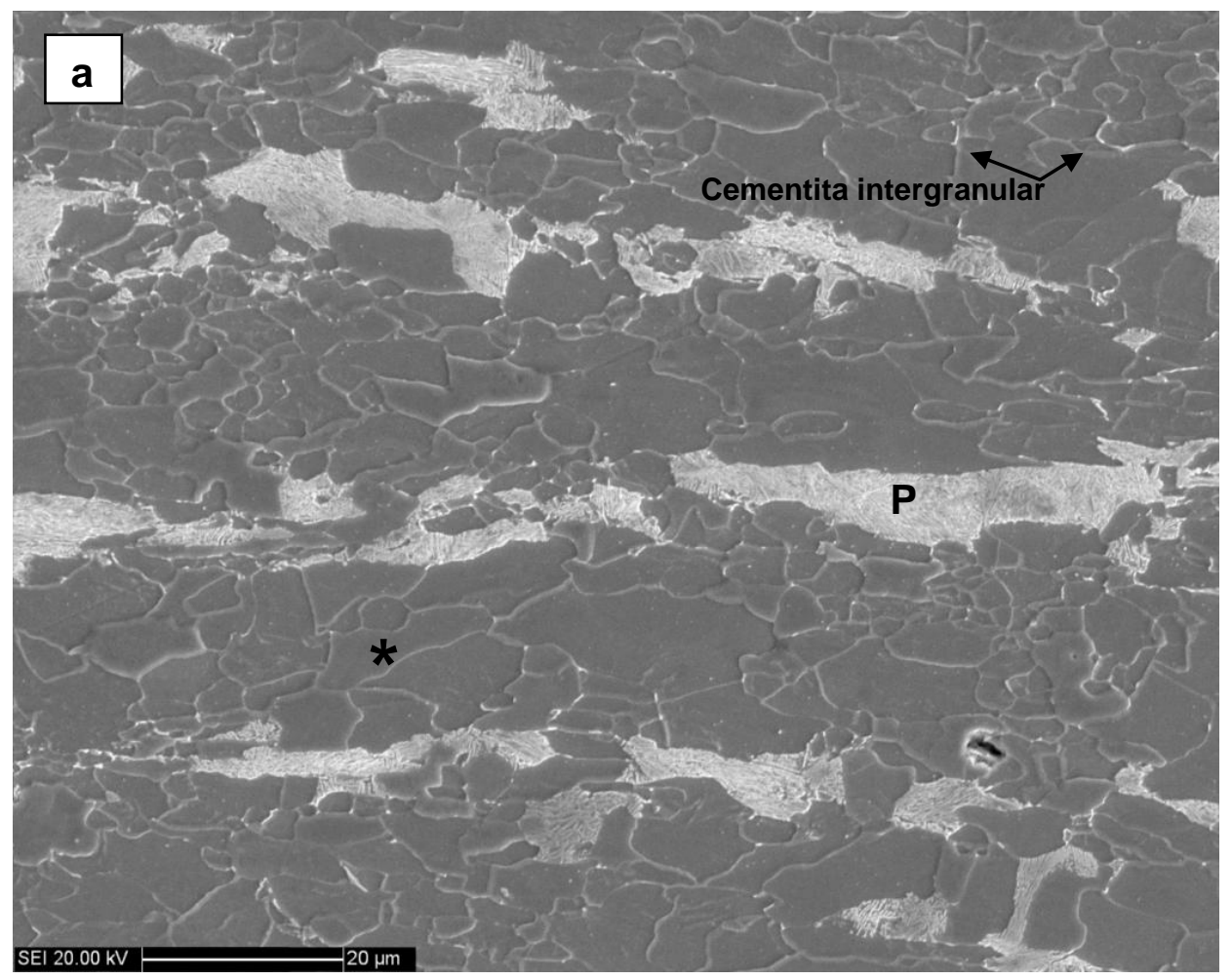

Figura 49 C-X65,: (a) Imagem de elétrons secundários: Detalhe da microestrutura da Figura 48. Com presença predominante de ferrita $\left({ }^{*}\right)$ e perlita $(P)$; nas regiões de contorno de grão. 


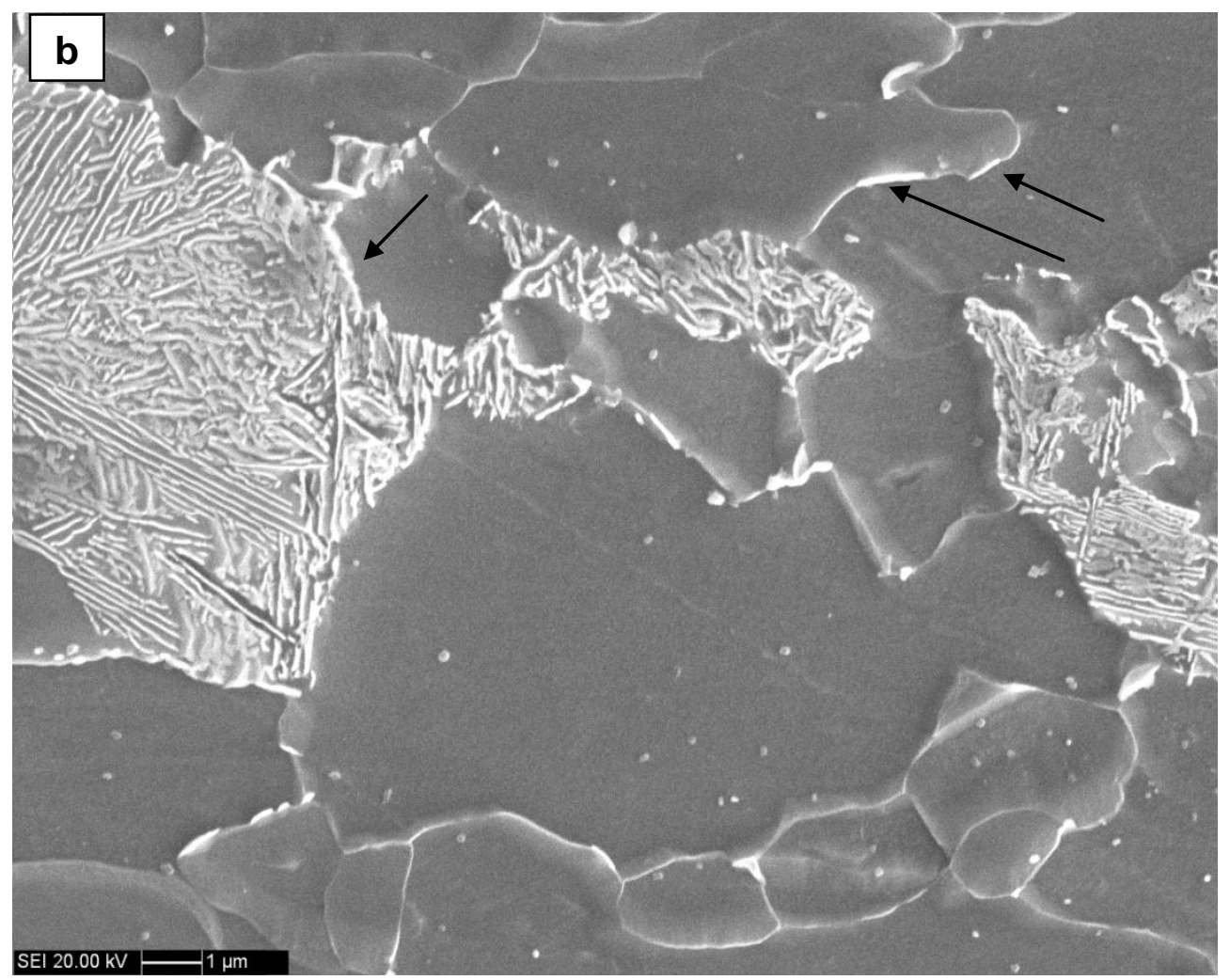

Figura 49 - continuação: C-X65 (b) Cementita intergranular, indicada pelas setas. Ataque: nital $2 \%$. MEV.

\subsubsection{TUBO API 5L X65 NÃO-SOUR}

Na Figura 50 é apresenta a microestrutura da amostra, com um aumento de 100x em MO. Pode-se observar que o aço apresenta um bandeamento orientado no sentido da laminação.

A microestrutura do tubo API 5L X65 não-sour é formada por ferrita com bandas de segregação (bandeamento), onde são encontrados grãos de ferrita, perlita e cementita intergranular (Figura 51). Comparando-se as Figuras 49 e 51, nota-se que o tubo X65NS apresenta maior fração de cementita intergranular do que a chapa C-X65. Para corroborar essa observação, realizou-se a uma análise quantitativa, com o seguinte procedimento: basicamente desenhou-se uma rede quadricular sobre a imagem de elétrons secundários das figuras anteriores. Numa imagem de 1280 pixels por 1024 pixels foram inseridas 67 linhas horizontais e 52 linhas verticais. $O$ procedimento foi o de contar as intersecções entre os cruzamentos das linhas e 
a cementita, isto é, quando um ponto de cruzamento entre uma linha horizontal e vertical pertencia a uma cementita, contou-se: 1; quando a fase cementita era longa o suficiente para cortar duas dessas intersecções, contou-se: 2; quando a fase cementita era cortada por apenas uma linha horizontal ou vertical, contou-se: 0. A porcentagem é igual ao número total de cruzamentos, dividido pelo número total de pontos da rede, multiplicado por 100.

Com tal procedimento obteve-se como resultado a fração de cementita intergranular de 3,3\% para a chapa C-X65 e de 5,7\% para o tubo X65-NS. Apesar de se dispor de apenas uma imagem para cada material, o resultado corrobora a observação qualitativa.

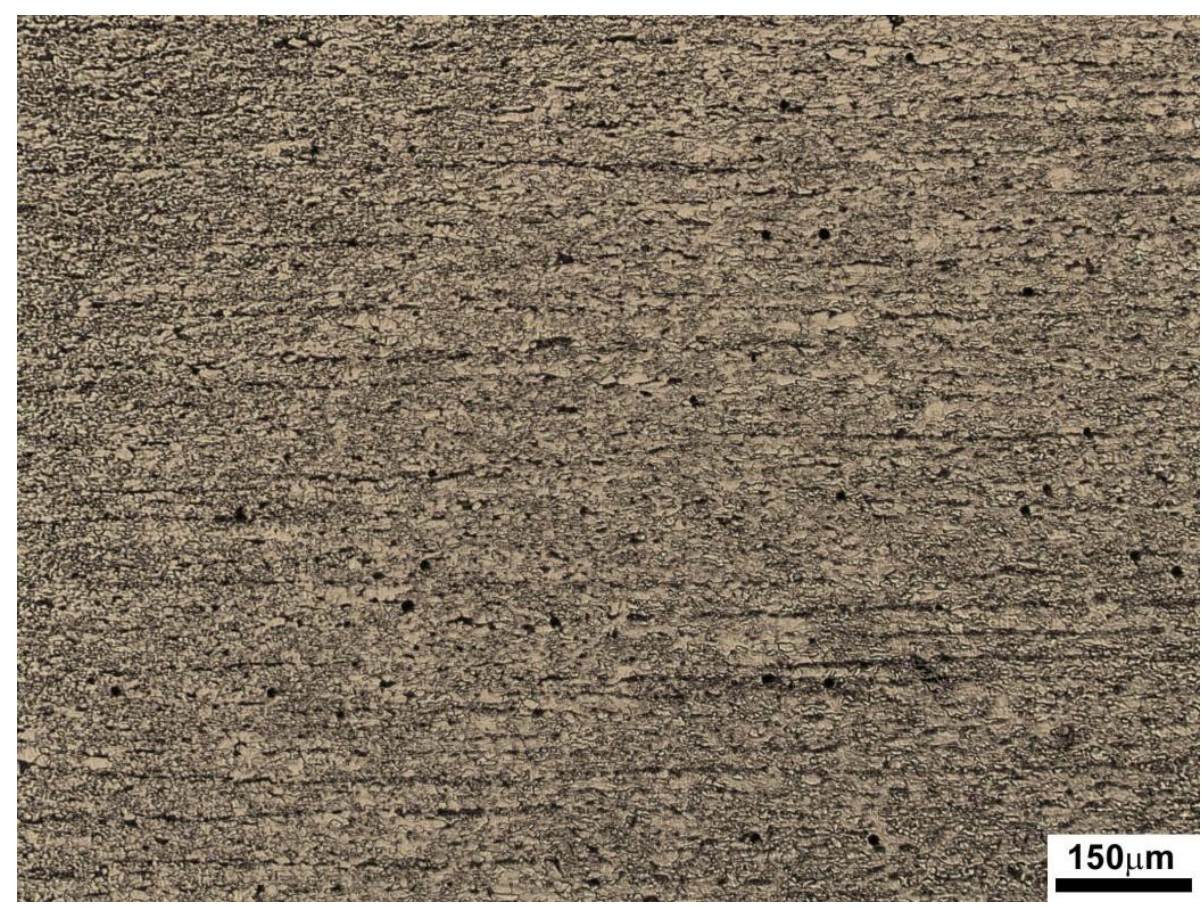

Figura 50 T-X65NS: Microestrutura da região central da seção transversal do tubo API 5L X65 não-sour. Nota-se bandeamento. Ataque: nital 2\%. Aumento:100x. MO. 

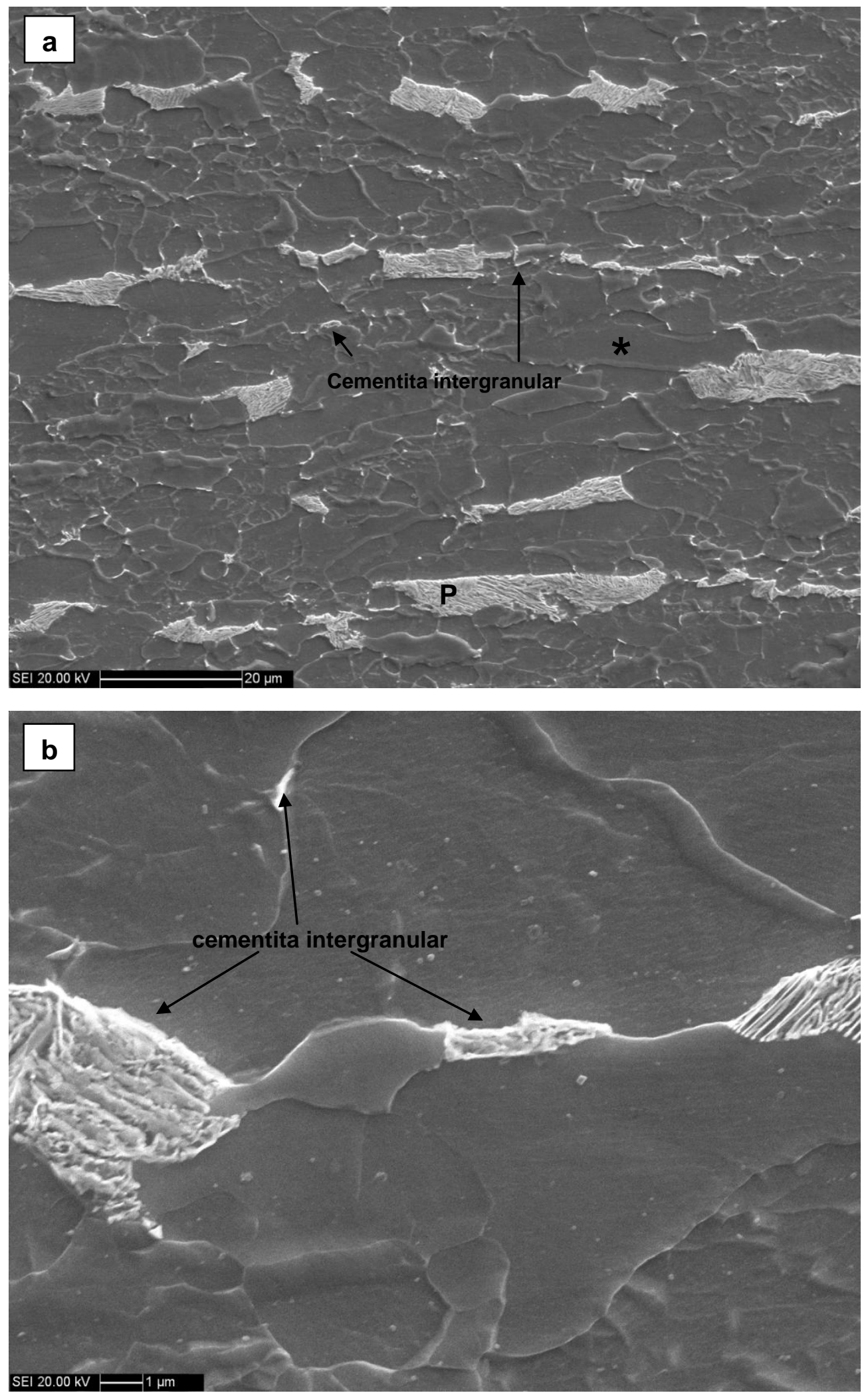

Figura 51 - continuação T-X65NS, Imagem de elétrons secundários: (b) Cementita intergranular. Ataque: nital 2\%. Aumento: 2500X. MEV 


\subsection{POLARIZAÇÃO LINEAR}

Para os aços estudados foram determinados os valores de $\mathrm{Rp}$, com a finalidade de comparar as taxas de corrosão, em meios contendo $\mathrm{H}_{2} \mathrm{~S}$, e verificar se há correlação entre a resistência à corrosão e a fragilização por hidrogênio. Os resultados obtidos estão descritos a seguir.

\subsubsection{RESISTÊNCIA DE POLARIZAÇÃO - SOLUÇÃO A $\left(5 \% \mathrm{NaCl}+0,5 \% \mathrm{CH}_{3} \mathrm{COOH}+\mathrm{H}_{2} \mathrm{~S}\right)$}

Na Figura 52 é apresentado o valor da Rp para a chapa X65. A inclinação da linha de tendência, que passa pelo ponto de $i=0$, determina o valor de $R p$, neste caso 142,4 $\Omega . \mathrm{cm}^{2}$, ademais o $E_{\text {corr }}$ de $-667 \mathrm{mV}, \mathrm{ECS}$. Da mesma maneira foram calculados os demais valores para os aços do presente estudo, obtendose valores de $E_{c o r r}$ numa faixa entre -660 e $-680 \mathrm{mV}$,ECS.

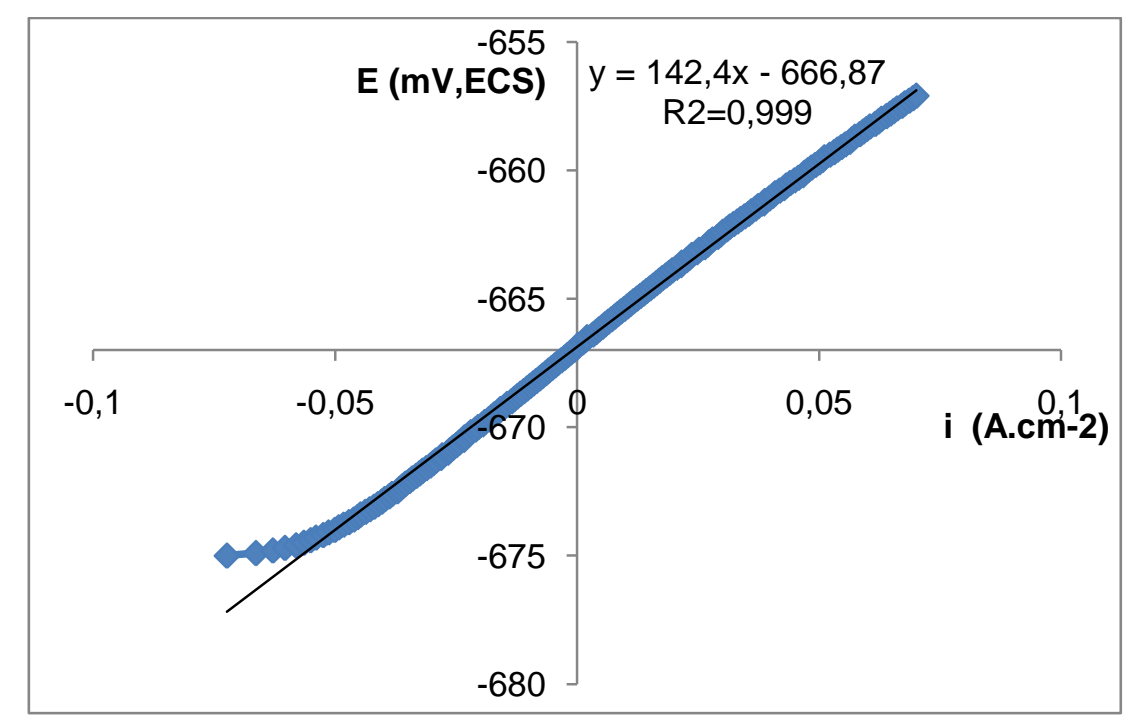

Figura 52 Exemplo de curva de polarização linear para a amostra C-X65 imersa na solução $A$. O valor da Rp é obtido por regressão linear, desprezando-se os pontos não alinhados. No presente caso, tem-se Rp com valor de $142,4 \Omega . \mathrm{cm}^{2}$. Em todos os casos foram obtidos ótimos ajustes ( $R^{2}$ sempre maiores do que 0,998$)$.

Na Figura 53 apresentam-se os valores de Rp em função do tempo, para os materiais na solução $A$. Todos os aços apresentam valores de Rp praticamente 
constantes em função do tempo. Nota-se, no entanto, que nos primeiros 10 minutos de imersão, há uma tendência de valores de Rp levemente mais baixos, mas, a partir daí, a Rp assume um valor constante. Foram realizados três ensaios para cada material.

Nota-se, na Figura 53, que quanto maiores os valores de Rp maior é a dispersão obtida, assim para o aço do tubo T-X65NS as 03 repetições apresentaram valores de Rp muito próximos, já o aço do tubo T-X65S apresentou os maiores valores de Rp, e sua dispersão foi maior. Apesar de terem sido realizadas apenas 03 repetições, foi feita a média e desvio padrão da $\mathrm{Rp}$ em cada tempo, para cada material. O resultado está apresentado na Figura 54, onde novamente, observam-se os mesmos resultados da Figura 53, ou seja: o aço T-X65NS foi o que apresentou a menor resistência à corrosão com menor dispersão -, seguido da chapa C-X65, da região de solda RS-X65S, e a maior resistência à corrosão foi obtida pelo tubo T-X65S, que apresentou as maiores dispersões de Rp.

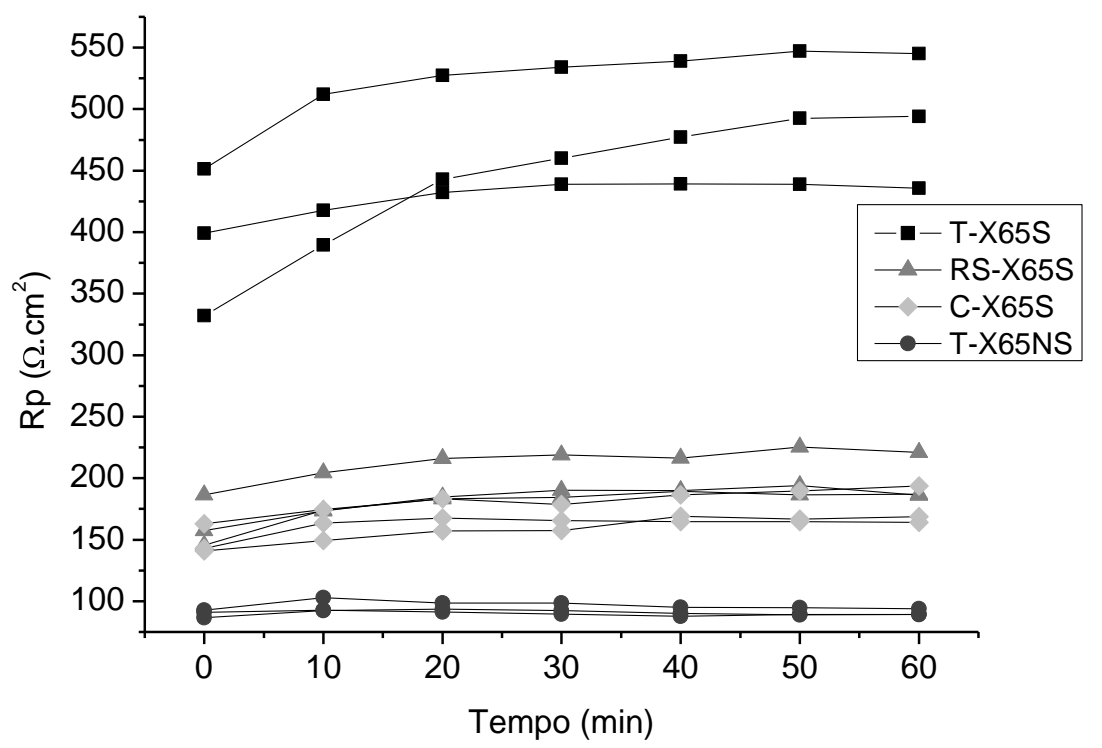

Figura 53 Resistência de Polarização (Rp) em função do tempo de imersão na solução A. Foram realizados 03 (três) ensaios para cada material. Os 03 resultados obtidos estão aqui apresentados. Destacam-se o tubo T-X65S por apresentar maiores valores de Rp e o tubo T-X65NS pelos menores valores. 


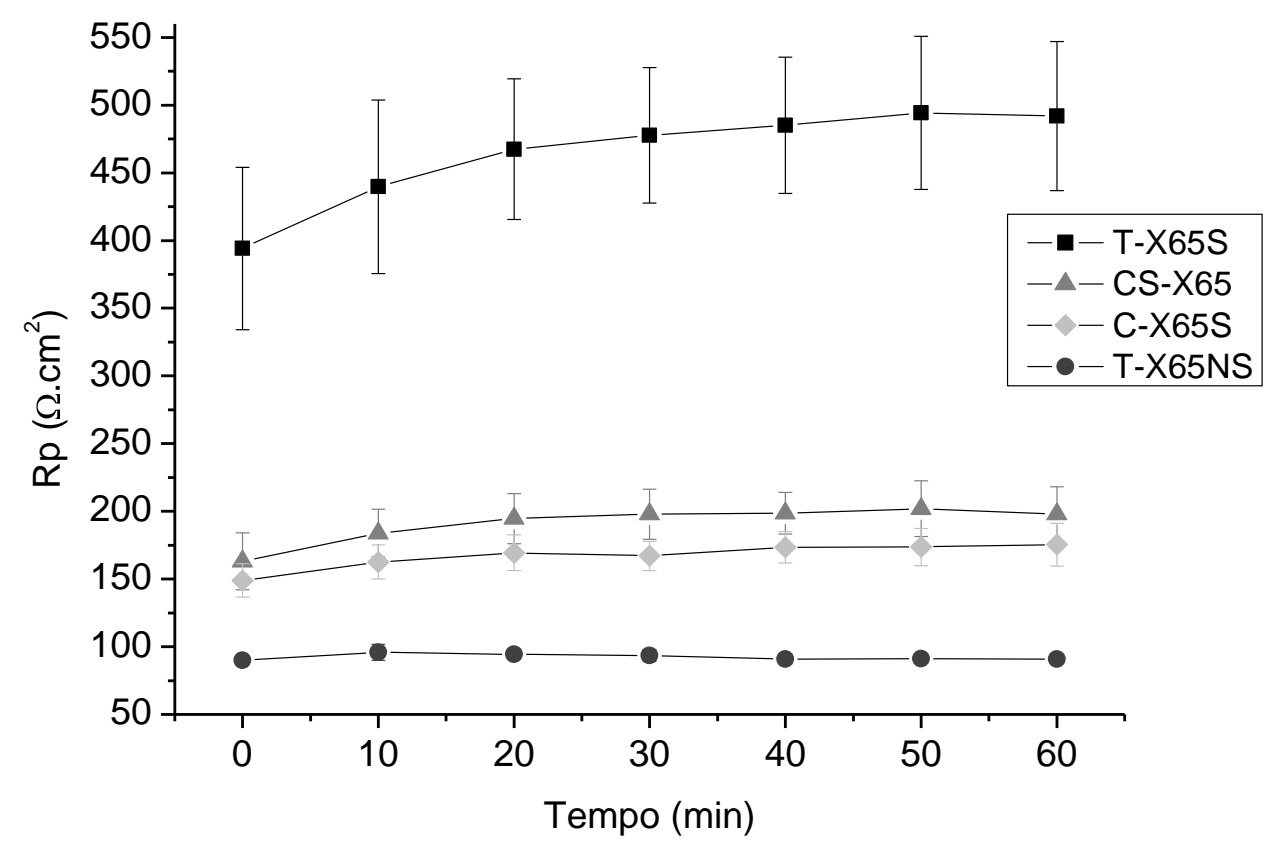

Figura 54 Valores médios e desvio padrão da Resistência de Polarização (Rp) em função do tempo de imersão. Solução A.

\subsubsection{RESISTÊNCIA DE POLARIZAÇÃO - SOLUÇÃO B (ÁGUA DO MAR SINTÉTICA)}

Na Figura 55 é apresentada uma curva experimental para a chapa API 5L X65. testada na solução $B$, para o cálculo da Rp foram desprezados os dados que não seguiam a tendência linear, a ausência destes dados não interfere no cálculo, porque a Rp é definida como a tangente à curva no potencial de corrosão, como foi apresentado na Figura 26. Os valores obtidos foram: Rp de

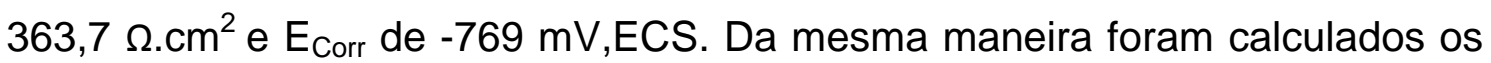
demais valores para os aços do presente estudo, obtendo-se valores de $\mathrm{E}_{\text {corr }}$ numa faixa entre -750 e $-780 \mathrm{mV}$, ECS. 


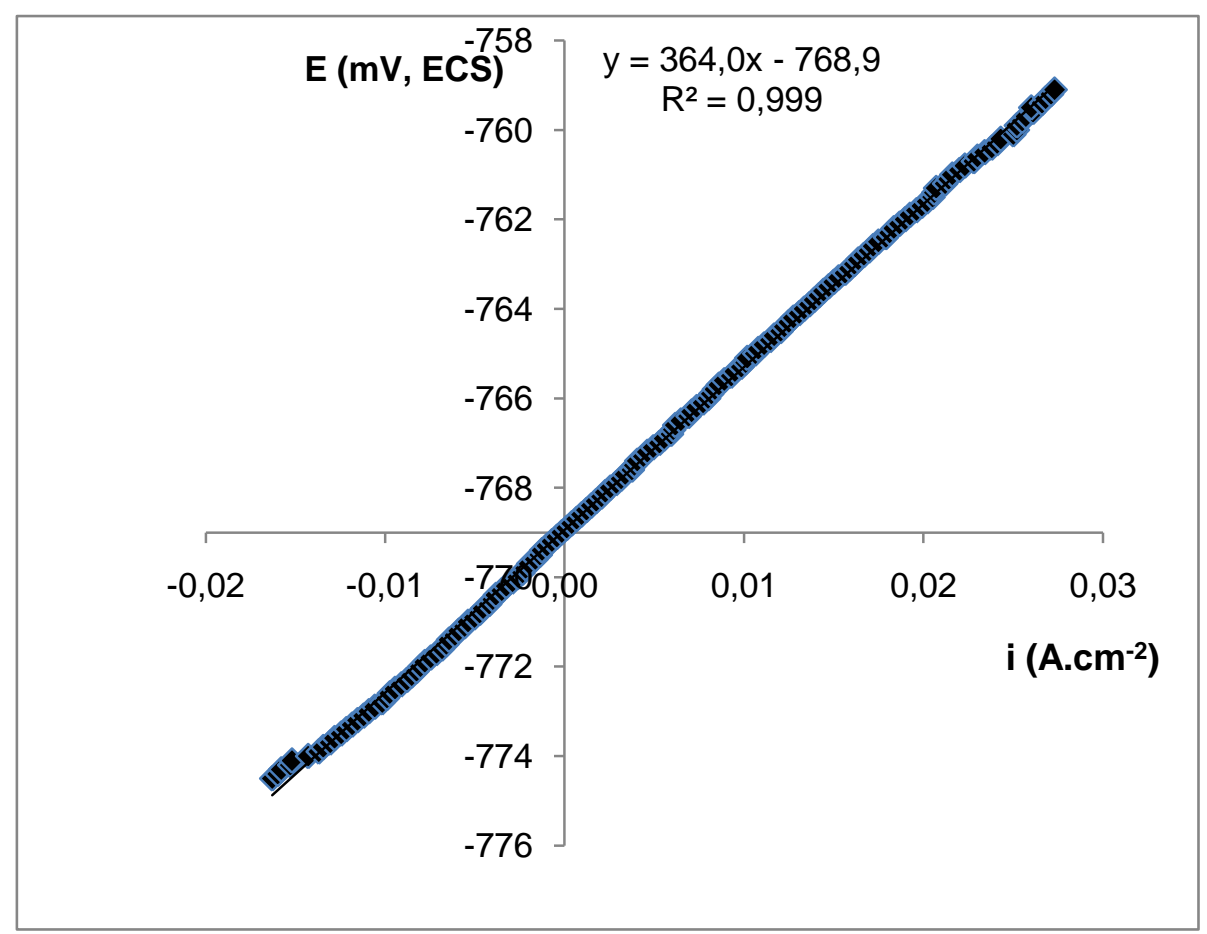

Figura 55 Exemplo de curva de polarização linear para a amostra C-X65 imersa na solução B. $O$ valor da Rp é obtido por regressão linear, desprezando-se os pontos não alinhados. No presente caso, tem-se $\mathrm{Rp}$ com valor de $364 \Omega . \mathrm{cm}^{2}$. Os ajustes obtidos $\mathrm{R}^{2}$ foram sempre maiores do que 0,997 .

Na Figura 56 são apresentados os valores de Rp em função do tempo, para os materiais testados na solução $B$. Todos os aços apresentam valores de Rp constantes em função do tempo; no início do ensaio encontram-se valores levemente mais baixos, no entanto, este comportamento é bem menos perceptível do que o encontrado para os aços na solução A (Figura 53). Foram realizados três ensaios para cada material nesta solução. 


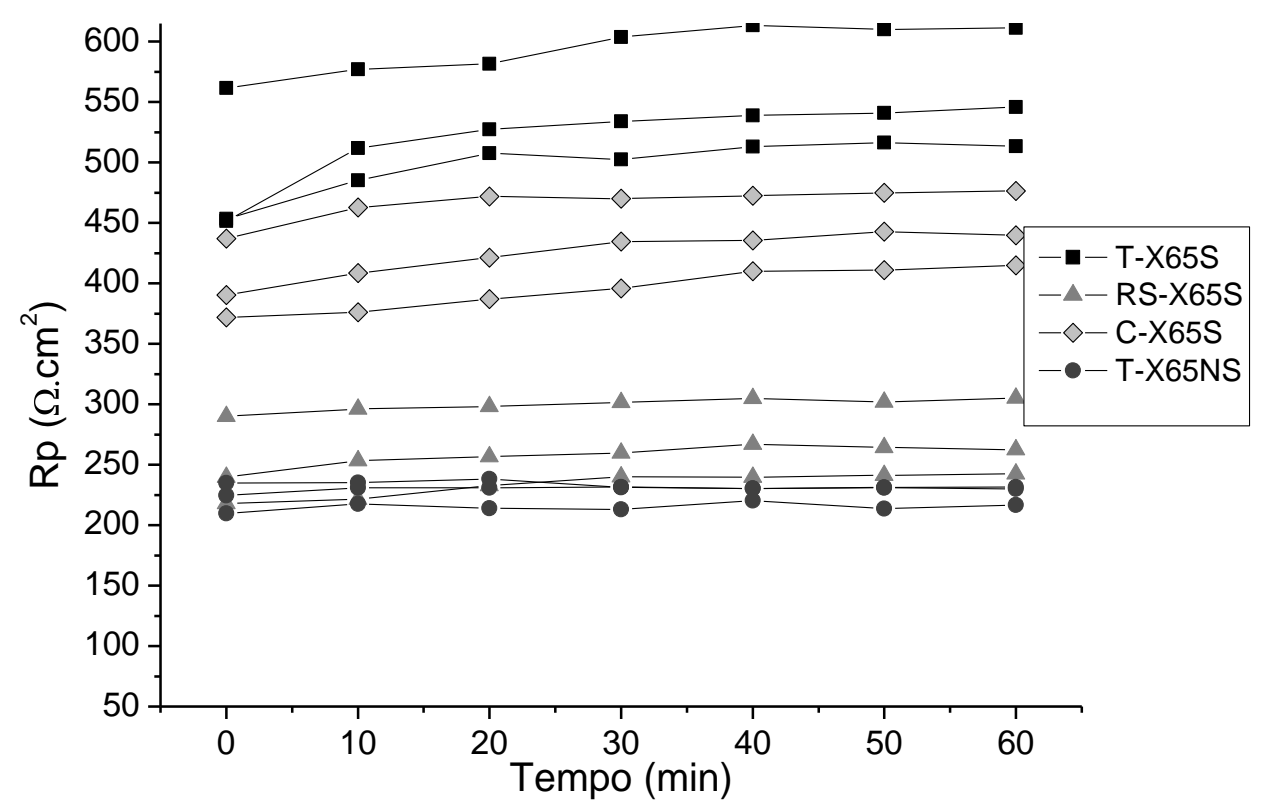

Figura 56 Resistência de Polarização (Rp) em função do tempo de imersão na solução B. Foram realizados 03 (três) ensaios para cada material. Destacam-se o tubo T-X65NS pelos menores valores de $\mathrm{Rp}$, os outros aços apresentaram valores próximos.

Nota-se, na Figura 56, que os valores de Rp para os aços estão numa faixa estreita de Rp entre 200 e $600 \Omega . \mathrm{cm}^{2}$. Como no caso da solução A, o aço do tubo T-X65NS apresentou valores de Rp muito próximos quando se comparam as 03 repetições, para os demais aços a dispersão entre as repetições foi maior.

Analogamente ao realizado para a solução A, para melhor visualização, fez-se para cada material a média e desvio padrão da Rp em cada tempo das 03 repetições. O resultado está apresentado na Figura 57 , onde se pode observar, com maior clareza, a tendência de cada aço: o aço T-X65NS foi o que apresentou a menor resistência de corrosão, com pouca dispersão, seguido da região de solda RS-X65S, chapa C-X65 e a maior resistência à corrosão foi obtida pelo tubo T-X65S.

Esta sequência de resistência à corrosão difere, da obtida para a Solução $A$, apenas pelo fato de que a chapa C-X65 superou significativamente a resistência à corrosão da amostra RS-X65S. 


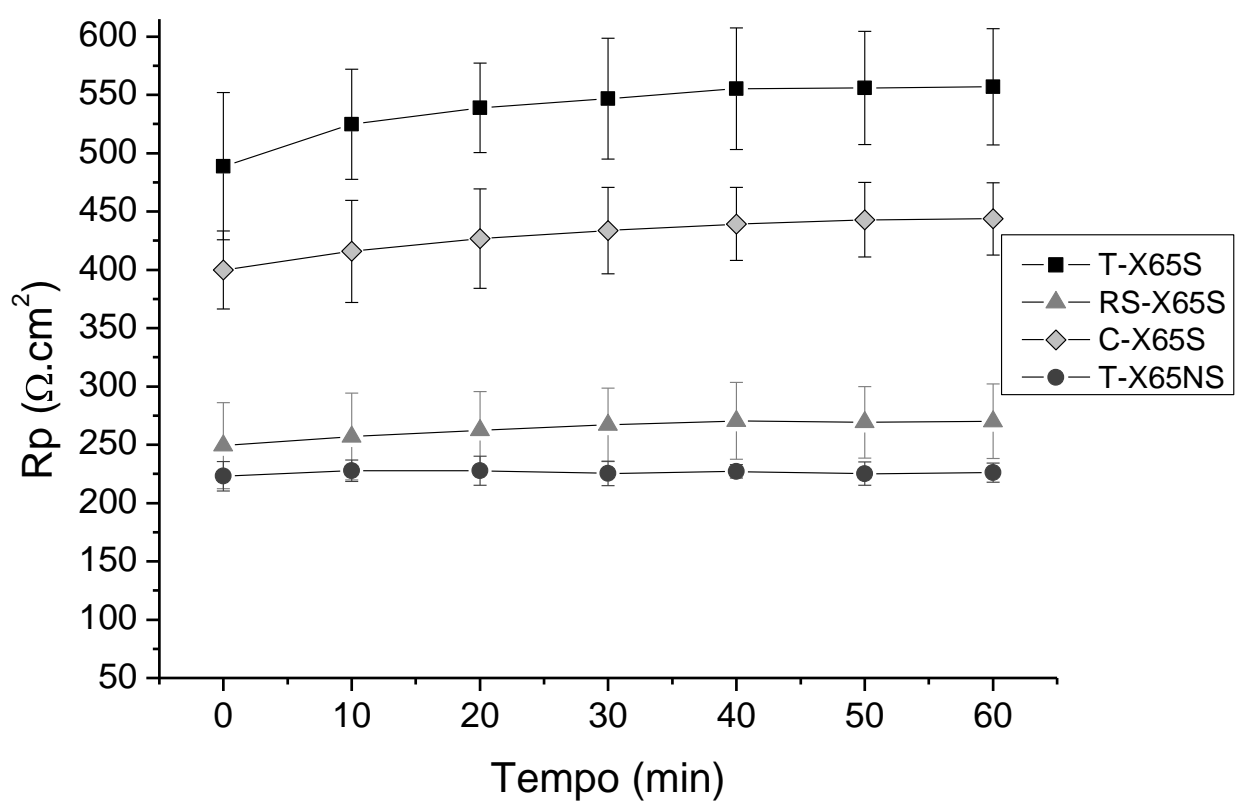

Figura 57 Valores médios e desvio padrão da Resistência de Polarização (Rp) em função do tempo de imersão. Solução B.

\subsubsection{MORFOLOGIA DA CORROSÃO}

A seguir estão apresentados os aspectos das superfícies após os ensaios de polarização linear das amostras nas soluções $A$ e B. Os exames foram realizados em MO e MEV, os resultados estão apresentados nas Figuras 58 a 65.

Após a imersão na solução A, foi observado, ao se retirar os corpos-de-prova, que há a formação de uma película fina de produto de corrosão de cor castanho, facilmente removida pela lavagem em água corrente, revelando uma superfície metálica opaca.

Nas Figuras 58 a 65 observa-se o aspecto da corrosão, após a remoção dessa película de produto. $\mathrm{O}$ aspecto da corrosão encontrada em cada material está de acordo com os resultados de Rp obtidos. Ou seja, o tubo T-X65S (Figuras 58 e 59) é o que apresenta o menor nível de corrosão superficial, pois, ainda são visíveis os riscos do acabamento de lixa 600 com alguma corrosão localizada. O mesmo vale para a região da solda (RS-X65S - Figura 60 e 61), 
que apresenta pouca corrosão generalizada e quase nenhuma corrosão do tipo localizada; por sua vez, a chapa C-X65 (Figuras 62 e 63) apresenta uma morfologia de corrosão muito parecida com aquela do T-X65S mas, com sinais de corrosão localizada mais intensa e, por fim, o tubo T-X65NS (Figuras 64 e 65) foi o material que maior intensidade de corrosão apresentou através deste exame visual, pois nota-se corrosão generalizada e localizada mais intensa. Vale ressaltar que a corrosão localizada observada em todos os casos está relacionada com 0 ataque das interfaces das inclusões com a matriz, semelhantemente ao encontrado no trabalho de Strobl (2010).

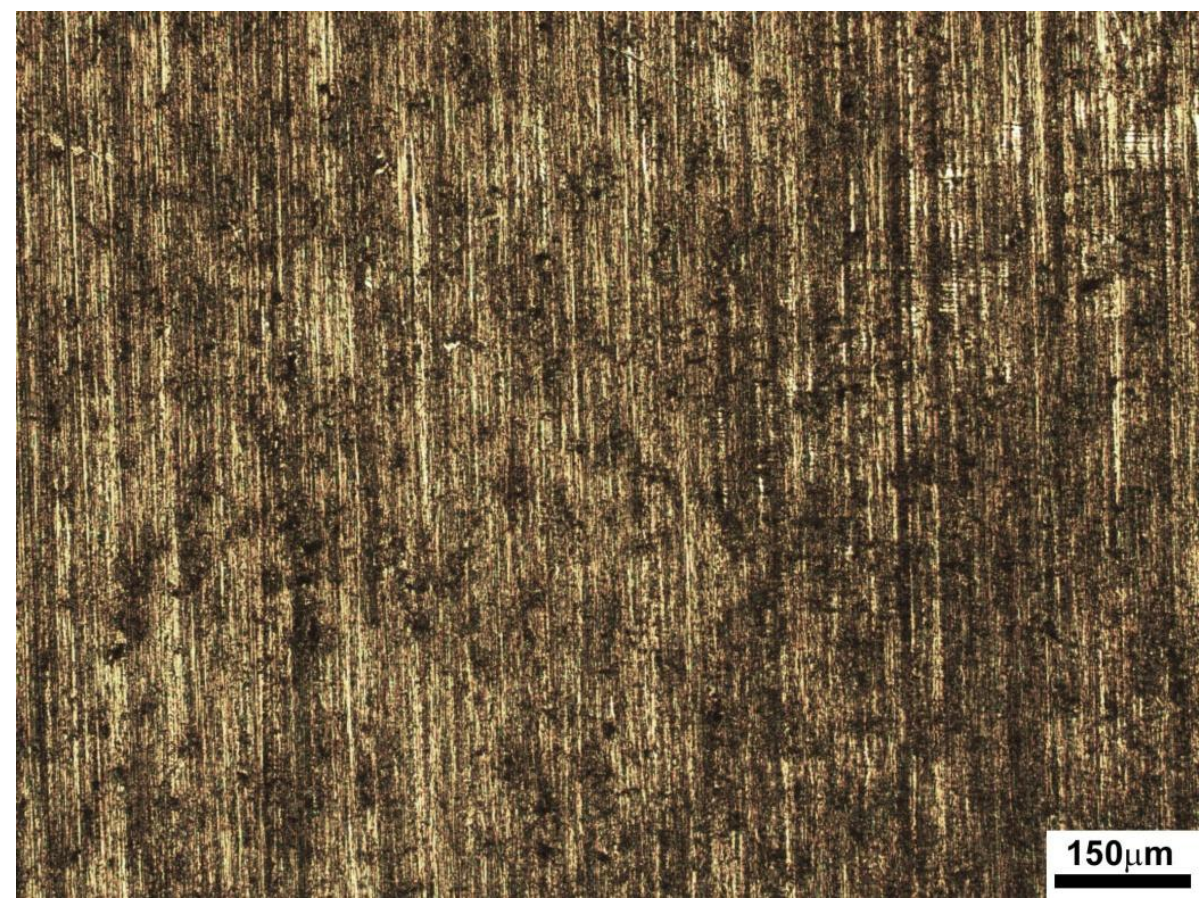

Figura 58 Morfologia da corrosão T-X65S. Pouca Corrosão uniforme, com baixo nível de corrosão localizada. . Solução A. Aumento:100X. MO. 

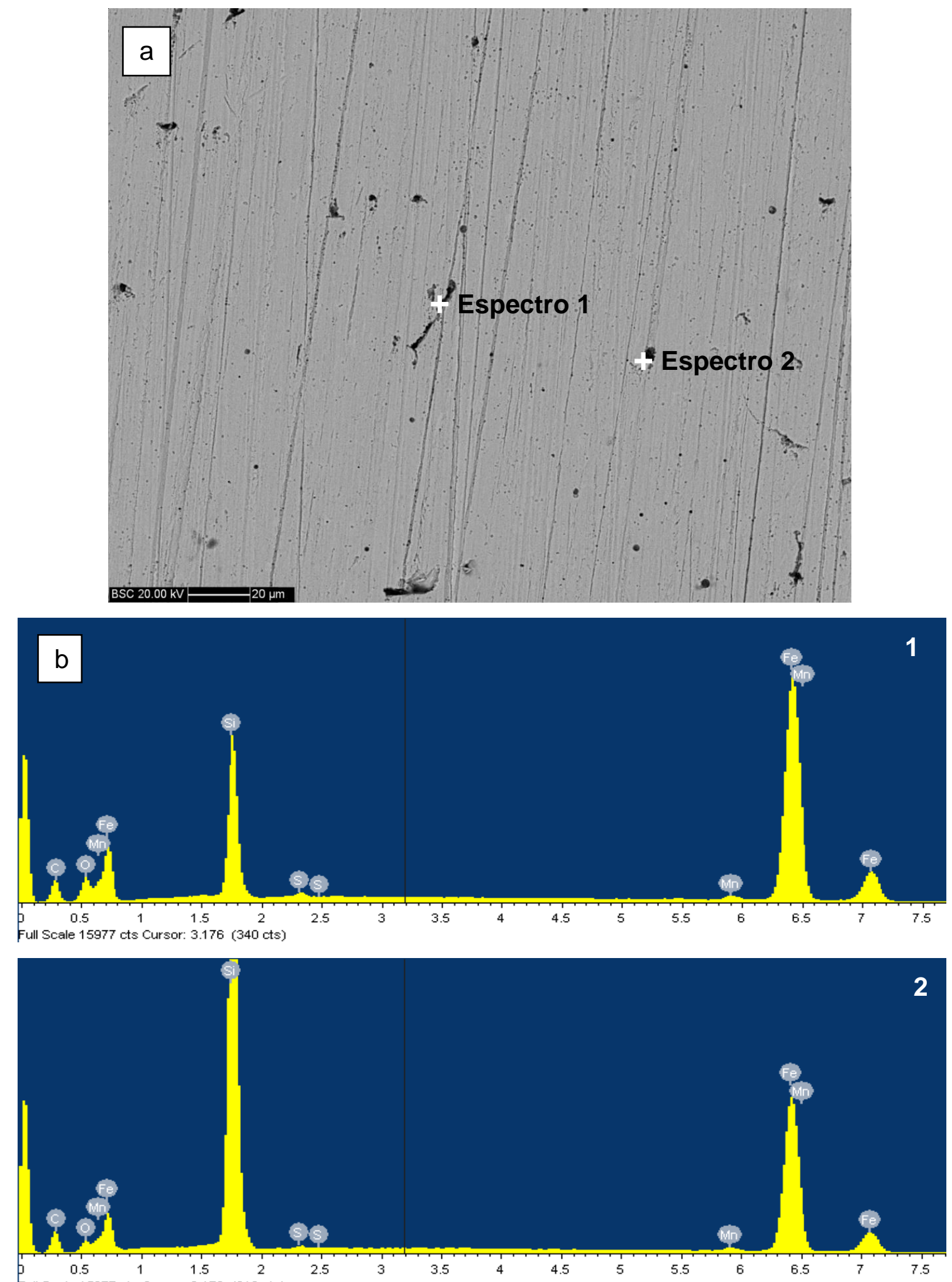

Figura 59 Morfologia de corrosão T-X65S, imagem de elétrons retrospalhados solução A. (a) Aspecto da superfície. (b) Análise química por EDS da superfície. MEV. 


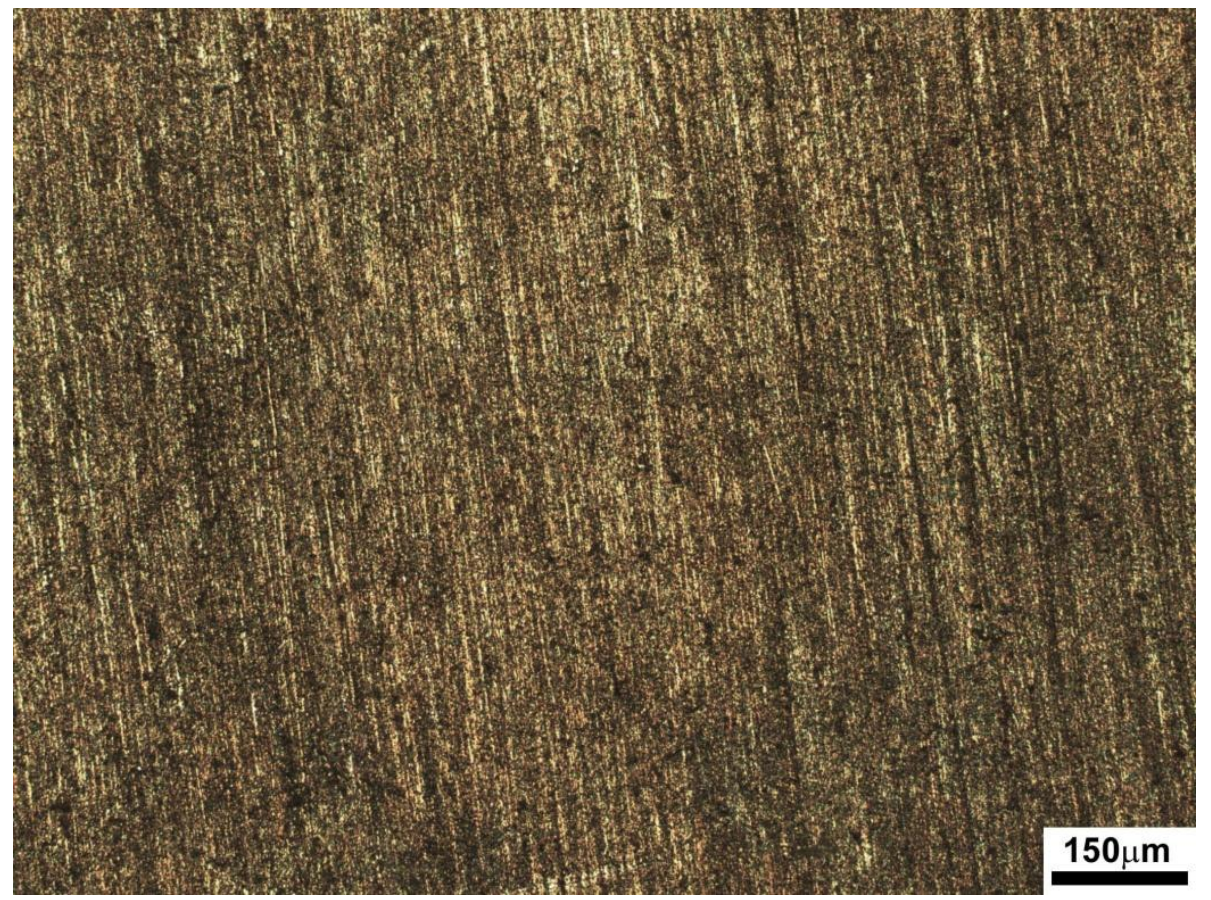

Figura 60 Morfologia da corrosão RS-X65S. Baixa corrosão uniforme, baixo nível de corrosão localizada. Solução A. Aumento: 100X. MO. 

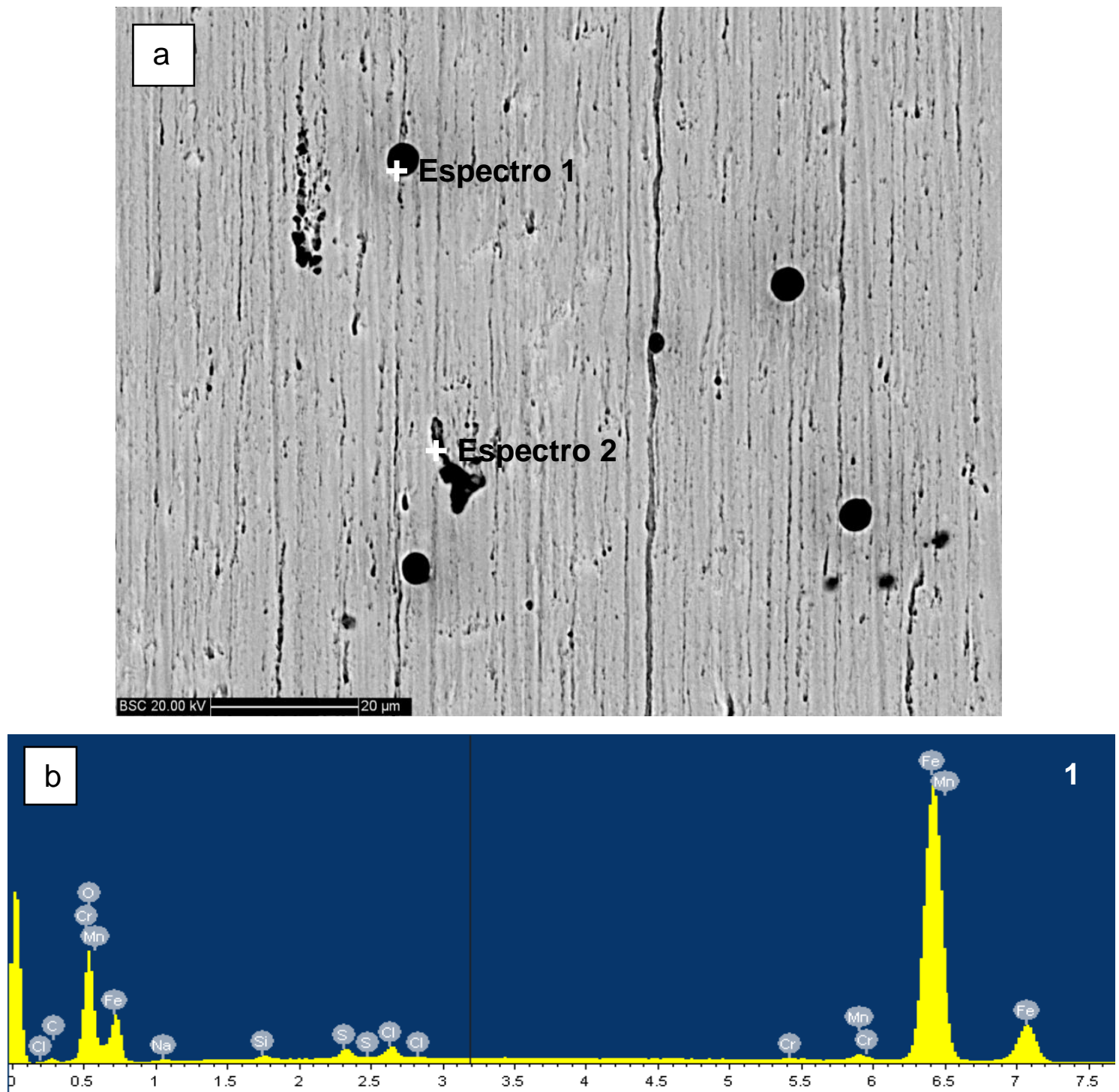

Full Scale $15977 \mathrm{cts}$ Cursor: 3.176 (283 cts)

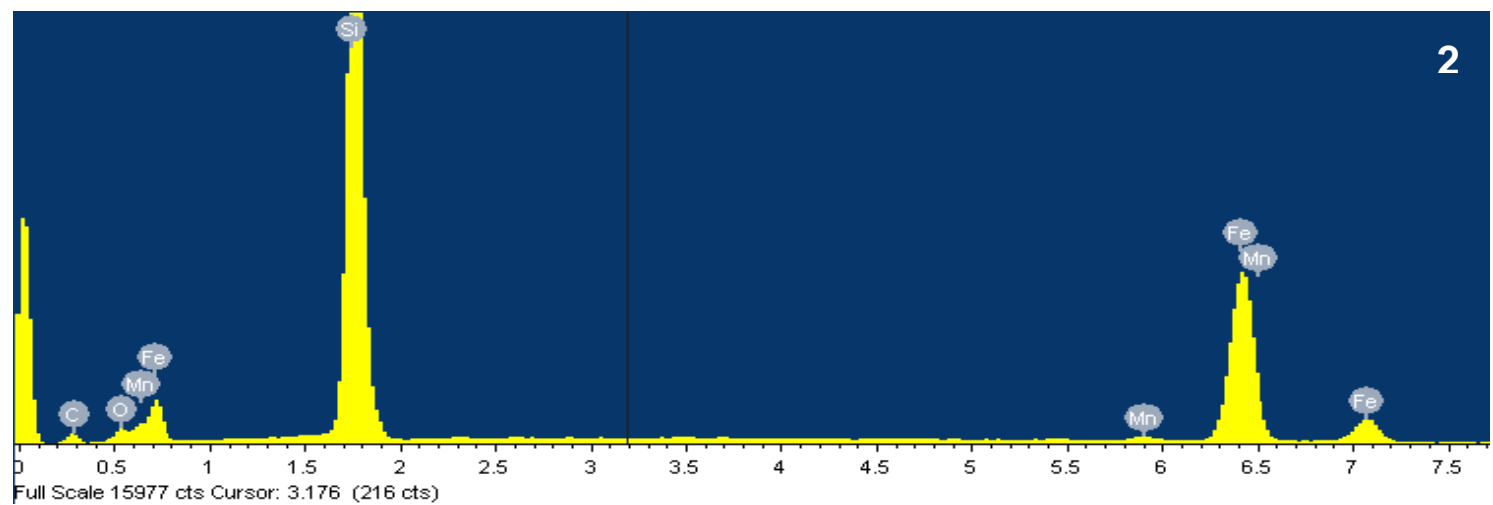

Figura 61 Morfologia de corrosão da RS-X65S, solução A. Imagem de elétrons retrospalhados. (a) Aspecto da superfície. (b) Análise química por EDS da superfície. MEV. 


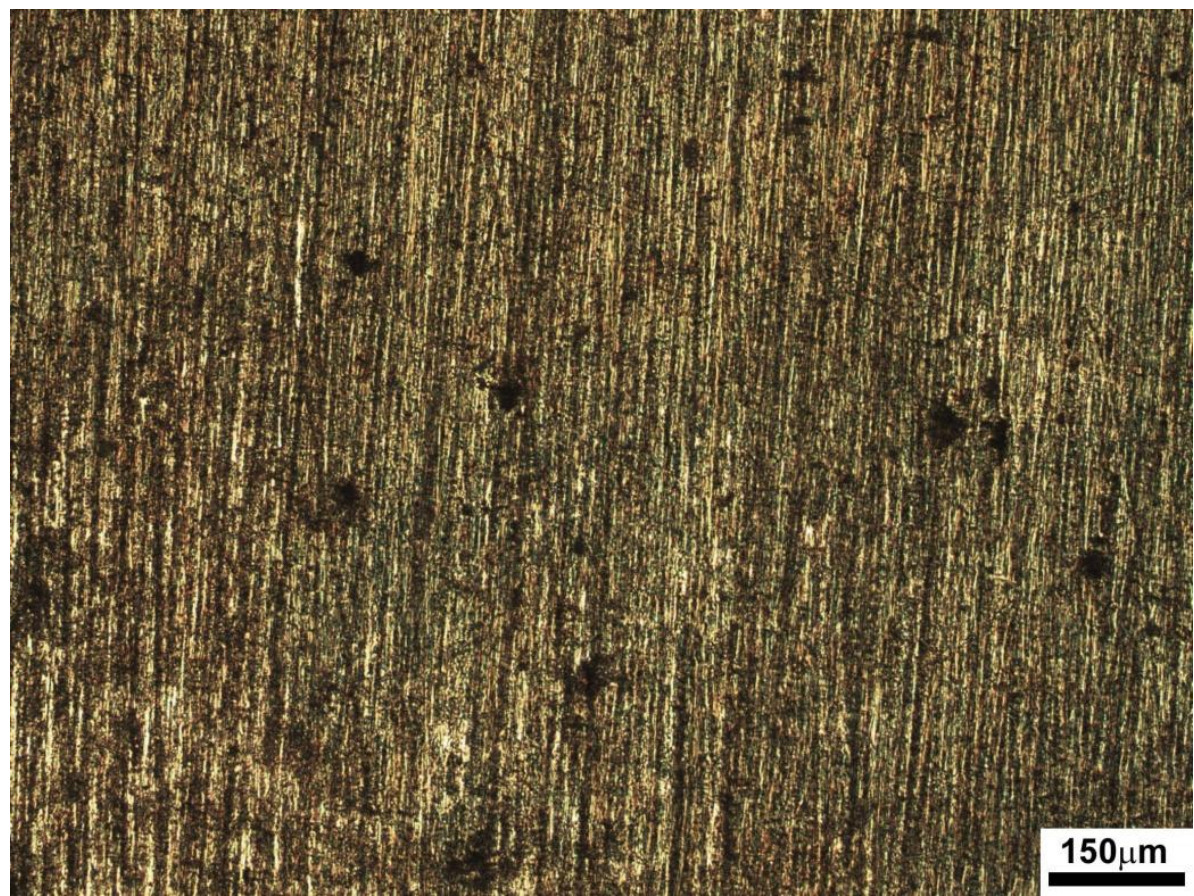

Figura 62 Morfologia da corrosão C-X65. Corrosão uniforme com nível médio de corrosão localizada. Solução A. Aumento: 100X. MO. 

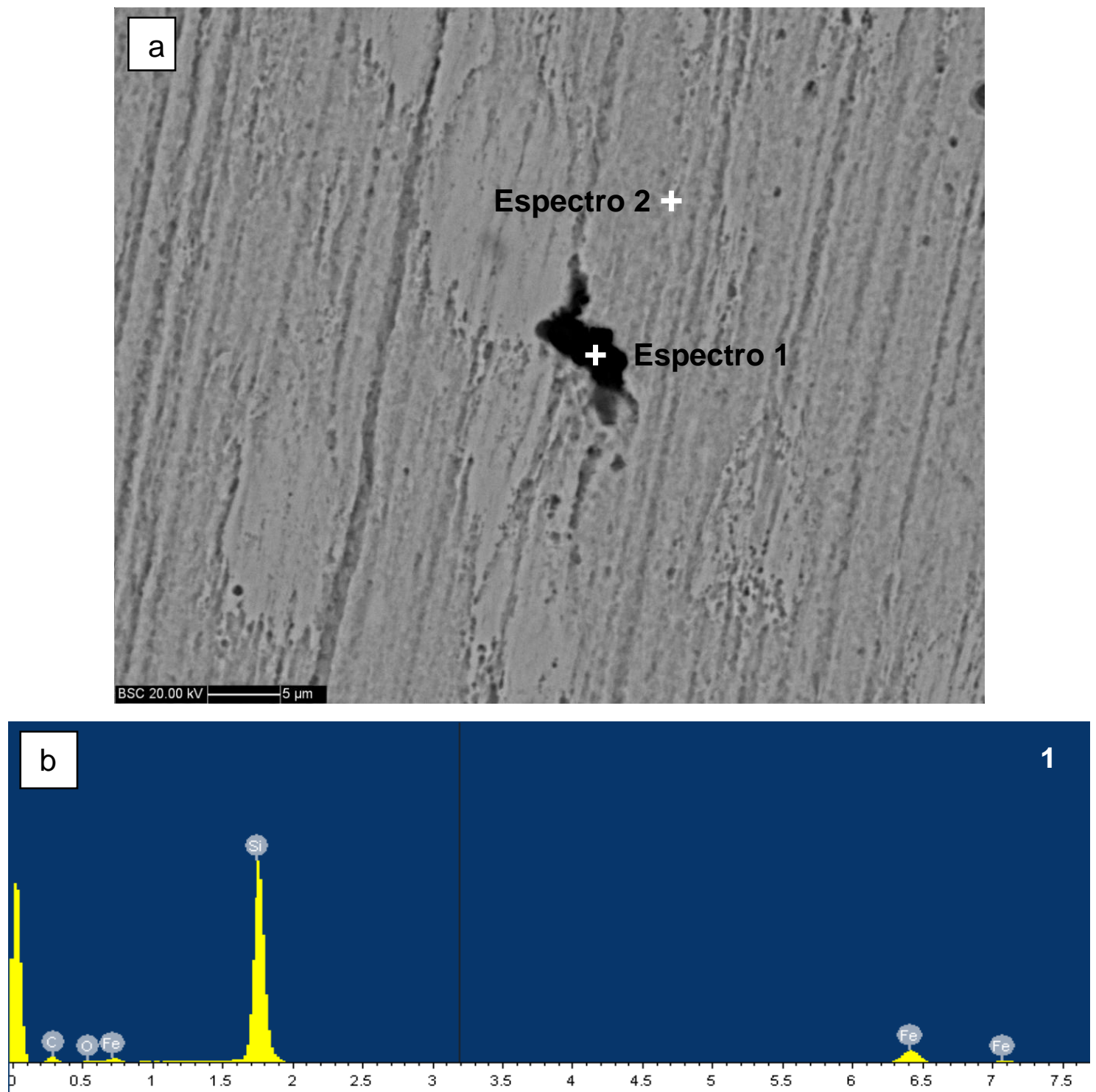

Full Scale $15977 \mathrm{cts}$ Cursor: 3.176 (44 cts)

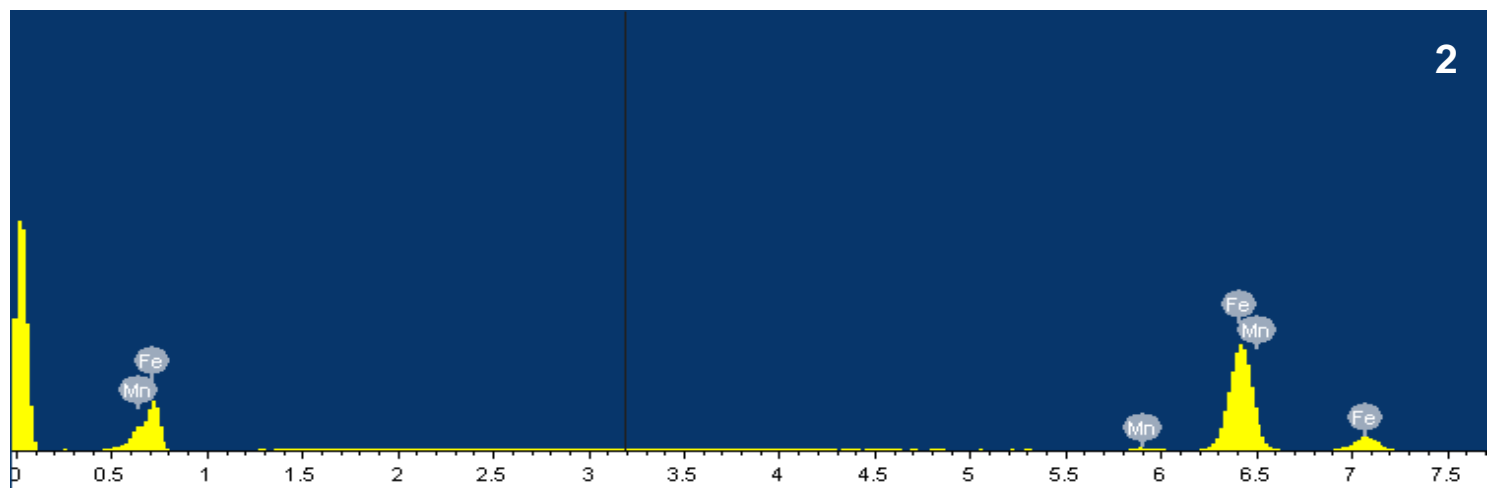

Full Scale $15977 \mathrm{cts}$ Cursor: 3.176 (90 cts)

Figura 63 Morfologia de corrosão C-X65, solução A. Imagem de elétrons retrospalhados, (a) Aspecto da superfície. (b) Análise química por EDS da superfície. MEV. 


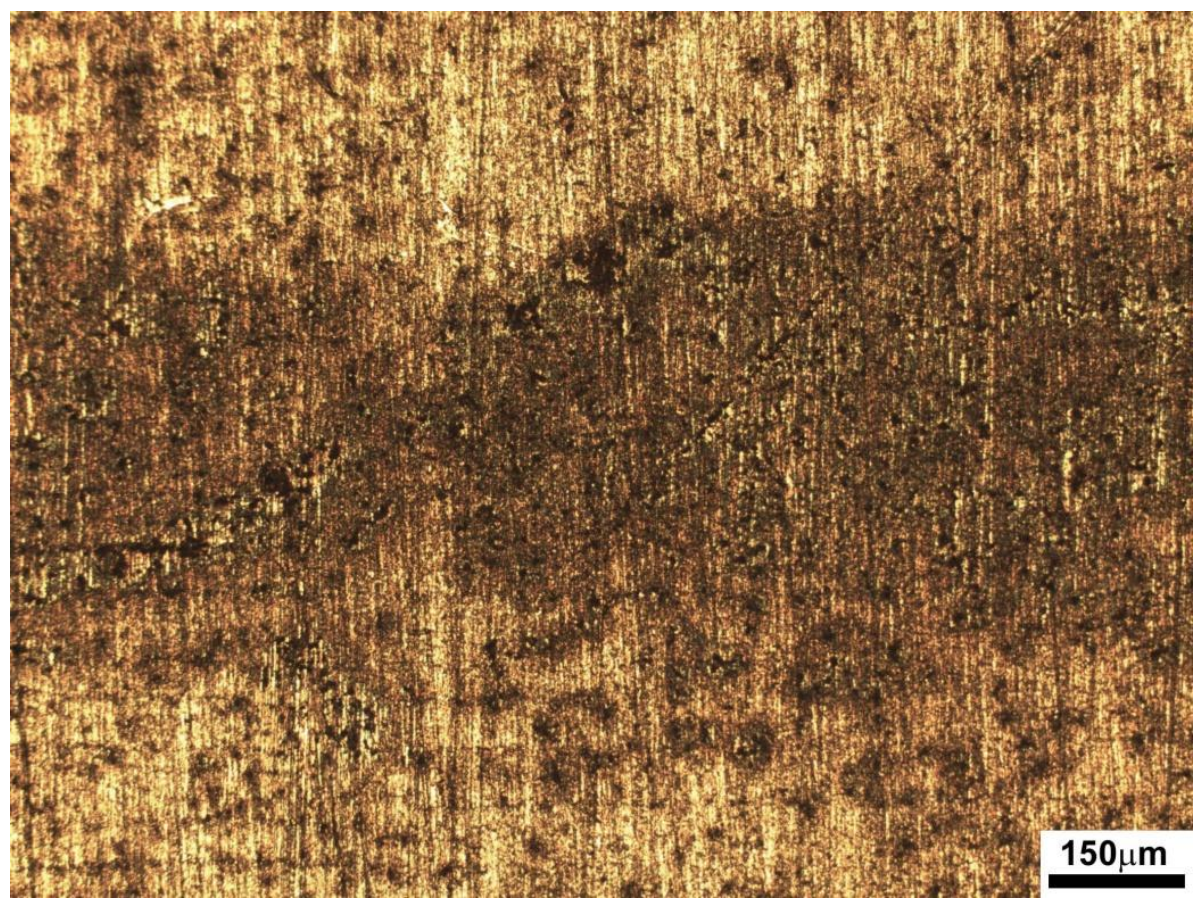

Figura 64 Morfologia da corrosão T-X65NS. Intensa corrosão uniforme com alto nível de corrosão localizada. Solução A. Aumento: 100X. MO. 

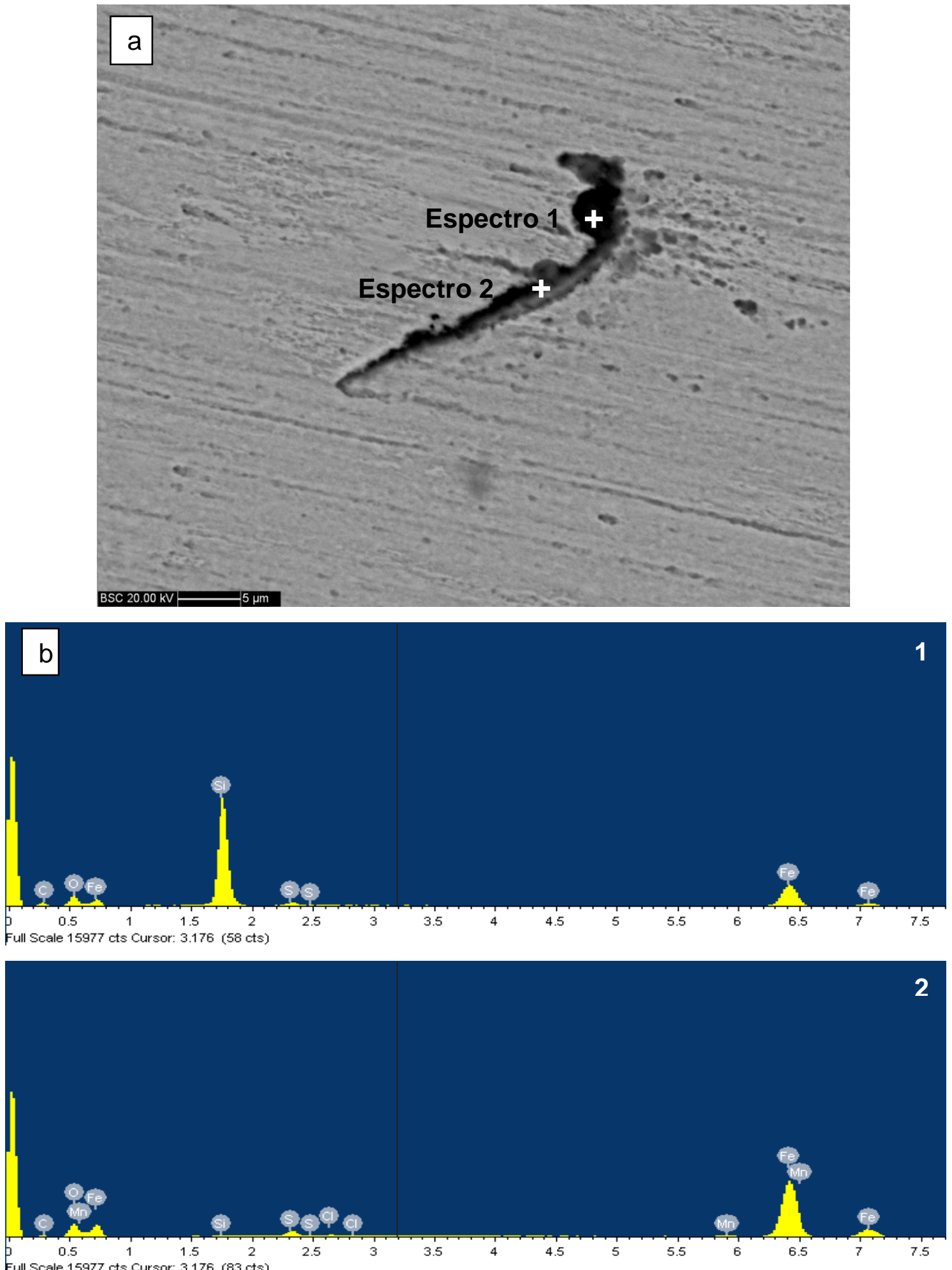

Figura 65 Morfologia de corrosão C-X65, solução A. Imagem de elétrons retrospalhados, (a) Aspecto da superfície. (b) Análise química por EDS da superfície. MEV. 
Após os ensaios na Solução B, foi observado, ao se retirar os corpos-de-prova, que há formação de uma camada de cor preta de produtos de corrosão, que apresentam pouca aderência e é facilmente removida pela lavagem em água corrente, revelando a superfície do metal. Estas camadas de produtos de corrosão são visivelmente mais grossas do que a película de produto de corrosão encontrada nos casos da Solução A. Nas Figuras 66 a 73 observa-se o aspecto da corrosão, após a remoção dessa camada de produto. $O$ aspecto da corrosão encontrada no $\mathrm{MO}$ é similar para três dos materiais estudados, que são: T-X65S, RS-X65S e T-X65NS (Figuras 66, 68 e 72). Nestes casos, a morfologia de corrosão apresentou grandes ilhas de corrosão localizada, pouco profundas, distribuídas pela superfície praticamente não atacada. Por sua vez, a amostra da chapa C-X65 caracterizou-se por apresentar uma morfologia de corrosão diferente dos demais materiais: o aspecto geral é de corrosão uniforme, mas há ataque localizado que dá sinais de acompanhar a orientação microestrutural do material. Não é possível afirmar que esta corrosão localizada está associada a inclusões.

Quando analisados por EDS foram encontrados, em todas as amostras, aglomerados de produtos contendo enxofre e cloro (Figuras 67, 69, 71 e 73); distribuído uniformemente em toda a superfície.

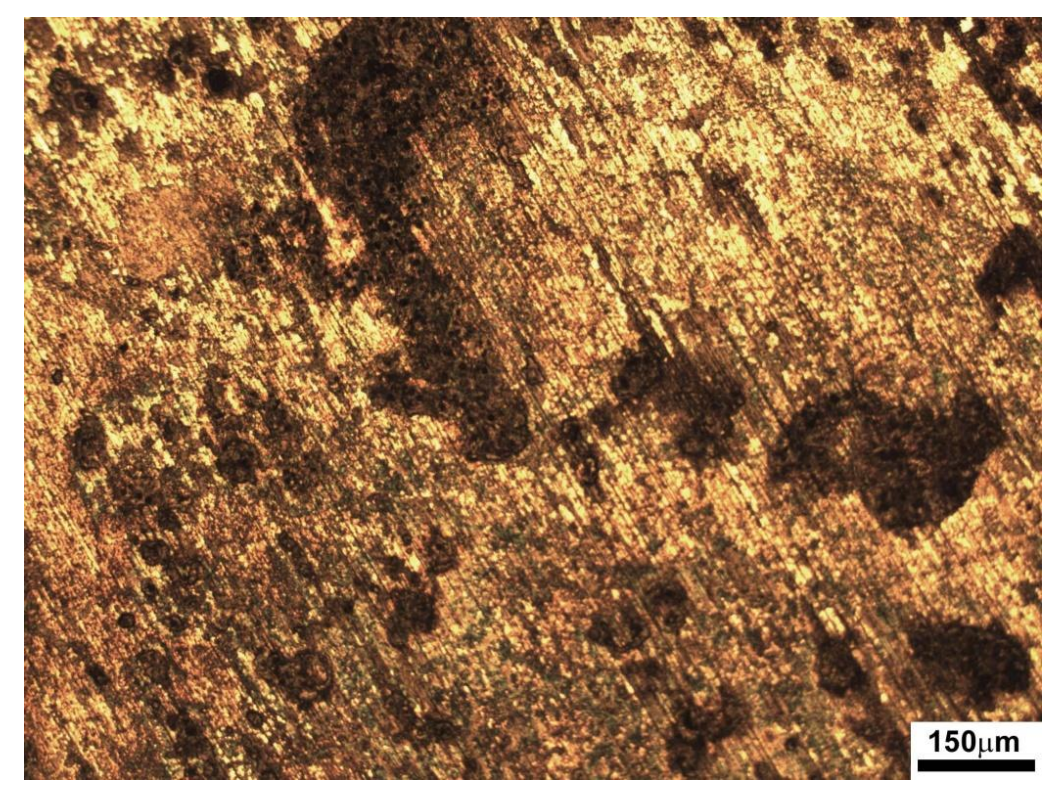

Figura 66 Morfologia da corrosão T-X65S. Corrosão uniforme com corrosão localizada, formando cavidades rasas, cercadas de regiões pouco corroídas. Solução B.

Aumento: 100X. MO. 

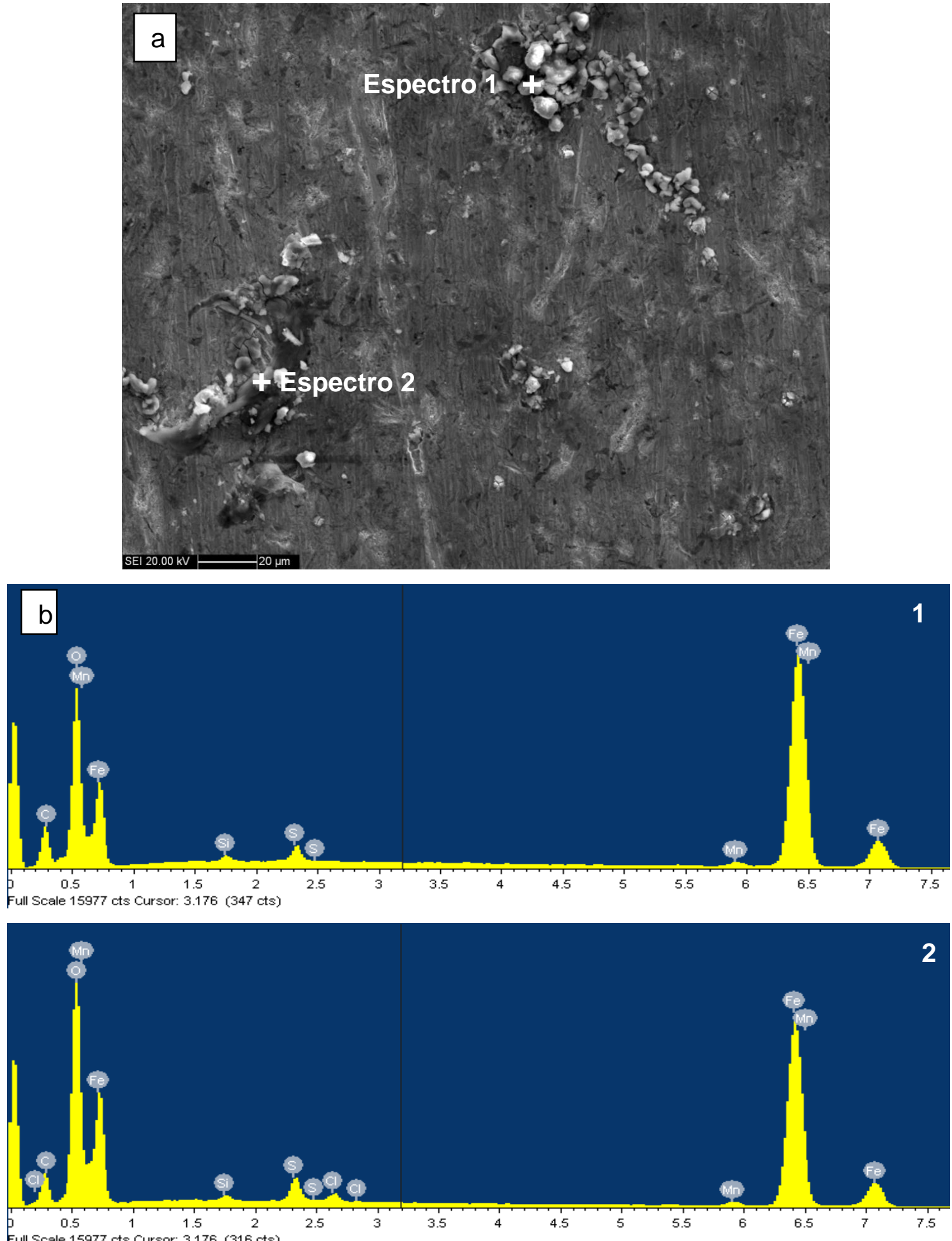

Figura 67 Morfologia de corrosão T-X65S, solução B. Imagem de elétrons secundários. (a) Aspecto da superfície. (b) Análise química por EDS da superfície. MEV. 


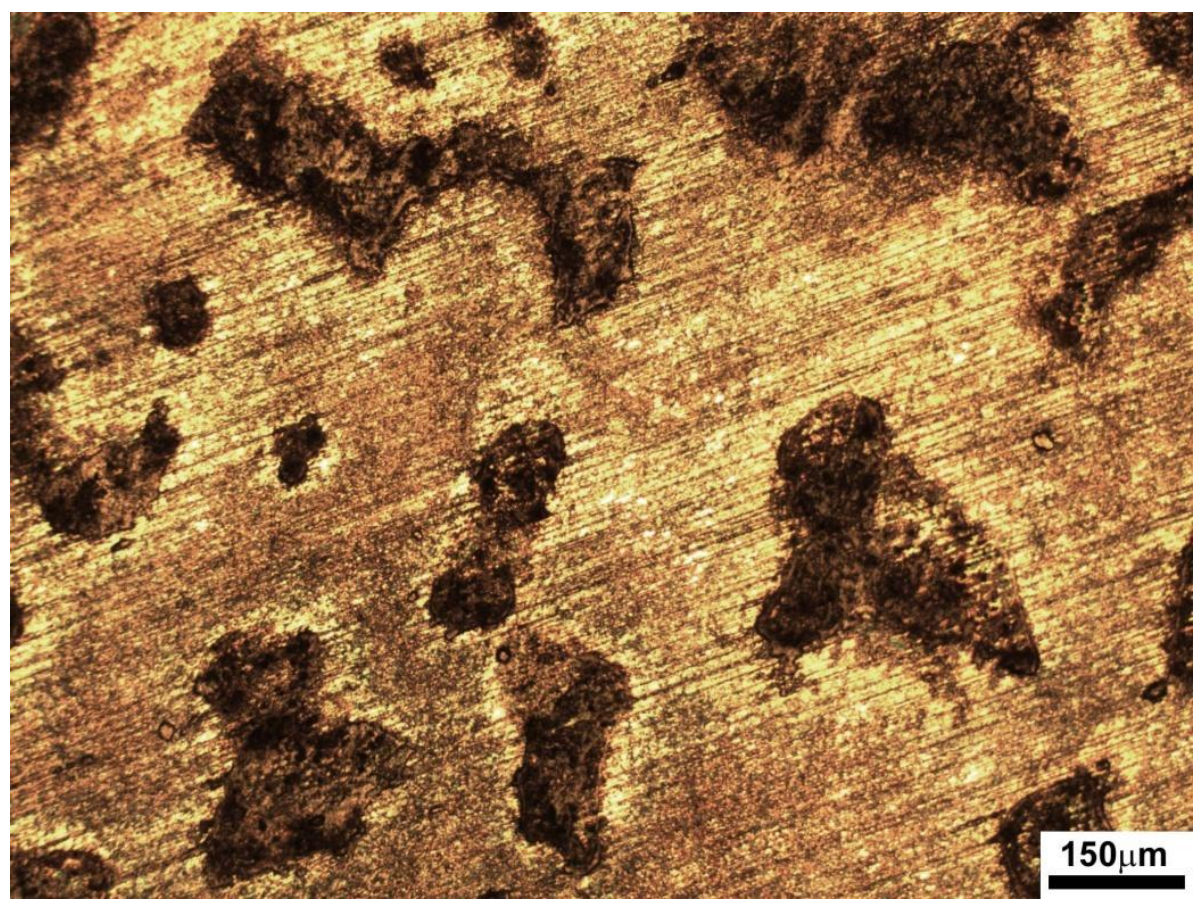

Figura 68 Morfologia da corrosão RS-X65S. Corrosão uniforme com de corrosão localizada. Solução B. Aumento: 100X. MO. 

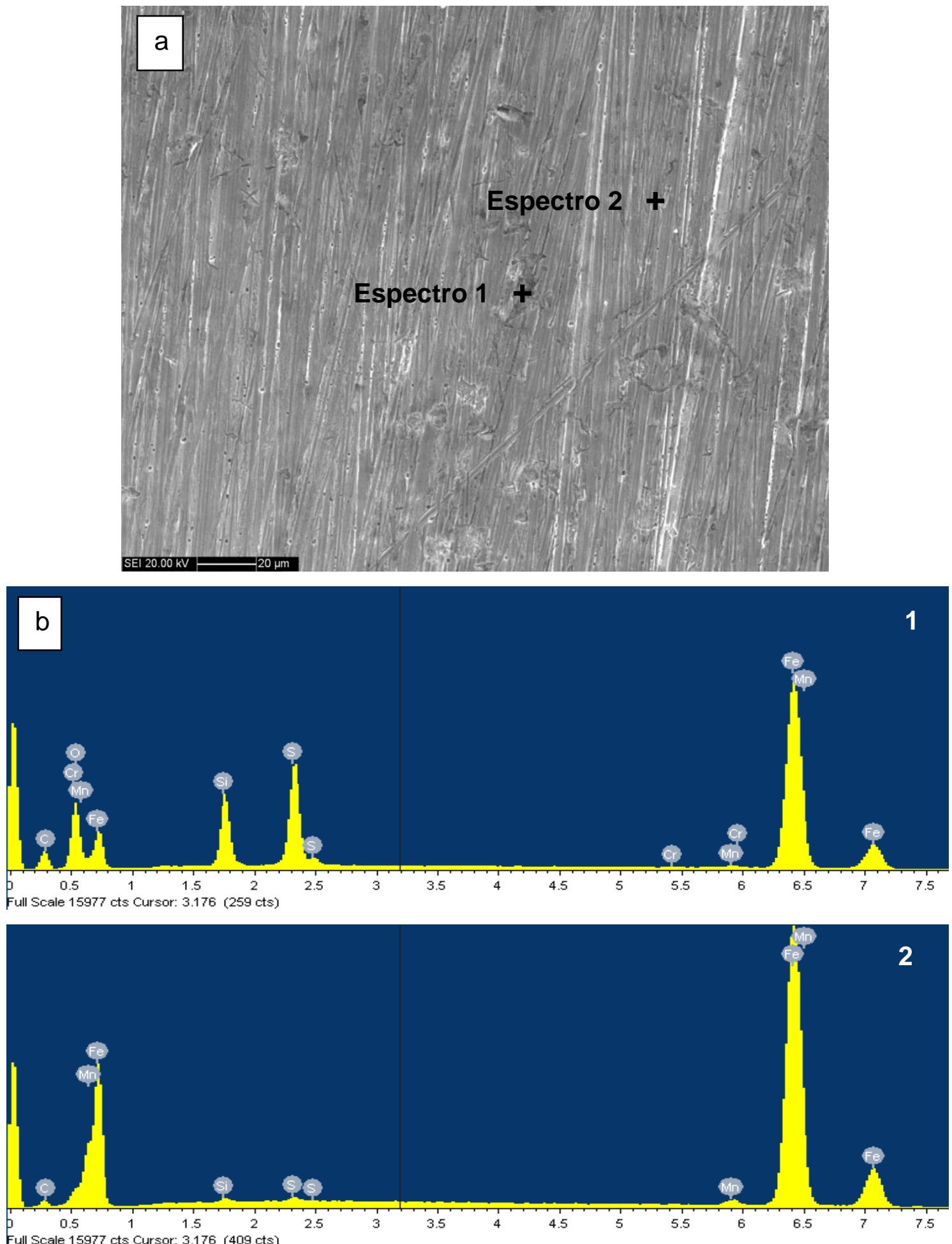

Figura 69 Morfologia de corrosão RS-X65S, solução B. Imagem de elétrons secundários. (a) Aspecto da superfície. (b) Análise química por EDS da superfície. MEV. 


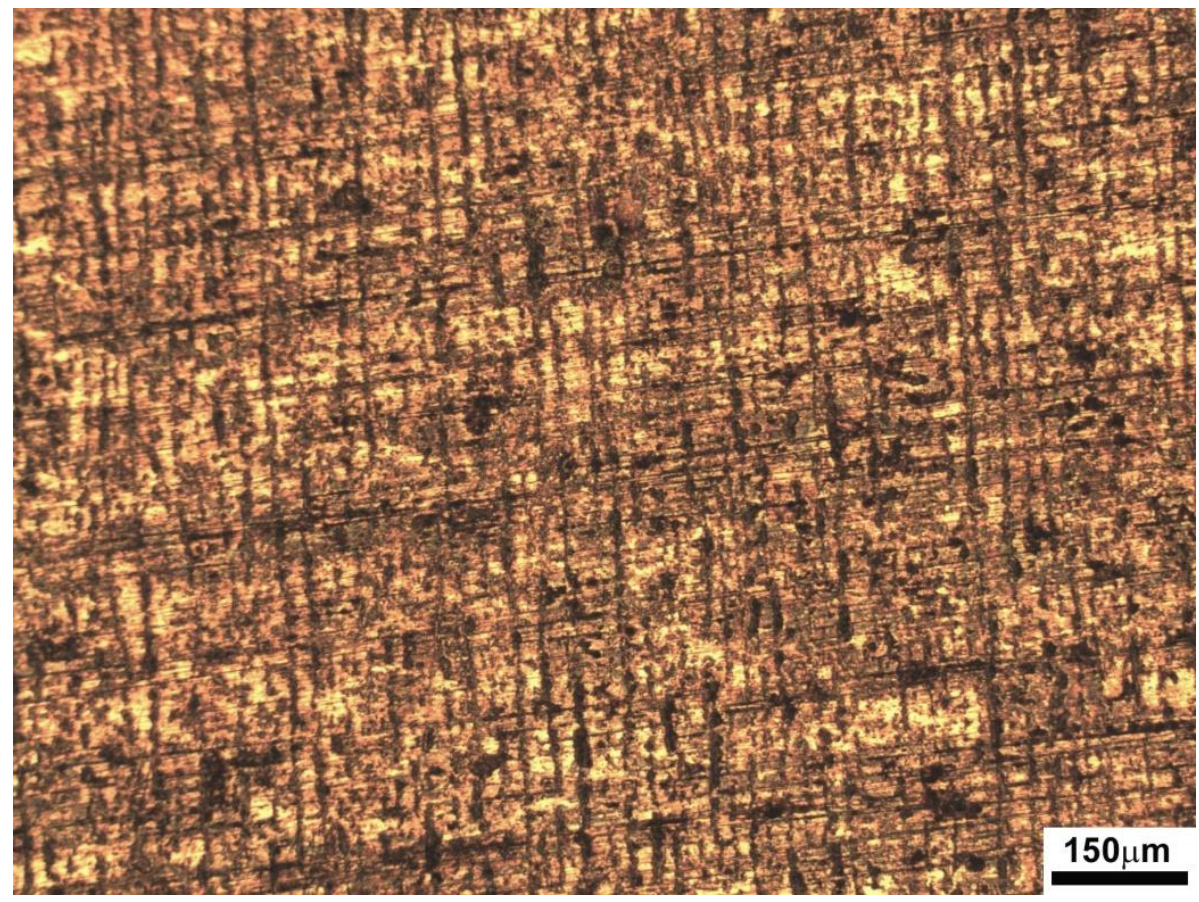

Figura 70 Morfologia da corrosão da C-X65. Corrosão uniforme com corrosão localizada. Solução B. Aumento: 100X. MO. 

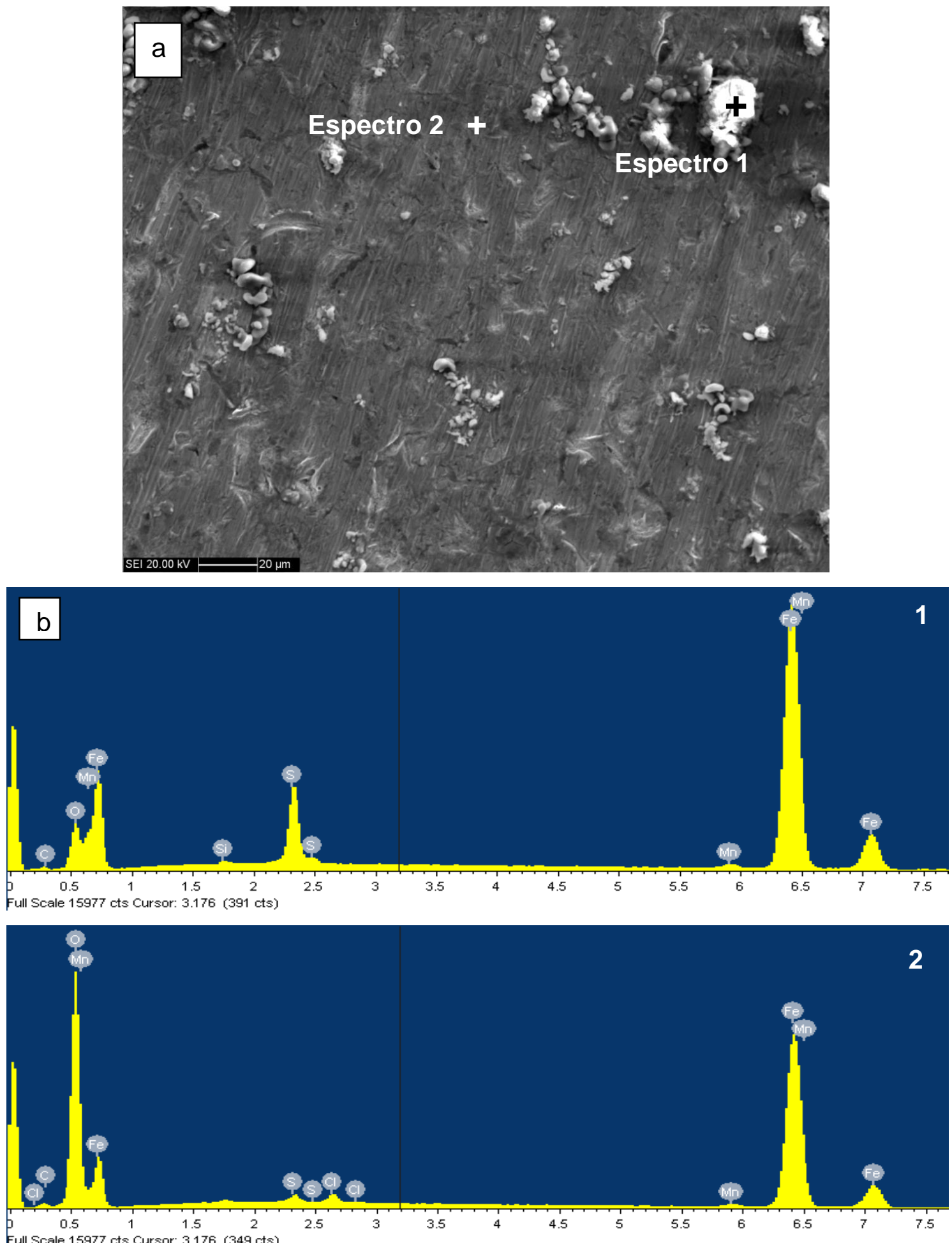

Figura 71 Morfologia de corrosão C-X65, solução B. Imagem de elétrons secundários. (a) Aspecto da superfície. (b) Análise química por EDS da superfície. MEV. 


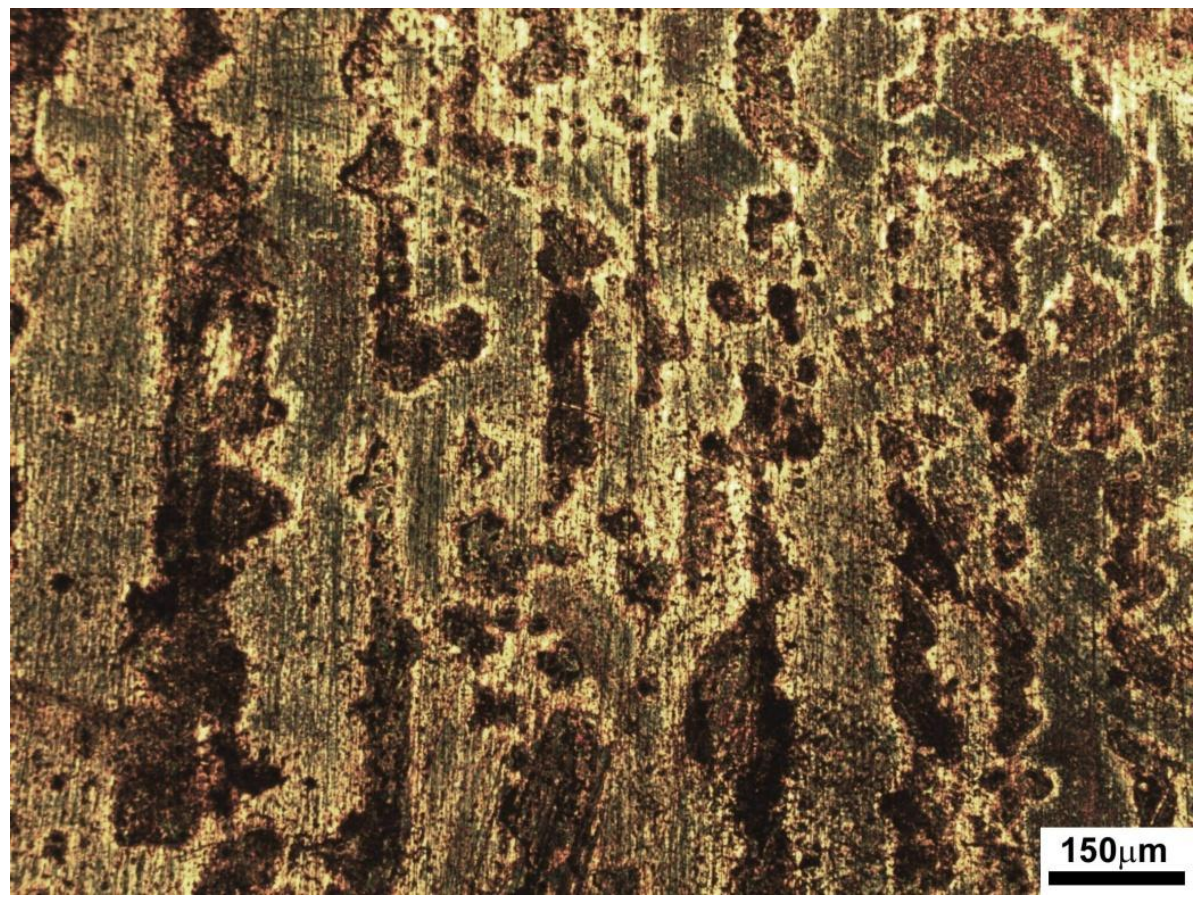

Figura 72 Morfologia da corrosão T-X65NS. Corrosão uniforme com corrosão localizada. Solução B. Aumento: 100X. MO. 

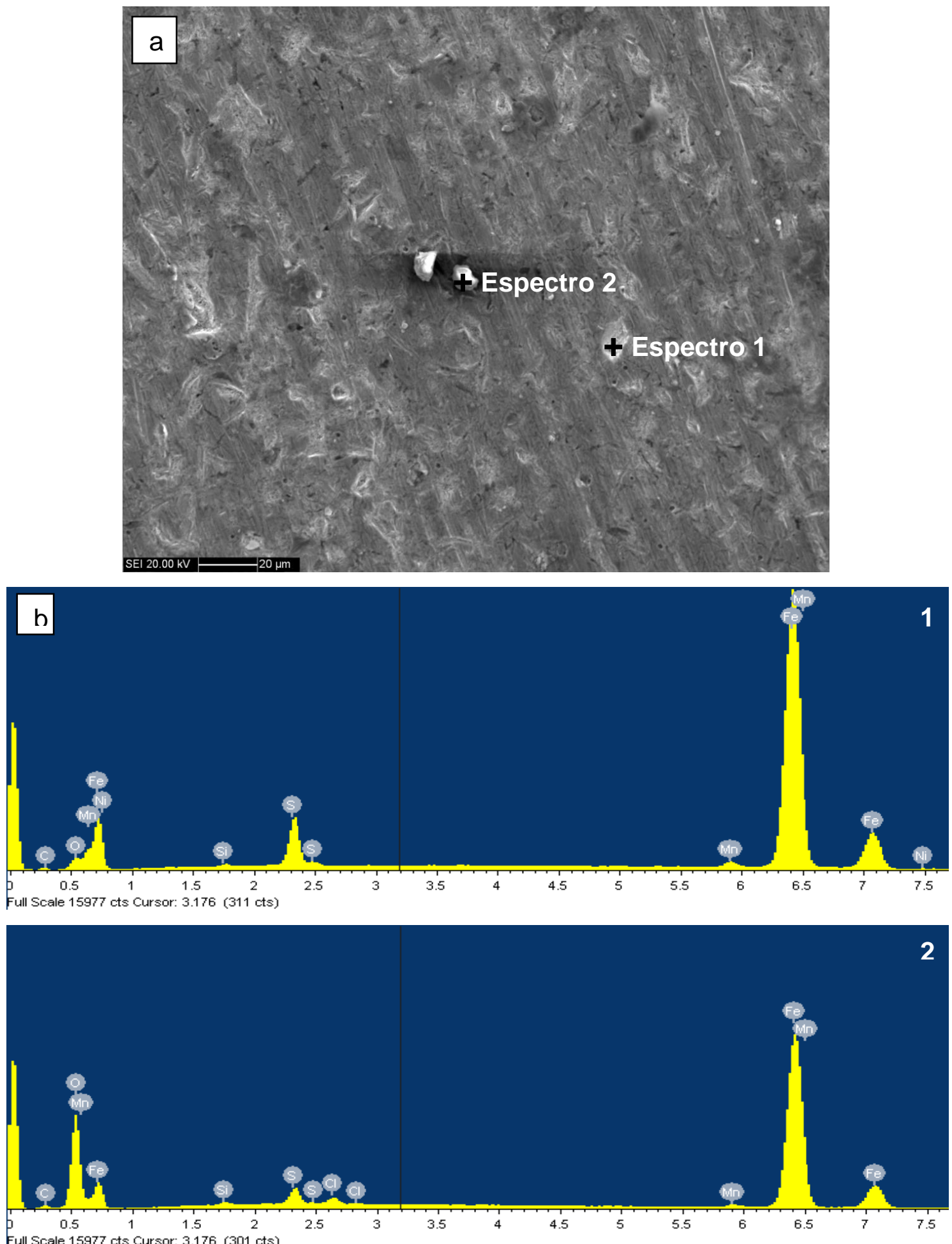

Figura 73 Morfologia de corrosão T-X65NS, solução B. Imagem de elétrons secundários. (a) Aspecto da superfície. (b) Análise química por EDS da superfície. MEV. 


\subsection{TRINCAMENTO INDUZIDO POR HIDROGÊNIO - HIC}

Os ensaios para a determinação da resistência a HIC são utilizados para conhecer a suscetibilidade de um aço ao trincamento em meios contendo sulfeto sem aplicação de carga. A norma NACE TM0284-2003 descreve procedimentos para a realização de testes de resistência a HIC, proporcionando um parâmetro de comparação dos resultados obtidos para diferentes aços. As soluções utilizadas não simulam um ambiente de trabalho específico, apenas fornecem condições severas para os ensaios.

Foram realizados os ensaios de trincamento induzido por hidrogênio segundo as recomendações da norma NACE TM0284-2003 nas soluções A e B. Durante o ensaio se observaram bolhas saindo dos corpos-de-prova indicando a formação de hidrogênio na superfície das amostras. Após o ensaio as amostras foram cortadas, embutidas, preparadas metalograficamente e observadas no $\mathrm{MO}$ e no $\mathrm{MEV}$; inicialmente as superfícies foram examinadas sem ataque metalográfico. Após esse exame, as amostras foram atacadas com reagente nital $2 \%$, com o fim de visualizar os pontos de nucleação e propagação das trincas.

\subsubsection{SOLUÇÃO A}

Após o ensaio de HIC na solução $A$, não foram encontradas trincas na superfície das amostras de T-X65S (Figura 74), região soldada RS-X65S (Figura 75) e chapa C-X65 (Figura 76), portanto, estes aços apresentaram resistência a HIC nesta solução. 


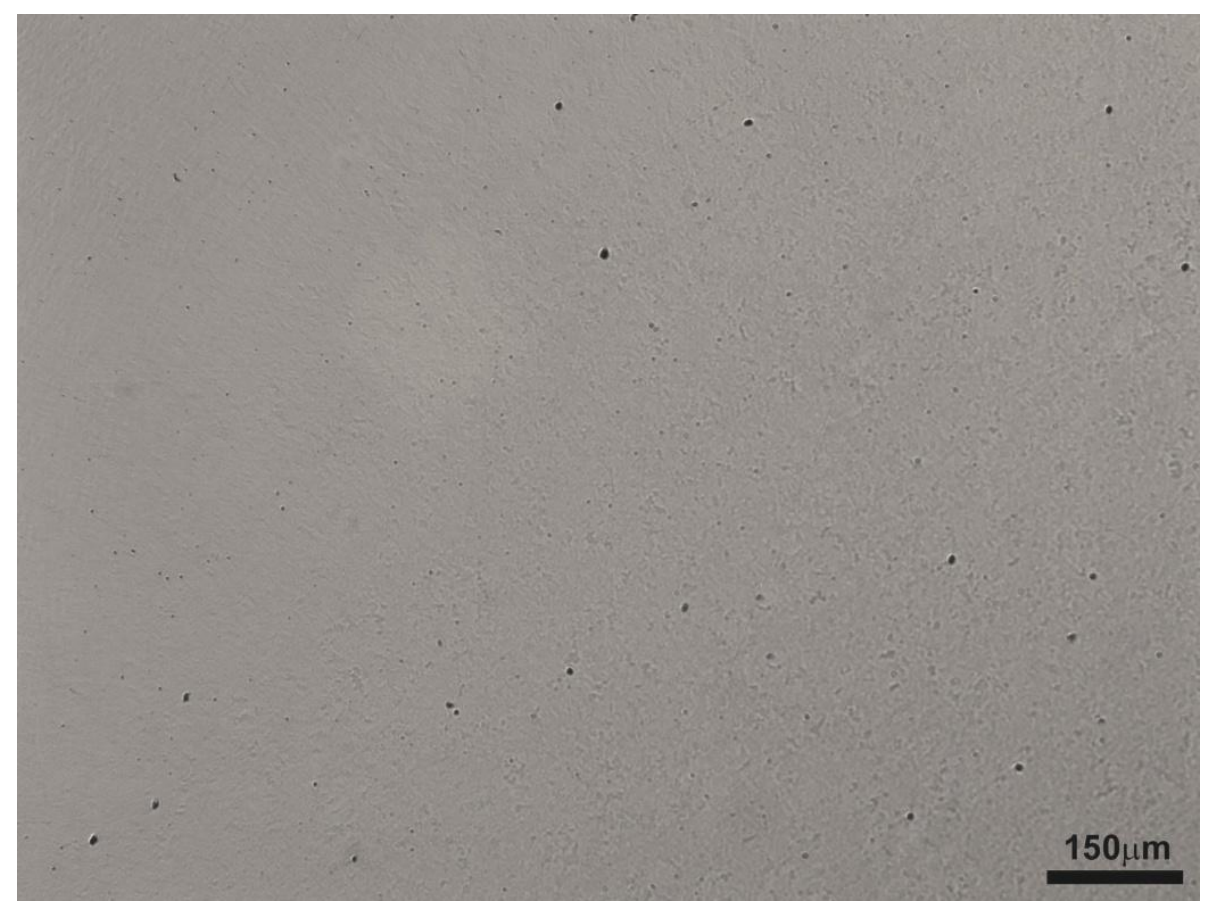

Figura 74 Superfície do tubo T-X65S após ensaio de HIC, solução A. Polimento: $1 \mu \mathrm{m}$, sem ataque. Aumento: $100 \mathrm{X}$. MO.

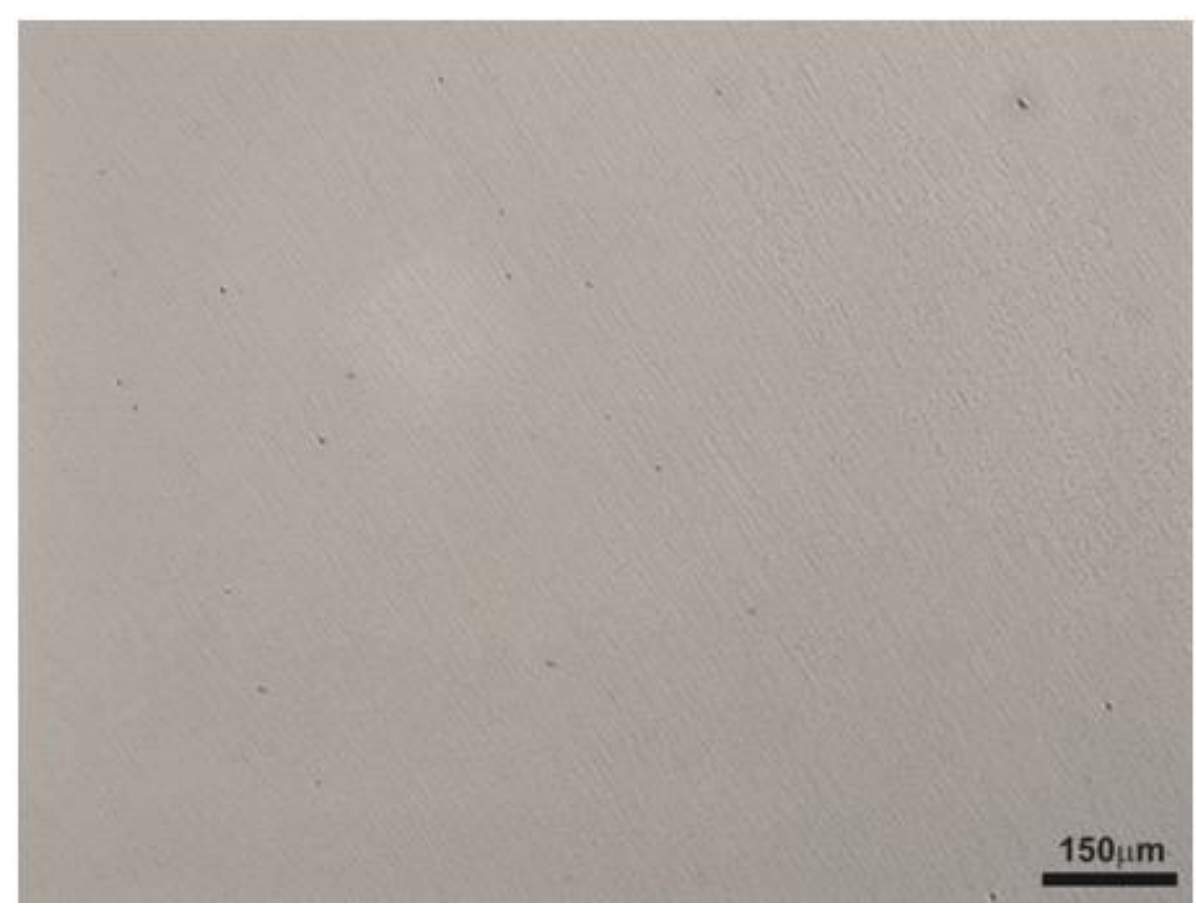

Figura 75 Superfície do tubo RS-X65S após ensaio de HIC, solução A. Polimento: $1 \mu \mathrm{m}$, sem ataque. Aumento: $100 \mathrm{X}$. MO. 


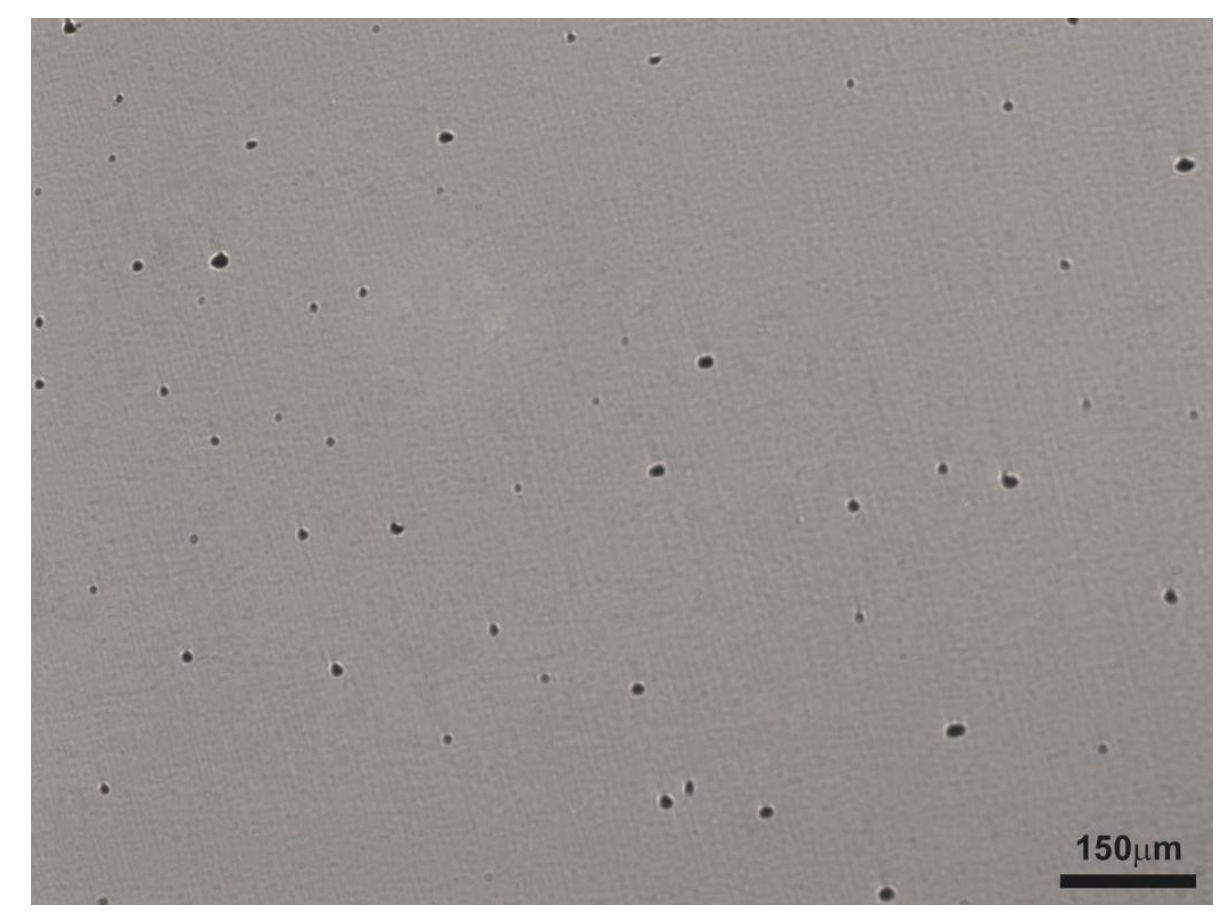

Figura 76 Superfície do tubo C-X65 após ensaio de HIC, solução A. Polimento: 1 $1 \mu \mathrm{m}$, sem ataque. Aumento: $100 \mathrm{X}$. MO.

Na Figura 77 é apresentada a superfície de uma das amostras de tubo T-X65NS, observada em MO com um polimento de $1 \mu \mathrm{m}$ sem ataque (o corpode-prova ensaiado foi seccionado em três partes, permitindo o exame em três diferentes superfícies - ver item 4.2.2 Trincamento induzido por hidrogênio: corpos-de-prova e procedimentos. Em todas as amostras foram encontradas trincas no centro da espessura, as trincas apresentam grande abertura e se estendem sobre a mesma linha, separadas por regiões sem trincamento. Neste exame não é possível visualizar os pontos onde foram nucleadas as trincas. Após verificar o trincamento no $\mathrm{MO}$ as amostras foram levadas ao MEV para encontrar os possíveis sítios de nucleação: os exames (Figura 78) não revelaram indícios precisos de que a trinca nucleasse nas inclusões. Este material apresenta nível de inclusões D4; assim sendo, no caminho de propagação da trinca é possível encontrar várias inclusões, no entanto, em nenhum caso foi encontrada evidência de nucleação da trinca a partir das inclusões. Algumas das inclusões foram analisadas por EDS, encontrando-se principalmente $\mathrm{Mn}$ e $\mathrm{Ca}$ em sua constituição (Figuras 78 b e c). 


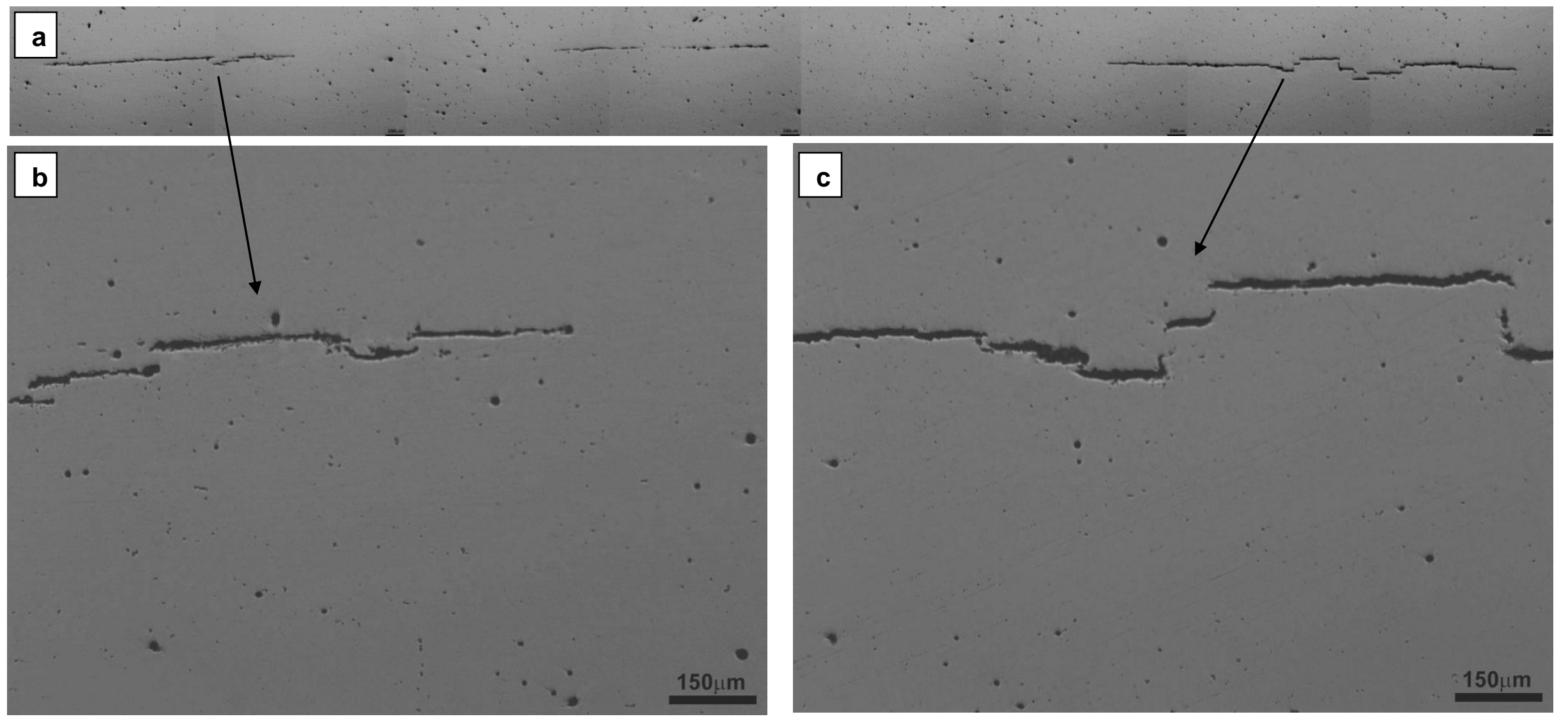

Figura 77 Trincamento encontrado na superfície do tubo T-X65NS (a) trincamento por toda a região central da amostra, aumento 50X, (b) e (c) trincamento em duas regiões especificas. Polimento $1 \mu \mathrm{m}$. Sem ataque. Aumento 100X. MO. 

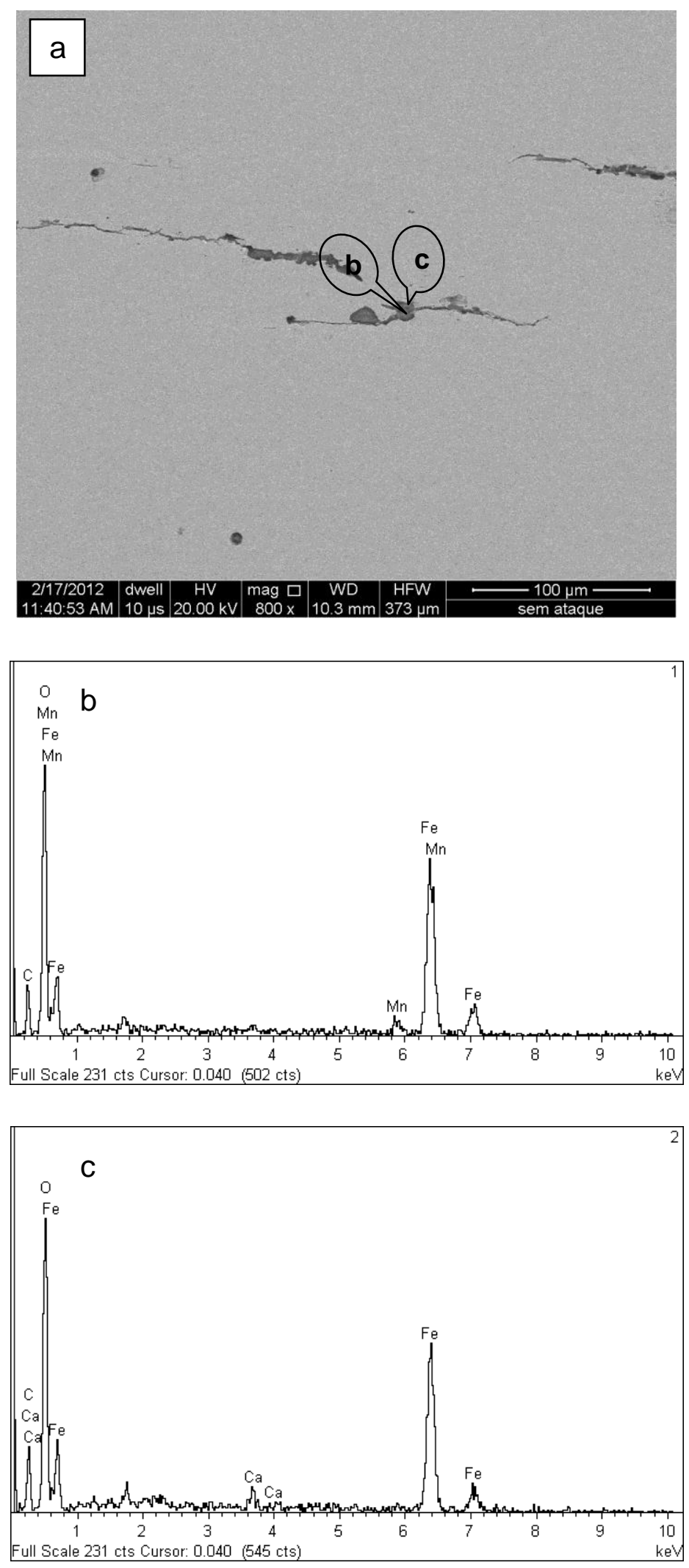

Figura 78 T-X65NS Imagem de elétrons restroespalhados. (a) Inclusões no caminho de propagação da trinca. Polimento $1 \mu \mathrm{m}$ sem ataque. (b) Análise química por EDS das inclusões: Mn e Ca. MEV. 
Após os exames em MEV sem ataque metalográfico, os corpos-de-prova foram atacados com reagente nital $2 \%$ e novamente examinados em MEV. Os resultados estão apresentados nas Figuras 79 a 83.

Nota-se primeiramente que a propagação das trincas acompanhou sempre a banda de segregação, indicando a importância da microestrutura nesse tipo de falha.

Em segundo lugar, observa-se que a nucleação das trincas não ocorreu devido a presença de inclusões, uma vez que, como no caso dos exames sem ataque, não foi encontrada nenhuma evidência de participação das inclusões na etapa de nucleação da trinca. As Figuras 80 e 81 são imagens da mesma região e mostram uma trinca mais curta em seu comprimento, onde é possível observar que a nucleação ocorreu devido à natureza da microestrutura (bandeamento); inclusive próximo dessa trinca, observa-se uma inclusão que não participou do processo de trincamento, sendo possível notar, na Figura 81, que a ponta da trinca desvia da direção da inclusão. Por sua vez, a Figura 82 apresenta uma região da trinca onde há duas inclusões de sulfeto (espectros de EDS das Figuras 82 b e c), no entanto, a trinca parece apenas tangenciar essas inclusões, não é possível afirmar que o caminho de propagação foi determinado pela presença destas inclusões.

Na tentativa de se encontrar evidências do local de nucleação das trincas, fezse o exame, quase que completo, de toda a superfície em MEV. Nessa oportunidade, foram encontradas evidências de nucleação de trinca em interfaces ferrita/cementita - cementita intergranular (Figura 83). Vale ressaltar que a trinca da Figura 83 encontra-se a aproximadamente $400 \mu \mathrm{m}$ abaixo da superfície da amostra. Pela norma NACE TM0284-2003, trincas nessa profundidade devem ser descartadas na contabilização dos parâmetros CSR, CLR e CTR. No entanto, isso não se aplica no presente caso, pois o objetivo é o de encontrar sítios propícios à nucleação de trincas.

Concluindo, tanto a nucleação, quanto a propagação das trincas na amostra de tubo T-X65NS, na solução $A$, deveu-se às características da microestrutura: respectivamente, presença de cementita em contornos de ferrita e bandeamento. Deve-se mencionar que a estrutura bandeada é uma estrutura 
complexa, pois contém ferrita, cementita, perlita. Em princípio, deve-se pesquisar quais arranjos, entre estes microconstituintes, levam à propagação da trinca. No entanto, a solução A é muito agressiva, dando origem a trincas relativamente grandes e muito abertas, o que impede a observação das evidências de propagação da trinca nesse nível microestrutural. No caso da nucleação foi possível encontrar a influência da cementita intergranular numa trinca relativamente pequena, mas na propagação tais evidências foram degradadas pelo próprio processo de trincamento. No próximo tópico são apresentados os resultados para a solução $\mathrm{B}$, a qual tem como característica uma menor agressividade. Como estão apresentados, mais adiante, nessas condições as trincas são menores e foi possível identificar o arranjo microestrutural que causa a nucleação e propagação da trinca.

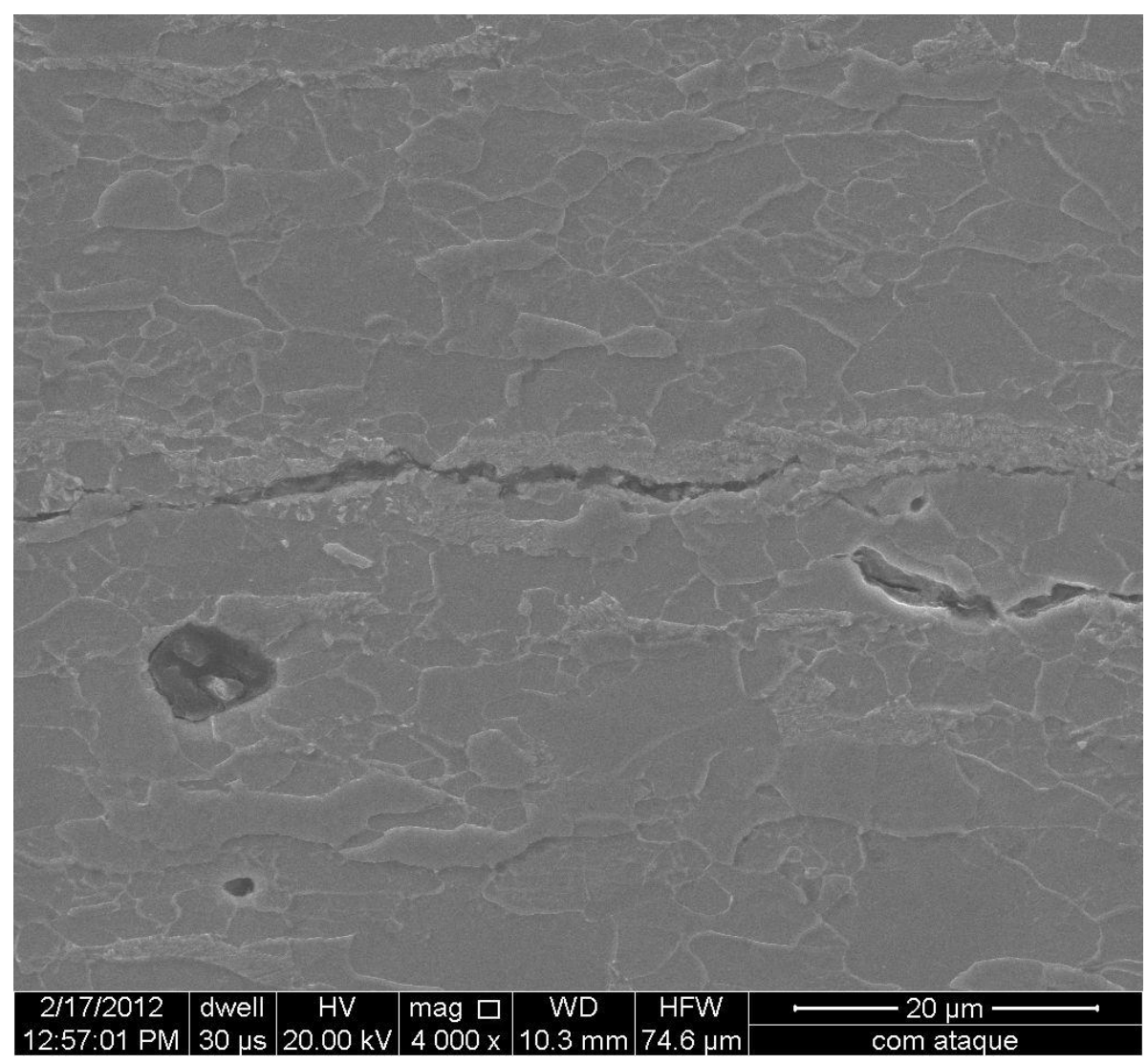

Figura 79 T-X65NS Imagem de elétrons secundários. Trinca na banda de segregação. Ataque nital $2 \%$. MEV. 


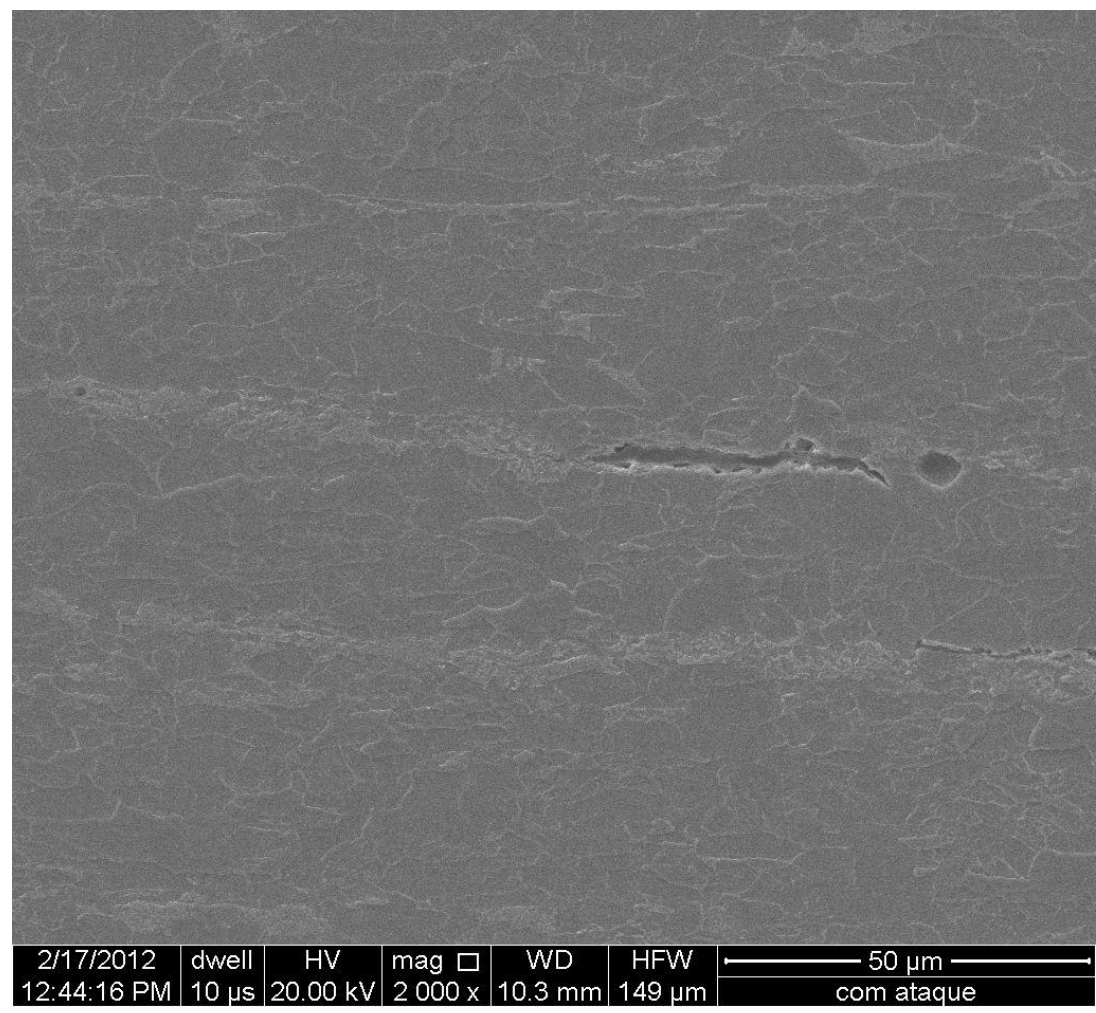

Figura 80 T-X65NS Imagem de elétrons secundários. Trinca na banda de segregação. Ataque nital $2 \%$. MEV.

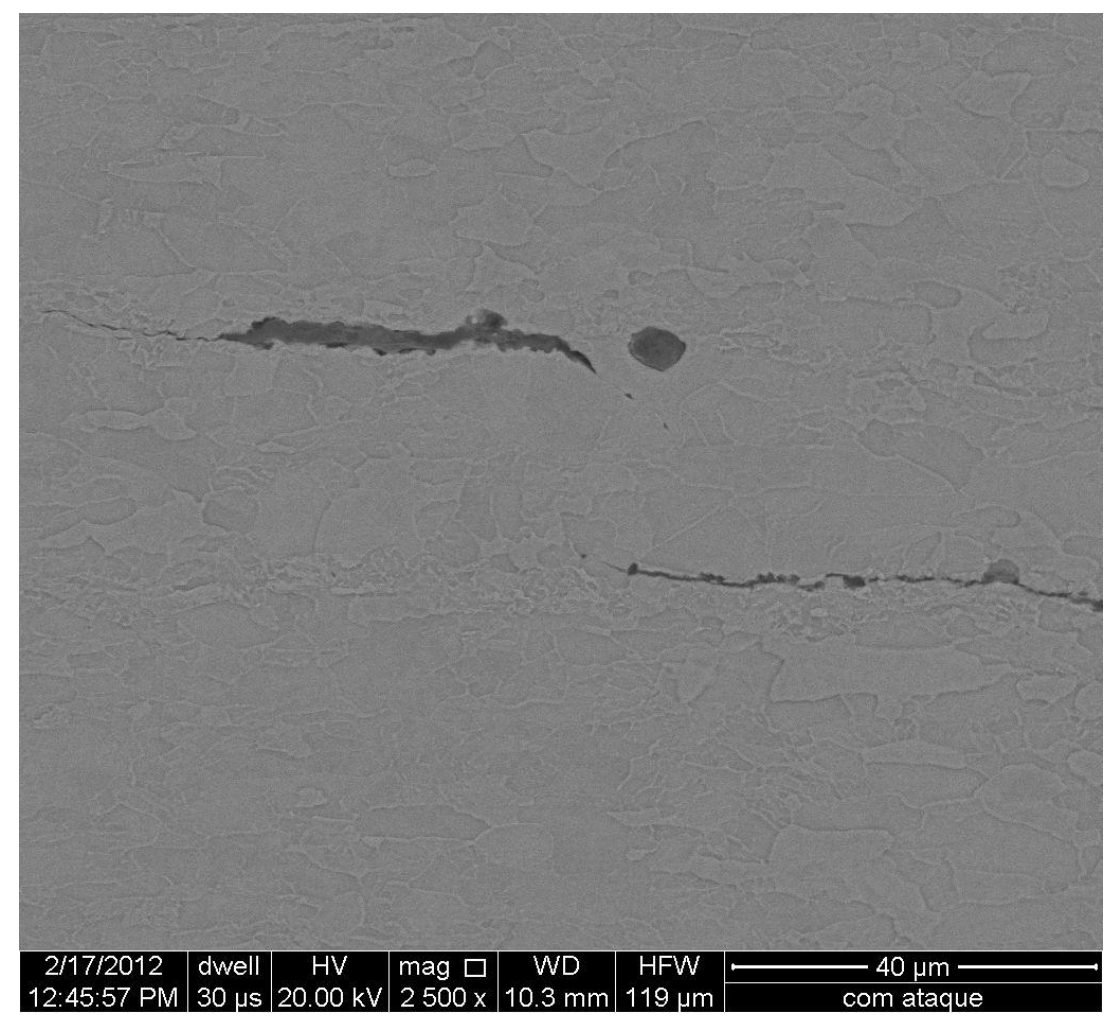

Figura 81 T-X65NS Imagem de elétrons retroespalhados. Trinca na banda de segregação. Ataque nital $2 \%$. MEV. 

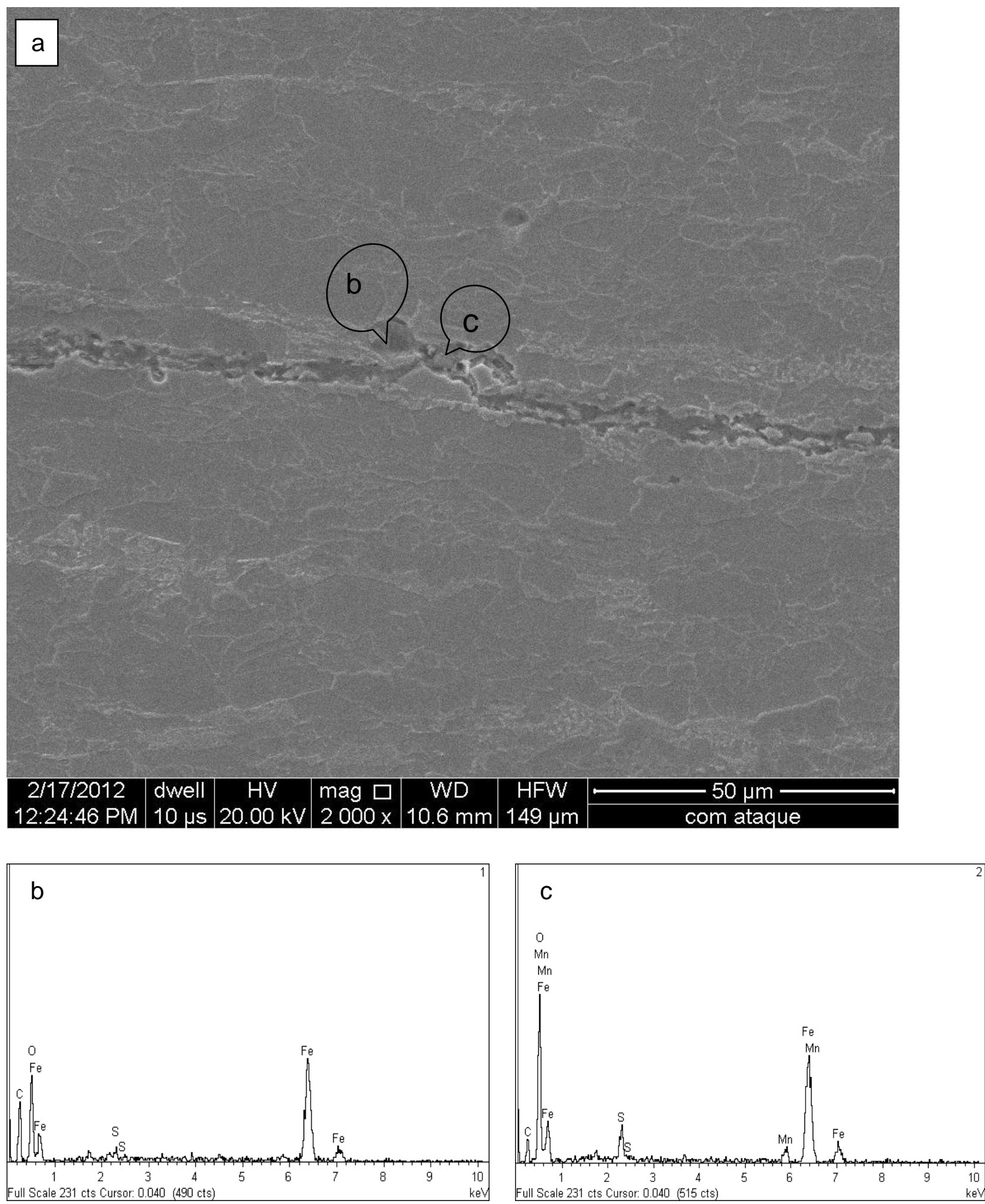

Figura 82 T-X65NS Imagem elétrons secundários. (a) Propagação da trinca na banda de segregação. (b) e (c) Análise por EDS de duas inclusões próximas da trinca: $\mathrm{Fe}, \mathrm{Mn}$ e S. 


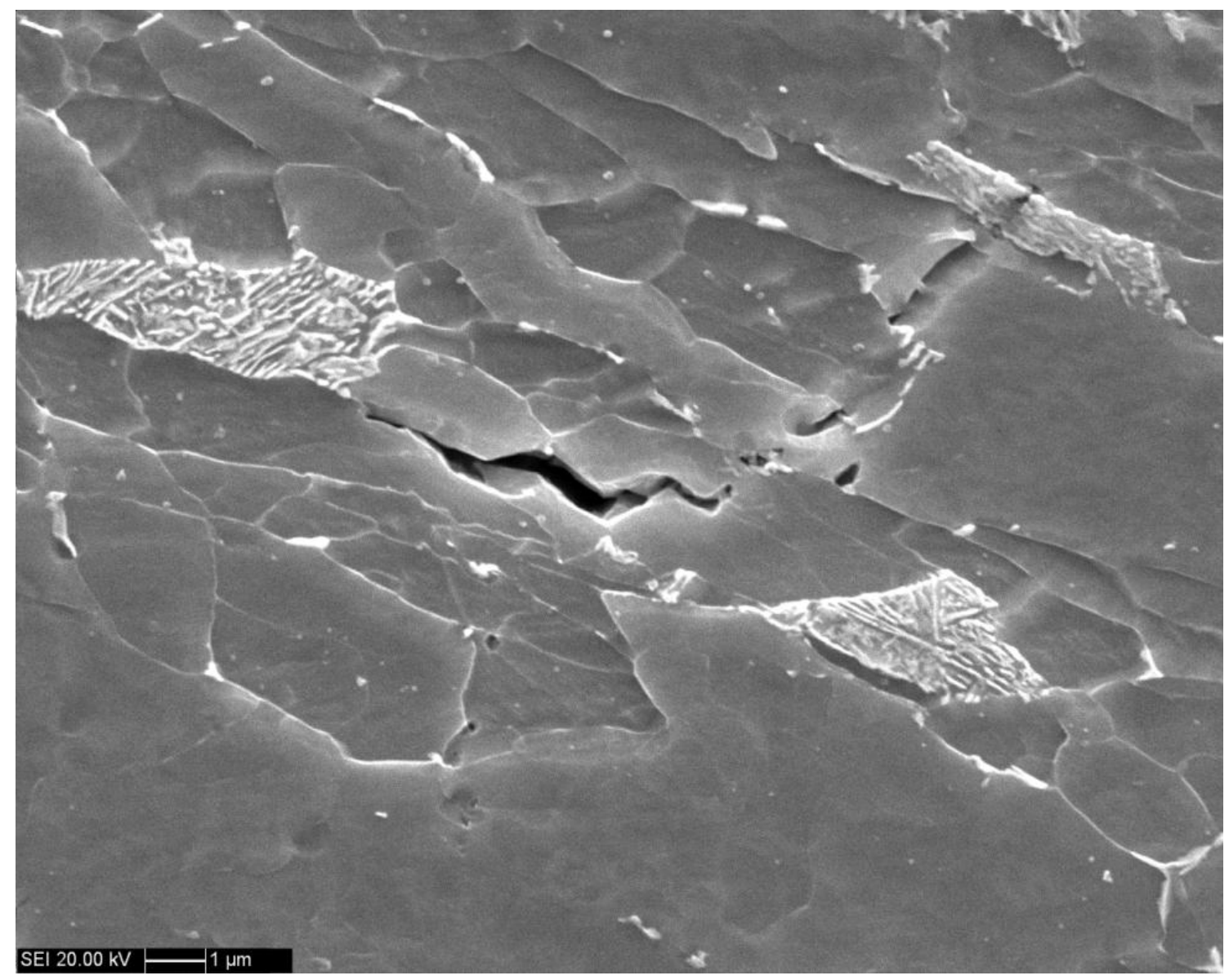

Figura $83 \mathrm{~T}$-X65NS com trinca nucleada na interface Ferrita/Cementita. Observam-se vários contornos de ferrita contendo cementita intergranular.

\subsubsection{SOLUÇÃO B}

Após o ensaio de HIC na solução B (água do mar sintética) foram cortadas amostras de cada corpo-de-prova e preparadas metalograficamente para realização da inspeção das superfícies. Nas amostras de tubo T-X65S não foram encontradas trincas, igualmente para as amostras da região soldada RS-X65S e da chapa C-X65. Para o tubo T-X65NS foram encontradas trincas na região central da espessura das amostras, mas o trincamento foi bem menos severo que o apresentado no ensaio na solução $A$, isso comprova que a solução A é mais agressiva (conforme mencionado por INTERNATIONAL IRON AND STEEL INSTITUTE, 1987). De fato, observaram-se trincas com comprimentos $100 \mu \mathrm{m}$ (Figura 84 a) e $70 \mu \mathrm{m}$ (Figura 84 b), enquanto na solução $A$ as trincas tinham de 2 a $5 \mathrm{~mm}$ de comprimento. 

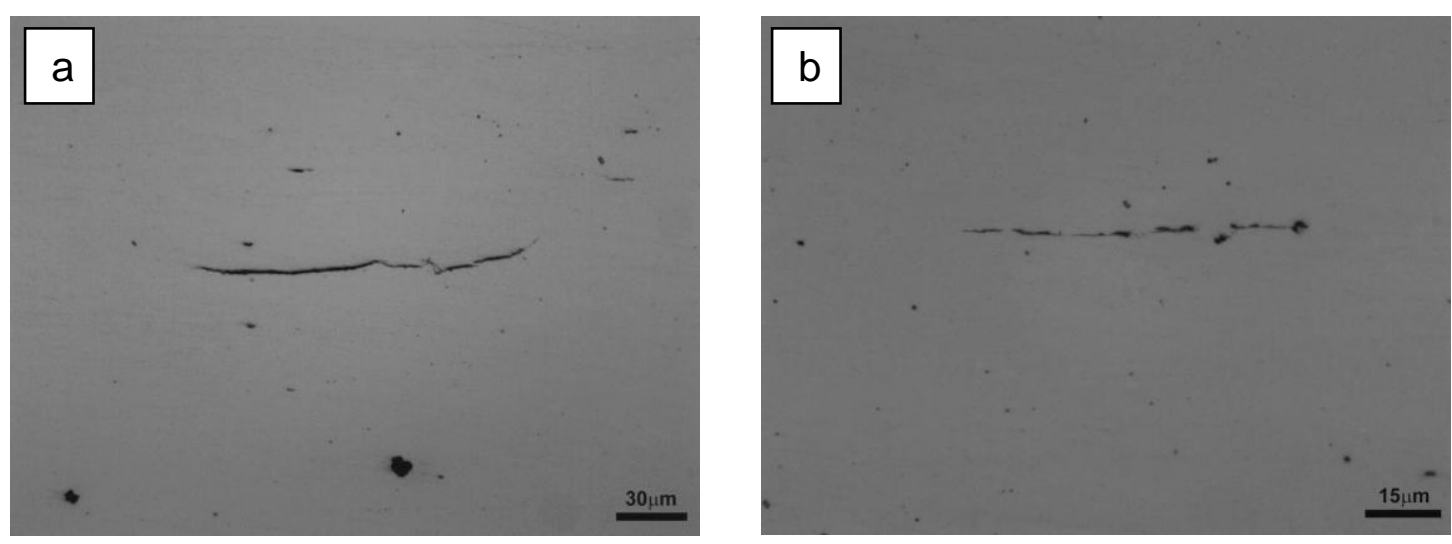

Figura 84 Aspecto da superfície do tubo T-X65NS após ensaio de HIC na solução B. Polimento $1 \mu \mathrm{m}$. Sem ataque. MO. (a) trincamento na região central da espessura, 500X. (b) trincamento na região central da espessura, 1000X.

As Figuras 84 a e b mostram que as trincas se formam alinhadas na região central das amostras, isto é, na direção de laminação. Na Figura 85 é apresentada uma trinca propagando-se pela região central da amostra, nas imagens do material sem ataque do mesmo modo que na solução $A$, não foram encontradas evidências que mostrem que o trincamento foi nucleado nas inclusões.

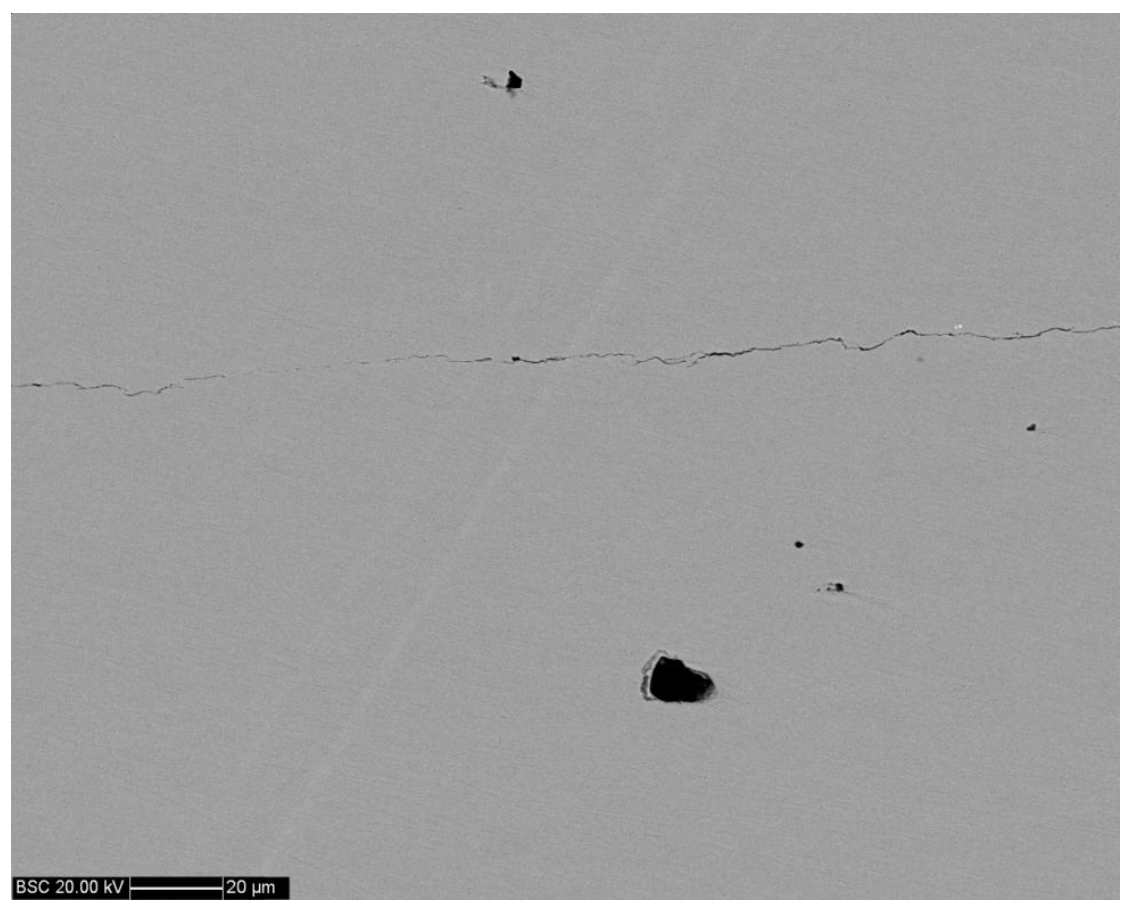

Figura 85 T-X65NS Imagem de elétrons restroespalhados, com Inclusões fora do caminho de propagação da trinca. Polimento $1 \mu \mathrm{m}$ sem ataque. MEV. 
As Figuras 86 a 88 mostram a propagação das trincas. Observa-se na Figura 86 que há preferência do hidrogênio pela interface dos filmes de cementita, pois encontra-se nessa figura um filme de cementita com a interface descolada da matriz em toda sua volta. Trata-se de trincamento, no entanto, esta trinca teve sua propagação interrompida, uma vez que o filme de cementita não tem continuidade.

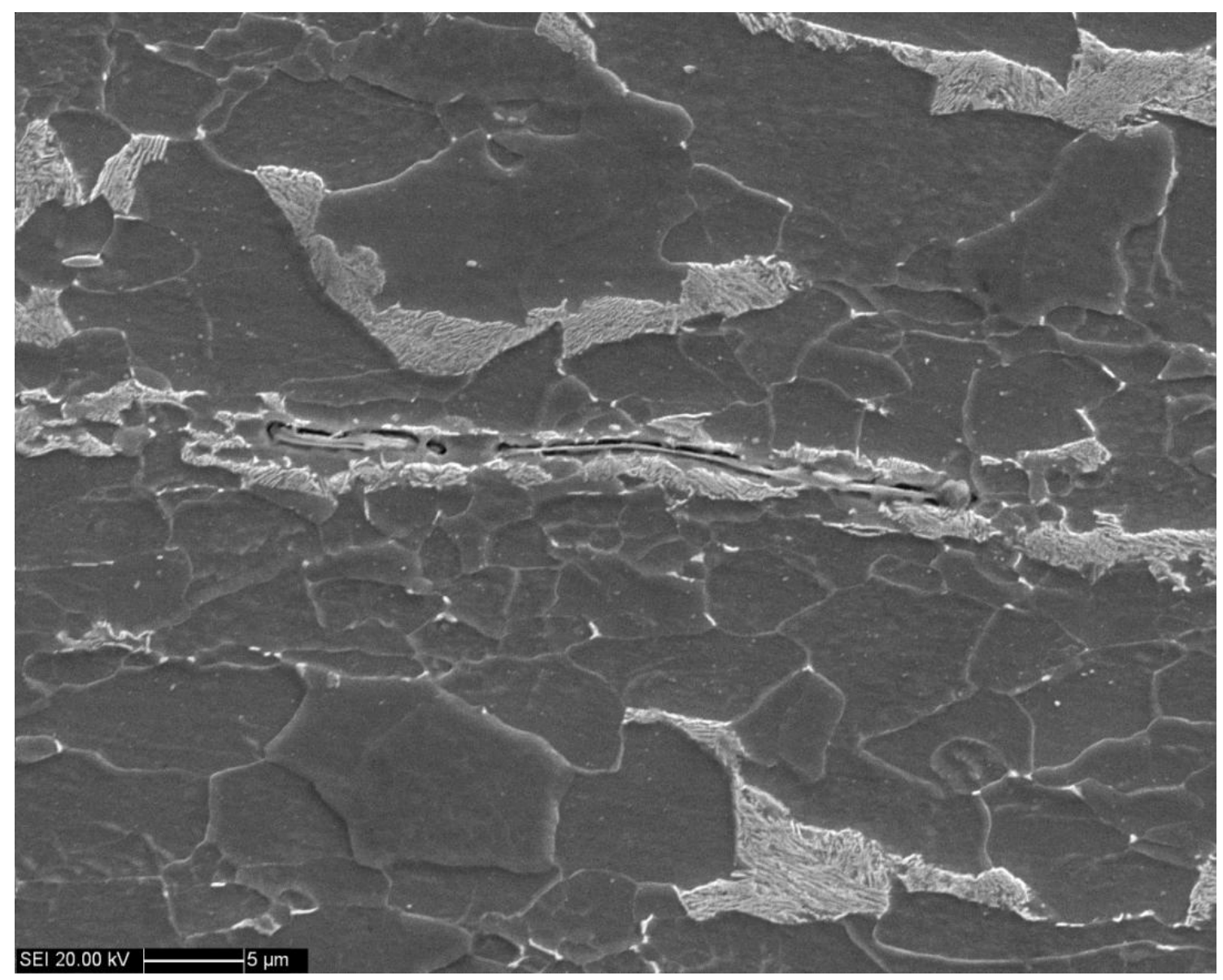

Figura 86 T-X65NS Imagem de elétrons secundários. Trinca nucleada na banda de segregação. Ataque nital 2\%. MEV.

Por sua vez, as Figuras 87 e 88 mostram o trincamento propagando em regiões de ferrita e perlita, mas, claramente seguindo o filme de cementita.

Outro ponto a se destacar é que a chapa C-X65 tem a mesma microestrutura do tubo T-X65NS, sendo que a chapa não apresentou trincamento. Foi comentado anteriormente, que a quantidade de filme de cementita na chapa 
C-X65 é menor do que a encontrada no tubo T-X65NS; concluí-se que a menor fração de filme de cementita na chapa é a explicação para seu bom desempenho.

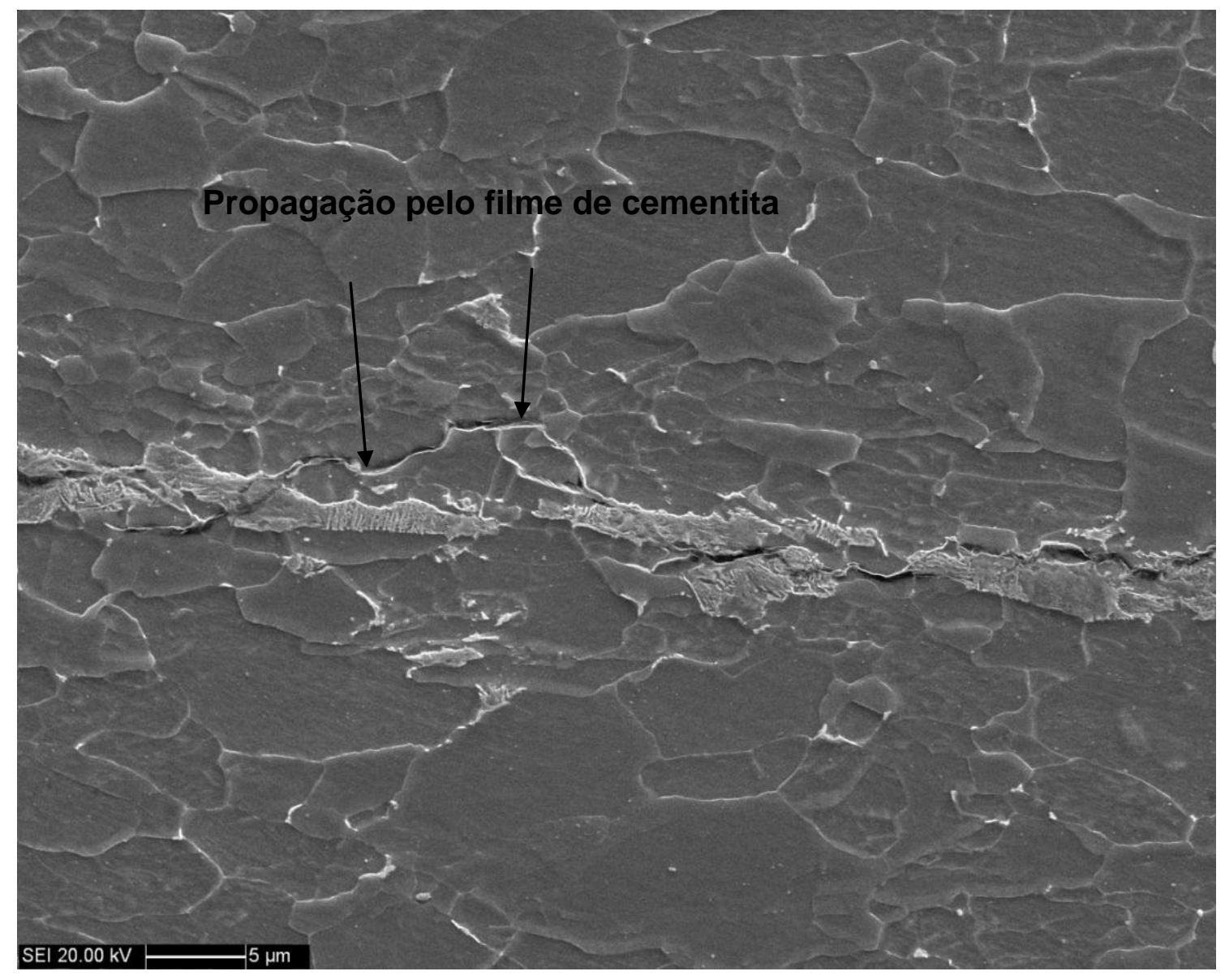

Figura 87 T-X65NS Imagem de elétrons secundários. Trinca nucleada na banda de segregação. Ataque nital 2\%. MEV. 


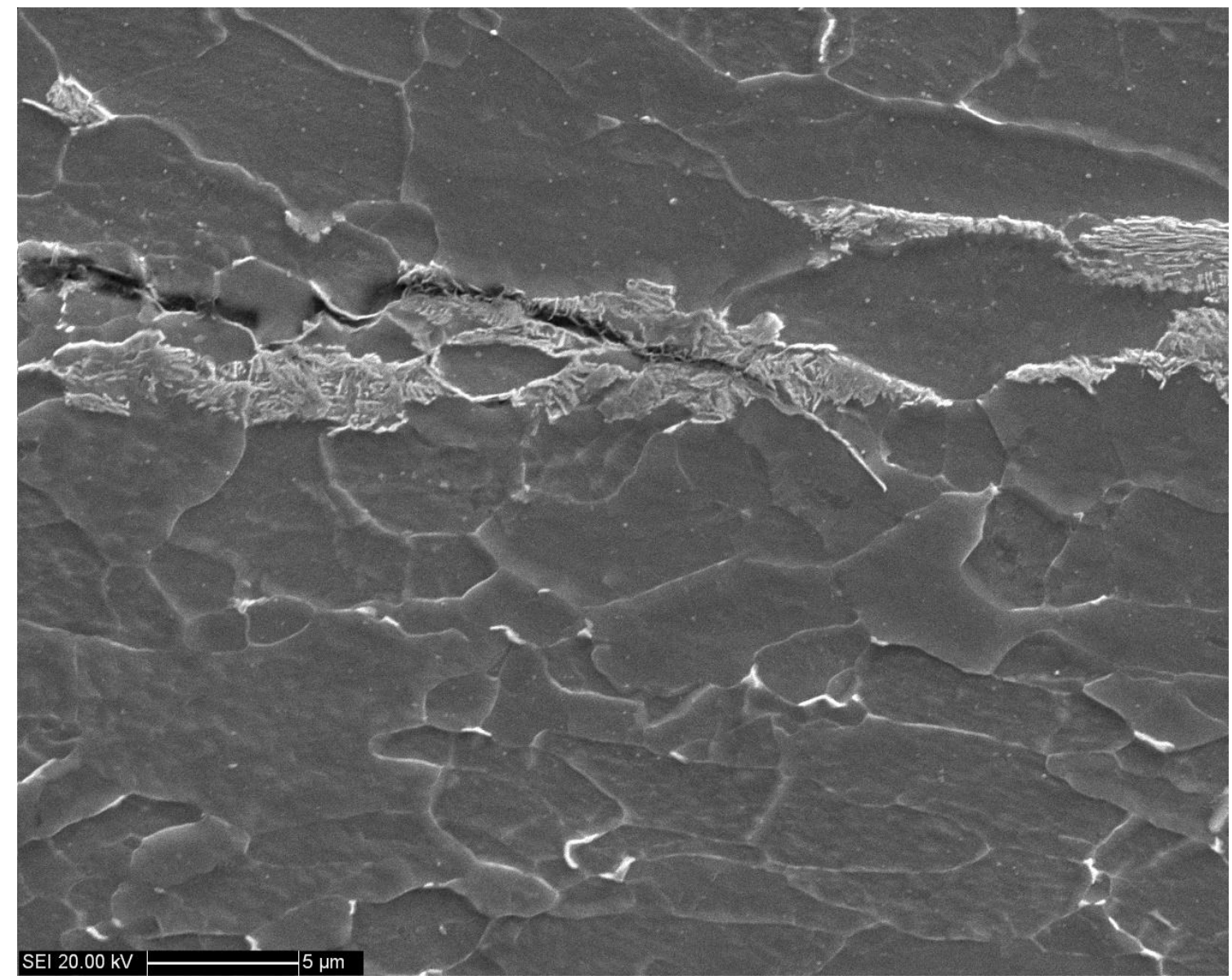

Figura 88 T-X65NS: trincamento propagando-se pela fase frágil. Ataque nital $2 \%$. MEV. 


\section{DISCUSSÃO}

\subsection{POLARIZAÇÃO LINEAR}

\section{Potenciais de Corrosão}

No trabalho de Biernat e Robins, 1972, são encontradas as equações dos equilíbrios do sistema $\mathrm{Fe}-\mathrm{H}_{2} \mathrm{O}-\mathrm{S}$ apresentados no diagrama de Pourbaix da Figura 24. Visando examinar as condições particulares da presente pesquisa, fez-se, a partir das equações de Biernat e Robins, 1972, a construção do diagrama de Pourbaix para 0 intervalo de potenciais de eletrodo entre -1 e $0 \mathrm{~V}, \mathrm{EH}$ e valores de $\mathrm{pH}$ entre 0 e 10. O resultado está apresentado na Figura 89, a qual inclui os valores de pH após a injeção de $\mathrm{H}_{2} \mathrm{~S}$ em cada solução segundo o recomendado pela norma NACE TM0284-2003, assim para a solução $\mathrm{A}$ pH: 3,3 e para a solução $\mathrm{B}$ pH: 5 .

Como já mencionado anteriormente, os $E_{\text {corr }}$ para a solução $A$ estão entre -680 e $-660 \mathrm{mV}$ ECS (-438 até $-418 \mathrm{mV} \mathrm{EH}$ ) e para os ensaios na solução $B$ tem-se os $E_{\text {corr }}$ na faixa de -750 e $-780 \mathrm{mV}$ ECS (-508 até -538 mV EH); estes valores estão indicados na Figura 89.

$O E_{c o r r}$ de um sistema eletrolítico é definido pelo cruzamento das curvas catódica e anódica, num diagrama $\mathrm{E}$ em função do | i |, colocando, portanto, seu valor no intervalo de potencial compreendido entre o potencial de equilíbrio da reação catódica e o potencial de equilíbrio da reação anódica.

Analisando-se primeiramente as reações do sistema desta pesquisa, tem-se como reação catódica a redução do hidrogênio e como anódica a oxidação do ferro. Nas condições experimentais, $0 E_{H_{+} / H 2}$ vale para a solução $A$,

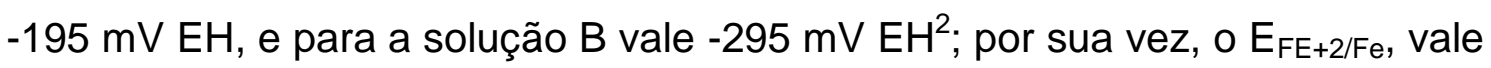
$-620 \mathrm{mV} \mathrm{EH}^{3}$. Observa-se que os $E_{\text {corr }}$ obtidos nas soluções $A$ e $B$ estão de

\footnotetext{
${ }^{2}$ Potenciais calculados através de $E_{H_{+} / \mathrm{H} 2}=-0,059 \mathrm{pH}$. Equilíbrio para a reação de hidrogênio a $25^{\circ} \mathrm{C}$.

${ }^{3}$ Potencial calculado através de $\mathrm{E}_{\mathrm{Fe}+2 / \mathrm{Fe}}=-0,44-0,0295 \log \left[\mathrm{Fe}^{+2}\right]$, com $\left[\mathrm{Fe}^{+2}\right]$ igual a $10^{-6} \mathrm{M}$.
} 
acordo com o esperado, podendo-se, em princípio, concluir que o processo corrosivo é determinado pela reação de hidrogênio.

No entanto, a presença de $\mathrm{H}_{2} \mathrm{~S}$ nos sistemas estudados dá origem a outras reações eletroquímicas. De fato, consultando o trabalho de Biernat e Robins, 1972, encontram-se equações para o equilíbrio de reações que podem ajudar a explicar os mecanismos de corrosão aqui encontrados. Estas reações estão representadas graficamente na Figura 89 e suas equações de equilíbrio são as seguintes:

(1) Reação $\mathrm{H}^{+} / \mathrm{H}_{2}: \quad 2 \mathrm{H}^{+}+2 \mathrm{e}=\mathrm{H}_{2}$

$$
E_{H+/ H 2}=-0,059 p H
$$

(2) Reação $\mathrm{Fe}^{+2} / \mathrm{Fe}: \quad \mathrm{Fe}^{+2}+2 \mathrm{e}=\mathrm{Fe}$

$$
E_{\mathrm{Fe}+2 / \mathrm{Fe}}=-0,44-0,0295 \cdot \log \left(\mathrm{Fe}^{+2}\right)
$$

(3) Reação FeS/Fe: $\quad \mathrm{FeS}+2 \mathrm{H}^{+}+2 \mathrm{e}-=\mathrm{Fe}+\mathrm{H}_{2} \mathrm{~S}$

$$
E_{F e S / F e}=-0,376-0,059 p H-0,0296 \cdot \log \left(H_{2} S a q\right)
$$

(4) Reação $\mathrm{FeS}_{2} / \mathrm{FeS}: \mathrm{FeS}_{2}+2 \mathrm{H}^{+}+2 \mathrm{e}-=\mathrm{FeS}+\mathrm{H}_{2} \mathrm{~S}$

$$
E_{\mathrm{FeS} 2 / \mathrm{FeS}}=-0,165-0,059 \mathrm{pH}-0,0296 \cdot \log \left(\mathrm{H}_{2} \mathrm{Saq}\right)
$$




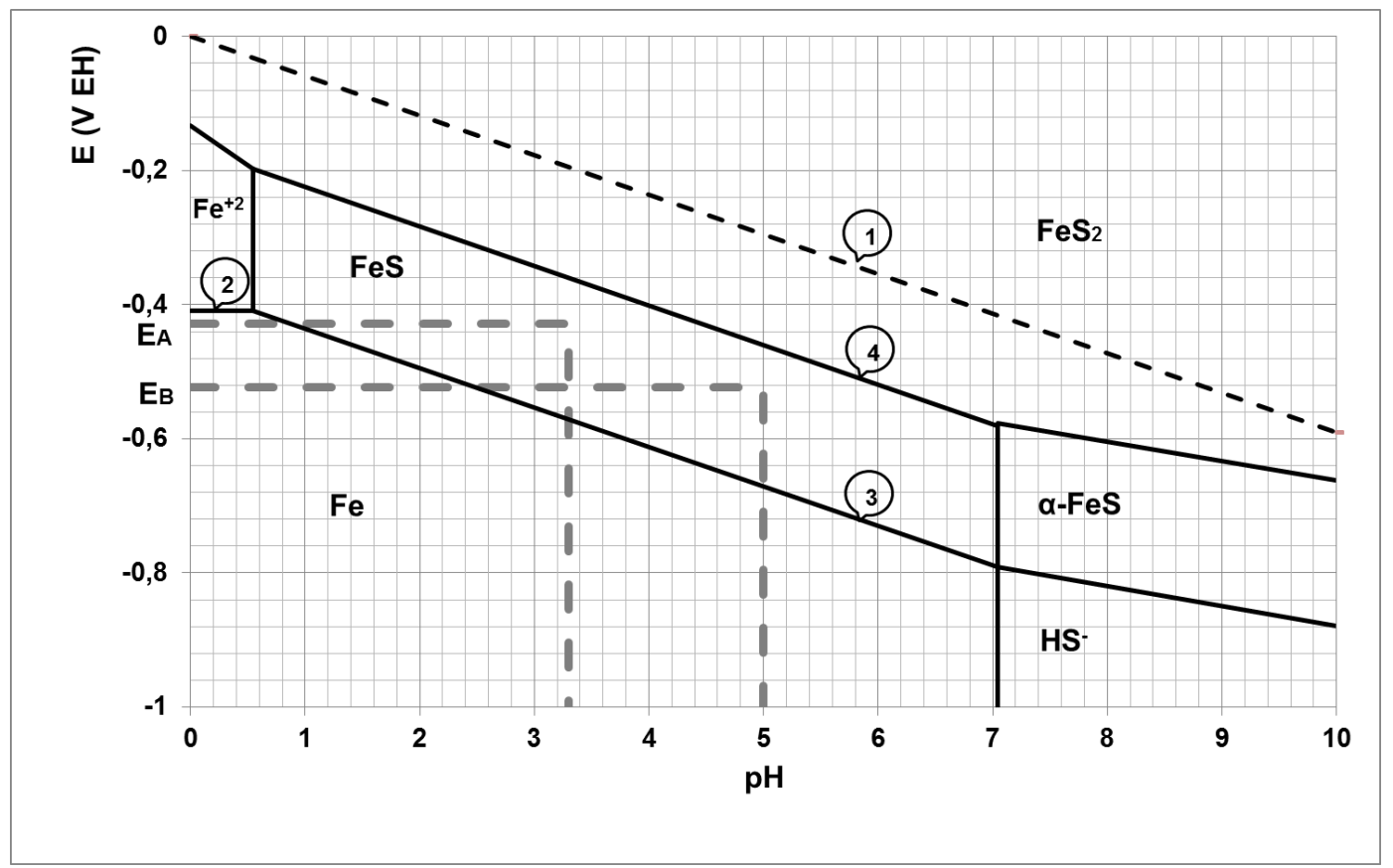

Figura 89 Detalhe do diagrama de Pourbaix para o sistema Fe- $\mathrm{H}_{2} \mathrm{O}-\mathrm{S}$, da Figura 24, com as indicações dos valores de $E_{\text {corr }}$ para as soluções $A$ e $B$.

A partir das reações (3) $\mathrm{FeS} / \mathrm{Fe}$ e (4) $\mathrm{FeS}_{2} / \mathrm{FeS}$ é possível calcular os respectivos potenciais de equilíbrio de cada reação (a atividade de $\mathrm{H}_{2} \mathrm{~S}_{\mathrm{aq}}$ foi considerada unitária, como feito no trabalho de Biernat e Robins, 1972). Com esse procedimento, obtém-se para a solução $A$, um $E_{\mathrm{FeS} / \mathrm{Fe}}$ de $-570 \mathrm{mV}$ EH e para a solução $B, E_{\mathrm{FeS} / \mathrm{Fe}}$ de $-670 \mathrm{mV} \mathrm{EH}$; para a reação $\mathrm{FeS}_{2} / \mathrm{FeS}$, os valores de potenciais de equilíbrio são: para a solução $A$, o $E_{\mathrm{FeS} 2 / \mathrm{FeS}}$ de $-360 \mathrm{mV} \mathrm{EH}$, e para a solução $\mathrm{B}, \mathrm{E}_{\mathrm{FeS} 2 / \mathrm{FeS}}$ de $-460 \mathrm{mV} \mathrm{EH}$.

Com os valores de potenciais de equilíbrio das reações de $\mathrm{H}^{+} / \mathrm{H}_{2}$, reação $\mathrm{FeS} / \mathrm{Fe}$, reação $\mathrm{FeS}_{2} / \mathrm{FeS}$ e reação $\mathrm{Fe}^{+2} / \mathrm{Fe}$, pode-se construir o eixo de potenciais e verificar que os valores de $E_{c o r r}$, obtidos para as soluções $A$ e $B$, estão numa faixa mais estreita do que aquela entre $\circ \mathrm{E}_{\mathrm{H}+/ \mathrm{H} 2}$ e $\circ \mathrm{E}_{\mathrm{Fe}+2 / \mathrm{Fe}}$, anteriormente mencionada. Isto fica claro, observando-se a Figura 90 que representa todos estes potenciais. 


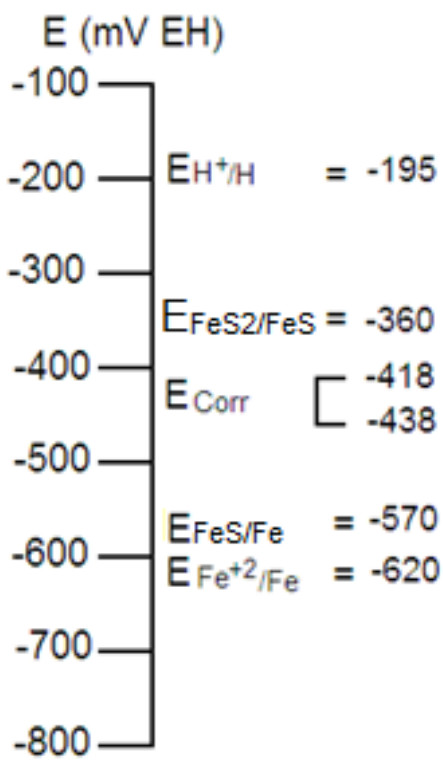

Solução A

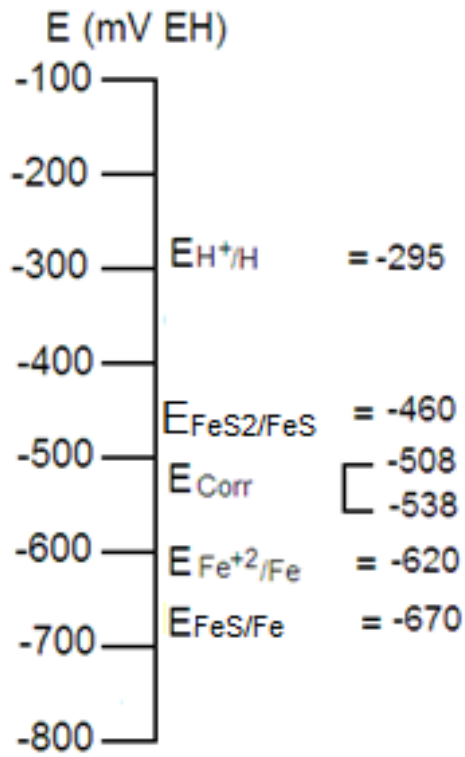

Solução B

Figura 90 Potenciais de eletrodo de equilíbrio para os sistemas da presente pesquisa e potenciais de corrosão obtidos experimentalmente.

É interessante notar que os potenciais de equilíbrio das reações que originam as reações parciais anódicas (reação $\mathrm{FeS} / \mathrm{Fe}$ e reação do $\mathrm{Fe}^{+2} / \mathrm{Fe}$ ) apresentam, em função da solução, uma inversão de posição de seus respectivos potenciais de equilíbrio, isto é, na solução $A$, a reação do $\mathrm{Fe}^{+2} / \mathrm{Fe}$ é menos nobre do que a reação $\mathrm{FeS} / \mathrm{Fe}$; e, na solução $\mathrm{B}$, a reação $\mathrm{FeS} / \mathrm{Fe}$ é menos nobre do que a reação do $\mathrm{Fe}^{+2} / \mathrm{Fe}$. Mais adiante, estão discutidas as consequências cinéticas dessa inversão.

Desta análise, conclui-se que os valores de $E_{\text {corr }}$ são determinados, para as duas soluções $A$ e $B$, pelas reações catódica do hidrogênio, catódica da reação $\mathrm{FeS}_{2} / \mathrm{FeS}$ e anódica $\mathrm{FeS} / \mathrm{Fe}$ e anódica do $\mathrm{Fe}^{+2} / \mathrm{Fe}$.

Além disso, as reações eletroquímicas $\mathrm{FeS} / \mathrm{Fe}$ e $\mathrm{FeS}_{2} / \mathrm{FeS}$ mostram que os procedimentos da norma NACE TM0284-2003, tanto para a solução A quanto para a solução $B$, impõem ao sistema uma região de formação de sulfeto de ferro ( $\mathrm{FeS}$ ) e próton-hidrogênio (Figura 89), que se transforma em hidrogênio atômico, levando a sua dissolução no $\mathrm{Fe}$ e consequentes processos de fragilização. 
Velocidade de Corrosão - Resistência de Polarização

Comparação da agressividade das soluções $A$ e B

A Figura 91 apresenta um gráfico comparativo dos valores médios de Rp nas soluções A e B para as amostras estudadas.

As Figuras 53 e 54 apresentam, respectivamente, os valores de Rp para cada ensaio e a média em cada tempo de imersão para a solução $A$. Uma vez que os valores de Rp foram praticamente constantes com o tempo de imersão, fezse para a presente análise o cálculo do valor médio da $\mathrm{Rp}$, para cada material imerso na solução $A$, utilizando-se todos os valores obtidos nos três ensaios, em todos os tempos. O mesmo procedimento foi adotado para a solução $B$, onde os resultados de cada ensaio estão apresentados na Figura 56 e a média em cada tempo de imersão, na Figura 57.

Observa-se na Figura 91, primeiramente, que a solução A é mais corrosiva do que a solução $B$, uma vez que todas as amostras apresentaram menor Rp para a solução A. Este resultado pode ser analisado através da estimativa das curvas de polarização das reações de eletrodo presentes em cada sistema. Sendo assim, a partir dos potenciais de eletrodo de equilíbrio, discutidos anteriormente, foram construídos gráficos esquemáticos das curvas de polarização das reações de eletrodo presentes em cada sistema (ferro imerso em solução $A$ e solução $B$ ). 


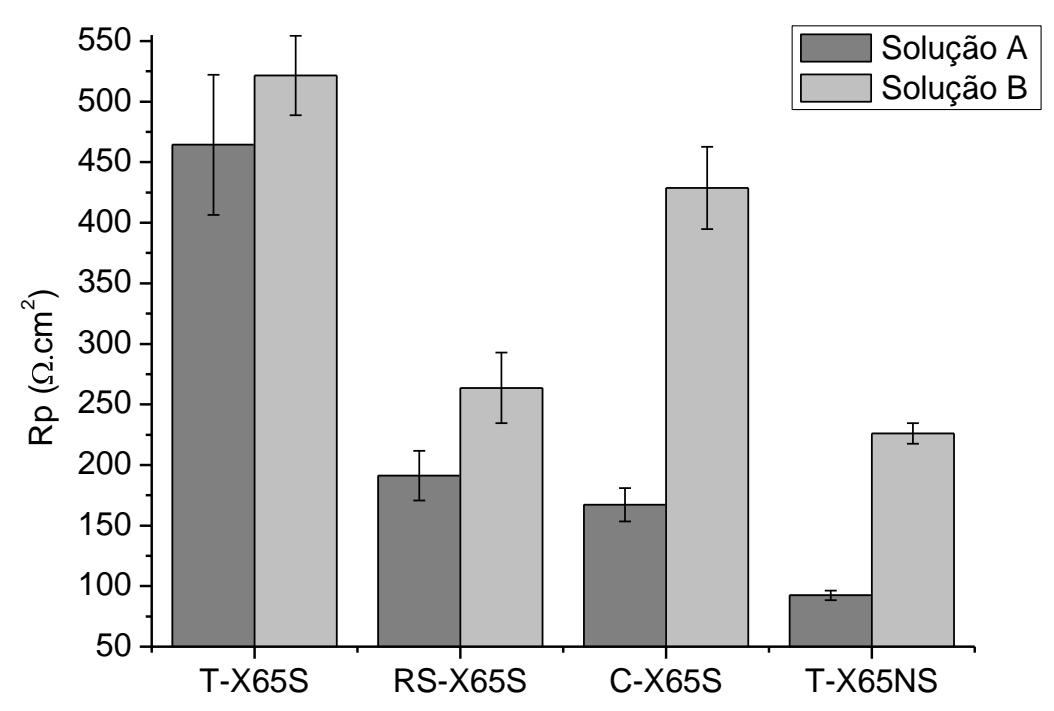

Figura 91 Comparação dos valores médios de Rp para as duas soluções e diferentes amostras.

As Figuras 92 e 93 apresentam as curvas de polarização para a solução A. Na Figura 92 tem-se as reações parciais (catódica e anódica) dos eletrodos de hidrogênio, reação $\mathrm{FeS}_{2} / \mathrm{FeS}$, reação $\mathrm{FeS} / \mathrm{Fe}$ e eletrodo de $\mathrm{Fe}^{+2} / \mathrm{Fe}$.

Os declives de Tafel utilizados estão no intervalo de (60 até $120 \mathrm{mV}$ ) (DRAŽıC; VAŠČIĆ, 1985), para a reação catódica do hidrogênio, foi usado um declive de Tafel catódico de $100 \mathrm{mV}$ e uma densidade de corrente de troca (ROBERGE, 2000) de $10^{-6} \mathrm{~A} . \mathrm{cm}^{-2}$; para a reação do ferro foi usado declive de Tafel anódico de $60 \mathrm{mV}$ e densidade de corrente de troca (REVIE; UHLIG, 2008) de $10^{-7} \mathrm{~A} . \mathrm{cm}^{-2}$, para as demais reações os declives de Tafel anódico e catódico foram de $80 \mathrm{mV}$, e densidades de corrente de troca de $5 \times 10^{-7} \mathrm{~A}_{\mathrm{cm}}{ }^{-2}$. Cabe destacar que os valores de densidade de corrente são uma estimativa, a partir de todas as considerações anteriores.

Nesse conjunto de curvas de polarização (Figura 92), as parciais que de fato determinam a cinética do eletrodo misto são: catódicas do hidrogênio e catódica da reação $\mathrm{FeS}_{2} / \mathrm{FeS}$; e, anódicas da reação $\mathrm{FeS} / \mathrm{Fe}$ e do ferro. Desse modo, o potencial de corrosão é determinado pelo cruzamento da reação catódica resultante (soma das curvas de hidrogênio com reação $\mathrm{FeS}_{2} / \mathrm{FeS}$ ) e 
reação anódica resultante (soma das curvas $\mathrm{FeS} / \mathrm{Fe}$ e $\mathrm{Fe}^{+2} / \mathrm{Fe}$ ). Tais resultantes e cruzamento estão apresentados na Figura 93. Novamente, observa-se que o potencial de corrosão experimental encontra-se no intervalo esperado.

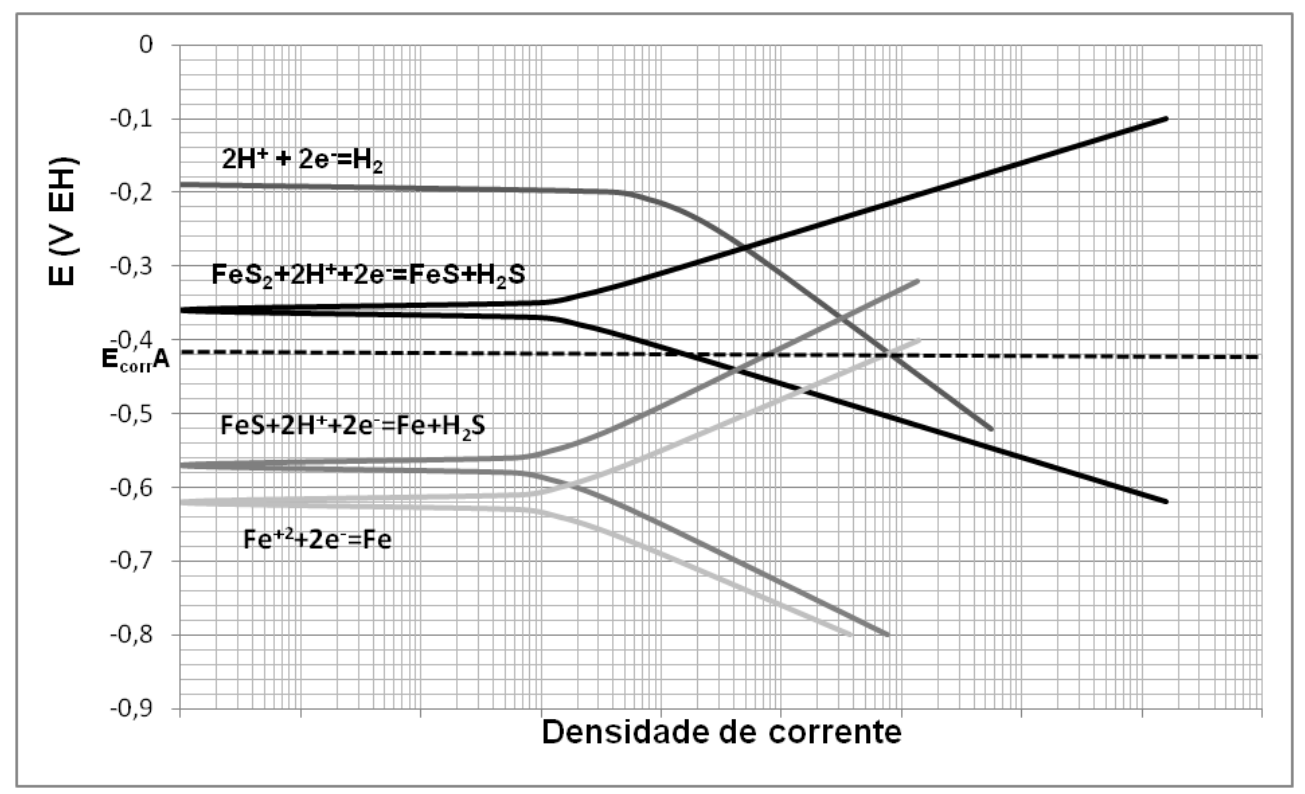

Figura 92 Curvas de polarização para as reações do sistema ferro em solução A. Indica-se o $\mathrm{E}_{\text {corr }}$ médio das amostras nessa solução.

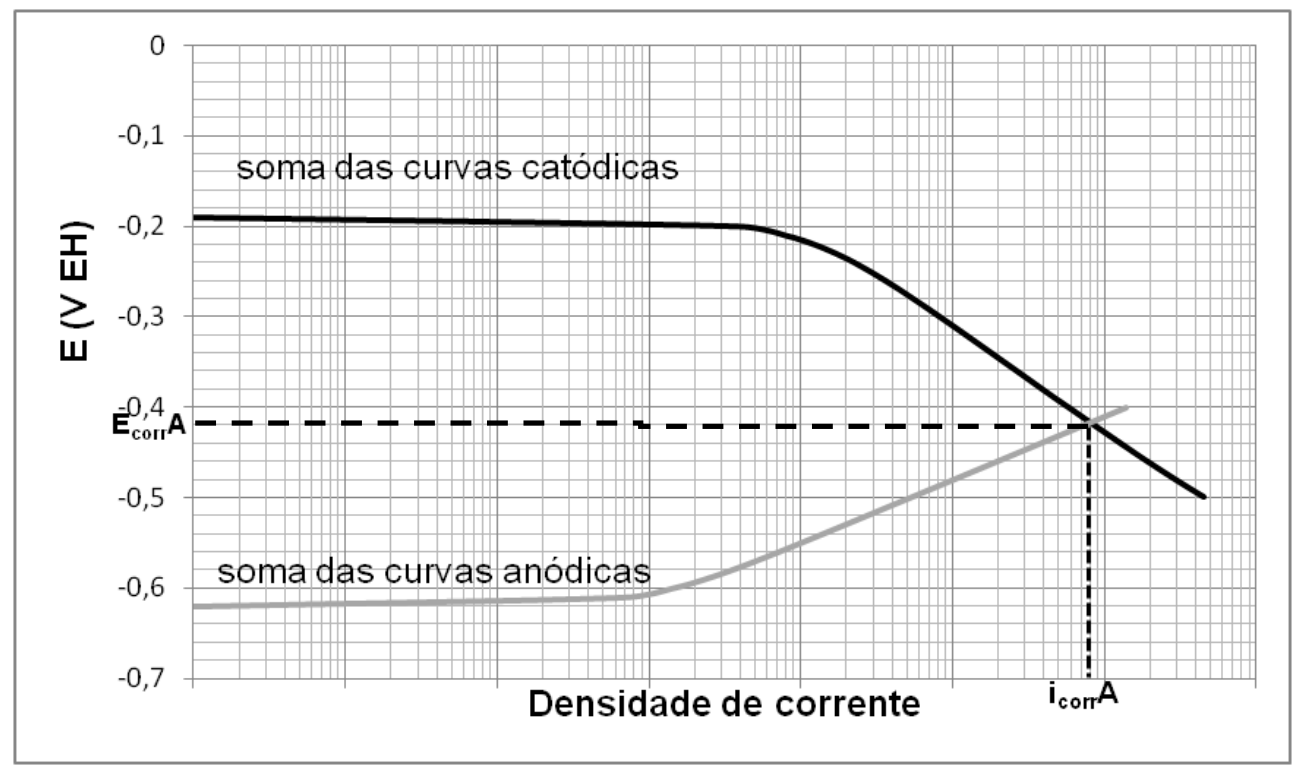

Figura 93 Curvas catódica e anódica resultantes para o sistema ferro em solução A. Indica-se o $\mathrm{E}_{\text {corr }}$ médio das amostras nessa solução. 
O mesmo procedimento foi aplicado para a solução $B$, obtendo-se o esquema apresentado na Figura 94. Primeiramente, observa-se que todos os potenciais de equilíbrio são menores daqueles obtidos na solução $A$. No caso específico da reação de hidrogênio, tem-se que, devido ao maior $\mathrm{pH}$ da solução $B$ (comparativamente à solução $A$ ), além da diminuição do potencial de equilíbrio do hidrogênio, tem-se também a diminuição da densidade de corrente de troca (WOLYNEC, 2003 - p.49-51); desse modo, a curva catódica do hidrogênio foi deslocada para menores potenciais e menores densidades de corrente. Outro aspecto a ser observado, é que a curva do ferro não se altera e, com os deslocamentos das demais reações, a curva anódica do ferro tornou-se mais nobre do que a parcial anódica da reação FeS/Fe.

Ainda como no caso da análise da solução $A$, também aqui foi construído o gráfico para as resultantes catódica e anódica (Figura 95). Novamente, observa-se que o potencial de corrosão experimental encontra-se no intervalo previsto.

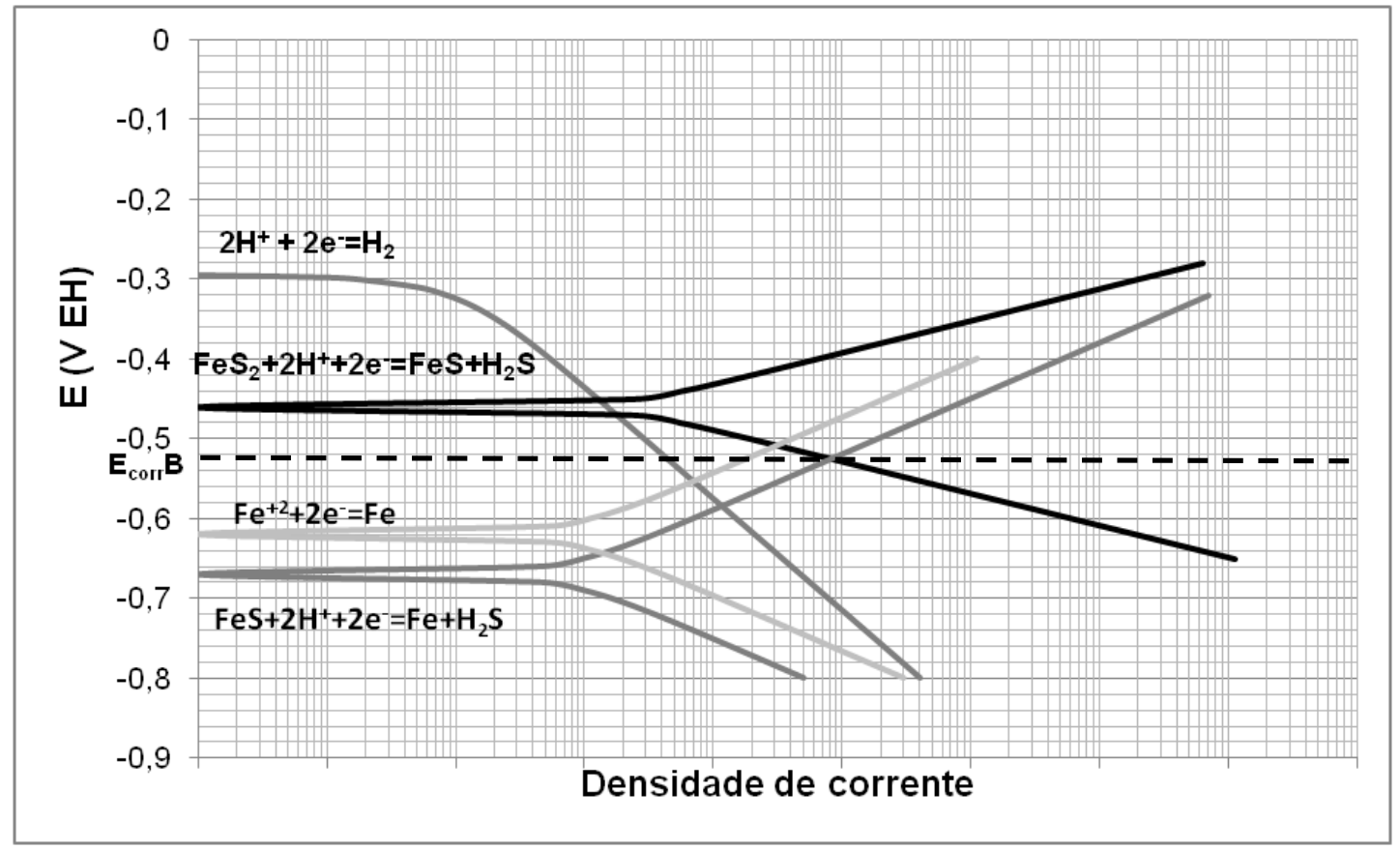

Figura 94 Curvas de polarização para as reações do sistema ferro em solução B. Indica-se o $\mathrm{E}_{\text {corr }}$ médio das amostras nessa solução. 


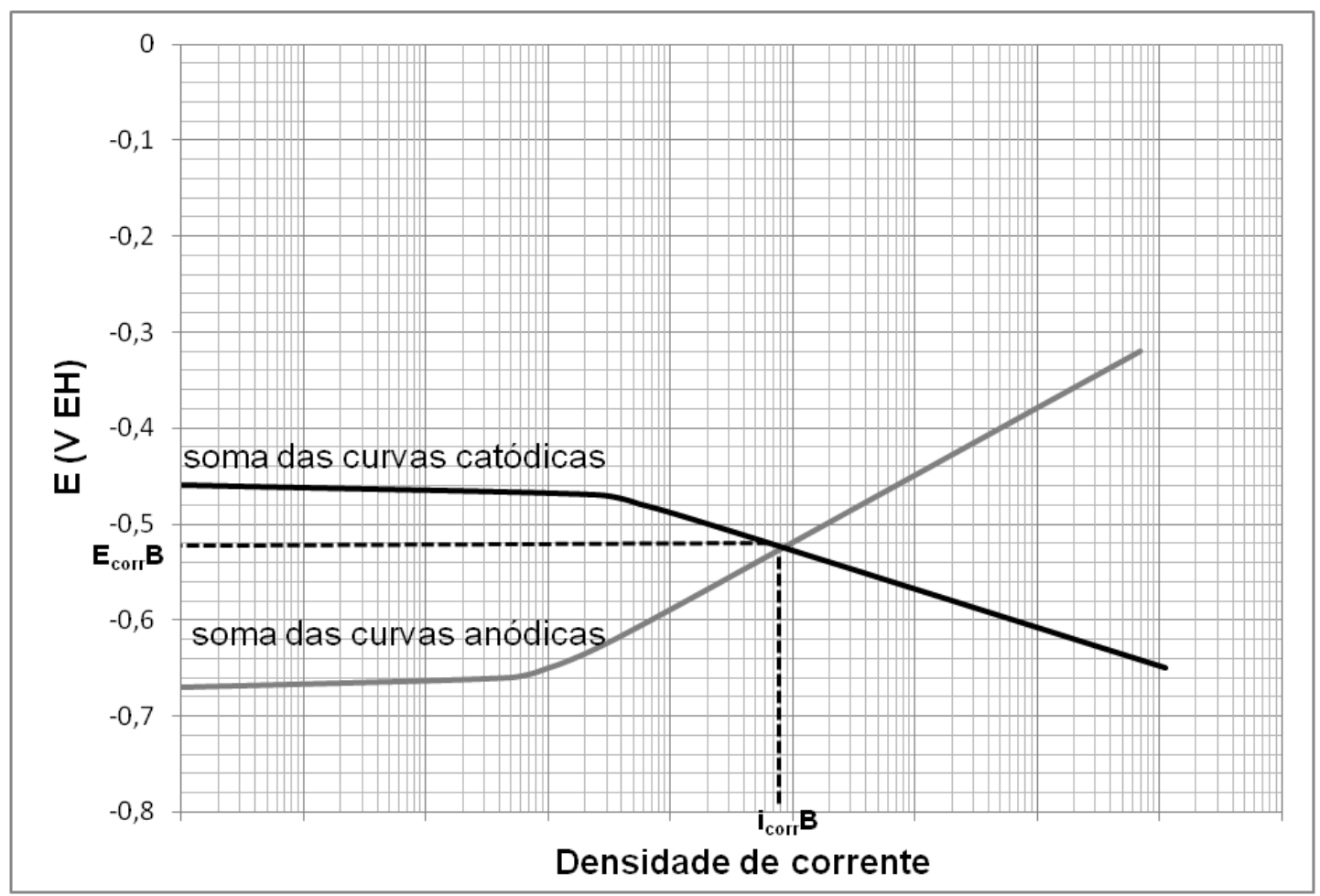

Figura 95 Curvas catódica e anódica resultantes para o sistema ferro em solução B. Indica-se o $E_{\text {corr }}$ médio das amostras nessa solução.

Por outro lado, o objetivo da construção das Figuras 92 a 95 foi o de discutir os mecanismos de corrosão para as amostras de aço quando imersas nas soluções A e B. Conforme apresentado anteriormente (Figura 91), experimentalmente foi encontrado que a solução $A$ é mais corrosiva do que a solução B. Este resultado fica esclarecido, quando se examinam as curvas das Figuras 92 a 95, ou, as curvas da Figura 96, onde estão apresentadas, para efeito de comparação, as curvas resultantes catódicas e anódicas para as duas soluções. Observa-se que a solução $A$ apresenta maiores $E_{\text {corr }}$ e $i_{\text {corr }}$ do que a solução $B$, concordando com os resultados experimentais.

Por sua vez, comparando-se as Figuras 92 e 94 é possível compreender porque a solução A é mais agressiva. A resposta está na posição da reação de hidrogênio. $\mathrm{O}$ diferente valor de $\mathrm{pH}$ entre as soluções justifica as diferentes resistências à corrosão obtidas. 


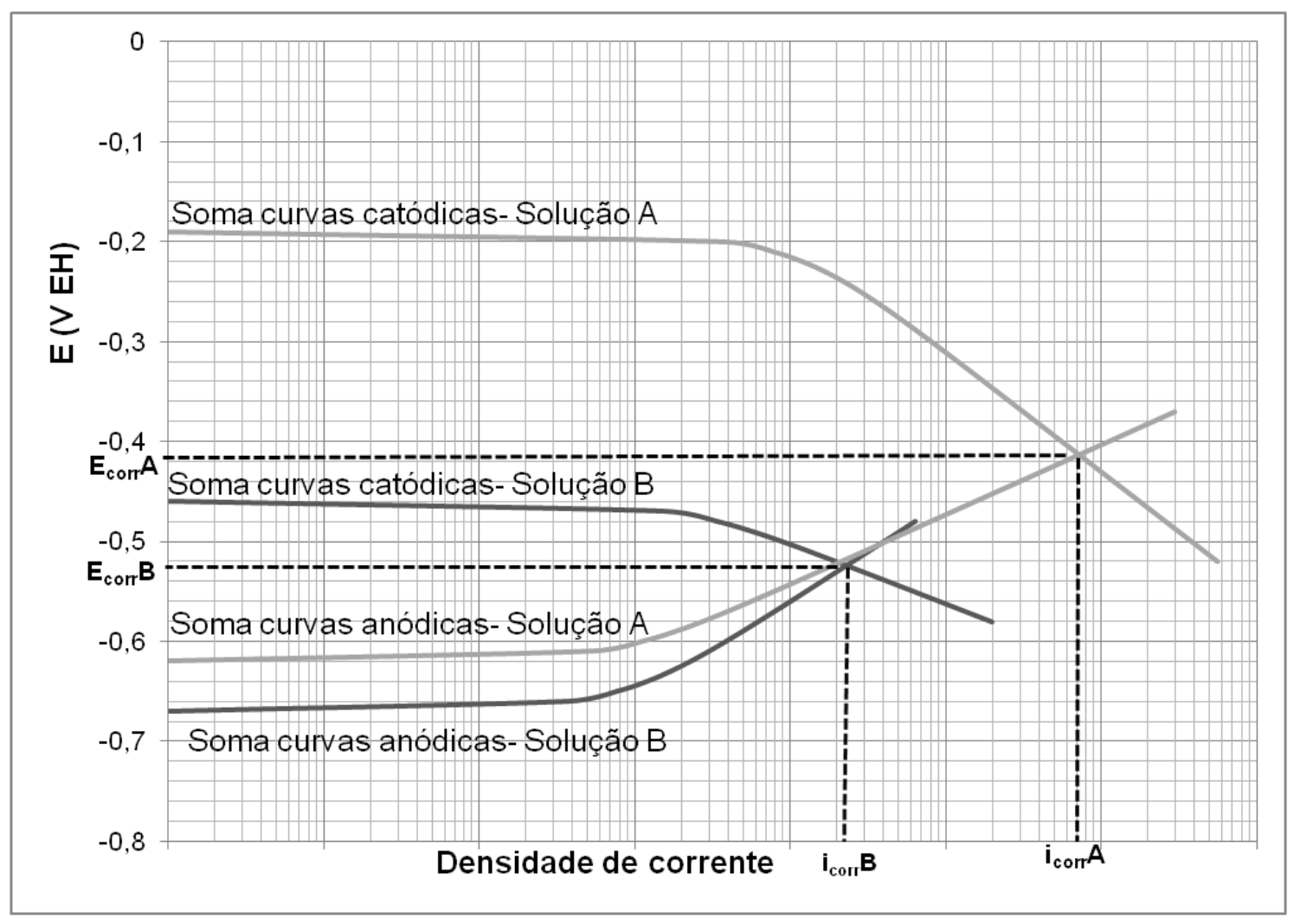

Figura 96 Comparação entre as soluções A e B. Curvas de polarização resultantes em cada caso, indicando o $\mathrm{E}_{\text {corr }}$ e a $\mathrm{i}_{\text {corr }}$.

No capítulo 5. Resultados, foi descrito que há formação de produtos de corrosão ricos em enxofre, nas duas soluções, que diferem na quantidade e espessura, isto é, a solução A apresenta uma película (fina) de produto castanho e a solução B origina uma camada (espessa) de produto preto. De fato, Veloz; González (2002), e Ma et al. (2000), relatam em seus trabalhos a formação de produtos de corrosão em aço SAE 1018 quando imerso em solução $A$ e $\mathrm{Fe}$ puro imerso em solução de $\mathrm{Na}_{2} \mathrm{SO}_{4}, \mathrm{H}_{2} \mathrm{SO}_{4}$ e $\mathrm{H}_{2} \mathrm{~S}$, respectivamente. Veloz; González (2002), que trabalharam com a solução A, relatam uma pequena quantidade de produto de corrosão formado, semelhantemente ao encontrado no presente trabalho.

Ainda no trabalho de Ma et al. (2000), os autores encontraram que os produtos de corrosão formados eram constituídos principalmente por FeS, além de estruturas metaestáveis como o $\mathrm{FeS}_{2}$, e outras. 
Segundo Garcia et al. (2001), os produtos de corrosão na presença de $\mathrm{H}_{2} \mathrm{~S}$ diminuem a taxa de corrosão dos aços.

Por sua vez, Vedage et al. (1993), trabalhou com o aço 4130 imerso em solução de $\left(3 \% \mathrm{NaCl}+\mathrm{H}_{2} \mathrm{~S}\right)$ encontrando que com a diminuição do $\mathrm{pH}$ a taxa de corrosão é aumentada. Vedage et al. (1993), explicaram esse comportamento através da mudança de atividade do íon sulfeto próximo à superfície do metal.

Conforme já mencionado, no presente trabalho, a solução A foi mais agressiva do que a solução $B$ e esse comportamento pode ser explicado pelas curvas de polarização das Figuras 92 a 96 . Além disso, os exames das superfícies corroídas indicaram uma maior quantidade de produto de corrosão no caso da solução B.

Em princípio, pode-se dizer que o produto de corrosão formado, na solução $B$, pode ter um efeito protetor contra a corrosão, conforme sugerido na literatura (GARCIA et al., 2001) e disso resulta a melhor resistência à corrosão dos materiais na solução $B$.

No entanto, a análise das Figuras 92 e 94 sugere um mecanismo que pode explicar a maior quantidade de produto de corrosão na solução $B$ e também sua menor taxa de corrosão, mas independente da capacidade protetora do produto formado.

$\mathrm{Na}$ Figura 92 - solução $\mathrm{A}$ - o $\mathrm{E}_{\text {corr }}$ mostra que as reações parciais apresentam densidades de corrente crescentes na seguinte ordem: reação $\mathrm{FeS}_{2} / \mathrm{FeS}$, a qual forma $\mathrm{FeS}$, seguida da reação $\mathrm{FeS} / \mathrm{Fe}$, que também forma $\mathrm{FeS}$ e, com maior densidade de corrente, a reação anódica do $\mathrm{Fe}^{+2} / \mathrm{Fe}$. Essa análise mostra que o aço imerso na solução A tem condições de formar o produto $\mathrm{FeS}$ em sua superfície e de dissolver o ferro, com taxa maior do que a formação desse produto.

Considerando-se agora a Figura 94 - solução B - o $E_{\text {corr }}$ indica a seguinte sequência crescente de densidades de corrente: reação $\mathrm{FeS}_{2} / \mathrm{FeS}$, que forma $\mathrm{FeS}$, seguida da reação anódica do $\mathrm{Fe}^{+2} / \mathrm{Fe}$, e com a maior densidade de corrente a reação $\mathrm{FeS} / \mathrm{Fe}$, que forma $\mathrm{FeS}$. 
Esta comparação, mostra que a corrosão do aço imerso na solução $B$ tem condições de formar maior quantidade de produto ( $\mathrm{FeS}$ ) e ao mesmo tempo dissolver o ferro numa velocidade menor do que a solução A. É importante notar que este raciocínio não descarta o efeito protetor da camada de FeS, mas independente de sua formação, o aço já tem uma velocidade de dissolução menor. Por sua vez, a maior quantidade de produto formado, pode acentuar a diminuição da dissolução do ferro.

\section{Comparação da Rp entre as diferentes amostras}

Nas Figuras 53 e 56 nota-se que nos primeiros minutos de ensaio, têm-se valores de $\mathrm{Rp}$ levemente mais baixos e, após 10 minutos de imersão, os valores tornam-se constantes com o tempo. Isso pode ser explicado considerando-se que, durante o processo de corrosão, a área exposta diminui: na etapa inicial dos ensaios tem-se uma maior área exposta devido a rugosidade originada pelo acabamento superficial de lixa \#600, a qual não é possível ser considerada na medição da área. Na medida em que o processo de corrosão ocorre, tem-se um polimento da superfície, diminuindo o seu valor.

Examinando-se a Figura 91, nota-se que as principais diferenças de resistência à corrosão entre os diferentes materiais estão no fato que o aço do T-X65S apresentou, nas duas soluções, o melhor desempenho.

Fazendo uma análise da resistência à corrosão de cada aço com relação a sua composição química tem-se que adições de $\mathrm{Cu}, \mathrm{Ni}$ e $\mathrm{Cr}$ são consideradas benéficas (PALMER; KING, 2004). Já os elementos $P$ e $C$ tem um efeito negativo sobre a resistência à corrosão (CLEARY; GREENE, 1967), (KIM et al, 2010 ). Observa-se que os elementos Cu e Ni não apresentam correlação entre sua quantidade e a resistência à corrosão (Tabela 7 e Figura 91), por isso podem ser descartados os seus possíveis efeitos. Já no caso do $\mathrm{Cr}$, nota-se que há uma tendência de aumento da Rp com o aumento em sua quantidade.

Para os elementos prejudiciais, $\mathrm{P}$ e $\mathrm{C}$, tem-se uma leve tendência para o caso do $\mathrm{P}$ : menores teores de $\mathrm{P}$ levam a maiores valores de Rp. Este foi o resultado 
obtido, para o material T-X65S que apresenta o menor teor de $\mathrm{P}$ e maior valor de Rp.

No entanto estes efeitos não levam em conta as variações microestruturais. $A$ literatura (LUCIO-GARCIA, 2009; HUANG, 1996) apresenta resultados que mostram que, em aços microligados, a presença de martensita e perlita são prejudiciais à resistência à corrosão; em outras palavras, quanto mais próxima de uma estrutura ferrítica, maior é resistência à corrosão. De fato, também este resultado foi encontrado, uma vez que o material de melhor resistência à corrosão (T-X65S) possui microestrutura composta de ferrita poligonal e acicular (Figura 46) e, apresentou os maiores valores de Rp.

No item 5.3.3. Morfologia da Corrosão, para a solução $A$, todos os aços apresentaram morfologia de corrosão similar, do tipo corrosão generalizada, e nos aços com maior quantidade de inclusões observou-se uma intensificação do ataque tipo localizado (Figuras 58 a 65). De fato, Strobl (2010), encontrou resultados semelhantes em sua pesquisa, isto é, a comparação entre tubos TX65S e T-X65NS, submetidos à solução $A$, mostraram uma morfologia de corrosão generalizada associada à corrosão localizada, que se iniciava nas interfaces das inclusões / matriz, no presente trabalho o T-X65NS apresentou a maior quantidade de inclusões o que acentuou a ocorrência de corrosão localizada na solução $A$. Já para a solução $B$ o resultado não foi evidente, devido à formação de produtos de corrosão os quais produziram ilhas com uma corrosão mais intensa e zonas pouco atacadas (Figuras 66 a 73). Nos exames em MEV, todas as superfícies apresentaram o mesmo aspecto, com as superfícies pouco atacadas com formação de compostos de enxofre. Assim não é possível afirmar para a solução $B$, que a maior velocidade de corrosão é provocada pela maior quantidade de inclusões. Isso reforça a hipótese de que a maior resistência à corrosão na solução $B$ se deve à posição relativa das curvas de polarização das reações envolvidas no sistema, conforme discutido anteriormente. 


\subsection{TRINCAMENTO INDUZIDO POR HIDROGÊNIO}

\section{Solução $A$}

Após o ensaio de HIC na solução $A$, foi encontrado que as amostras de T-X65S, região soldada RS-X65S e chapa C-X65, não apresentaram trincas nas superfícies examinadas, tal como é apresentado nas Figuras 74 a 76.

No entanto, a amostra de T-X65NS apresentou trincamento (Figura 77). Conforme está discutido mais adiante, esse trincamento foi provocado por trincas nucleadas e propagadas nas bandas de segregação - regiões de ferrita, perlita, cementita intergranular, sem participação das inclusões. Quer dizer, nesse caso, a falha ocorreu devido à microestrutura do material.

A microestrutura tem um papel importante na resistência a HIC, porque microestruturas alinhadas com baixa resistência à fratura promovem caminhos de propagação das trincas (ELBOUJDAINI; REVIE, 2009).

Segundo Liou et al. (1996), e Wang et. al. (2002), as interfaces matriz/carbonetos são sítios de ancoramento de hidrogênio: interface ferrita/carboneto, interfaces da perlita, interface ferrita/cementita esferoidizada, ou seja, independentemente da geometria do carboneto, sua interface com a fase ferrita é sítio de ancoramento de hidrogênio; além disso, também são sítios de ancoramento as interfaces e discordâncias em estrutura martensítica (WANG et. al., 2002). Lembrando que as regiões de bandeamento apresentam maior quantidade desse tipo de interface, estas se tornam regiões mais susceptíveis à nucleação da trinca induzida por hidrogênio.

Por sua vez, quando a microestrutura é constituída por uma matriz de ferrita granular, ferrita acicular e microconstituinte $M / A$ disperso, a resistência à nucleação da trinca induzida por hidrogênio é aumentada (PARK et al., 2008). Fato comprovado pelo resultado obtido com a amostra de tubo T-X65S, uma vez que existe uma distribuição uniforme de microconstituinte M/A na matriz, e este atua como um acumulador irreversível de hidrogenio, evitando a concentração de tensões em regiões específicas. Acredita-se que o ancoramento de hidrogênio continua ocorrendo, no entanto, o hidrogênio é 
uniformemente distribuído pelo material sem atingir as condições críticas para a falha.

O presente trabalho permitiu comparar a microestrutura refinada, acima descrita, com um caso de material bandeado (T-X65NS), onde o ancoramento de hidrogênio ocorre em regiões com orientação preferencial dos microconstituintes, além de serem regiões com fases frágeis (carbonetos), o que leva à nucleação e propagação das trincas (Figuras 77 e 81).

Espera-se, então, que materiais com estruturas bandeadas sejam susceptíveis ao HIC. No entanto, a amostra de chapa C-X65, apresenta estrutura bandeada (Figura 49 a), praticamente igual à encontrada no T-X65NS (Figura 51) e, neste caso, a chapa C-X65 não apresentou trincamento.

Inicialmente, para explicar esse comportamento adverso, pode-se pensar nos efeitos das diferenças de composição química entre os dois aços. Mas, as diferenças não explicam esse comportamento. A chapa C-X65 apresenta, maior teor de $\mathrm{C}$ e maior teor de $\mathrm{N}$ do que o tubo T-X65NS. Seria esperado que a chapa apresentasse pior desempenho, devido aos maiores teores de intersticiais.

Por sua vez, nos exames microestruturais foi possível identificar uma maior quantidade de cementita intergranular no T-X65NS que na C-X65 (Figuras $49 \mathrm{e}$ 51) e, após os ensaios de HIC, os exames realizados para a identificação dos sítios de nucleação de trinca (exames em MEV) mostraram que tanto a nucleação quanto a propagação das trincas ocorrem pela cementita intergranular (Figura 83).

Portanto, chega-se à conclusão que a nucleação e a propagação das trincas, na amostra de tubo T-X65NS, na solução $A$, deveu-se às características microestruturais: especificamente, à presença de cementita em contornos de ferrita.

A solução A é muito agressiva, originando trincas amplas e longas que prejudicam a observação dos pocessos de nucleação e propagação. No caso da nucleação foi possível encontrar a influência da cementita intergranular 
numa trinca relativamente pequena (Figura 83), mas na propagação tais evidências foram degradadas pelo próprio processo de trincamento.

\section{Solução B}

O mesmo resultado foi obtido na solução $B$, isto é, apenas a amostra de tubo T-X65NS sofreu fratura por HIC (Figura 84). No entanto, há uma diferença: 0 nível de trincamento foi muito menor no caso da solução $B$.

Esta pesquisa revelou que a solução $\mathrm{B}$ é menos agressiva tanto quanto à corrosão, quanto à fragilização. Não é possível dizer que existe a tendência de menor trincamento quando $\mathrm{Rp}$ é maior, mas no presente caso, esse comportamento foi verificado. No entanto, é necessário ressaltar que: para um mesmo eletrólito, e igual teor de $\mathrm{H}_{2} \mathrm{~S}$, a ocorrência de HIC está diretamente relacionada com os fatores microestruturais (composição química, presença de inclusões alongadas e bandas de segregação).

Na Figura 86 pode se observar a nucleação da trinca, apresentando uma preferência do hidrogênio pela interface dos filmes de cementita. Esses tipos de interfaces atuam como acumuladores irreversíveis de hidrogênio (LIOU et al., 1996). Conforme mencionado anteriormente, o filme de cementita foi descolado da matriz em toda sua volta, consequentemente o trincamento teve sua propagação interrompida, uma vez que o comprimento do filme de cementita é finito e não havia outras fases duras para permitir a continuidade da propagação da trinca.

O avanço da trinca pela microestrutura aparece nas Figuras 87 e 88 onde a propagação segue a interface do filme de cementita com regiões de ferrita e perlita.

Os resultados obtidos nos exames de MEV para a solução B estão de acordo com o encontrado para a solução A (Figura 83), onde se observou que a nucleação da trinca ocorre na interface ferrita/cementita. Os resultados da solução B ajudaram a esclarecer os observados para a solução $A$, na qual devido a sua maior agressividade não foi possível identificar o microconstituinte causador da propagação da trinca. Na solução B, por ser menos agressiva, o trincamento não se encontrava numa fase avançada, possibilitando a 
identificação do efeito negativo dos filmes de cementita precipitados em contornos de ferrita e perlita.

Como mostrado anteriormente na Figura 51, há precipitação de filme de cementita tanto nos contornos ferrita/ferrita como de ferrita/perlita. As Figuras 87 e 88 mostram que o trincamento aparece independente do tipo de contorno (ferrita/ferrita ou ferrita/perlita). Neste caso, em particular, esse filme tem um papel fundamental na nucleação e na propagação das trincas.

Sempre se deve lembrar do efeito prejudicial das inclusões neste tipo de falha, no entanto, os aços testados receberam tratamento de inclusões com cálcio e magnésio, o que minimizou os riscos de nucleação de trincas a partir das inclusões, ficando em evidência os microconstituintes.

Um ponto importante é que a chapa C-X65 apresenta uma microestrutura semelhante ao tubo T-X65NS, sendo que a chapa não apresentou trincamento. A diferença encontrada, como foi mencionado para a solução $A$, é que a quantidade de filme de cementita na chapa C-X65 é menor do que a encontrada no tubo T-X65NS; concluí-se que a menor fração de filme de cementita intergranular na chapa é a explicação para seu bom desempenho nas duas soluções.

\subsection{COMENTÁRIOS FINAIS}

Pretende-se neste item listar os principais fatores que levam à melhoria do desempenho dos aços ARBL, quando utilizados em componentes que trabalham em ambiente sour. Esta lista foi elaborada a partir da revisão bibliográfica realizada, bem como dos resultados e discussão aqui apresentados.

Os fatores listados obedecem uma hierarquia: a sequência apresentada, a seguir, inicia-se pelo principal fator que deve ser combatido para a eliminação do trincamento induzido por hidrogênio. É importante mencionar que esta lista 
foi baseada no trabalho de Gray (2012), com alterações/inclusões provenientes da presente pesquisa.
a. Concentração e pressão de $\mathrm{H}_{2} \mathrm{~S}$. (Diminuir)
b. Tenacidade do material. (Aumentar.)
c. Teor de $\mathrm{S}$ no aço. (Diminuir.)
d. Tratamento de inclusões (com Ca e Mg). (Realizar)
e. Microestrutura*:

i. Fases duras (Eliminar cementita intergranular; bandas de perlita e outras fases duras contínuas.)

ii. Bandeamento (Eliminar)

iii. Segregação (Diminuir)

f. Teor de C $(<0,06 \%)$.

g. Teor de $\mathrm{P}(<0,015 \%)$.

h. Tensões residuais. (Diminuir)

i. $\mathrm{pH}$ do eletrólito. (Aumentar)

j. Inibidores da absorção de hidrogênio. (Cu no aço, para $\mathrm{pH}>5$; Ni; $\mathrm{Co}$ )

k. Resistência à corrosão. **

${ }^{*}$ A microestrutura depende da composição química (C, S, P, Mn, Si, Al, V, Ti e $\mathrm{Nb}$ ) e do processo de conformação da chapa, o qual deve impedir a formação de fases duras alinhadas e bandeamento de perlita. Em outras palavras: a microestrutura refinada, com carbonetos dispersos, deve ser objetivada.

**É certo que a primeira etapa do processo de dano por hidrogênio é o processo corrosivo. No entanto, ainda não é possível dizer que existe uma correlação entre a resistência à corrosão e o trincamento induzido por hidrogênio em aços ARBL. A presença do veneno catódico $-\mathrm{H}_{2} \mathrm{~S}$ - é o fator crítico nos fenômenos que envolvem trincamento.

Para obter o aço microligado ótimo para aplicações sour, essas medidas devem ser tomadas em conjunto para obter os melhores resultados. As boas práticas na fabricação de tubulações destinadas a "sour service" são a chave para desenvolver produtos resistentes ao HIC. Por ser um tema de grande impacto na economia mundial, são muitas as pesquisas nessa área, mas o 
caminho em busca de opções, que melhorem a resistência mecânica e possam minimizar os danos devidos ao hidrogênio, está aberto. 


\section{CONCLUSÕES}

Esta pesquisa permitiu obter as seguintes conclusões:

1. Aços microligados projetados para aplicação sour service apresentaram maiores valores de resistência de polarização, indicando maior resistência à corrosão nas soluções A e B da norma NACE TM02842003.

2. Os aços de maior resistência à corrosão apresentaram menores teores de fósforo em sua composição química, maior fração de microconstituintes na forma de ferrita (poligonal e acicular) e menor quantidade de inclusões.

3. É possível explicar as velocidades de corrosão e os potenciais de corrosão dos aços microligados nas soluções NACE TM0284-2003 através da estimativa teórica das curvas de polarização (trechos de Tafel) das reações envolvendo $\mathrm{Fe}, \mathrm{H}_{2}, \mathrm{FeS}_{2}$, $\mathrm{FeS}$ e $\mathrm{H}_{2} \mathrm{~S}$. O potencial de corrosão obtido experimentalmente, quando comparado com as curvas estimadas, explicam os valores de resistência de polarização obtidos, bem como, a quantidade de produto de corrosão formado na superfície, indicando que se trata de FeS.

4. O aço do tubo T-X65NS foi o único que apresentou trincamento nas soluções A e B. Encontrou-se que a nucleação e propagação das trincas ocorreram seguindo a cementita intergranular.

5. As microestruturas refinadas (constituídas por ferrita acicular, poligonal e $\mathrm{M} / \mathrm{A}$ ), com baixos níveis de inclusões, ofereceram maior resistência ao trincamento dos aços ARBL submetidos a meios contendo $\mathrm{H}_{2} \mathrm{~S}$ úmido.

6. A menor quantidade do filme de cementita intergranular presente na chapa C-X65 comparativamente com o tubo T-X65NS, foi a causa do não trincamento dessa chapa. 


\section{REFERÊNCIAS}

AMERICAN PETROLEUM INSTITUTE. API specification 5L. Specification for Line Pipe, Washington, DC. 2004.

ASM Metal Handbook. Volume 01, Properties and Selection: Irons, Steels, and High-Performance Alloys. 10 $0^{\text {th }}$ Edition Metals Handbook. 1993.

ASTM Estándar E45. Standard Test Methods for Determining the Inclusion Content of Steel. ASTM INTERNATIONAL 2011.

ASTM Estándar G59-97 Standar test method for conducting potentiodinamic polarization resistance measurement, ASTM INTERNATIONAL 2009.

ASTM G101-04. Standard Guide for Estimating the Atmospheric Corrosion Resistance of Low-Alloy Steels. ASTM INTERNATIONAL 2010.

ASTM Estándar G102-89 Standar practice for calculation of corrosión rates and related informationfrom electrochemical measurement, ASTM INTERNATIONAL 2010.

ASTM G148 97. Standard Practice for Evaluation of Hydrogen Uptake, Permeation, and Transport in Metals by an Electrochemical ASTM INTERNATIONAL 2003.

BAUER J.; FLUÜSS P.; AMORIS E.; SCHWINN V.; Microstructure and properties of thermomechanical controlled processing steels for pipeline applications. Ironmaking and Steelmaking, v 32, n. 4, 2005.

BEACHEM C. D. A new model for hydrogen-assisted cracking (hydrogen "embrittlement"), Metallurgical Transactions, v. 3, n. 2, p.441-455, 1972.

BEZERRA P.S.A, Jóia C.J.B.M., Assunção F.C.R., Proceedings of 18 Congresso Brasileiro de Corrosão, Rio de Janeiro, , ABRACO, Rio de Janeiro, nov.1995. 
BIERNAT R. J.; ROBINS R. G. High-temperature potential/ph diagrams for the iron-water and iron-water-sulphur systems. Electrochimica Acta. v. 17, p. 12611283, 1972.

CAO J.; LIU Q. YONG Q.; SUN X. Precipitation of MC phase and precipitation strengthening in hot rolled $\mathrm{Nb}-\mathrm{Mo}$ and $\mathrm{Nb}-\mathrm{Ti}$ steels. Journal of iron and steel research, v. 14, n.3, p. 51-55, 2007.,

ČIPERA, M., MIKULOVÁ, D. The influence of microstructure on hydrogen induced cracking in gas pipeline steels. Metal 2010. Rožnov pod Radhoštěm, Česká Republika. 2010.

CLEARLY, H. J.; GREENE N. D. Corrosion properties of iron and steel. Corrosion Science. v. 7, p. 821 to 831. 1967.

CUDDY, L. J. The Effect of Microalloy Concentration on the Recrystallization of Austenite During Hot Deformation. The Metallurgical Society/AIME, pp. 129140, 1982.

DEARDO A. J.; Metallurgical basis for thermomechanical processing of microalloyed steels, Conference "thermomechanical process" 24-26 may 2000. Ironmaking and steelmaking, v. 28 n. 2, 2001.

DOMIZZI G.; ANTERI G.; OVEJERO-GARCIA J. Influence of sulfur content and inclusion distribution on the hydrogen induced blister cracking in pressure vessel and pipeline steels. Corrosion. Science. v. 43, p. 325-339, 2001.

DRAŽIC D. M.; VAŠČIĆ V. The inflection point in the polarization curve and its use in corrosion rate measurement, Corrosion. Science. v. 25, No 7, p. 483491, 1985.

ELBOUJDAINI M. REVIE R. W. Metallurgical factors in stress corrosion cracking (SCC) and hydrogen-induced cracking (HIC). Journal of Solid State Electrochemistry, v. 13 n. 7, p. 1091-1099, 2009. 
FANG H.; BROWN B.; NESIC S. Effects of Sodium Chloride Concentration on Mild Steel Corrosion in Slightly Sour Environments. Corrosion Science. v. $67 \mathrm{n}$ $1,2010$.

GARCIA L.A.C.J.; JOIA C.J.B.M; CARDOSO E. M.; MATTOS O.R.

Electrochemical methods in corrosion on petroleum industry : laboratory and field results. Electrochimica Acta, v. 46, p. 3879-3886, 2001.

GOLOVANENKO S.A., ZIKEEV V. N., SEREBRYANAYA E. B., POPOVA L.V.. Effect of alloying elements and structure on resistance of structural steels to hydrogen embrittlement, Bardin central scientific. Research institute of ferrous metallurgy. Translated from Metallovedenie i Termicheskaya Obrabotka Metallov, No. 1, pp. 2-14, January, 1978.

GONZÁLEZ J. A.; MOLINA A.; ESCUDERO M. L.; ANDRADE C. Errors in the electrochemical evaluation of very small corrosion rates-polarization resistance method applied to corrosion of steel in concrete. Corrosion Science, v. 25, n. 10, p. 917-930, 1985.

GORNI A. A.; SILVEIRA J. H. D.; REIS J. S.S. Um panorama do desenvolvimento recente de chapas grossas e suas aplicações. Corte \& Conformação de Metais, p. 78-93, Novembro, 2006.

GRABKE H. J.; RIECKE E. Absorption and diffusion of hydrogen in steels. Materials Technology, v. 34, n. 2 p. 331-342, 2000.

GRAY J. M. technology of microalloyed steel for large diameter pipe, international journal of pressure vessels and piping, v. 2, n. 2 p.95-122, 1973.

GRAY J. M. Low manganese sour service linepipe steel. Microalloyed steels for sour service. International seminar, São Paulo Brazil 20-22 august 2012.

HILL, R. T. Offshore oil and gas development activities and challenges. proceding of microalloyed steels for the oil and gas industry Symposium, TMS. P. 15-26, 2007. 
HILLENBRAND H. G.; GRAF, M.; KALWA C. Development and production of high strength pipeline steels. EUROPIPE GmbH Formers. 4940878 Ratingen, Germany, 2001.

HILLENBRAND H. G.; KALWA C. High strength line pipe for project cost reduction High Strength Line Pipe for Project Cost Reduction. World pipelines, v. 2, n. 1, 2002.

HINCAPIE-LADINO D.; STROBL H.; GONZALEZ-RAMIREZ M. F.; PEREZ DE OLIVEIRA M.; GOLDENSTEIN H.; ALONSO-FALLEIROS N. Inclusion behavior at the corrosion process of API $5 \mathrm{I} \times 65$ pipes. Rio Pipeline Conference and Exposition 2011, Rio de Janeiro, Brasil, Sept. 2011.

HOU H.; CHEN Q.; LIU Q.; HAN H. Grain deformation of a Nb-Ti microalloyed steel through heavy deformation controlled colling. Journal of materials processing technology, v.137, p173-176, 2003.

HUANG, F., LI, X. G., LIU, J., QU, Y. M., JIA, J., DU, C. W. Hydrogen-induced cracking susceptibility and hydrogen trapping efficiency of different microstructure X80 pipeline steel. Materials. Science. v. 46, p. 715-722, 2010.

INTERNATIONAL IRON AND STEEL. High strength low alloy steels. Brussels, Iron and Steel Institute, 1987. Cap 3, 3.1-3.33.

JIN, T.Y., LIU, Y.F., CHENG, Y.F. Effect of non-metallic inclusions on hydrogeninduced cracking of API5L X100 steel. International journal of hydrogen energy v. 35, p. 8014-8021, 2010.

KIM W. K.; KOH S. U.; YOUNG Y. B.; KIM K. Y. Effect of environmental and metallurgical factors on hydrogen induced cracking of HSLA steels. Corrosion Science v. 50, p. 3336-3342. 2008.

LIOU H. Y.; SHIEH R. I., WEI F. I.; Wang S. C. Roles of Microalloying Elements in Hydrogen Induced Cracking Resistant Property of HSLA Steels, Corrosion Science. 49 (1993) 389. 
LIOU H.Y.; WANG S. C.; HSIEH I. Effect of microstructures on hydrogen embrittlement and absorbed energies in low carbon steel. China steel Technical report, v. 10, p. 22-31, 1996.

LOUTHAN, M.R. Hydrogen Embrittlement of metals: A primer for the failure analyst, US Department of Energy Document WSRC-STI-2008, v. 62, 2008.

MA H. A.; CHENG X.; CHEN S.; WANG C.; ZHANG J., YANG H. An ac impedance study of the anodic dissolution of iron in sulfuric acid solutions containing hydrogen sulfide. Journal of Electroanalytical Chemistry, v. 451, p. 11-17. 1998.

MA, H.; CHENG, X.; LI, G.; CHEN, S. The influence of hydrogen sulfide on corrosion of iron under diferent conditions. Corrosion Science, 42, p. 16691683, 2000.

MAJTA J.; MUSZKA K. Mechanical properties of ultra fine-grained HSLA and Ti-IF steels. Materials Science and Engineering, v. 464, p. 186-191, 2007.

MISAWA T. The mechanism of atmospheric rusting and the protective morphous rust on low alloy Steel. Corrosion Science, v. 14, p. 279-289, 1974.

NAM N.D.; KIM J.G. Effect of niobium on the corrosion behaviour of low alloy steel in sulfuric acid solution, Corrosion Science. 52 (2010) 3377-3384.

NACE Standard MR0103-2007. Materials Resistant to Sulfide Stress Cracking in Corrosive Petroleum Refining Environments. NACE INTERNATIONAL, 2007.

NACE Standard TM0177-2005. Laboratory Testing of Metals for Resistance to Sulfide Stress Cracking and Stress Corrosion Cracking in H2S Environments. NACE INTERNATIONAL, 2005.

NACE Standard TM0284-2003. Evaluation of pipeline and pressure vessel steels for resistance to hydrogen-induced cracking. NACE INTERNATIONAL, 2003.

NAMBOODHIRI T.K.G. Hydrogen Damage of Metallic Materials: Introduction, Importance of hydrogen damage, Classification of hydrogen damage, Control of 
hydrogen damage. Disponivel em: <knol.google.com/k/prof-t-k-govindannamboodhiri/hydrogen-damage-of-metallic> accesso em 12 maio 2011.

OGATA P. H. Caracterização microestrutural do aço para tubo API-X65 em diferentes regiões da chapa como laminada e apos austenitização e resfriamento sob diversas taxas de resfriamento. 2009. 122p. Dissertação (mestrado)- Escola Politecnica, Universidade de São Paulo, São Paulo, 2009.

OKAMOTO M.A. danos causados pelo hidrogênio em aços API 5L X65 E X80, 2010, 80 p. Trabalho de Formatura apresentado à Escola Politécnica da Universidade de São Paulo, 2010.

PALMER A. C.; KING R. A. Subsea Pipeline Enginering. 1 ed. Pennwell corporation, USA, 2004, p. 570.

PALMIERI I. Pre-sál e seus desafios quanto à seleção e materiais metálicos, trabalho apresentado no $66^{\circ}$ congresso da ABM, julho 2011, São Paulo

PARK G. T.; KOH S. U.; JUNG H. G. KIM K. Y. Effect of microstructure on the hydrogen trapping efficiency and hydrogen induced cracking of linepipe steel. Corrosion Science, v. 50, p. 1865-1871, 2008.

PRESOUYRE G.M. Trap theory of hydrogen, Acta Metallurgica. 28, 895-911, 1979.

PRESSOUYRE G.M.; BLONDEAU R. L.; CADIOU. J. HSLA Steels with Improved Hydrogen Sulfide Cracking Resistance. Materials for energy systems v. 6, n. 1, p. 59-64, June 1984.

RAVI K.; RAMASWAMY V.; NAMBOODHIRI T. K. G. Effect of molybdenum on the resistance to $\mathrm{H} 2 \mathrm{~S}$ of high sulphur microalloyed steels. Materials Science and Engineering, A 169, p.111-118, 1993.

REVIE R.W.; UHLIG H.H. Corrosion and Corrosion Control, $3^{\text {th }}$ ed., John Wiley and Sons, N.Y. USA, 2008.

ROBERGE P. R. Handbook of corrosion engineering, Mc Graw-Hill, N.Y. USA, 2000. 
ROSSUM, J.R. Fundamentals of Metallic Corrosion in Fresh Water. The Roscoe Moss Co. 1980.

SALLES M. Corrosão por $\mathrm{H}_{2} \mathrm{~S}$ em FCC, $1^{\circ}$ Curso Funcional em FCC e Tratamento DEA, 1990.

SASTRI V. S.; GHALI E.; ELBOUJDAINI M. Corrosion Prevention and Protection Practical Solutions, John Wiley \& Sons Ltd, Ottawa, pag.423-459, 2007.

SERNA S.; MARTÍNEZ H.; LÓPEZ S.Y.; GONZÁLEZ-RODRÍGUEZ J.G.; ALBARRÁN J.L. Electrochemical technique applied to evaluate the hydrogen permeability in microalloyed steels, International Journal of Hydrogen Energy. 30, p. 1333-1338, 2005.

SINGH M. M.; GUPTA A. Corrosion Behavior of Mild Steel in Acetic Acid Solutions. Corrosion Science, v. 56, n. 4, p. 371-379. 2000.

STALHEIM D. G. The Use of High Temperature Processing ( HTP ) Steel for High Strength Oil and Gas Transmission Pipeline Applications. Fifth International Conference on HSLA Steels, Chinese Society of Metals, China, November, 2005.

STALHEIM, D. G.; BARNES, K. R.; MCCUTCHEON, D. B. Alloy designs for high strength oil and gas transmission linepipe steels. Proceding of microalloyed steels for the oil and gas industry Symposium, TMS, p. 73-108, 2007.

STRATMANN M.; BOHNENKAMP K.; RAMCHANDRAN T. The influence of copper upon the atmospheric corrosion of iron. Corrosion Science, v. 27, n. 9 , p. 905-926, 1987.

STROBL COSTA H. Influência das Inclusões sobre a Corrosão Localizada de Aços ARBL na Presença de Sulfeto, 2010, 64 p. Trabalho de Formatura apresentado à Escola Politécnica da Universidade de São Paulo, 2010. 
TAIRA T., MATSUMOTO K., KOBAYASHI Y., TAKESHIGE K., KOSASU I. Development of super tough acircular ferrite steel for line pipe- optimization of carbon And niobium content in low carbon steels. Conference proceeding of international conference on technology and aplications of HSLA steels. American Society for Metals. October 1983.

TEOH L.L. Thermo-mechanical processingand microstructure of microalloyed steel bar and wire rod products, jornal of materials processing technology, v. 48, p. 475-481, 1995.

TOTAL S.A. Publications. Sour Gas: A history of expertise. Total 2007. pp. 24 . Disponível em: < http://www.total.com/MEDIAS/MEDIAS_INFOS/239/EN/sourgas-2007.pdf> accesso em 12 junho. 2012.

TSUKADA K.; WATANABE I. The Progress of Thermo-Mechanical Control Process for HSLA Plate in Japan. Engineering Materials, v. 17, p. 84-85, 1993.

VAGAPOV R.K.; Frolova L.V.; Kuznetsov Y.I. Inhibition Effect of Schiff Bases on Steel Hydrogenation in H2S Containing Media , Protection of Metals, 2002, v. 38, n.1, p. 27-31. 2002.

VEDAGE H.; RAMANARAYANAN T.A.; MUMFORD J.D.; SMITH S.N.

Electrochemical Growth of Iron Sulfide Films in H2S-Saturated Chloride Media. Corrosion. V. 49, n. 2, p. 114-121, 1993.

VELOZ, M. A.; GONZÁLEZ, I. Electrochemical study of carbon steel corrosion in buffered acetic acid solutions with chlorides and H2S. Electrochimica Acta, v. 48, p. 135-144, 2002.

WANG S.H., LUU W.C., HO K.F., WU J.K. Hydrogen permeation in a submerged arc weldment of TMCP steel, 77, 447-454, 2002.

WOLYNEC, S.Técnicas eletroquímicas em corrosão. $1^{\text {st }}$ ed. São Paulo, SP: Editora da Universidade de São Paulo - EDUSP, 2003. v. 1. 166 p. 
XIAO F. LIAO B.; SHAN Y.; QIAO G.; YONG ZHONG Y.; ZHANG C.; YANG K. Challenge of mechanical properties of an acicular ferrite pipeline steel. Materials Science and Engineering, v 431, p. 41-52, 2006.

XU B.; YONG Y. M.; BAO L. X.; LIU Z. Y.; GUO G. D. Modelling of microstructure evolution during hot rolling of a high-Nb HSLA steel,. Mater Sci, v. 45 , p. $2580-2590,2010$.

XUE, H.B., CHENG, Y.F. Characterization of inclusions of X80 pipeline steel and its correlation with hydrogen induced cracking. Materials. Science. v. 53, p. 1201-1208, 2011.

ZAKROCZYMSKI T. Entry of Hydrogen into Iron Alloys from the Liquid Phase; In: ORIANI R.A.; HIRTH J.P. ŚMIAŁOWSKI M. Hydrogen Degradation of Ferrous Alloys. Noyes Publications, Park Ridge, New Jersey, U.S.A., 1985.

ZHAO M.; YANG K.; SHAN Y. Comparison on strength and toughness behaviors of microalloyed pipeline steels with acicular ferrite and ultrafine ferrite. Materials Letters, v. 57, p.1496-150, 2003. 